MAY 31989

MLM-MU-89-65-0010

\title{
PRIMATE POLONIUM METABOLIC MODELS AND \\ THEIR USE IN ESTIMATION OF SYSTEMIC RADIATION DOSES FROM BIOASSAY DATA
}

FINAL REPORT

MARCH 15, 1989

Principal Investigator: N. Cohen, Ph.D.

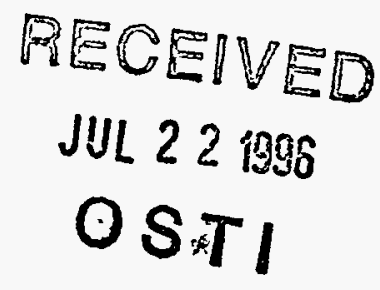

New York University Medical Center Institute of Environmental Medicine A.J. Lanza Research Laboratories Tuxedo, New York 10987
Report Prepared for: Henry B. Spitz, Ph.D. Polonium Dosimetry Project Manager EG\&G Mound Applied Technologies P.O. Box 3000
Miamisburg, Ohio 45343-0987

\footnotetext{
- A major portion of the following report was originally submitted by Dr. Alan Fellman as a Ph.D. dissertation to the Graduate School of Arts and Science, New York University, New York (1989).
}

NIGTRIRITIDN OF THIS DOCUMENT IS UNLIMTED.

\section{DRAT}


DISCLAIMER

Portions of this document may be illegible in electronic image products. Images are produced from the best available original document. 


\section{FINAL REPORT}

to

\section{MOUND LABORATORY}

Title of Project:

Period Covered by Report:

Principal Investigator:

Staff:

Date of Report:
Primate Polonium Metabolic Models and

Their Use in Estimation of Systemic

Radiation Doses From Bioassay Data
February 1, 1988 to January 31, 1989

Norman Cohen, Ph.D.

Alan L. Fellman, Ph.D.

David P. Hickman, Ph.D.

Lowell G. Ralston, Ph.D.

Linda S. Ayres, A.A.S.

March 15, 1989

\section{DISCLAIMER}

This report was prepared as an account of work sponsored by an agency of the United States Government. Neither the United States Government nor any agency thereof, nor any of their employees, makes any warranty, express or implied, or assumes any legal liability or responsibility for the accuracy, completeness, or usefulness of any information, apparatus, product, or process disclosed, or represents that its use would not infringe privately owned rights. Reference herein to any specific commercial product, process, or service by trade name, trademark, manufacturer, or otherwise does not necessarily constitute or imply its endorsement, recommendation, or favoring by the United States Government or any agency thereof. The views and opinions of authors expressed herein do not necessarily state or reflect those- of the United Stafes Government or aný ageñcy therèoof. ${ }^{\cdots \cdots}$ 


\section{EXECUTIVE SUMMARY}

A polonium urinary excretion model was derived at New York University Medical Center's Institute of Environmental Medicine (NYUMCIEM) to estimate the systemic radiological dose to workers based on their excretion of polonium in urine over time. This model was developed as part of a limited research program to evaluate polonium urinalysis monitoring results which were accumulated as part of the routine health physics monitoring during the mid-1940s through the early 1970s. The model is independent of the time sequence of exposure, treating each urinalysis result as potentially reflecting a new acute input of $20 \mathrm{Po}$ into the urinary compartment. Statistical criteria have been developed to test each data point to determine whether the result represents a new polonium uptake event. The systemic body content of polonium and internal radiation dose are estimated from the urinary output using newly determined metabolic parameters of polonium gleaned from studies of polonium in the non-human primate. The significance of the dose estimates are examined by defining the degree of uncertainty attached to them through comprehensive statistical testing procedures and retrospective quality control considerations.

Many parameters necessary for dosimetry calculations (such as organ partition coefficients and excretion fractions), were evaluated from metabolic studies of $20 \mathrm{Po}$ in two species of non-human primates. Four tamarins and five baboons were injected intravenously with 200 Po citrate. Excreta and blood samples were collected for up to 203 days post administration for tamarins and up to 91 days post administration for baboons. Baboons were sacrificed by exsanguination at 1 day, 1 week, 2 weeks, 1 month, and 3 months post exposure. Complete necropsies were performed and all excreta and the majority of all organ, skeletal, and tissue samples were analyzed radiochemically for their 210Po content. 
Excretion fractions of ${ }^{210} \mathrm{Po}$ in the two species of non-human primates were found to be markedly different from data reported elsewhere in other species, including humans. The tamarin excreted approximately $19.7 \%$ of the systemic ${ }^{20} \mathrm{Po}$ in urine and $68.8 \%$ in feces. The baboon excreted approximately $37.7 \%$ and $55.1 \%$ of the systemic ${ }^{210}$ Po in urine and feces, respectively. These new findings differ with other models which predict that approximately $10 \%$ and $90 \%$ of polonium will be excreted in urine and feces, respectively. The ${ }^{20} \mathrm{Po}$ excretion rate in the baboon was much more rapid than in the tamarin. The biological half-time of 210 Po excretion in the baboon was approximately 15 days while in the tamarin, the ${ }^{20} \mathrm{Po}$ excretion rate was in close agreement with the 50 day biological half-time predicted by ICRP 30 .

A thorough review of the polonium urinalysis procedure showed that significant recovery losses resulted when metabolized $20 \mathrm{Po}$ (i.e., $20 \mathrm{Po}$ which has crossed a biological membrane) was deposited out of raw (i.e., unprocessed) urine. A comparison study was performed to test this finding using urine samples from baboons and tamarins which had been injected with ${ }^{20} \mathrm{Po}$. Aliquots of baboon and tamarin urine were traced with ${ }^{208 \mathrm{Po}}$, ashed in nitric acid, converted to a chloride solution, and deposited onto a nickel disc in a plating cell while the other aliquots were poured without processing into a plastic cup and deposited onto a copper disc. In some cases, the 2000 recovery using ashed urine samples exceeded that using unprocessed samples by more than one order of magnitude.

Determination of the residual blood volume in all organ and tissue samples was accomplished by labeling red blood cells of the baboon with ${ }^{\mathrm{s}} \mathrm{Cr}$ prior to exsanguination. It was then possible to separate sample ${ }^{210} \mathrm{Po}$ measurements into tissue content and residual blood content.

The spleen was by far the organ with the highest post-exsanguination residual blood concentration, with an average of $0.51 \pm 0.19 \mathrm{ml} / \mathrm{g}$. The blood-borne polonium added a significant amount of $20 \mathrm{Po}$ to the total measured in the spleen, ranging from an additional $23.5 \%$ at one day post exposure to $10.4 \%$ at 91 days post exposure. The lungs, with 0.23 
$\pm 0.05 \mathrm{ml} / \mathrm{g}$, had the next highest concentration of residual blood, which accounted for increases of $28.6 \%$ and $7.3 \%$ to the polonium content at one day and 91 days post exposure, respectively. Liver and kidneys had residual blood concentrations of approximately $0.1 \mathrm{ml} / \mathrm{g}$. Unlike the spleen and lung, the liver and kidney polonium content were not greatly affected by the addition of blood-borne polonium.

Polonium-210 was found to distribute throughout the soft tissues of the baboon but not with organ partition coefficients for liver, kidneys, and spleen as predicted by the ICRP 30 polonium metabolic model. Fractional distribution of 0.29 for liver, 0.07 for kidneys, and 0.006 for spleen were determined. These three organs did exhibit the greatest $20 \mathrm{Po}$ levels on a per gram basis, with kidneys having the highest concentration followed by liver and spleen. Retention times for ${ }^{20} \mathrm{Po}$ in tissues could be described by single exponential functions and had biological half-times ranging from 15 to 50 days. 


\begin{abstract}
A Polonium metabolic model was derived and incorporated into a Fortran algorithm which estimates the systemic radiation dose from 210 Po when applied to occupational urine bioassay data. The significance of the doses estimated are examined by defining the degree of uncertainty attached to them through comprehensive statistical testing procedures.

Many parameters necessary for dosimetry calculations (such as organ partition coefficients and excretion fractions), were evaluated from metabolic studies of ${ }^{210} \mathrm{Po}$ in non-human primates. Two tamarins (on two separate occasions) and six baboons were injected intravenously with $210 \mathrm{Po}$ citrate. Excreta and blood samples were collected. Five of the baboons were sacrificed at times ranging from 1 day to 3 months post exposure. Complete necropsies were performed and all excreta and the majority of all skeletal and tissue samples were analyzed radiochemically for their $210 \mathrm{Po}$ content.

The ${ }^{210} \mathrm{Po}$ excretion rate in the baboon was more rapid than in the tamarin. The biological half-time of $210 \mathrm{Po}$ excretion in the baboon was approximately 15 days while in the tamarin, the 200 Po excretion rate was in close agreement with the 50 day biological half-time predicted by ICRP 30 . Excretion fractions of $210 \mathrm{Po}$ in the non-human primates were found to be markedly different from data reported elsewhere in other species, including man.

A thorough review of the Po urinalysis procedure showed that significant recovery lọsses resulted when metabolized $210 \mathrm{Po}$ (i.e., ${ }^{210} \mathrm{Po}$ which has crossed a biological membrane) was deposited out of raw (i.e, unprocessed) urine. A comparison study was performed to test this finding using urine samples from baboons and tamarins which had been injected with ${ }^{210 P o . ~}$
\end{abstract}


Polonium-210 was found to be distributed throughout the soft tissues of the baboon but not with the partition coefficients for liver, kidneys, and spleen that are predicted by the ICRP 30 metabolic model. A fractional distribution of 0.29 for liver, 0.07 for kidneys, and 0.006 for spleen was determined. Retention times for ${ }^{210} \mathrm{Po}$ in tissues could be described by single exponential functions and had biological half-times ranging from 15 to 50 days. 


\section{Table of Contents}

1 Introduction ....................................................................................................... 1

2 Literature Review ...................................................................................... 3

2.1 Environmental Polonium .............................................................................. 3

2.2 Metabolism ..................................................................................................... 4

2.2.1 Route of Exposure ................................................................................... 4

2.2.2 Distribution .......................................................................................... 7

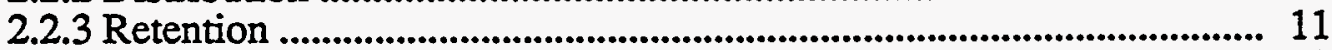

2.2.4 Excretion ..................................................................................... 12

2.2.5 Species Differences ........................................................................ 16

2.3 Toxicity and Pathology ...................................................................... 18

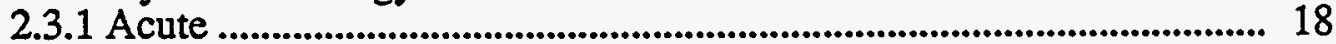

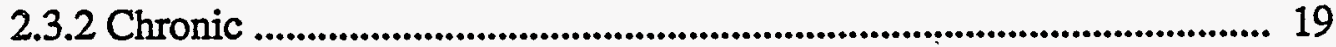

2.3.3 Clinical Effects In Man ........................................................................ 22

2.4 Epidemiology ..................................................................................................... 23

3 Experimental Methods ................................................................................. 35

3.1 Rationale For Using Non-human Primates …………........................................ 35

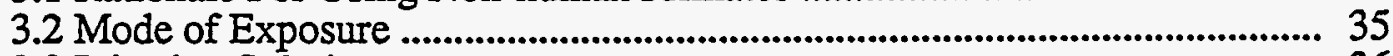

3.3 Injection Solution .......................................................................................... 36

3.4 Metabolic Studies of 210Po In Non-human Primates ................................... 38

3.5 Counting System Descriptions .................................................................... 43

3.6 Data Handling .................................................................................................... 44

3.7 Quality Control ............................................................................................ 45

4 Excretion and Distribution of Po in Non-human Primates ................................... 53

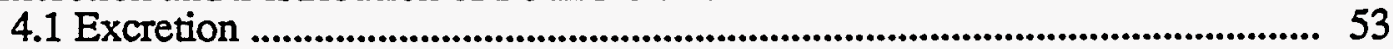

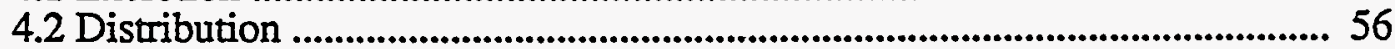

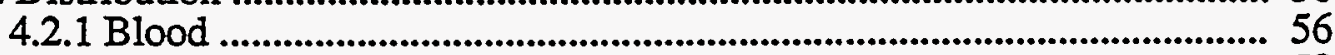

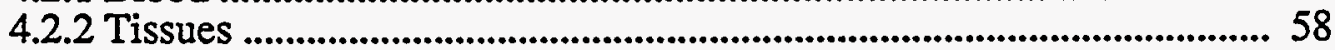

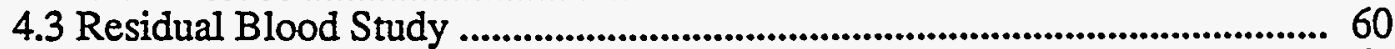

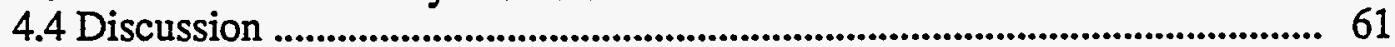

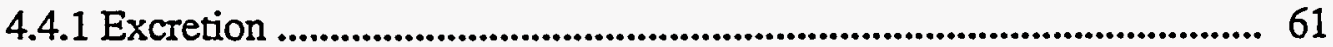

4.4.2 Blood Retention .................................................................................... 63

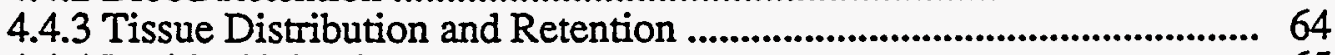

4.4.4 Residual Blood ........................................................................................ 65

5 Mound Laboratory Po Urinalysis Monitoring ................................................... 87

5.1 Duplication of the Mound Laboratory Procedure ............................................. 89

5.1.1 Ashed vs. Unashed Urine ............................................................... 90

5.1.2 Dosimetric And Other Implications ....................................................... 93

5.1.3 Summary ................................................................................................ 97

5.2 Systemic Dosimetry Model for Po ....................................................... 97

5.2.1 ICRP And Other Models ......................................................................... 97

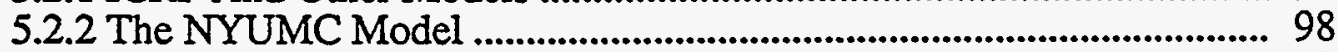

5.2.3 Model Validation ............................................................................. 107

6 Summary of Significant Findings ........................................................................ 125 


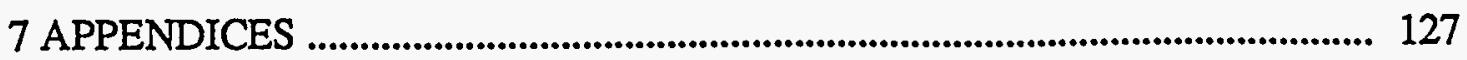

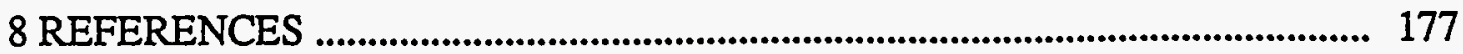




\section{Table of Tables}

2.1 Experimental Data On The Biological Retention Of 210Po In Various

Tissues Following Intravenous Administration .

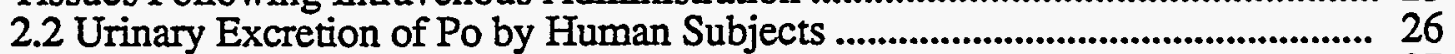

2.3 Urinary Po Excretion Parameters In Man ........................................................ 27

2.4 Summary of Effects of Po on Experimental Animals ....................................... 28

3.1 Total Po Recovered in Three Organs of the Rat Reticuloendothelial System and Per Cent of Total in Each Organ

3.2 Tamarins used in study of Po metabolism

3.3 Baboons used in study of Po metabolism

3.4 Lower Limits of Detection

4.1 Excretion of Po by Non-human Primates

4.2 Material Balance of Injected Po

4.3 Baboon Organ and Tissue Po Content

4.4 Percent of Po Body Content in Baboon Tissues ................................................ 70

4.5 Distribution of Systemic Po in Selected Organs of the Baboon ....................... 71

$4.651 \mathrm{Cr}$ Blood Labeling Results ....................................................................... 72

4.7 Baboon Organ Weights and Residual Blood Concentration ............................ 73

4.8 Residual Blood 210Po Contribution to Various Tissues ................................... 74

5.1 Unashed/Untraced Procedure Comparison for Po Urinalysis ........................... 110

5.2 Summary of Unmetabolized Po Recoveries ................................................. 111

5.3 The Effect of a Water Bath on Po Recovery ............................................. 111

5.4 Metabolic Parameters For Systemic Po .......................................................... 112

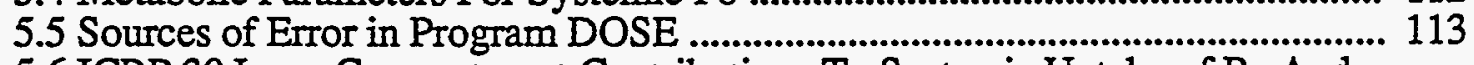

5.6 ICRP 30 Lung Compartment Contributions To Systemic Uptake of Po And Subsequent Urinary Excretion Following An Acute Inhalatory Intake .................. 114 


\section{Table of Figures}

2.1 Organ 210Po Retention in Mice ..................................................................... 29

2.2 Polonium-210 Excretion in Rats ..................................................................... 30

2.3 Urinary Excretion Of 210Po In Man ........................................................... 31

2.4 Excretion of 210Po by Male Worker Following Occupational Accident ......... 32

2.5 Excretion of 210 Po by Female Worker Following Occupational Accident ..... 33

2.6 Retention of 210Po In Blood of Female Worker Following Occupational

Accident ............................................................................................................. 34

3.1 A Comparison of Chemical Form on Disappearance of Po From The Blood .. 50

3.2 Plating Cell Used to Deposit Po onto Ni .......................................................... 51

3.3 Typical 51Cr Spectrum Residual Blood Volume Measurement ........................ 52

4.1 Tamarin Urinary 210Po Excretion ..................................................................... 75

4.2 Tamarin 504 Fecal 210Po Excretion ............................................................. 76

4.3 Baboon Urinary 210Po Excretion .................................................................... 77

4.4 Baboon Fecal 210Po Excretion .................................................................... 78

4.5 Tamarin Blood 210Po Retention ................................................................. 79

4.6 Baboon B156, B1060 and B1046 210Po Whole Blood Retention ..................... 80

4.7 Baboon B806 210Po Blood Retention .............................................................. 81

4.8 Polonium-210 Retention in the Liver and Kidney Following Serial Sacrifice

of Five Adult Female Baboons .......................................................................... 82

4.9 Polonium-210 Retention in the Spleen, Adrenal Gland, and Pancreas

Following Serial Sacrifice of Five Adult Female Baboons .................................... 83

4.10 Polonium-210 Retention in the Thyroid and Ovaries Following Serial

Sacrifice of Five Adult Female Baboons

84

4.11 Polonium-210 Retention in the Lungs and Skeleton Following Serial

Sacrifice of Five Adult Female Baboons ................................................................. 85

4.12 Relative Concentration of 210Po in Several Tissues Following Serial

Sacrifice of Five Adult Female Baboons ............................................................... 86

5.1 Unashed/Untraced Method Plating Cell ........................................................ 115

5.2 The Effect of Radiochemistry on Baboon Urinary 210Po Excretion ................... 116

5.3 Radiochemistry Correction Function for Po Recovery ...................................... 117

5.4 The Effect of Radiochemistry on Tamarin Urinary 210Po Excretion ............... 118

5.5 Comparison of Non-human Primate and Human Urine 210Po Excretion Data

From the Unashed/Untraced Method ....................................................................... 119

5.6 Polonium Excretion of a Human Volunteer ................................................. 120

5.7 Effect of Correction Function on Unashed/Untraced Human 210Po Urinary

Excretion Data ............................................................................................ 121

5.8 Schematic of Material Transfer Following Deposition in the Lung .................. 122

5.9 The ICRP 30 Lung Model ................................................................................ 123

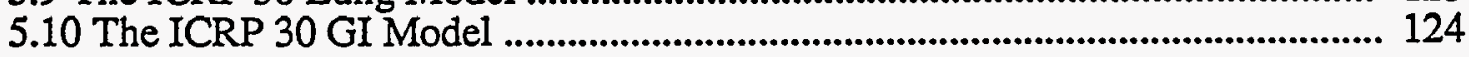




\section{Introduction}

Polonium-210 (200) is a naturally occurring $5.3 \mathrm{MeV}$ alpha particle emitter (radiological half-life of 138.4 days) which can also be anthroprogenically produced. In 1943, Monsanto Chemical Company began large scale chemical separation of $210 \mathrm{Po}$ from irradiated bismuth metal ingots for the Dayton Project. This work was a major part of the United States government's Manhattan Project, as the ${ }^{20} \mathrm{Po}$ in combination with beryllium was used as a neutron source to initiate the fission reaction for detonation of the atomic bomb (Gilbert 1969).

The goal of this research was to develop a model to estimate systemic dose resulting from occupational exposure to ${ }^{210} \mathrm{Po}$. In addition, a thorough evaluation of the uncertainty associated with the dose estimate was to be made through comprehensive statistical testing procedures and extensive retrospective quality control considerations. Knowledge of this uncertainty is important for the development of meaningful epidemiological relationships of a dose-response nature.

Early health monitoring data show that some workers were excreting measureable quantities of 20Po in urine and feces (Sheehan 1964a; Silverman 1944; Spoerl 1951). As part of the health monitoring program, workers were required to submit urine samples at frequent intervals, usually on a weekly basis (Spoerl 1950). Results of the ${ }^{20} \mathrm{Po}$ urinalyses were compared to a pre-determined "tolerance limit." Work restrictions were assigned whenever an individual was found to excrete Po in excess of the tolerance limit. The work restriction would be removed whenever the Po level dropped below the tolerance limit. Polonium-210 was processed extensively until 1959, when the program was reduced in scale. The $210 \mathrm{Po}$ bioassay program continued into the 1970s. Polonium urinalysis data has been collected for approximately 2000 workers who were monitored during this program, covering a period of about 28 years. 
The major route of Po exposure was probably by inhalation (which also involves a significant ingestion component via the mucociliary clearance mechanism), although other routes such as direct ingestion, wounds, and/or by absorption through the skin, cannot be definitively excluded as possible contributors to intake.

Unlike bone seeking alpha emitters, Po translocates from primary deposition sites into the circulatory system and redistributes throughout the soft tissues of the body, effectively resulting in whole body irradiation. Metabolic information on the biokinetics of Po in man was determined to be statistically insufficient to accurately define systemic dose from urine bioassay data. Therefore, a study of the excretion rates, retention times, and distribution of $20 \mathrm{Po}$ at various body sites after controlled exposures in non-human primates was performed as a necessary adjunct to the interpretation of historical health monitoring bioassay data. Metabolic parameters determined in this study have been incorporated into a new Po dosimetry model. 


\section{Literature Review}

\subsection{Environmental Polonium}

Due to the decay of $U$ series nuclides, low levels of $20 \mathrm{Po}$ are present naturally in air, water, biota, and foodstuffs. An extensive review of the sources and distribution of environmental 20Po and normal metabolic levels in man has been published by Parfenov (1974).

The average daily dietary intake of $210 \mathrm{Po}$ has been estimated to range from 37 to 370 $\mathrm{mBq}(1$ to $10 \mathrm{pCi})$ per day based on average concentrations of the radionuclide in foodstuffs (Hill 1965). Hill calculated an average intake of $118 \mathrm{mBq}(3.2 \mathrm{pCi}) /$ day for individuals in Great Britain and Holtzman estimated an average intake of $67 \mathrm{mBq}(1.8$ pCi)/day for individuals in the U.S. based on excretion analyses (Holtzman 1963). Excretion of ${ }^{210} \mathrm{Po}$ averaged $70 \pm 17 \mathrm{mBq}(1.90 \pm 0.46 \mathrm{pCi}) /$ day in feces and $23 \pm 9 \mathrm{mBq}$ $(0.63 \pm 0.25 \mathrm{pCi}) /$ day in urine of 12 unexposed men (Holtzman et al. 1976).

Concentrations of 210Po in human tissues have been measured in the U.S., Great Britain, and the Soviet Union (Holtzman 1966; Blanchard 1967; Ladinskaya et al. 1973; Parfenov 1974). Skeletal 210Po concentrations ranged from 1.3-1.5 Bq (35-40 pCi)/kg and exceeded soft tissue ${ }^{20} \mathrm{Po}$ concentrations due to ingrowth and physical trapping of ${ }^{20} \mathrm{Po}$ formed from the decay of $210 \mathrm{~Pb}$ within the bone matrix. Unlike ${ }^{20} \mathrm{~Pb}$, which has a relatively long half-time in bone, approximately half of the ${ }^{20} \mathrm{Po}$ formed from ${ }^{210} \mathrm{~Pb}$ decay is transported to soft tissues and ultimately excreted. Hair had $3.3 \mathrm{~Bq}(89.5 \mathrm{pCi}) / \mathrm{kg}{ }^{20} \mathrm{Po}$ and may be an important means of excretion in addition to the fecal and urinary route. Polonium-210 soft tissue concentrations were greatest in the liver and kidneys. Ladinskaya et al. reported concentrations of 973 and $762 \mathrm{mBq}$ (26.3 and $20.6 \mathrm{pCi}) / \mathrm{kg}$ (samples 
from adults) and Blanchard reported $537 \pm 74$ and $418 \pm 81 \mathrm{mBq}(14.5 \pm 2.0$ and $11.3 \pm$ $2.2 \mathrm{pCi}) / \mathrm{kg}$ (samples from 18 individuals whose ages ranged from 6-78 years) for the two organs, respectively.

Particular attention has been given to the levels of $210 \mathrm{Po}$ in tobacco and its hypothesized role as a cofactor in lung cancer production in smokers (Cohen 1978). Reported dose estimates vary, but in general "the doses cover the range from probably insignificant to possibly significant, depending upon the importance of hot spots (BEIR 1988)."

\subsection{Metabolism}

\subsubsection{Route of Exposure}

\section{Inhalation}

Inhalation of aerosols or particles containing ${ }^{20} \mathrm{Po}$ atoms results in the initial deposition of the nuclide on the lung surfaces. Following such an event, lung epithelia will be irradiated by alpha particles emitted as a result of 2000 decay. In time, the radionuclide may become systemic by one or more mechanisms. During and immediately following exposure, the ionic or soluble Po can be absorbed into the bloodstream. The insoluble and colloidal Po particles are eliminated from the lung with an effective half-time of 18-35 days (Moroz and Parfenov 1972). An exception observed in experiments with rabbits demonstrated a slow phase clearance of only six days following intratracheal administration of the nuclide (Morrow and Della Rosa 1964). Some of these aggregates may break.up with time, thereby enabling additional absorption of Po into the blood. 
The second mechanism leading to systemic uptake involves transport of particles containing Po up the tracheobronchial tree by means of the "mucociliary escalator," resulting in its eventual presence in the gastrointestinal tract. Subsequently, absorption of Po may occur across the gut membrane.

In their study of 200 Po distribution following intratracheal injection in the rat, Thomas and Stannard (1964c) showed that colloidal Po can become incorporated in the tracheobronchial lymph nodes. However, prolonged retention in the lymph nodes does not occur as is often seen for actinides due to rapid dissolution of colloidal particles (Moroz and Parfenov 1972).

Kimball and Fink (1950) reported that 30\% of an inhaled aerosol of neutralized Po chloride was retained on the surface of rat lungs 24 hours after exposure. The authors noted that technical difficulties encountered during exposures introduced considerable uncertainty in the data. Rats exposed to a $0.28 u \mathrm{MMD}$ 20Po-chloride aerosol in $0.1 \mathrm{~N}$ $\mathrm{HCl}$ had an estimated lung and trachea deposition of $25 \%$ of the total dose, with an equal amount of Po found in the gastrointestinal tract following a 5-hour exposure (Berke and DiPasqua 1964). Twenty minute nose-only exposure to a freshly neutralized 20Po aerosol with 0.046 um $\mathrm{CMD}$ (0.34 um $\mathrm{MMD}$ ) resulted in a mean pulmonary deposition of about $33 \%$ in rats, divided equally between the upper and lower portions of the respiratory tract (Casarett 1964b).

Six dogs were exposed to a $20 \mathrm{Po}$ chloride carried on a sodium chloride aerosol of CMD 0.04 um (Smith et al. 1961). Average deposition in the respiratory tract was 64\%, with values ranging from 48-77\%. These data are consistent with work done by Morrow et al. (1958), who found an average respiratory deposition of $63 \%$ in seven healthy human subjects after inhalation of a sodium chloride aerosol of a similar mean particle size. 


\section{Ingestion}

A second major route of uptake for Po is through the gastrointestinal tract. Ingestion of contaminated food or water, smoking when one's hands are contaminated, and swallowing Po-containing aerosols after their inhalation will lead to some degree of GI absorption of the radionuclide. Among the heavy elements, Po occupies an intermediate position with regard to absorption; it is absorbed more easily than the actinides, e.g. $U$ and Pu, but less easily than Ra (Moroz and Parfenov 1972).

Two rats exposed via gavage to approximately $18.5 \mathrm{kBq}(500 \mathrm{uCi}) / \mathrm{kg}$ of freshly neutralized 20 Po chloride absorbed 2.4 and $4.8 \%$ of the dose (Silberstein et al. 1950a). Following gavage administration of $0.5 \mathrm{kBq}(14 \mathrm{uCi}) / \mathrm{kg}$, approximately 3 to $5 \%$ of the dose was absorbed by rats (Spoerl and Anthony 1956). Stannard determined average fractional absorption values ( $f_{1}$ values) of 0.05 for male rats and 0.045 for female rats by balance studies after correcting for the amount of Po assumed to be excreted into the intestine via the bile (Stannard 1954; Stannard 1964a).

Two different chemical forms of Po, a colloidal hydroxide and a soluble citrate, were administered to cats by gavage in a series of experiments (Morrow et al. 1964b). When Po was placed in the stomach, significant amounts were absorbed (0.6 to 1.6\%) from the stomach independent of chemical form over a seven hour period. In contrast, significant differences were observed between the two chemical forms when the solution was placed in isolated duodenal loops of the small intestine. Over a ten hour period, absorption was up to forty times greater for the citrate solution. The authors noted that in the stomach, gastric acidity converted the colloidal Po to a soluble form, making absorption comparable to the monomeric citrate form. The percentage of administered 
dose absorbed in the cat was less than in the rat, but due to the limited length of time of the cat experiments (7-10 hours), the total amount of absorption may not have been measured.

A male patient hospitalized with chronic myeloid leukemia volunteered to ingest 7 $\mathrm{Bq}(0.19 \mathrm{nCi}) 210 \mathrm{Po} / \mathrm{kg}$ body weight in drinking water (Silberstein et al. 1950b). Absorption of Po may have reached $10 \%$, although the authors noted that the estimate was largely conjectural and may have been considerably less than this amount.

\section{Skin Absorption}

Polonium can penetrate the skin upon contact. A 210Po chloride solution placed on the bottom of the paws of mice was absorbed at the rate of $0.08-0.4 \%$ per day (Gorham 1950). Fink (1950) attempted to measure the absorption of Po chloride directly through human skin and concluded absorption occurred at less than $2 \%$ per day.

\subsubsection{Distribution}

In the blood, Po has been shown to be associated almost exclusively with erythrocytes (Campbell and Talley 1954; Thomas 1955; Thomas 1964). Blood from rats and dogs was sampled at four days post injection, with $90 \%$ of the Po found associated with the red blood cells (Campbell and Talley 1954). The authors also showed that almost all of the Po in the blood was bound to the globin fraction of hemoglobin. Thomas (1964) showed that following intravenous and oral administration of neutralized Po chloride solution to rats, $84 \pm 11$ and $104 \pm 9 \%$ of the red cell Po activity were associated with the hemoglobin fractions, respectively, and $87 \pm 8$ and $74 \pm 3 \%$ of plasma activity were associated with the plasma proteins, respectively. Consistent with the work of Campbell and Talley, the Po associated with the hemoglobin was found bound to the globin. Distribution within the plasma was related to the plasma protein concentrations 
as would be expected since the Po affinity is relatively strong for most plasma proteins (Feldman and Saunor 1964; Thomas 1964). Similar results were obtained by Thomas following intravenous administration of Po to rabbits. Thomas also noted that the mode of binding of Po by protein moieties in the blood was not related to the chemical form of the injection solution used.

Polonium forms colloidal aggregates in neutral solution in vitro (Finkel et al. 1953). Following intravenous administration or absorption from the gastrointestinal tract, Po will form colloidal complexes with proteins (Moroz and Parfenov 1972). Not surprisingly, Po aggregates are preferentially found in the cells of the reticuloendothelial system (RES) after intravenous administration. Finkel et al. (1953) recovered between 30 and $60 \%$ of the retained Po in the liver, spleen, kidneys, and skeleton (the majority of the skeletal Po burden was assumed to be associated with bone marrow) of rats 66 days after intravenous injection of Po chloride.

Injection solution parameters such as chemical form and $\mathrm{pH}$ will determine the degree of colloid present initially, and this will influence early uptake by the reticuloendothelial elements. For example, Casarett (1964a) found Po aggregates in the spleen of rats with an average size of less than 50 atoms when the citrate was administered compared to approximately 500 atoms after administration of a neutral saline solution.

No aggregates were observed in tissue samples after oral administration to both cats and rats (Casarett 1964a). Intestinal absorption of Po in presumably nonaggregate form leads to maximum association with hemoglobin, resulting in a smaller fraction of Po in the cells of the RES and the absence of colloidal aggregates (BEIR 1988). Autoradiographic studies show that the distribution of nonaggregated Po is the same irrespective of the route of administration, the size of the dose, and the chemical form of the Po administered. These studies also show that even after animals received intravenous 
solutions with a maximum of large aggregates, less than $20 \%$ of the Po content of their soft tissues was contributed by Po contained within large aggregates. It is the nonaggregated Po which is responsible for the delivery of the majority of radiological dose (Casarett 1964a; Stannard and Casarett 1964). Therefore unlike other alpha particle emitters such as plutonium, Po dosimetry need not consider "hot spot" contributions; the average dose to tissue is the pertinent quantity (BEIR 1988).

Once in the bloodstream (following either intravenous administration or after absorption from the lung or gastrointestinal tract), Po distributes throughout the body. While initial accumulation of colloidal aggregates occurs in the RES, the nuclide is found in practically all organs and tissues (Moroz and Parfenov 1972).

In rats, spleen and kidney are the tissues with the highest concentration of Po following single intravenous administration (Fink 1950; Stannard 1964a; Stannard 1964b; Stannard 1988). These sites might therefore be expected to receive some of the highest radiological doses following exposure. Expressed as the percentage of the total administered dose per tissue at one day post intravenous exposure to Po chloride, Fink (1950) found $18 \%$ in liver, $14 \%$ in muscle, $12 \%$ in blood, $11 \%$ in skin, $11 \%$ in skeleton, $8 \%$ in kidneys, $4 \%$ in spleen, $2 \%$ in lung and less than $1 \%$ in testis. Rats administered the nuclide via gavage also had maximum percentages of the total absorbed Po per gram in spleen (2.9\%) and kidney (1.2\%) ten days post exposure (Fink 1950). Liver, lymph nodes, and bone marrow are other tissues which concentrate Po in excess of the mean tissue concentration.

Polonium was administered intravenously to cats as the citrate and the neutralized hydroxide resulting in similar organ and tissue distribution 7 to 10 hours after exposure 
(Morrow et al. 1964b). On a per gram basis normalized to liver Po concentration in a cat exposed to the citrate, the spleen relative concentration factor was highest (3.7), followed by blood (2.9), kidney (2.4), lung (1.9), and small intestine (0.8).

Parfenov and Poluboyarinova (1969) administered Po nitrate subcutaneously to dogs. The kidneys had the highest initial concentration of the nuclide, followed by the lymph nodes $>$ liver $>$ spleen $>$ adrenal gland $>$ lungs $>$ muscle $>$ skeleton. Initially the liver had the highest percentage of the total administered dose per organ with $25.1 \%$. Other tissues and organs with relatively high initial amounts of Po included skeletal muscle (21.0\%), blood (13.3\%), kidneys (11.8\%), skeleton (4\%), and spleen and lungs (1.8\% each). The biological half-times for Po retention in these tissues ranged from a low of 43 days in the kidney to a high of 75 days in the skeleton.

Mice exposed via intraperitoneal injection of Po were found to have significant ovarian and testicular Po concentrations (Samuels 1966a; Samuels 1966b). Polonium was found in the reproductive tissues of mice after intravenous administration of Po chloride (Finkel et al. 1953). During the first 66 days post exposure, no organ with the exception of the spleen had a higher concentration of the nuclide than the ovaries. Kidney and lymph nodes had Po concentrations similar to the ovaries, which were approximately 2-4 times greater than was the concentration of Po in the liver.

The radiological dose to the testis may be augmented by the fact that Po clearance from that organ may be slower than from most organs and tissues. Relative to other tissues, the concentration of Po in rat testis steadily increases as a function of time (Fink 1950).

Fink (1950) measured the Po content of the tissues of a volunteer subject who died from acute lymphatic leukemia six days after receiving Po chloride. The liver had the highest tissue concentration of Po (21.0\% of the injected dose per $\mathrm{kg}$ organ weight) 
followed by spleen (17.0\%), kidneys (13.6\%), testes (4.3\%), and lung (4.1\%). In terms of total Po per tissue, the liver contained $43 \%$ of the injected dose, followed by kidneys (5.0\%), spleen (4.1\%), blood (3.9\%), and lungs ( $2.5 \%)$. The author believed that the liver values were inaccurately high due to the assay of what was possibly a non-representative aliquot. However, studies with the baboon (described in Sections 3 and 4) indicate that Po distribution in the liver is uniform. With the exception of the liver, these data are in good agreement with the percentage of intravenously injected dose seen in rat organs and tissues (Fink 1950).

\subsubsection{Retention}

The rate of biological clearance of Po from the various organs is best described by exponential functions with one or two loss constants (Stannard, 1964b). Long term distribution studies with the rat showed that Po is lost from most tissues via a rapid early phase followed by a slower phase of varying duration and half-time. An exception to this general rule was noted for the testis, where clearance occurred as a single exponential with a half-time of approximately 153 days. Composite biological half-times for Po in rats include 11 days for liver, 31 days for spleen, 38 days for kidney, and 31 days whole body. A summary of biological half-times for various organs and tissues following intravenous Po administration is presented in Table 2.1.

In contrast to the kinetics observed in the rat testis (Stannard 1964b), data from Samuels (1966b) can be used to estimate a 27 day biological half-time for Po in mice testis. These data were collected from 30-140 days post intraperitoneal injection. Retention of Po in the kidneys over the same test period could be represented by a 50 day biological half-time. The retention curves appear in Figure 2.1. The Po half-time estimates for these organs are admittedly only approximations, as only six points are 
available for the regression analysis and the first measurement was not made until 30 days post exposure. Additional error is introduced by assuming single exponential kinetics for the two organs in the absence of data prior to day 30 and by using average testis and kidney weights for mice (Ivanyi et al. 1972; Foster et al. 1983) to estimate total organ Po content. Nevertheless, the retention curves fit to these data do qualitatively suggest that the radiological dose imparted from the Po to the testes might only be a factor of 2-4 less than the kidney dose.

Polonium biological organ retention half-times of approximately 35 days appear consistently throughout the literature. Where data describing early as well as long-term elimination are available (such as following inhalation exposure to the dog and rat), rapid phase clearance with half-times of a few days followed by the 30-40 day slow phase have been observed.

\subsubsection{Excretion}

Excretion of Po has been characterized for a number of animal species as well as for man. Elimination of Po from the body begins almost immediately following exposure. A large percentage of the nuclide is excreted in a rapid phase via the digestive tract when exposure is by the ingestion or inhalation routes. The liver has been shown to play a significant role in the removal of systemic Po via the bile to the feces (Fink 1950).

Fifty per cent of the inhaled dose was excreted by dogs during the first three days post exposure, principally via the feces (Smith et al. 1961). Total excretion by the rat following inhalation exposure was not quite as rapid, with approximately $23 \%$ of the total dose recovered in excreta during the first ten days (Berke and DiPasqua 1964). The authors measured a cumulative fecal-to-urine ratio of 6.6 after 60 days for systemic Po after exposure via the inhalation route. Casarett (1964b) collected $82 \%$ of the total dose 
in excreta after "nose-only" inhalation exposure to rats over 30 days, with at least 60 percent having been collected during days 1-10 post exposure. Fecal-to-urine Po ratios peaked through days $1-4$ at a value slightly under 30 before decreasing to ratios ranging from $10-13$ beyond day five.

A similar Po excretion pattern is followed after oral administration of Po. Almost $40 \%$ per day of the administered dose was excreted by rats via the fecal route during the first two days, with levels dropping precipitously to less than $0.1 \%$ per day by day seven (Fink 1950). Urinary output of Po was an order of magnitude greater during the first ten days after the ingestion exposure than following intravenous exposure. Fecal-to-urine ratios after the ingestion exposure were similar to the 10-13 range measured following inhalation exposure, although ratios during the first few days post exposure were not nearly as high.

Consideration of absorbed Po in urine after oral administration resulted in markedly different excretion fractions when compared to the other routes of exposure. The percentage of urinary output of Po by rats was much higher with the exception of day one, with an average fecal-to-urine ratio of approximately two (Stannard 1964a). This same trend was also noted by Spoerl and Anthony (1956). Polonium excretion curves fit to data presented by Stannard (1964a) following intravenous administration of Po chloride to male rats can be used to estimate a fecal-to-urine ratio equal to 10 (shown in Fig. 2.2). Over-all fecal-to-urine ratios for systemic Po through 60 days in the rat have been given as 6.6 for inhalation, 3.3 for oral, 13.3 for intratracheal, and 13.0 for intravenous exposures (Berke and DiPasqua 1964).

Human occupational and controlled exposures to Po have been summarized by Jackson and Dolphin (1966). A mean effective half-time of 31.4 days for Po excreted in urine was reported for 18 individuals occupationally exposed (Naimark 1948; Naimark 
1949). When Po urinalysis data from 17 more workers was included in the analysis, a mean effective half-time of 34 days was calculated (Spoerl 1951). Excreta samples from two exposed workers were measured after a defective Po-Be source ruptured (Foreman et al. 1958). Polonium excretion could be characterized by a two compartment exponential model for both feces and urine. Fecal excretion occurred with a rapid phase half-time of 0.6 days followed by a 19.6 day slow phase. Initial Po urine excretion occurred with a 0.75 day half-time, followed by a slow phase with a 37 and 47 day half-time for the two individuals. The ratio of ${ }^{210} \mathrm{Po}$ excreted in feces to that excreted in urine decreased with time, with values greater than 100 for the first week decreasing to approximately 10 five months after the accident. Similar kinetics were reported by Sheehan (1964a), who measured a mean effective half-time of 33 days ( 43 day biological) in two accident cases and by Taylor (1970), who measured a mean effective half-time of 37 days (50 day biological) for 7 individuals accidentally exposed to ${ }^{20} \mathrm{Po}$.

Potential exposure to six workers was caused by the escape of $259 \mathrm{MBq}(7 \mathrm{Ci})$ from a Po-Be source (Callihan and Ross 1952). All urinalysis measurements for Po were below the lower limit of detection, but analyses of one worker's feces did indicate that some intake had occurred. Rapid elimination of Po continued through the first four days post exposure, followed by clearance with an approximate effective half-time of 25 days.

As part of the work done at the University of Rochester Manhattan Project, four patients hospitalized with generalized lymphosarcoma or chronic myeloid leukemia were injected with tracer amounts of 2000 chloride (Fink 1950). Excretion data were reported and have been widely referenced as evidence that Po retention kinetics in humans are similar to those determined from animal experiments. Since patient \#2 died six days following the administration of Po, only data from patients 1,3 , and 4 have been examined here. The daily percentages of Po excreted in the urine are given in Table 2.2 . 
The Po urinary excretion data for the three patients are shown in Fig. 2.3. The data were fit using a weighted nonlinear least squares regression method which will be detailed in Section 3.4. The urinary excretion parameters are listed in Table 2.3.

Urinary excretion half-times of 30-50 days have been determined in the majority of animal experiments for Po. The data presented by Fink would result in a similar urinary half-time for Po only if the data from the three individuals (or four by including case \#2) were combined prior to least squares regression to the single exponential model. However, an analysis of covariance test examining the log transformed bioassay results indicates that the data sets from the three individuals cannot be grouped together. The statistical procedure rejects the hypothesis that the intercepts of the urinary Po excretion curves are equal, $\mathrm{p}<0.01$. The biological half-time estimates range from a low of 13.9 days to a high of 32.0 days, although these differences are not statistically significant. These data are admittedly limited in number, but they indicate that urinary excretion of systemic Po in man may be more rapid than is predicted by the animal data presented in the literature.

The urinary excretion functions regressed to the urinary $20 \mathrm{Po}$ data for the three human volunteers can be used to estimate the urinary excretion fraction for systemic Po. The resultant fractions range from $0.02-0.05$, which are in reasonably good agreement with the urinary 20Po excretion fraction in rats based on the data of Fink (1950) and Stannard (1964a; 1964b).

The Po excretion data of two workers who were believed to have been exposed to the nuclide via absorption through the skin have also been examined via regression analysis. On August 28, 1944, a male supervisor in an electrodeposition laboratory handled a foil containing an estimated 44.4 MBq (1.2 Ci) of 20Po. Daily urine sampling and weekly fecal sampling for Po began immediately and continued for 64 days 
(Silverman 1944). Urinary and fecal Po effective half-times were determined to be 27.9 \pm 1.3 days ( 34.9 days biological) and $24.2 \pm 2.4$ days (29.3 days biological), respectively (Fig. 2.4).

A female technician at Mound Laboratory in Miamisburg, Ohio was involved in an incident in which a Po solution was accidently splashed on her face. Unpublished urine, feces, and blood Po bioassay data reveals relatively rapid excretion rates for the nuclide (Spitz 1987). As shown in Fig. 2.5, 2000 in urine was excreted with a $12.0 \pm 1.6$ day half-time (13.1 day biological) and fecal Po was excreted with a $23.7 \pm 9.3$ day half-time (28.6 day biological). Fig. 2.6 shows that the ${ }^{20}$ Po retention in the whole blood had a $17.7 \pm 0.9$ day half-time (20.3 day biological). Only nine blood measurements were made over several months following the accident, compared to 38 urine measurements and 16 feces measurements.

\subsubsection{Species Differences}

The overall distribution and excretion patterns for Po among the species described in the literature reveal many similarities. One notable exception is the metabolism of the nuclide observed in the rabbit. Fink (1950) injected one rabbit with a solution of Po chloride and noted that while fecal excretion was consistent with that observed in the rat, urinary excretion of Po was significantly greater. After 10 days, $35 \%$ of the injected dose had been excreted via the urine by the rabbit, compared to only $0.91 \%$ by the rat in the same time period. The tissue distribution differences mirrored the relatively high urinary output of Po. Many of the rabbit soft tissues had lower concentrations of Po, and the loss from tissues proceeded at a faster rate than in other species. One notable exception was the rabbit kidney, which had three times the Po concentration to that of the rat on a per gram basis. 
Similar differences in rabbit metabolism of Po were observed following intratracheal administration (Morrow and Della Rosa 1964). Retention in the lung can be described by an initial rapid phase followed by a slower phase. Fecal excretion of Po was consistent with that observed in the rat, but urinary excretion of the nuclide was again much greater in the rabbit. During the initial 30 days post exposure, the rabbit excreted $30 \%$ of the administered dose in urine. The rat excreted only $2 \%$ of the administered dose in urine during 70 days post exposure (Thomas and Stannard 1964c). The overall rabbit excretion half-time for Po was 20 days compared to the 30 days for the rat.

In contrast to the rapid rate of Po excretion by the rabbit, the rate of excretion of the radionuclide by the dog was slow compared to other species, regardless of the route of administration (Stannard and Smith 1964). The greatest difference occurred after intravenous exposure. The difference was only reflected in the rate of Po excretion. The urine-to-fecal excretion ratio for the dog was not different than for the rat.

Polonium content and retention in tissues of various species exhibit some variability, but the overall relationship (i.e., ratios) between levels in the different organs is relatively constant (Moroz and Parfenov 1972). Liver, spleen, kidneys and lymph nodes are the tissues with the highest Po concentrations in all species, although most of the organ data in the literature was generated without consideration of the contribution of the organ's residual blood Po to the total organ burden. Since Po tends to associate strongly with erythrocytes and plasma proteins, "blood-free" Po organ burdens would provide the most accurate means of comparing Po distribution. 


\subsection{Toxicity and Pathology}

\subsubsection{Acute}

Acute toxicity of Po has been studied in a number of animal models. In a pilot study, Fink (1950) determined an $L D_{5030}$ of $1.1 \mathrm{kBq}(30 \mathrm{uCi}) / \mathrm{kg}$ in Wistar-Rochester rats following intravenous administration. Additional study resulted in an $\mathrm{LD}_{\text {sorso }}$ of $1.6 \mathrm{kBq}$ $(43 \mathrm{uCi}) / \mathrm{kg}$ and an $\mathrm{LD}_{50 / 40}$ of $1.0 \mathrm{kBq}(27 \mathrm{uCi}) / \mathrm{kg}$. These data are similar to those of Davis (1950a), who measured $\mathrm{LD}_{\text {sorso }}$ values of $1.6 \mathrm{kBq}$ (43 uCi)/kg and $1.3 \mathrm{kBq}$ (36 $\mathrm{uCi}) / \mathrm{kg}$ in male and female Sprague-Dawley rats, respectively. Similar lethality was observed in CF\#1 female mice, with a reported $\mathrm{LD}_{\mathrm{s0} / 30}$ of $1.4 \mathrm{kBq}(36.5 \mathrm{uCi}) / \mathrm{kg}$ (Finkel et al. 1953). The CFW strain of mice was found to be somewhat more resistant to the lethal effects of Po. Spoerl and Anthony (1956) measured average $\mathrm{LD}_{\text {soro }}$ values of 3.0 and 3.7 $\mathrm{kBq}(80$ and $100 \mathrm{uCi}) / \mathrm{kg}$ for males and females, respectively. At Mound Laboratory, lifespan shortening in dogs, cats, and rabbits following intravenous administration of Po was also studied. $\mathrm{LD}_{\text {soro }}$ values of $2.6 \mathrm{kBq}(70 \mathrm{uCi}) / \mathrm{kg}$ in the dog and rabbit and $2.5 \mathrm{kBq}$ (69 $\mathrm{uCi}) / \mathrm{kg}$ in the cat were determined (Davis and Jolley 1951; Davis et al. 1952).

Della Rosa and Stannard (1964) studied acute toxicity of Po in the rat following oral, intratracheal, and intraperitoneal administration, and compared their data with the effects observed by others after intravenous administration. Their work established that the tissue differences resulting from the various exposure routes do not alter the lethal effects of Po, although lethality took longer to develop following intraperitoneal exposure.

As a toxic agent with widespread distribution in the body, Po has numerous degenerative effects. These include sclerotic changes in blood vessels (particularly in the testes and kidneys), atrophy of lymph nodes, pancreas, thymus, spleen, and bone marrow, 
involution of growing cartilage, general arteriosclerosis, and hypoplastic and hyperplastic changes in pulmonary lymphoid tissue (BEIR 1988). Cowden (1952) noted that the kidneys, gonads, lymphoid tissue, and blood were the organs in rats most sensitive to the ionizing radiation of $P o$.

At dosage levels ranging from $33.3 \mathrm{~Bq}$ to $1.3 \mathrm{kBq}(0.9$ to $35 \mathrm{uCi}) / \mathrm{kg}$ 200 Po chloride administered intravenously, kidneys showed consistent degenerative changes. At 100 days post exposure, renal lesions were observed in rats receiving the $33.3 \mathrm{~Bq}(0.9 \mathrm{uCi}) / \mathrm{kg}$ dose. Casarett (1964c) found enlarged, swollen, distorted epithelial cells in some of the proximal convoluted tubules in rats 42 days after exposure to $185 \mathrm{~Bq}(5 \mathrm{uCi}) / \mathrm{kg}$. Cortical arterioles had thickened walls due to swollen endothelial cells. At $37 \mathrm{~Bq}(1 \mathrm{uCi}) / \mathrm{kg}$, these changes were also observed in rats, but not until the period from 250 to 445 days post exposure. Casarett noted that while vascular changes may not be observed during the early stages, ischemia may result from radiation induced arterial spasm prior to the advent of conspicuous vascular change. He concluded that the early development of pale kidneys was indicative of an early reduction in the renal blood supply.

Hematological and pathological effects of Po on gastrointestinal, reproductive, reticuloendothelial, and various other tissues of rats have been reported (Cowden et al. 1950; Zipf 1950). The effects of Po on experimental animals at various acute dose levels have been summarized and partially reproduced here in Table 2.4 (Spoerl and Anthony 1956).

\subsubsection{Chronic}

Casarett (1964c; 1964d) studied and compared the pathological changes induced by both the single and multiple intravenous administration of Po to rats of the Wistar strain. No direct effects of Po were observed in the liver. This is in contrast to studies where 
Sprague-Dawley rats injected biweekly with $74 \mathrm{~Bq}(2 \mathrm{uCi}) / \mathrm{kg}$ developed hyperplasia of bile-duct epithelium with fatty degeneration and fibrosis and necrosis of liver-cord cells (Spoerl and Anthony 1956). Rats administered $74 \mathrm{~Bq}(2 \mathrm{uCi}) / \mathrm{kg}{ }^{20} \mathrm{Po}$ chloride intravenously at 14-day intervals showed a general pattern of lesions similar to that resulting from single doses of $296 \mathrm{~Bq}(8 \mathrm{uCi}) / \mathrm{kg}$ (Cowden and Zipf 1951). However, the lesions appeared at a faster rate and proceeded ultimately to greater severity, which the authors attributed to an ever increasing dose rate in conjunction with the presence of subacute lesions. Nephrosclerotic changes resulted from single doses of $370 \mathrm{~Bq}(10 \mathrm{uCi}) / \mathrm{kg}$ and in the multiple dose group receiving $56 \mathrm{~Bq}(1.5 \mathrm{uCi}) / \mathrm{kg} /$ month, although the damage was less severe in the latter group. Dose estimates at these two exposure levels are comparable.

Damage to the hematopoietic tissues was similar regardless of the dose regimen with one exception. In multiple dose experiments only, marked hemorrhage of the spleen was common. Hypoplasia and atrophy of seminiferous epithelium resulted in rats of both experimental groups. However, onset of the condition was more rapid in the single dose animals.

Pulmonary hemorrhage and edema resulted from administration of high doses of Po. Rats receiving $3.7 \mathrm{~Bq}(0.1 \mathrm{uCi}) / \mathrm{kg} /$ month developed obstructive pulmonary emphysema, but rats in the higher dose groups (11.1 and $56 \mathrm{~Bq} / \mathrm{kg} / \mathrm{month}$ ) did not develop this disease. Marked atrophy of pulmonary lymphatic tissue occurred in the high dose animals.

A common measure of an agent's toxicity is the degree of life-span shortening which results following exposure. When the Po body burden was maintained in rats at $1.85 \mathrm{~Bq}(0.05 \mathrm{uCi}) / \mathrm{kg}$, the resultant life-span shortening was not significant (Stannard et al. 1964). At higher doses, however, a linear relationship exists between dose and 
life-span shortening, with a slope of approximately 4.3 weeks of life-span shortening per $37 \mathrm{~Bq}(1 \mathrm{uCi}) / \mathrm{kg}$. Unlike gamma or $\mathrm{x}$-radiation, fractionating the dose over many exposure episodes does not reduce the life-span shortening effectiveness of Po. Applicable to both the single and multiple exposure situations, this supports the observation that the alpha radiation emitted from Po produces a high degree of irreversible damage (Blair 1964). Stannard et al. (1964) estimated that alpha particles emitted from Po have a relative biological effectiveness (RBE) of 20 based on their life-span shortening data. Samuels (1966b) suggested that the RBE of Po may be as high as 50 based on oocyte destruction induced on Harvard Swiss-Wistar mice following intraperitoneal injection.

Blair (1964) found the life-span shortening effect of Po to be equal to that of plutonium and about five times as great as radium. Finkel (1953) described the relative toxicity of some alpha particle emitters as follows: 7:3:2:1:1 corresponding to ${ }^{239} \mathrm{Pu}:{ }^{210} \mathrm{Po}:{ }^{22 \mathrm{U}}:{ }^{23} \mathrm{U}:{ }^{226 \mathrm{Ra}}$.

Male rats exhibited an increased incidence in malignant tumors of all types at multiple intravenous ${ }^{20} \mathrm{Po}$ doses of $0.85,3.7$, and $11.1 \mathrm{~Bq}(0.023,0.1$, and 0.3 uCi)/kg/month (Casarett 1964b). Carcinogenic effects of Po could not be established for individual malignancies. Interestingly, a carcinogenic effect of Po was not seen in females due at least in part to a reduction in the incidence of mammary carcinoma with increasing dose and shorter survival time. Casarett noted that the increasing ovarian atrophy resulting from increased doses may have a role in the reduction of cancer incidence, since normal ovarian function favors the development of mammary neoplasms in rats. A similar carcinogenic effect of Po in Sprague-Dawley rats was not observed (Spoerl and Anthony 1956). Many tumors were observed in their study population (36\% of the rats developed tumors), but the incidence was not significantly greater than that of the control group. 
The carcinogenic effect of Po on the rat lung was observed after intratracheal administration of 37 and $74 \mathrm{~Bq}$ ( 1 and $2 \mathrm{uCi}$ ) per lung (Dusan et al. 1977). The incidence of tumors was enhanced when the Po was administered in conjunction with quartz dust, which increases Po retention and therefore increases dose to pulmonary tissue. Multiple intratracheal instillations totaling from $5.6-111 \mathrm{~Bq}(0.15-3 \mathrm{uCi}){ }^{20} \mathrm{Po}$ resulted in malignant lung tumors in 47 to $91 \%$ of exposed Syrian golden hamsters (Little et al. 1973). Tumor frequency was greater when a lower but relatively uniform dose was delivered to lung tissue compared to when a higher dose was delivered to a small volume of tissue. The carcinogenic effect of single intratracheal instillations of $20 \mathrm{Po}$ in saline was enhanced by subsequent instillations of Po free saline, indicating the importance of noncarcongenic secondary factors in the expression of radiation-induced lung cancer (Little et al. 1985).

\subsubsection{Clinical Effects In Man}

Little data has been reported describing clinical effects of Po-induced injury in man. Workers who had estimated body burdens of 37-185 Bq (1-5 uCi) ${ }^{20}$ Po developed hematologic changes, asthenia, functional impairment of the liver, kidneys, and reproductive organs, and changes in protein, carbohydrate, and pigment metabolism (Kozlova and Omelianenko 1963). Two episodes have been described whereby adolescents came in contact with a ruptured Po-Be source. In one incident, four individuals had estimated 20Po body burdens ranging from 18.5-399.6 Bq (0.5-10.8 uCi) (Guskova et al. 1964). Radiation sickness was not observed over an 18 month period, but changes in liver function (increased blood levels of bilirubin) and kidney function (decreased flow of renal plasma) occurred. Following the second incident, ten children with estimated ${ }^{20} \mathrm{Po}$ 
body burdens ranging from 7.4-259 $\mathrm{Bq}(0.2-7, \mathrm{uCi})$ showed no clear changes in general health over a four year period, although some impairment of the protein-forming function of the liver beginning at 21 months was observed (Shantyr et al. 1969).

Three chemists inadvertantly exposed to a $210 \mathrm{Po}$ aerosol sustained estimated maximum doses of $4.8 \mathrm{~Bq}(0.13 \mathrm{uCi}) / \mathrm{kg}, 7.0 \mathrm{~Bq}(0.19 \mathrm{uCi}) / \mathrm{kg}$, and $42.2 \mathrm{~Bq}(1.14$ $\mathrm{uCi}) / \mathrm{kg}$, corresponding to body burdens of $10,11.8$, and $88.1 \mathrm{uCi}$, respectively (Naimark 1948). No evidence of kidney damage was found. Subclinical depression of the hematopoietic system was suspected for the two individuals receiving the higher doses, although the data were considered insufficient to support the findings. Clinical observations were made 15 years after four individuals inhaled ${ }^{20}$ Po which had escaped from a Po-Be source resulting in body burdens ranging from 5.6-49.2 Bq (0.15-1.33 uCi) (Jialiu et al. 1982). The general conditions of the patients were good and no obvious abnormalities were discovered. However, small spots were observed on the lens epithelia of two of the individuals. These may be related to the $20 \mathrm{Po}$ exposure since cataracts and other degenerative changes of the eye have been reported in dogs (Markelov et al. 1964; Volkova 1961) and rats (Sproul et al. 1964) which had been exposed by various routes.

\subsection{Epidemiology}

The mortality of more than 22,000 British workers employed by the Atomic Weapons Establishment has been studied (Beral et al. 1988). Of the 638 individuals who had been monitored for Po exposure at some point during their employment, an excess standardized mortality ratio $(\mathrm{p}=0.03$ ) was determined for cancer of the kidney, although it was based on only three deaths. It should be noted that many individuals in the cohort were monitored for internal contamination by more than one radionuclide, and that two of the three individuals who died from kidney cancer were also monitored for uranium. 
To date, no epidemiological studies of a dose-response nature have been published on the health effects caused by Po exposure. The Mound Laboratory cohort is the largest group of persons occupationally exposed to ${ }^{20} \mathrm{Po}$. The dosimetry data which can be generated with the model developed from this research will be used by epidemiologists at the Los Alamos National Laboratory in their ongoing investigation of mortality among the Mound employees. 
TABLE 2.1 EXPERIMENTAL DATA ON THE BIOLOGICAL RETENTION OF 20PO IN VARIOUS TISSUES FOLLOWING INTRAVENOUS ADMINISTRATION*

\begin{tabular}{lcccc}
\hline \hline \multicolumn{5}{c}{$\begin{array}{c}\text { Biological Half-Time } \\
\text { (days) } \\
\text { Species }\end{array}$} \\
\hline \multirow{5}{*}{ Tissue } & Rabbit & Rat & Mouse & ICRP 30 \\
\cline { 2 - 5 } Kidney & 18 & 38 & 43 & 50 \\
Liver & 11 & 11 & 43 & 50 \\
Spleen & 8 & 31 & 18 & 50 \\
Lung & 8 & 47 & 23 & \\
Muscle & - & 38 & 42 & \\
Blood & - & 56 & - & \\
Skeleton & - & 23 & - & \\
Lymph Nodes & - & 56 & - & \\
\hline \multirow{5}{*}{ Reference } & Moroz and Par- & Stannard & Finkel et al. & ICRP 1979 \\
& fenov 1972 & $1964 \mathrm{~b}$ & 1953 & \\
\hline \hline
\end{tabular}

- adapted from Moroz and Parfenov 1972 
TABLE 2.2 URINARY EXCRETION OF PO BY HUMAN SUBJECTS*

\begin{tabular}{|c|c|c|c|}
\hline \multirow[b]{2}{*}{ Days Post } & \multicolumn{3}{|c|}{ Per Cent Injected Dose Excreted Per Day } \\
\hline & Subject 1 & Subject 3 & Subject 4 \\
\hline 1 & 0.2 & 0.090 & 0.069 \\
\hline 2 & 0.048 & 0.125 & 0.063 \\
\hline 3 & 0.056 & 0.153 & --. \\
\hline 4 & 0.038 & 0.146 & 0.056 \\
\hline 5 & 0.031 & $-\ldots$ & 0.064 \\
\hline 6 & 0.030 & 0.059 & 0.060 \\
\hline 7 & 0.021 & 0.157 & 0.052 \\
\hline 8 & 0.033 & 0.086 & 0.053 \\
\hline 9 & -- & 0.080 & 0.044 \\
\hline 10 & --- & 0.103 & $\ldots$ \\
\hline 11 & ... & 0.077 & 0.044 \\
\hline 12 & --- & -- & 0.040 \\
\hline 13 & --- & 0.059 & 0.038 \\
\hline 14 & $\ldots$ & 0.080 & $\ldots$ \\
\hline 15 & -.. & 0.070 & --- \\
\hline 16 & -.- & 0.069 & -.- \\
\hline 17 & --- & 0.070 & --- \\
\hline 18 & --- & 0.056 & -- \\
\hline 39 & -.- & 0.043 & --- \\
\hline 43 & 0.016 & -.. & - - \\
\hline 70 & $\ldots$ & 0.021 & --- \\
\hline
\end{tabular}

- data from Fink (1950) 
TABLE 2.3 URINARY PO EXCRETION PARAMETERS IN MAN`

\begin{tabular}{ccccc}
\hline \hline Patient & $\begin{array}{c}\text { Half-Time** } \\
\text { (days } \pm \text { se) }\end{array}$ & P-value & $\begin{array}{c}\text { Intercept } \\
(\% \mathrm{DD} / \text { day } \pm \mathrm{se})\end{array}$ & P-value \\
\hline 1 & $32.0 \pm 2.4$ & $<0.05$ & $0.04 \pm 0.01$ & $<0.05$ \\
3 & $27.9 \pm 0.6$ & $<0.05$ & $0.11 \pm 0.01$ & $<0.05$ \\
4 & $13.9 \pm 0.5$ & $<0.05$ & $0.07 \pm 0.01$ & $<0.05$ \\
\hline \hline
\end{tabular}

- data from Fink (1950)

* Biological 
TABLE 2.4 SUMMARY OF EFFECTS OF PO ON EXPERIMENTAL ANIMALS•

\begin{tabular}{|c|c|c|c|c|c|}
\hline $\begin{array}{c}\text { Dose } \\
(\mathrm{kBq} / \mathrm{kg})\end{array}$ & Animal & Lethality & $\begin{array}{l}\text { Histo- } \\
\text { pathological }\end{array}$ & $\begin{array}{l}\text { Hemato- } \\
\text { logical }\end{array}$ & Gross \\
\hline $1.85-3.7$ & $\begin{array}{l}\text { cat, dog, } \\
\text { rabbit, } \\
\text { mouse }\end{array}$ & $\begin{array}{l}L D_{\text {sog }} \\
20 \text { days: } \\
2.96 \mathrm{kBq} / \mathrm{kg}\end{array}$ & $\begin{array}{l}\text { massive } \\
\text { tissue } \\
\text { destruction }\end{array}$ & $\begin{array}{l}\text { severe loss of } \\
\text { lymphocytes, } \\
\text { WBC, RBC, } \\
\text { hemoglobin }\end{array}$ & $\begin{array}{l}\text { weight loss, } \\
\text { lethargy, } \\
\text { death }\end{array}$ \\
\hline $1.30-1.67$ & rat & $\begin{array}{l}\mathrm{LD}_{\text {so, }} \\
20 \text { days: } \\
1.48 \mathrm{kBq} / \mathrm{kg}\end{array}$ & $\begin{array}{l}\text { massive } \\
\text { tissue } \\
\text { destruction }\end{array}$ & $\begin{array}{l}\text { severe loss of } \\
\text { lymphocytes, } \\
\text { WBC, RBC, } \\
\text { hemoglobin }\end{array}$ & $\begin{array}{l}\text { weight loss, } \\
\text { lethargy, } \\
\text { death }\end{array}$ \\
\hline $0.37-1.1$ & rat & $\begin{array}{l}L D_{50,}, \\
50-250 \\
\text { days }\end{array}$ & $\begin{array}{l}\text { rapid kidney } \\
\text { damage }\end{array}$ & $\begin{array}{l}\text { moderate to se- } \\
\text { vere loss of } \\
\text { WBC, effects on } \\
\text { RBC and } \\
\text { hemoglobin as rat } \\
\text { is dying }\end{array}$ & weight loss \\
\hline $0.04-0.4$ & rat & $\begin{array}{l}\mathrm{LD}_{50} \\
300-500 \\
\text { days }\end{array}$ & $\begin{array}{l}\text { slow kidney } \\
\text { damage }\end{array}$ & $\begin{array}{l}\text { early WBC re- } \\
\text { duction followed } \\
\text { by recovery }\end{array}$ & $\begin{array}{l}\text { moderate } \\
\text { weight loss }\end{array}$ \\
\hline $0.02-0.04$ & rat & $\begin{array}{l}10-20 \% \\
\text { reduced } \\
\text { life span, } \\
\text { male only }\end{array}$ & $\begin{array}{l}\text { occassional mild } \\
\text { kidney } \\
\text { and/or thyroid le- } \\
\text { sions }\end{array}$ & none & none \\
\hline 0.01 & rat & none & none & none & none \\
\hline
\end{tabular}

-adapted from Spoerl and Anthony (1956) 
Figure 2.1 Retention of 210Po in testes and kidneys of mice following intraperitoneal exposure to a weakly acidic Po solution (data from Samuels 1966b).

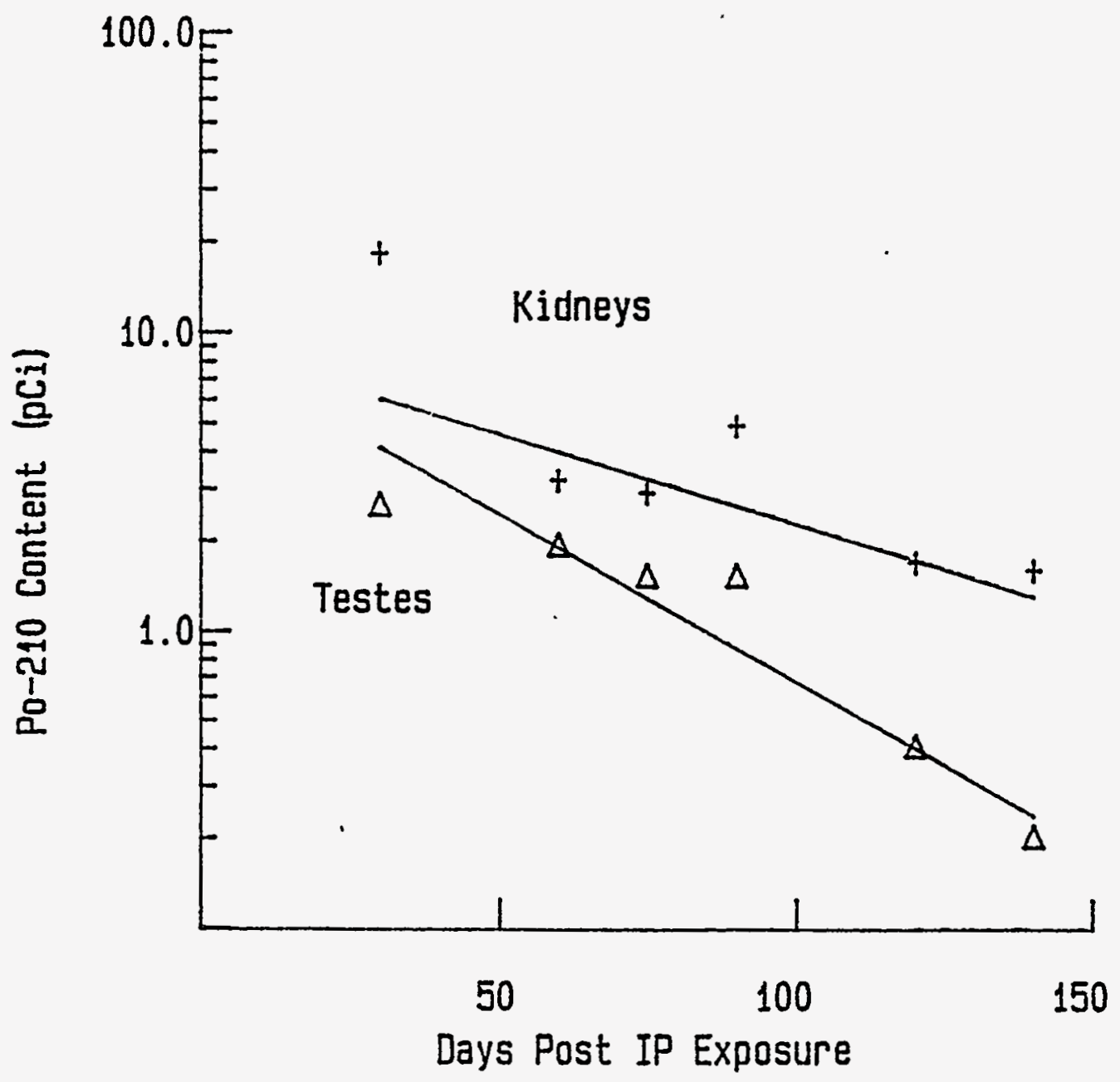


Figure 2.2 Urinary and fecal excretion of Po by rats following intravenous administration of $210 \mathrm{Po}$ chloride (curves fitted to data presented by Stannard 1964a).

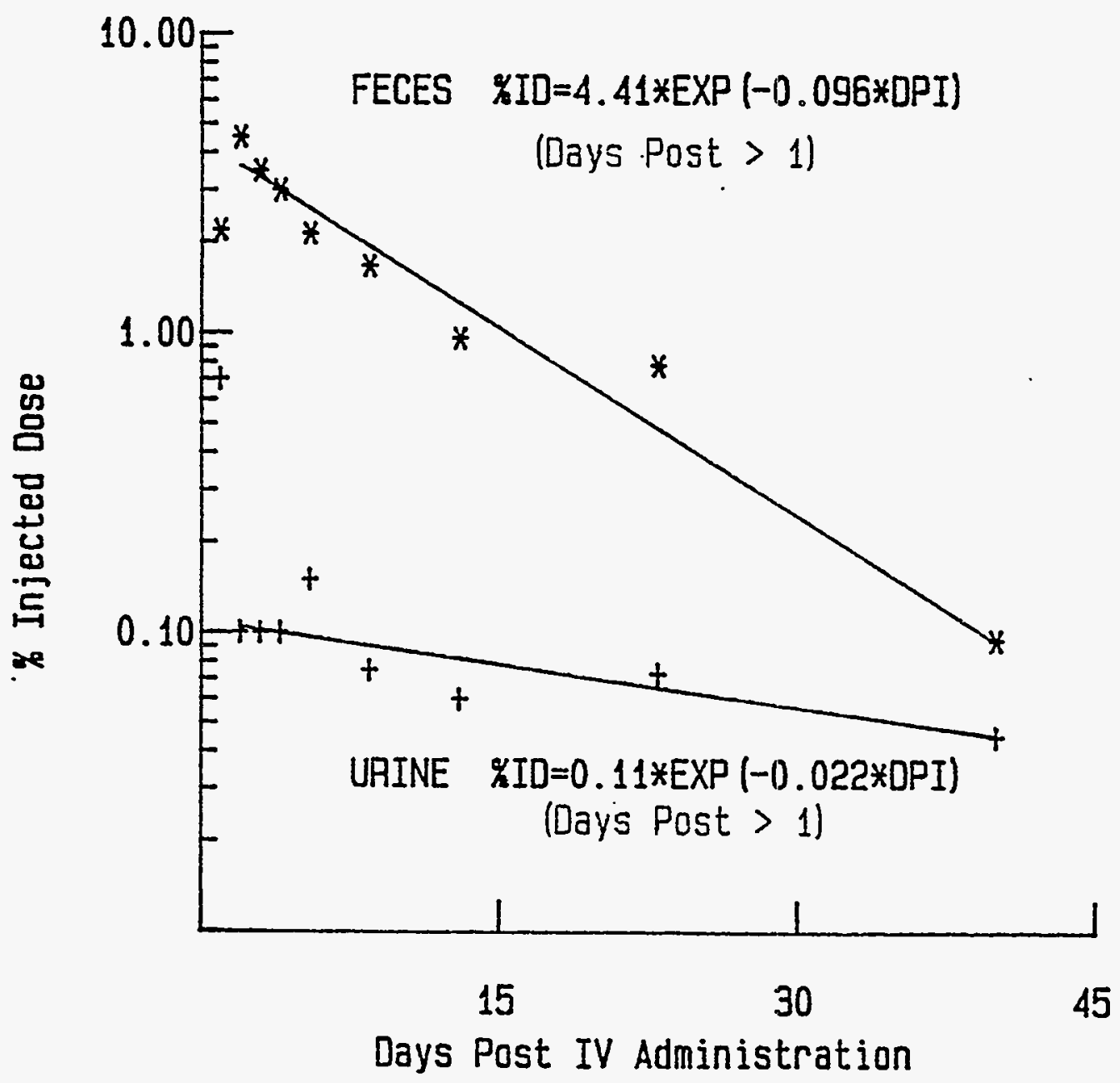


Figure 2.3 Urinary ${ }^{210}$ Po excretion by man from three volunteers after IV administration of Po chloride (data from Fink 1950).

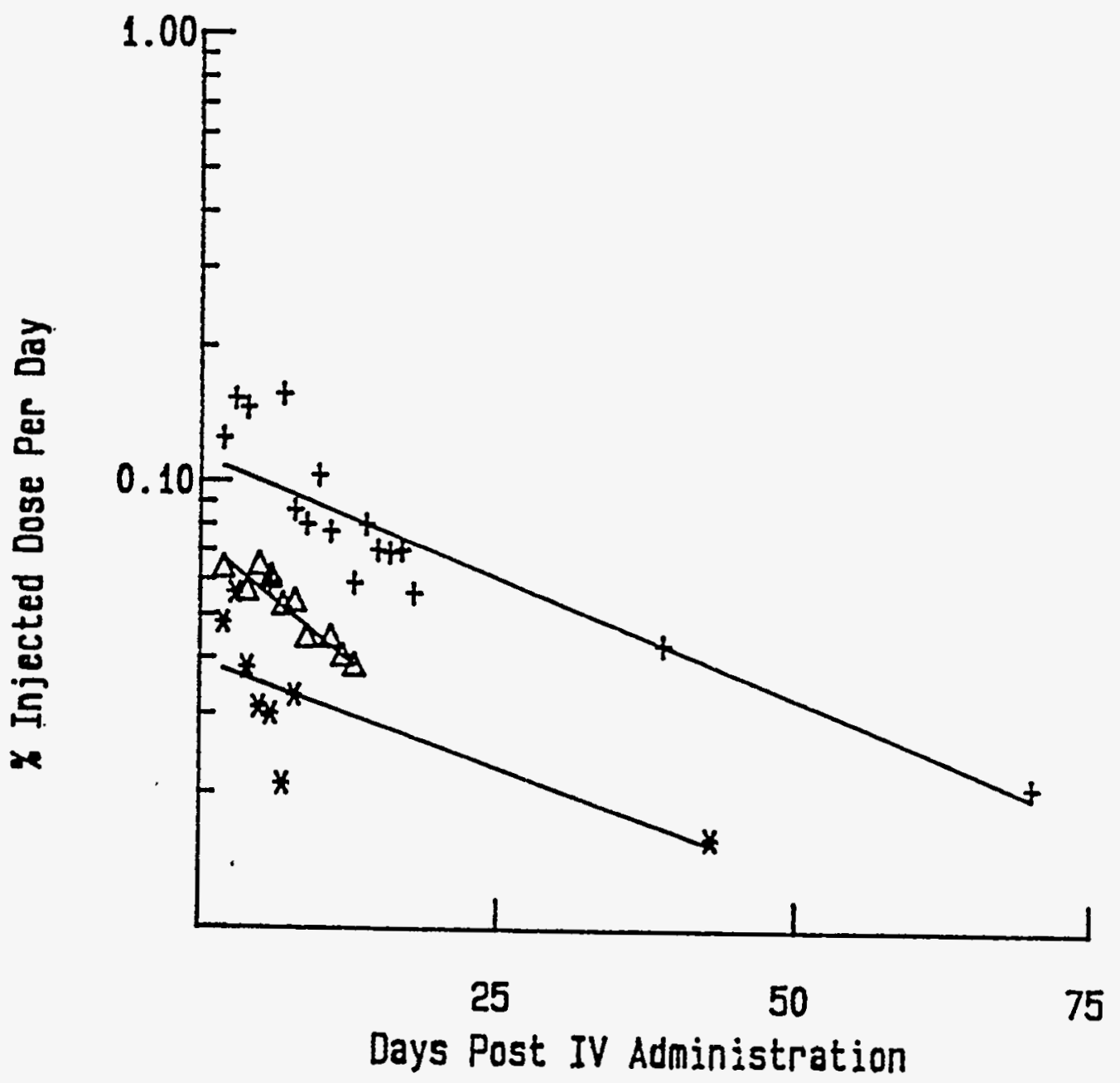


Figure 2.4 Urinary and fecal excretion of Po by a male who had handled a foil contaminated with approximately $44.4 \mathrm{MBq}$ (1.2 Ci) of 200 Po (curves fitted to data presented by Silverman 1944).
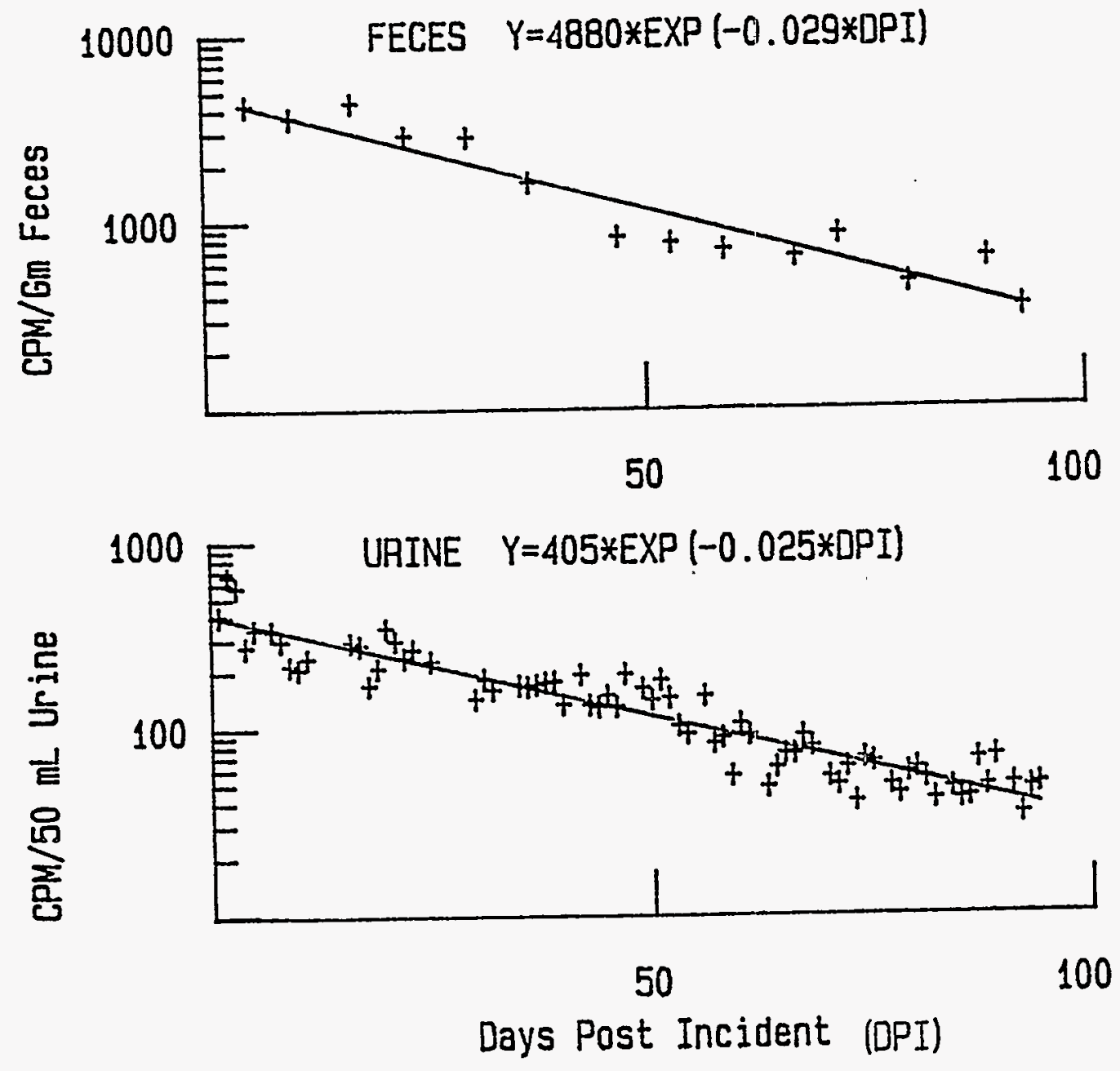


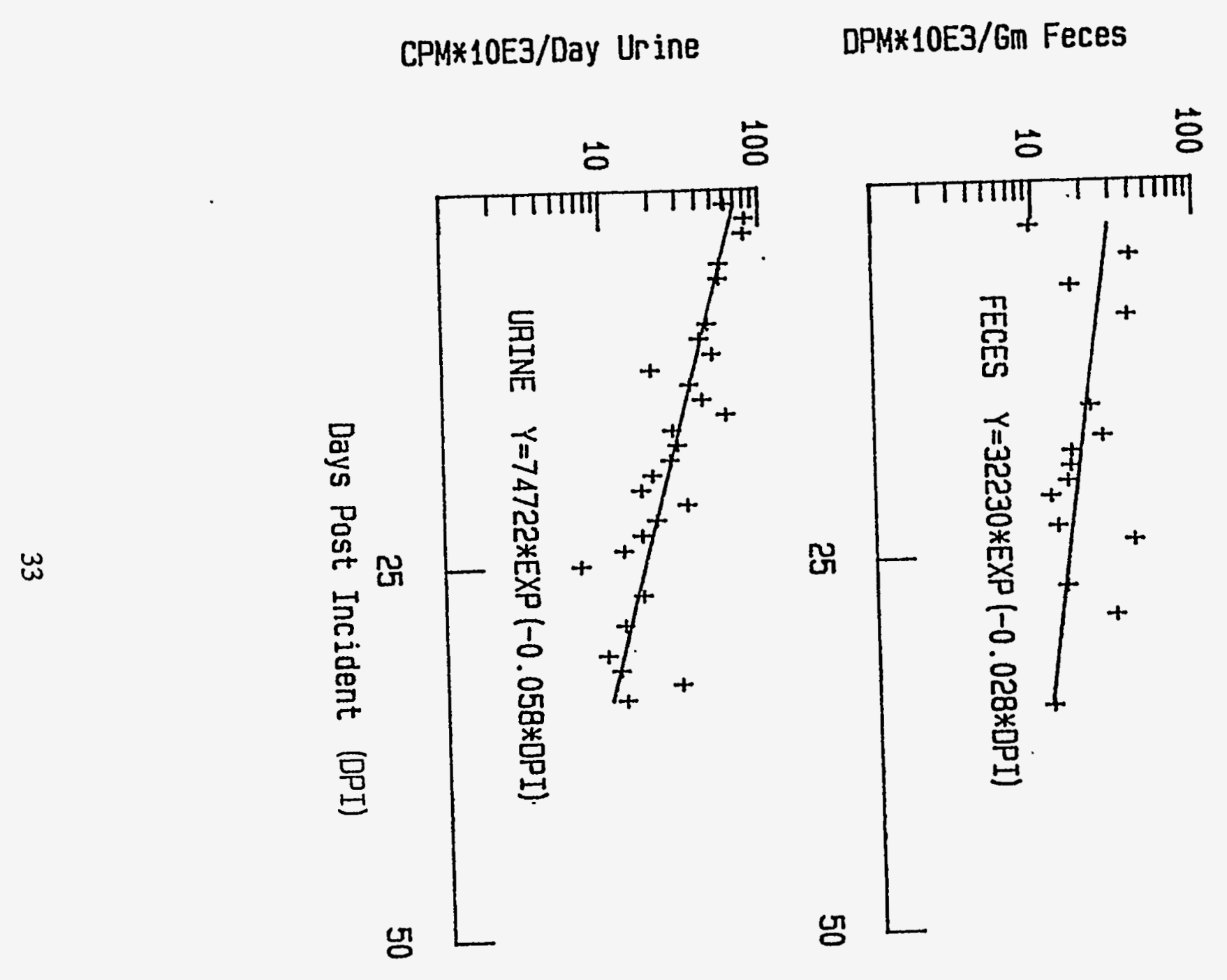

零

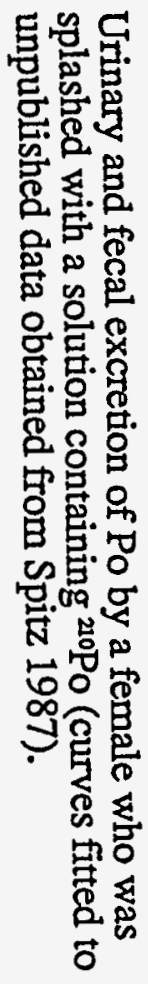


Figure 2.6 Retention of 210Po in the blood of a female who had been splashed with a solution containing an unknown but significant quantity of the radionuclide (curve fitted to unpublished data obtained from Spitz 1987).

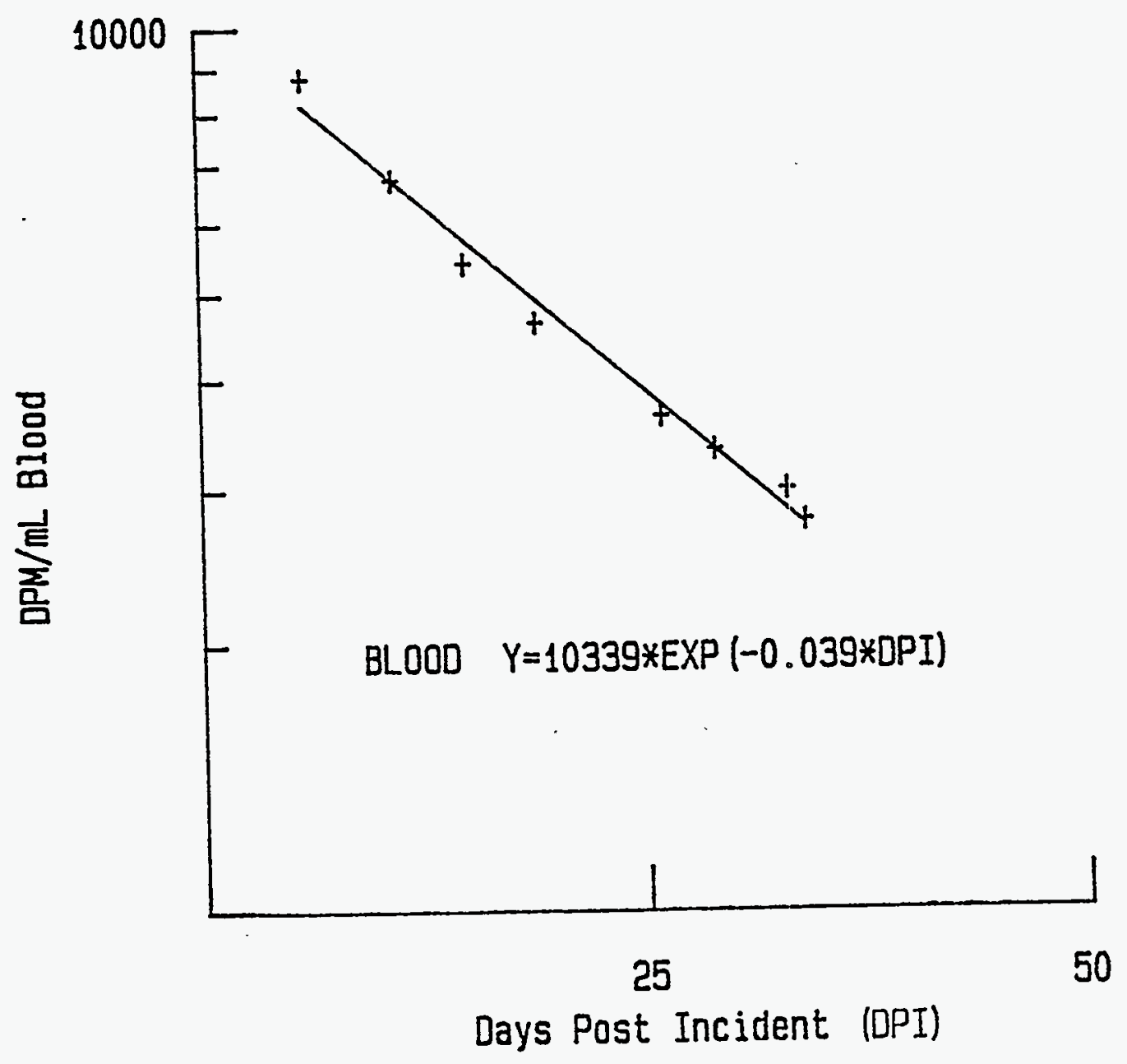




\section{Experimental Methods}

\subsection{Rationale For Using Non-human Primates}

Studies of Po metabolism in any non-human primate species have not been previously reported. The excretion rates, retention times, and distribution of $20 \mathrm{Po}$ within and among various body sites after controlled exposures in baboons and tamarins were determined and utilized in the Po dosimetry model described in Section 5.

The assumption that kinetics and branching fractions observed in the baboon are applicable to humans is based on genetic considerations, anatomical similarities between the two species, and the body of literature recognizing the physiological parallelism which exists in many areas. These include metabolic comparability in relevant areas of hematology, blood chemistry, reproduction, endocrinology, and the metabolism of pharmacological drugs (Vagtborg 1967). In addition, biokinetic studies of radionuclides, have shown that baboons are similar to man with regard to retention and excretion patterns for those bone-seeking actinides with relatively long half-times (Cohen and Wrenn 1972) as well as for the shorter lived actinide curium (Cohen et al. 1983).

\subsection{Mode of Exposure}

The metabolic studies of $P o$ in non-human primates consisted entirely of animals exposed via intravenous administration. The usefulness of utilizing this route of exposure have been eloquently stated by Fink (1950, p.40):

"...it permits the introduction and immediate wide dispersal within the body of a definite amount of material at a definite time and thus gives results that are ordinarily more easily interpretable than in the case of experiments in which indefinite amounts of material may 
gradually continue to enter the general circulation over indefinite periods of time. The interpretation of the results of experiments in which more commonly encountered routes of entry are employed is then made easier by the groundwork of intravenous experiments available for comparison. Similarly, single doses were used to facilitate the execution of the experiments and the interpretation of results."

There are, however, some obvious limitations to intravenous metabolic studies. Unlike inhalation or ingestion, the intravenous route is not the most frequently encountered exposure route (except for the occasional wround accident) for man. Injected 20.0 does not pass through a biological membrane such as the lung or gastrointestinal lining prior to entering the blood. Consequently, results from intravenous studies are highly dependent on the physicochemical form of the Po injected. However (as will be discussed in the next section), the form of $210 \mathrm{Po}$ used in these studies represents to as great a degree as possible that which would pass through a membrane following deposition in an external organ.

\subsection{Injection Solution}

The physicochemical form of a material significantly affects its biological behavior. As discussed in Sections 2.1.1 and 2.1.2, some metabolic parameters observed in previously published studies of Po showed differences when a soluble solution (e.g., Po citrate) was compared to a colloidal solution (e.g., neutralized Po chloride).

The colloidal properties of Po were studied by filtering solutions through molecular filters under various conditions (Morrow et al. 1964a). Drastic changes in filterability were produced by altering the ionic strength and the complexing agent. In general, solutions with noncomplexing constituents such as $\mathrm{NaCl}-\mathrm{NaOH}$ were less than $10 \%$ filterable at $\mathrm{pH} 6-8$ while greater than $90 \%$ filterable when the solution $\mathrm{pH}$ was dropped 
to 2 or raised to 10 . Addition of complexing agents such as sodium citrate or sodium carbonate produced almost complete filterability of Po. It has been concluded from one study that filterability of Po is greatly enhanced by citrate (Feldman and Saunor 1964). The authors further conclude that in tracer concentrations of Po in blood, about $75 \%$ is bound to citrate.

Three ${ }^{20} \mathrm{Po}$ solutions were used to investigate the retention by the blood and distribution among the reticuloendothelial system (RES) tissues of colloidal Po in rats (Thomas and Stannard 1964a): (1) neutral NaOH (pH of 7); (2) $0.15 M$ citrate; and (3) acid diluted with $0.5 \mathrm{~N} \mathrm{HCl}$. Initial disappearance from the blood of $20 \mathrm{Po}$ in the acid and citrate solutions was much slower than in the neutralized solution. However, as shown in Figure 3.1, the rate of 210Po loss from the blood was slower for the neutralized solution after the initial clearance of the nuclide. The rapid initial blood loss of neutralized 20Po was reflected in the corresponding uptake by the RES tissues relative to the citrate and acidified solutions. As shown in Table 3.1, only $13.7 \%$ of the 210 Po was recovered in the RES tissues from the citrate solution compared to $62.3 \%$ and $38.9 \%$ for the two neutralized solutions (aged 4 months and 15 days, respectively) at 20 minutes post injection. The relatively high RES tissue ${ }^{20}$ Po content would be expected since the radionuclide exists predominantly in a colloidal state after neutralization of the solution (Morrow et al. 1964a; Thomas and Stannard 1964b).

The criteria for selection of a Po injection solution for use in the non-human primate metabolic studies were as follows: 
(1) A chemical matrix which would keep Po in a stable, "soluble" form in order to emulate the diffusible state of Po across biological membranes.

(2) A chemical matrix which would be compatible with and non-toxic to blood constituents.

(3) Solution $\mathrm{pH}$ which was comparable to previous Po studies.

(4) A solution which was ultrafilterable $(0.22 u \mathrm{M})$ to ensure a pyrogen and colloidal free medium.

(5) A solution which was reproducible and easy to prepare.

The citrate solution best meets the specified criteria. Its capacity to emulate a diffusible state of ${ }^{210}$ Po capable of crossing biological membranes was exhibited in cats (Morrow et al. 1964b). When colloidal 210Po solutions were administered via gavage, the acidic environment in the stomach caused 210Po aggregates to break up and hence become available for absorption to the same extent as soluble 210 Po citrate. Ionic Po or soluble complexes are most likely the principle forms absorbed (Stannard and Casarett 1964); once entering the circulation from the gastrointestinal tract, the chemical form played only a secondary role in Po organ distribution and excretion. Morrow et al. (1964a) concluded that "The citrate complex appears to be a form of Po compatible with biological use that will be relatively free of colloid on administration." The procedure for preparation of the $210 \mathrm{Po}$ citrate solution for intravenous administration to non-human primates is described in Appendix C.

\subsection{Metabolic Studies of ${ }^{210} \mathrm{Po}$ In Non-human Primates}

Two adult female tamarins (Saquinus labiatus) were each given single intravenous injections of ${ }^{210} \mathrm{Po}$ citrate in the femoral vein on two separate occasions (Table 3.2). Excreta collections were made daily for a period of 90 days post injection after the first injection and for 14 days after the second injection. A few urine and fecal samples from tamarin \#T504 were also collected approximately 200 days post injection. Urine samples 
were acidified with concentrated $\mathrm{HCl}$ and fecal samples were dried prior to storage and analysis. Infrequent blood samples were taken from T500 and T504; entire blood samples were analyzed.

Six female adult baboons (Papio anubis) were exposed to $20 \mathrm{Po}$ as the citrate via single injection into the femoral vein. Doses were chosen which would be both chemically and radiologically non-toxic. Baboons B806 and B1046 were injected with approximately $37 \mathrm{~Bq}(1 \mathrm{uCi}) / \mathrm{kg}$ (compared with the 7.4-11.1 $\mathrm{Bq} / \mathrm{kg}$ injected into the other baboons) so as to permit radiochemical determinations of $210 \mathrm{Po}$ in bioassay samples and tissues at times as great as 90 days post exposure. Injection data is summarized in Table 3.3.

The tamarins were housed on site at New York University Medical Center (NYUMC) while the baboons were housed at the Laboratory for Experimental Medicine and Surgery in Primates (LEMSIP) of the NYUMC. All animals were maintained in individual cages positioned over excreta collectors constructed from wood, wire mesh, and plastic lining. Wastes fell through the floor bars of the cages onto the wire mesh surface. The plastic liner was extended beneath the wire mesh. A hole was cut in the center of the plastic to funnel the urine into a collecting basin. Fecal material remained on the wire mesh and was easily transfered into plastic cups.

Urine and fecal samples were collected daily (urine only from B514). Urine samples were acidified with $1 \mathrm{~mL}$ of concentrated $\mathrm{HCl}$ per $100 \mathrm{~mL}$ of urine (to retard the loss of Po to container walls) and then stored for analysis. Feces samples were dried in plastic cups and stored for analysis.

Urine samples were analyzed using a procedure modified from that originally developed for water, vegetation, soil, and Microsorban filters at the U.S. Department of Energy's Environmental Measurements Laboratory (EML 1983). The modifications 
involved changes in plating times and temperature. The procedure (summarized in Appendix A) uses a $50 \mathrm{~mL}$ aliquot of sample spiked with ${ }^{2} \mathrm{Po}$ tracer which is wet ashed with concentrated $\mathrm{HNO}_{3}$. Once digested, the sample is dissolved in $100 \mathrm{~mL}$ of $0.5 \mathrm{NHCl}$ and a $10 \mathrm{~mL}$ aliquot is transfered to a plating cell. The plating cell (Fig. 3.2) consists of an inverted $30 \mathrm{~mL}$ polypropylene bottle with the bottom removed and a screw cap-mounted base. A $2.22 \mathrm{~cm}$ diameter disc punched from a $0.64 \mathrm{~mm} \mathrm{Ni}$ sheet is placed in the cap. The bottle is screwed into the cap forming a leak-free seal with the disc, and the $10 \mathrm{~mL}$ sample solution is poured into the inverted bottle. Approximately $10 \mathrm{~mL}$ of $0.5 \mathrm{~N} \mathrm{HCl}$ is added to the plating cell along with $1 \mathrm{~mL}$ of saturated ascorbic acid, reducing $\mathrm{Fe}^{+3}$ which interferes with the spontaneous deposition of Po (Hursh 1958).

A glass stirring paddle suspended from an electric mótor capable of maintaining at least $100 \mathrm{rpm}$ is suspended in the solution. Each sample is stirred for two hours. Polonium is spontaneously deposited on one side of the Ni disc. The disc is removed, rinsed with water and ethanol and counted with a $300 \mathrm{~mm}^{2}$ silicon surface barrier solid state detector. The $5.15 \mathrm{MeV}$ and $5.3 \mathrm{MeV}$ alpha peaks of ${ }^{208 \mathrm{Po}}$ and ${ }^{210 \mathrm{Po}}$, respectively, are resolved using a 1024 channel multichannel analyzer (MCA). The recovery fraction is directly determined for each sample using the ${ }^{208} \mathrm{Po}$ tracer.

The procedure used at Mound Laboratory for determining the ${ }^{210} \mathrm{Po}$ level in urine was duplicated. A comparison of the urinalysis method (which includes addition of $208 \mathrm{Po}$ tracer and wet ashing prior to spontaneous deposition) with the direct deposition method used at Mound was then performed to test the effect of radiochemical procedure on recovery. A description of the study and the results are the subject of Section 5.1.

The analytical procedure for the determination of 210 Po in fecal samples is the same for the tamarin and baboon samples, with one exception. While the entire mass of a tamarin fecal sample is wet ashed in concentrated $\mathrm{HNO}_{3}$, the baboon fecal samples have 
to be homogenized using a Spec Ball Mill Shaker prior to taking a 10-15 gram aliquot for analysis. The samples are wet ashed to dryness and brought to a volume of $100 \mathrm{~mL}$ in dilute $\mathrm{HCl}$. A $10 \mathrm{~mL}$ aliquot is taken, traced with a suitable amount of $208 \mathrm{Po}$, reduced to dryness and brought back up to $100 \mathrm{~mL}$ volume in dilute $\mathrm{HCl}$ prior to plating. ${ }^{1}$

Whole blood samples ( $10 \mathrm{~mL}$ heparinized) were drawn periodically post injection. On average, samples were taken from each animal (depending on scheduled sacrifice time) at 1 hour post injection, and then daily over the first week followed by weekly and then monthly sampling. Four blood samples were drawn from B1060 during the first hour post injection so as to accumulate the data necessary to describe the rapid phase kinetics exhibited by Po in the blood.

Hematocrits were taken and then blood samples were separated into cellular and serum constituents by ultracentrifugation. One $\mathrm{mL}$ aliquots of red cells and plasma were spiked with ${ }^{203} \mathrm{Po}$ tracer, wet ashed with concentrated $\mathrm{HNO}_{3}$, and converted to a $1 \mathrm{~N} \mathrm{HCI}$ solution prior to plating of Po onto Ni discs. Radiochemical procedures for the analyses of $210 \mathrm{Po}$ in bioassay samples are given in Appendix A.

With the exception of B514, all of the baboons were sacrificed as part of the Po distribution study. Baboons were sacrificed at 1 day, 1 week, 2 weeks, 1 month, and 3 months post exposure. All sacrifices were carried out by exsanguination. Complete necropsies were conducted immediately following death, with all soft tissues and organs removed and individually weighed. Thorough disarticulation of the skeletons were then carried out. The entire skeleton of B1046 (the first animal to be sacrificed) was analyzed radiochemically as were aliquots of muscle samples taken from various areas of the body;

1 At the outset of the study, a few samples were homogenized and split. An entire aliquot was traced with ${ }^{208} \mathrm{Po}$ prior to wet ashing. The other aliquot was ashed, diluted and then traced. The comparison showed that no ${ }^{210} \mathrm{Po}$ was lost during the initial wet ashing process. 
concentration of ${ }^{210} \mathrm{Po}$ in skeleton and muscle were seen to be relatively consistent. Therefore, the total skeletal 210Po burdens of the other four animals were calculated based on the activity measured in the right femur, and the total muscle 210 Po burdens were calculated by multiplying the average concentration of two or three samples taken from different areas of the body by the entire muscle mass.

Soft tissues and skeleton samples were stored in a freezer. Radiochemical analysis of all major organs were performed in addition to the skeletal and muscle samples. The radiochemical procedure utilized was similar to those described above for the other types of bioassay samples. Wet ashing in concentrated $\mathrm{HNO}_{3}$ preceded spiking with a suitable quantity of ${ }^{208}$ Po tracer. Samples were brought to dryness, converted to a $1 \mathrm{~N} \mathrm{HCl}$ solution and plated onto $\mathrm{Ni}$ discs prior to alpha spectrometry.

$\underline{\text { Residual Blood Study }}$

Polonium exhibits a relatively long retention time in the blood (Fink 1950; Stannard 1964b). It was considered possible therefore that analyses of tissues for 200 Po content would be artificially high due to the presence of some ${ }^{20} \mathrm{Po}$ in the residual blood contained within the tissue or organ mass, even after exsanguination. To account for this possibility, residual blood measurements were made for all soft tissue and skeletal samples by utilizing the following modified ${ }^{51} \mathrm{Cr}$ red blood cell labeling technique (Frank et al. 1979): A $5 \mathrm{~mL}$ blood sample was drawn from each baboon approximately 24 hours prior to exsanguination. The red blood cells were separated and labelled with 0.7-4.6 $\mathrm{kBq}(20-125 \mathrm{uCi}){ }^{\mathrm{s}} \mathrm{Cr}$. The labelled red cells were incubated for 30 minutes and refrigerated overnight. After removal of the culture media, the red cells were washed several times with sterile saline. The $10 \mathrm{~mL}$ aliquot of labelled blood was drawn into a syringe and reinjected into the animal about 10 minutes prior to exsanguination. Further details of the procedure appear in Appendix B. 
Chromium-51 emits a $325 \mathrm{keV}$ gamma ray with an abundance of $9.83 \%$. All of the baboon samples were counted for this photon with an 8 " $\times 4$ " NaI(Tl) detector in the whole body counting facility prior to $20 \mathrm{Po}$ analysis (a typical spectrum appears in Figure 3.3). The gamma rays emanating from the blood collected during exsanguination were counted to quantify the blood ${ }^{51} \mathrm{Cr}$ concentration. Tissue sample counts of the $325 \mathrm{keV}$ ${ }^{s 1} \mathrm{Cr}$ gamma were then used to quantify the volume of blood contained within the sample mass. The concentration of ${ }^{210} \mathrm{Po}$ in the blood at time of death was determined radiochemically. Tissue sample 20 Po measurements could then be separated into tissue content and residual blood content. The results from the residual blood procedure appear in Section 4.4.3.

\subsection{Counting System Descriptions}

Two types of alpha radiation detection systems were used for these studies. Polonium deposited spontaneously onto Ni discs from all bioassay samples were counted with $300 \mathrm{~mm}^{2}$ silicon surface barrier solid state detectors and analyzed by a 1024-channel per spectrum multichannel analyzer (MCA). A low background alpha/beta proportional counter was used for tracer and injection solution calibration and to count Po deposited on $\mathrm{Cu}$ discs out of raw urine as part of the study on the duplication of the Mound Laboratory procedure.

Gamma counting of the ${ }^{51} \mathrm{Cr}$ labelled erythrocytes in baboon organ and tissue samples was done with an $8 " \times 4 " \mathrm{NaI}(\mathrm{Tl})$ detector in the graded $\mathrm{Z}$ shielded whole body counting facility. Spectral analysis was accomplished using a MCA. 


\subsection{Data Handling}

Polonium-210 excretion and organ retention data were analyzed on a microcomputer via either the weighted nonlinear or linear least squares regression technique available on MicroTSP2 software. Nonlinear regression is an iterative technique which determines the best fit function (as defined statistically by the function with the minimum sum of squares of residuals). It can be used on both linear and nonlinear data. Partial derivatives are computed on initial parameter estimates and data are regressed to those derivatives. The sum of squares of the residuals is calculated. The parameter estimates are then altered slightly in an attempt to improve the fit and the process repeats, driving eventually to the parameter estimates resulting in the minimum sum of squares of the residuals (Draper and Smith 1981).

For some data sets, a linear regression performed on the log transformed data resulted in a sum of squares of the residuals which was lower than that from the nonlinear model. A comparison of the regression statistics (such as the standard error of the regression and standard errors of the parameter estimates) from both the linear and nonlinear techniques provided the basis for the selection of the best statistical regression.

In regression analysis, the assumption is made that all observations have equal variance (Neter and Wasserman 1974). The variance in bioassay data is influenced by the variance associated with the analytical procedure, the count rate error and most importantly by the biological variance. The assumption of heteroscedasticity is incorrect for the data sets generated in the study of Po metabolism in non-human primates. The statistics generated by a least squares procedure are biased as a result of the unequal variances in the data. When regressing data to the function $Y=k \cdot \exp [-l a m b d a \cdot X]$, the

2 MicroTSP was developed and is currently distributed by Quantitative Micro Software, Irvine, California. 
best fit curve tends to lie closest to the high data points so as to minimize the sum of squares of the residuals. But these data points have the largest biological variance; they should therefore be given less relative weight in determining the line of best fit.

A weighting series may be applied to the data prior to performing the regression to obtain parameter estimates with minimum variance. ${ }^{3}$ The weighting series used for the majority of the metabolic data was based on the assumption that the variances are proportional to the "predicted" excretion or retention model. Briefly, the applicable function is regressed to the unweighted data. The weighting series is then generated from the residuals squared for each datum and its corresponding "predicted" value. MicroTSP calculates the mean of the weighting series and then multiplies both the dependent (e.g., $\mathrm{cpm} / \mathrm{mL}$ urine, per cent injected Po/day, organ Po content, etc.) and independent (e.g., days post first sample date, days post injection, etc.) variable by the ratio of the weighting series to its mean (Hall and Lilien 1987). The function is then regressed to the "weighted" data to determine the model parameter estimates and the least squares curve.

\subsection{Quality Control}

Counting system paramaters such as background count rate and detection efficiency were routinely monitored throughout the study period. Backgrounds were usually run overnight in the alpha spectrometry chambers and averaged $0.02 \pm 0.01 \mathrm{cpm} 20 \mathrm{Po}$ for 154 measurements. A total of 46 reagent blank samples were processed; they averaged $0.04 \pm$ $0.03 \mathrm{cpm} 200 \mathrm{Po}$. The detection efficiency was maintained by calibration with a ${ }^{208} \mathrm{Po}$

standard traceable to the National Bureau of Standards. A relatively high activity

3 The data weighting technique utilized was modified from a technique described by Skrable et al. 1988.

4 The ${ }^{208}$ Po standard was plated from Standard Reference Material \#4327 which had a specific activity of $77 \mathrm{~Bq} / \mathrm{g} \pm 1.4 \%$. 
${ }^{241,233} \mathrm{Am}$ source (10548 dpm) was also utilized to check the detection efficiencies. The efficiency of all three silicon surface barrier detectors was consistent, averaging $0.28 \pm$ $0.005 \mathrm{cpm}$ per dpm.

The alpha proportional counter had an average background count rate equal to one cpm. The efficiency was maintained with the ${ }^{208 \mathrm{Po}}$ standard as well as electroplated 239,200 Pu standards prepared by the United States Department of Energy's Environmental Measurement Laboratory. Alpha detection efficiency averaged $0.52 \pm 0.01 \mathrm{cpm}$ per dpm.

The $2.06 \mathrm{E}-3$ efficiency of the $\mathrm{NaI}(\mathrm{Tl})$ gamma detector was determined in the 320-350 keV region with a ${ }^{133} \mathrm{Ba}$ stick source in a meter arc geometry (source purchased from the New England Nuclear Corporation). Background count rates were collected prior to sample counting and averaged $268.4 \pm 10.9 \mathrm{cpm}$. The lower limit of detection (Altshuler and Pasternack 1963; Pasternack and Harley 1971; Harley 1986) for all counting systems are listed in Table 3.4 .

Blood and excreta samples collected from tamarins and baboons prior to administration were assayed to determine the average natural. levels of $20 \mathrm{Po}$. The background count rates were then subtracted from samples collected post injection to accurately calculate the percentage of administered dose in bioassay samples. 
TABLE 3.1 TOTAL PO RECOVERED IN THREE ORGANS OF THE RETICULOENDOTHELIAL SYSTEM AND PER CENT OF THIS TOTAL IN EACH ORGAN*

\begin{tabular}{|c|c|c|c|c|}
\hline $\begin{array}{l}\text { Solution } \\
\text { injected }\end{array}$ & $\begin{array}{l}\text { Total recovered } \\
\text { Po in RES } \\
\text { (\% dose) }\end{array}$ & $\begin{array}{l}\text { \% of } \\
\text { Lung }\end{array}$ & $\begin{array}{c}\text { otal in } \\
\text { Liver }\end{array}$ & $\begin{array}{c}\text { ch organ } \\
\text { Spleen }\end{array}$ \\
\hline Neutral \#1 & 62.3 & 47.4 & 41.6 & 11.1 \\
\hline Neutral \#2 & 38.9 & 7.0 & 89.2 & 3.9 \\
\hline Acid & 22.2 & 32.9 & 56.1 & 11.1 \\
\hline Citrate & 13.7 & 13.8 & 70.6 & 15.5 \\
\hline
\end{tabular}

- Tissues analyzed at 20 minutes after injection.

Neutral \#1, aged 4 months; neutral \#2, aged 15 days.

from Thomas and Stannard 1964a, p. 19. 
TABLE 3.2 TAMARINS USED IN STUDY OF PO METABOLISM

\begin{tabular}{lcccc}
\hline \hline Tamarin & Injection Date & $\begin{array}{c}\text { Body Weight } \\
(\mathrm{kg})\end{array}$ & $\begin{array}{c}\text { Dose } \\
(\mathrm{Bq} / \mathrm{kg})\end{array}$ & $\begin{array}{c}\text { Days on } \\
\text { study }\end{array}$ \\
\hline T500 & $1 / 30 / 87$ & 0.549 & 87.7 & 90 \\
T504 & $1 / 30 / 87$ & 0.550 & 94.4 & 90 \\
T500 & $5 / 12 / 88$ & 0.583 & 12.6 & 14 \\
T508 & $5 / 12 / 88$ & 0.440 & 13.7 & 14 \\
\hline \hline
\end{tabular}

TABLE 3.3 BABOONS USED IN STUDY OF PO METABOLISM

\begin{tabular}{lcccc}
\hline \hline Baboon & Injection Date & $\begin{array}{c}\text { Body Weight } \\
(\mathrm{kg})\end{array}$ & $\begin{array}{c}\text { Dose } \\
(\mathrm{Bq} / \mathrm{kg})\end{array}$ & $\begin{array}{c}\text { Days on } \\
\text { study }\end{array}$ \\
\hline B1054 & $4 / 01 / 87$ & 10.1 & 9.62 & 1 \\
B156 & $4 / 01 / 87$ & 11.0 & 8.88 & 7 \\
B1060 & $6 / 22 / 87$ & 16.6 & 8.14 & 14 \\
B1046 & $1 / 31 / 87$ & 13.0 & 29.6 & 30 \\
B806 & $1 / 31 / 87$ & 13.0 & 28.9 & 91 \\
B514 & $2 / 02 / 88$ & 16.5 & 5.55 & 80 \\
\hline \hline
\end{tabular}


TABLE 3.4 LOWER LIMITS OF DETECTION (LLD)

\begin{tabular}{lccc}
\hline \hline & \multicolumn{3}{c}{ Detector } \\
\cline { 2 - 4 } & $\begin{array}{c}\text { Silicon alpha } \\
\text { spec. }\end{array}$ & $\begin{array}{c}\text { Alpha } \\
\text { proportional }\end{array}$ & $\begin{array}{c}8^{\prime \prime} \times 4 " \\
\text { NaI(TI) }\end{array}$ \\
\hline Counter Efficiency & 0.28 & 0.52 & $2.06 \mathrm{E}-3$ \\
Counter Bkg. (cpm) & $0.02 \pm 0.01$ & $1 \pm 0.5$ & $268 \pm 11$ \\
Radiochemical Yield & 0.8 & 0.8 & -- \\
Reagent Blank (cpm) & $0.04 \pm 0.04$ & 1 & -- \\
LLD (100 min.) $(\mathrm{mBq})$ & $5.8^{\mathrm{z}}$ & $18.3^{\mathrm{z}}$ & $44.3 \mathrm{~Bq}$ \\
LLD (30 min.) $(\mathrm{mBq})$ & $10.3^{\mathrm{z}}$ & $33.3^{\mathrm{z}}$ & $109.3 \mathrm{~Bq}$ \\
\hline \hline
\end{tabular}

$$
\mathrm{LLD}=\frac{2 \cdot 1.645}{\mathrm{t} \cdot \mathrm{Eff} \cdot \text { Yield }} \sqrt{(\mathrm{bkg}+\mathrm{blk} \text { counts })+\left(\mathrm{SEM}_{\mathrm{bkg}}\right)^{2}+\left(\mathrm{SEM}_{\mathrm{blk}}\right)^{2}}
$$

b

$$
\mathrm{LLD}=\frac{2 \cdot 1.645}{\mathrm{t} \cdot \mathrm{Eff}} \sqrt{(\mathrm{bkg} \text { counts })+\left(\mathrm{SEM}_{\mathrm{bkg}}\right)^{2}}
$$

where:

alpha and beta $=0.05$

$\mathrm{t}=$ time $(\mathrm{min})$

Eff $=$ detector efficiency $(\mathrm{cpm} / \mathrm{Bq})$

Yield $=$ radiochemical recovery determined with tracer

$\mathrm{bkg}=$ single background count

blk $=$ single reagent blank count

SEM = standard error about the mean of multiple measurements 
Fig. 3.1 Disappearance of 210Po from the blood of rats. The neutralized (colloidal) form disappeared rapidly prior to the onset of sampling and then proceeded at a slower rate than did the acidified and citrated forms (from Thomas and Stannard 1964a, p. 18).
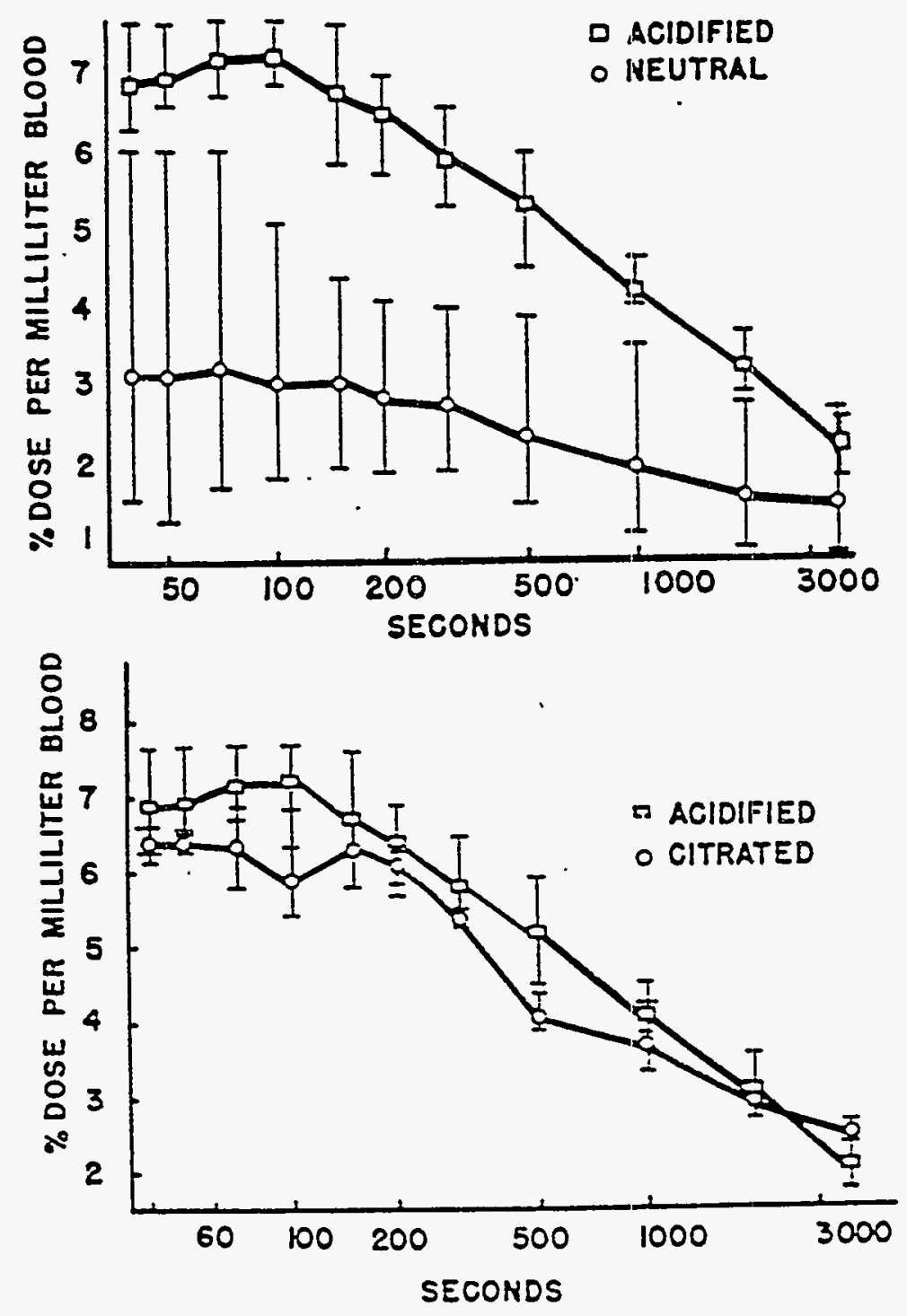
Fig. 3.2 Plating cell used to deposit Po onto Ni.

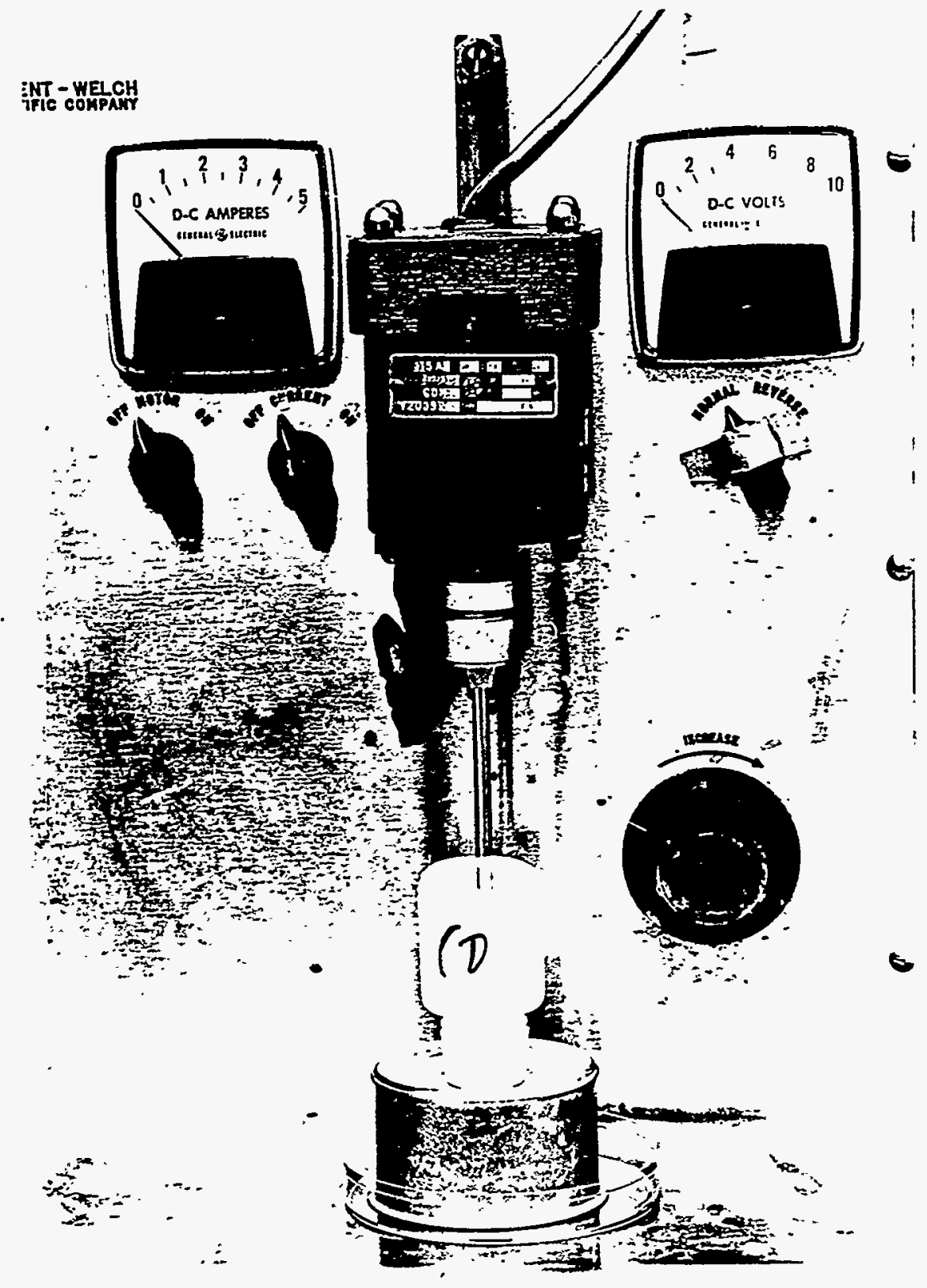


Fig. 3.3 Typical ${ }^{\text {s1 }} \mathrm{Cr}$ gamma spectrum from an 8 " by 4" NaI(TI) detector used to determine the volume of residual blood in tissue samples.

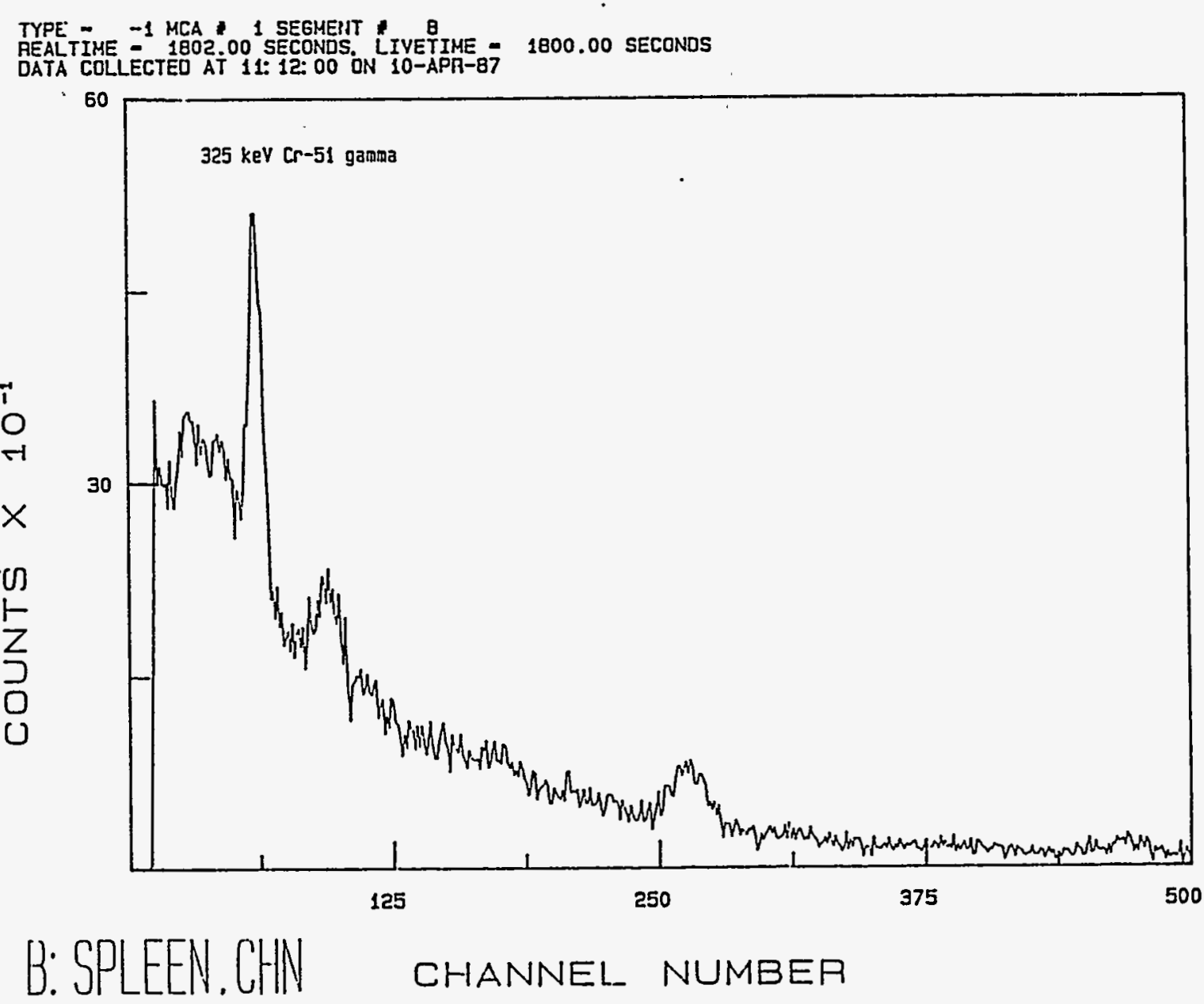




\section{Excretion and Distribution of Po in Non-human Primates}

The data presented below which describe excretion and distribution of $200 \mathrm{Po}$ in tamarins and baboons have been adjusted for radioactive decay and consequently represent biological mechanisms only. The "effective" values which incorporate both the biological and physical decay are used in the Po dosimetry model presented in Section 5. Since the amounts of injected Po were high relative to counter background and reagent blank count rates, the relative errors on excreta, blood, and tissue samples ranged from 2-10 percent of the actual measurement.

\subsection{Excretion}

\section{Tamarins}

Urinary Po excretion in the tamarin is best described by single exponential kinetics with a biological half-time of $45.2 \pm 2.1$ days over 203 days (Figure 4.1). The total urinary Po output, based on the least squares curve, is $19.7 \pm 1.1 \%$ of the injected dose.

Ninety consecutive daily fecal samples plus an additional five samples from 195-205 days post injection were collected. Feces samples from T504, T508, and T500 (second injection only) were analyzed.

Polonium-210 excretion in feces is best described by a single exponential during the initial 205 days post exposure with a biological half-time of $54.3 \pm 3.9$ days (Figure 4.2). The excretion curve predicts that a total of $68.8 \pm 28.8 \%$ of the injected dose is excreted via the feces (assuming that the single exponential clearance continues to infinity).

\section{Baboons}

Excretion of Po by the baboon is characterized by single exponential kinetics through 90 days. (The excretion data from both species of non-human primates appear in Appendix D.) Excretion via both urine and feces proceeded more rapidly than expected. 
That is, most of the available human occupational Po data as well as metabolic studies with other animal species indicate biological excretory half-times of approximately 50 days for Po. Figures 4.3a and 4.4a show that Po was excreted by the baboon with biological half-times of $15.6 \pm 1.5$ days for urine and $14.4 \pm 2.5$ days for feces. As can be seen in Figures $4.3 \mathrm{~b}$ and $4.4 \mathrm{~b}$, the curves describing Po excretion by the baboon are only slightly changed when the concentration of Po (i.e., activity of $20 \mathrm{Po}$ per gram urine or feces), rather than the daily output, are examined. The biological half-time estimate is reduced for both pathways, to 12.4 and 13.6 days for urine and feces, respectively. Therefore it would appear that the volume of excreta does not influence the 20 Po kinetics for either urine or feces. Regression analysis for the fecal data does not include Po recovered during the first four days post injection due to the extreme variability observed in the fecal Po output during this initial period. All of the baboons (with the exception of B806) eliminated a large quantity of the administered dose (12-14\%) on either day 2,3 , or 4 of the experiment.

The Po fecal-to-urine output ratio in baboons was markedly different from data reported elsewhere for other species, including the limited data for humans. The urinary excretion function parameters show that $37.7 \pm 4.0 \%$ of the injected activity is excreted via the urine. Total fecal Po excretion is $55.1 \pm 11.2 \%$ of the injected dose, resulting in a fecal-to-urine ratio of $1.5 \pm 0.3$. Table 4.1 presents a summary of excretion parameters found in this study for non-human primates following intravenous administration of Po citrate. In contrast, earlier studies conducted at the University of Rochester discussed in Section 2.1.4 estimate a fecal-to-urine ratio of ten following intravenous administration of Po. Likewise, Foreman et al. (Foreman et al. 1958) indicated that Po content recovered in feces was at least ten times the Po content recovered in urine after two workers were occupationally exposed to $210 \mathrm{Po}$. 
An examination of the blood and fecal data from B806 (sacrificed at 91 days post injection) suggests that as much as half of the ${ }^{20} \mathrm{Po}$ in the syringe was inadvertantly injected into the femoral muscle. For example, at ten minutes post injection, the blood from each of the other exposed animals contained $50-70 \%$ of the injected dose. On the other hand, the Po in the blood of B806 accounted for only 37.8\% of the injected dose at that time. To a lesser degree, B156, with $52.9 \%$ of the injected dose present in the blood at ten minutes, and B1054, with $50.0 \%$ of the injected dose present at ten minutes, may also have received some intramuscular administration. Retention measurements of the nuclide in the blood of B806 indicates that, for the first week, Po levels did not decline significantly after the completion of an initial rapid phase. The blood Po level was relatively constant from day 2 (14.8\% of the injected dose) to day 14 (11.9\% of the injected dose). It could be that the slower than expected clearance of the Po from the blood was due to a slow and constant absorption of 200 Po from the muscle into the blood.

The B806 excretion pattern of ${ }^{20} \mathrm{Po}$ in feces during the first few days after exposure also support the possibility of a combination of intravenous and intramuscular administration. An immediate and precipitous drop in fecal content consistently followed peak fecal Po output during days 2-4 for the three other studied baboons. Polonium-210 output in the feces of B806 followed a different pattern during the first week. A large (12-14\%) daily maximum excretion was not noted in B806's feces, as was the case for B156 and B1046. Rather, levels ranging from 1.1-3.8\% of the injected dose were found in fecal samples collected from day 2 through day 8 post injection, with levels increasing daily from day 4 through day 7 post injection. Continued input of Po into the bloodstream during the first few days (presumably from the muscle deposit) could account for the observed fecal excretion pattern during this time period. 
Due to the possibility that B806 was exposed via both the intravenous and intramuscular routes, its Po excretion data were compared to the data from the other exposed baboons via an analysis of covariance test. For both the urinary and fecal excretion data, there were no statistically significant differences found between either the - slopes (i.e., biological half-times) or the intercepts of the excretion functions $(p>0.05)$. Therefore, the B806 excretion data were combined with the data from the other baboons for the determination of the Po urinary and fecal excretion functions.

\subsection{Distribution}

\subsubsection{Blood}

\section{Tamarins}

A total of 13 blood samples were drawn from the tamarins on study for 20Po metabolism. Two samples were taken minutes after injection and samples were also drawn at $1,2,5,6,21,133,149$, and 202 days post injection. These samples are sufficient to estimate a two phase exponential retention of Po by the blood using the nonlinear least squares method (Figure 4.5). An early rapid phase retention with a half-time of $12.1 \pm 1.4$ minutes continues until the Po blood level is reduced to approximately $20 \%$ of the injected dose. A later slow phase then follows with a $37.3 \pm$ 15.5 day half-time. These parameters give an approximation of the retention of Po in the tamarin blood since the total number of samples was limited. It is possible that the slow phase described may actually be an intermediate phase with a half-time somewhat more rapid than 37.3 days followed by an additional phase with a longer retention half-time. Total blood volume is estimated to be $7 \%$ of body weight. 


\section{Baboons}

Approximately all of the injected Po was recovered in the baboon excreta, blood, and tissue samples. Table 4.2 lists the material balance of the injected dose. (Determination of the total quantity of $210 \mathrm{Po}$ excreted in urine and feces for B806 was estimated by extrapolation of the previously derived curves since some of the samples were not analyzed.)

Figures 4.6 and 4.7 show the retention of $210 \mathrm{Po}$ citrate in the blood of baboons. It is clear from these curves that differences exist among animals in the percentage of Po remaining in the blood at the beginning of the slow phase. The blood Po levels of B156 (7 day study) and B1060 (14 day study) drop to approximately $11 \%$ of the injected dose during the initial rapid phase, with Po leaving the blood with a half-time of $38.7 \pm 6.0$ minutes. The slow phase follows with a half-time of $8.4 \pm 3.1$ days. Rapid phase kinetics cannot be determined for the other animals due to the lack of early blood samples drawn during the first day post exposure. Slow phase retention of Po in the blood of B1046 (30 day study) is controlled by similar kinetics as noted for B156 and B1060, with a half-time of $12.5 \pm 2.7$ days. However, twice as much of the injected dose is still present in the blood at the onset of the slow phase. Of course, differences observed among the blood retention curves may also be partially due to portions of the administered Po being injected intramuscularly. As with the tamarin, these data are not sufficient to determine whether there is an additional, slower phase of Po retention in the blood.

The blood $210 \mathrm{Po}$ data for B806 is separated graphically into plasma and red blood cell content for the samples taken through day 21. After completion of the rapid phase clearance, the red cell fraction contains 3-4 times more total Po than the plasma. On a weight basis, red cell Po concentration exceeds that of plasma by a factor of 5.5. Slow 
phase Po clearance commences with $16.6 \%$ of the injected dose estimated in the circulatory system. The loss of 20po from the plasma and red cells is consistent with the $19.1 \pm 2.5$ day retention half-time observed for total blood Po, a rate almost double that exhibited for Po clearance from the blood of the other baboons. This longer retention in the blood of B806 may be indicative of a sustained or continuous input of Po into the bloodstream from the deposit believed to have been injected into the femoral muscle.

\subsubsection{Tissues}

While measureable levels of Po were recovered in all organs assayed, distribution was clearly not uniform throughout the soft tissues. The distribution data for ${ }^{210} \mathrm{Po}$ in baboon tissues appears in Table 4.3. Kidney and liver cells accumulated the most ${ }^{20} \mathrm{Po}$, with concentrations in excess of 0.1 percent injected dose per gram wet weight of tissue during the first week post injection. The concentration of $20 \mathrm{Po}^{\circ}$ in the spleen was of an intermediate level, containing approximately one-third that determined in the kidney and liver. The lung, adrenal gland, and pancreas had 200 Po concentrations approximately one-tenth that of kidney and liver.

The expressions which describe the change in the content of tissues are referred to as "retention functions." This terminology is often used interchangeably with the loss of material from a tissue. A true retention function describes the temporal retention of material by the cellular mass of the tissue which certainly is affected by Po being recycled among all organs and soft tissues. However, this study of the biokinetics of 2000 in the baboon was not intended to account for recycling between compartments via the circulatory system. 
Stannard (1964b) described the retention of Po in various tissues of the rat as consisting of a rapid and slow phase. In that study, exponential kinetics for biological loss were assumed and composite half-times were derived by combining data from the two phases. Retention of 210Po by baboon tissues in this study is best described by using a single phase exponential model. These curves for baboon tissues are shown in Figures 4.8, 4.9, 4.10, and 4.11. Partition coefficients (i.e., the fraction of the administered Po initially deposited in an organ) and retention half-times are given in Table 4.5. Loss of 210Po from the liver proceeds more rapidly than from all other tissues, with a half-time of 15.4 days. Kidney, spleen, pancreas, and skeleton comprise an intermediate group with half-times ranging from 25-35 days. Lungs, ovaries, and thyroid lose ${ }^{20} \mathrm{Po}$ more slowly, exhibiting retention half-times of 45-50 days.

As noted by Stannard (1964b), there is a shift in the tissue distribution pattern of 2000 with time because loss rates vary among tissues. In Table 4.4, 210Po content of each organ or tissue is expressed as the percent of the body content on a per organ and per gram wet tissue weight basis. The changes in the relative distribution of $210 \mathrm{Po}$ with time can be seen graphically for some tissues in Figures 4.12 (on a per gram wet weight basis). The spleen and skeleton retain a relatively constant fraction of the body content. The percentage of the Po body content found in the pelt undergoes a dramatic increase, climbing from 5\% at day 1 to greater than $50 \%$ at day 91 . This results from the pelt maintaining 5-7\% of the administered Po throughout the study period while the levels of the radionuclide declined in all other tissues. A similar trend is also observed to a lesser extent in the ovaries and brain. The kidney undergoes an increase in percentage of Po body content during the initial 30 days post injection before falling off between day 30 and day 91 . The muscle contains an increasing percentage of the body content through the first 30 days. However on a wet weight basis, the concentration of Po in muscle 
tissue is relatively constant over that period. The increase in total muscle Po may only reflect the differences in the total muscle mass of the study animals. The fraction of the body content present in the blood first drops and then remains relatively constant through 30 days. The relative increase in the fraction of the body content reported for the blood of the rat from day 30 to day 400 post injection (Stannard 1964b) was not observed in the baboon during the 91 day study period.

\subsection{Residual Blood Study}

Exsanguination is never $100 \%$ efficient in removing the volume of blood from the circulatory system. In metabolic studies with cats, exsanguination removed 50-93\% of the total blood volume (Morrow et al. 1964b). Nevertheless, all of the tissue 20 Po contents presented in the previous section can be considered as "blood-free" measurements. If significant quantities of measured Po were resident within the "residual" blood volume of the sample and not within the cells of the tissue itself, an accompanying overestimation of the organ Po content would result. The exact origin of an emitted alpha particle (i.e., whether the Po atom is actually located in blood vs. a tissue cell of an organ) is important for dosimetry.

Thomas (1955) constructed a crude model in an attempt to estimate the fraction of alpha radiation damage in tissue due to Po carried by erythrocytes. For example, depending on the diameter of the blood vessels contained within the spleen, $17-44 \%$ of the effective dose may be contributed by blood-borne Po. Using data from Stannard (1964a), Thomas showed that $86 \%$ of all alpha energy expended in the body was contributed by blood-borne Po after single gavage administration, but only $14 \%$ was contributed by blood-borne Po after intravenous administration. 
Consideration of Po distribution following its intravenous administration to the baboon does not include any contribution of effective dose to tissue from blood-borne Po. Certainly alpha energy from blood-borne Po will irradiate soft tissue in some cases. However, it is assumed that much of the $14 \%$ of the total alpha energy estimated by Thomas to have originated in the blood will be dissipated intravascularly. A further reduction in tissue dose from blood-borne Po results from the geometric distribution of alpha particles emitted from within blood cells bathing the tissue surfaces.

- The residual blood data for baboon tissues are summarized in Tables 4.6, 4.7, and 4.8. Table 4.6 gives the blood concentration of ${ }^{51} \mathrm{Cr}$ and the measurement of total blood volume. Table 4.7 lists several organ weights and the concentration of residual blood within those organs after exsanguination. Table 4.8 gives the contribution of blood-borne Po to organ Po burdens for a number of organs. As would be expected, much of the ${ }^{20} \mathrm{Po}$ measured in bone marrow samples was due to residual blood Po. The 210Po content of the lungs and spleen were reduced by approximately $25 \%$ for the initial days post injection to account for the blood-borne Po. The contributions of blood-borne Po in other organs, such as the liver and kidneys, were not as significant as that observed for the spleen and lung tissue.

\subsection{Discussion}

\subsubsection{Excretion}

Differences were found in the Po excretion fractions and half-times for the two species of non-human primates. The tamarin excretes approximately $20 \%$ of the injected dose via the urine (to infinity) with a 45.2 day half-time. In comparison, the baboon excretes $38 \%$ of the injected amount via the urine (to infinity) with a 15.6 day half-time. 
These data indicate a possible species difference in the metabolism of Po. Both non-human primate species differ from rats with respect to Po excretion. As discussed in Section 2, rats excrete a total of 5-10\% of systemic Po in the urine, which is significantly different than both species of non-human primates examined in this research.

The tamarin excretes $69 \%$ of the injected $20 \mathrm{Po}$ in feces, while the baboon excretes $55 \%$ in feces. These estimates do have large relative errors associated with them (approximately 20-40\%), and any species difference in total ${ }^{20} \mathrm{Po}$ fecal excretion cannot be shown to be statistically significant. Regardless, the 20Po fecal-to-urine ratio observed in the non-human primates following intravenous injection (ranging from 1.5-3.5) is significantly lower than for rats, which was reported to be equal to 10 (Berke and DiPasqua 1964).

The urinary and fecal ${ }^{20} \mathrm{Po}$ excretion data in the non-human primates suggest the existence of a long term phase of Po excretion which could not be adequately characterized during 90 days of study. At 90 days post injection, the daily urinary Po elimination constants is estimated to be 0.004 day-s $^{-3}$ (corresponding to a 160 day biological half-time). Similarly for the tamarin, the urinary Po elimination constant at 90 days post injection is estimated to be 0.002 day-1 $^{-1}$ (corresponding to a 300 day biological half-time). The composite elimination rates in both species are much more rapid over the entire 90 day period. Estimates of total 210 Po excreted by both routes (which can be predicted from the integrated single exponential excretion functions) total $89 \%$ and $93 \%$ for the tamarin and baboon, respectively. Likewise, re-evaluation of data presented by Fink (1950)

5 Estimated daily urinary elimination constant can be estimated:

$\lambda=\mathrm{A}_{\mathrm{t}} / \mathrm{BB}_{\mathrm{t}}$

where,

$\mathrm{A}_{\mathrm{t}}=$ daily quantity of polonium eliminated prior to sacrifice

$\mathrm{BB}_{\mathrm{r}}=$ body burden at time of sacrifice 
indicate that $89 \%$ of the intravenously administered 20 Po was excreted by a human volunteer based on the sum of the integrated single exponential urinary and fecal excretion functions. A relatively small percentage of Po excreted with a longer half-time might describe some or all of the 7-10\% of the administered dose unaccounted for by the single phase excretion functions. Study of Po metabolism in rats over long term periods (e.g., in excess of 400 days) indicated that loss of Po from most tissues and the whole body does indeed include a slow phase component (Stannard 1964b).

It is possible that a portion of the body burden is excreted in hair. Ladinskaya et al. (1973) reported 210Po concentrations in human hair to be higher than $210 \mathrm{Po}$ soft tissue and skeletal concentrations in persons exposed solely to environmental levels of the nuclide. The baboon pelt samples contained from 5-7\% of the injected dose, corresponding to $5 \%$ of the body content on day one post injection and 53\% of the body content on day 91 post injection. This trend was also seen in dogs following inhalation exposure to Po, as the percentage of body content in the pelt increased steadily from $11 \%$ on day 28 to $51 \%$ on day 149 post exposure (Smith et al. 1961). The majority of activity was found in the hair follicles. Unfortunately, the baboon samples assayed were not separated into the hair, skin, and fat components which comprise the pelt.

\subsubsection{Blood Retention}

The retention of $200 \mathrm{Po}$ in the blood of the five baboons in the study exhibited similar kinetics, although some differences were found with regard to the percentage of the administered dose remaining in the circulatory system at the conclusion of the initial rapid phase. The slow phase commenced within a few hours post injection, with approximately $11 \%$ of the injected activity in the blood of B156 and B1060, 17\% in the blood of B806, and $22 \%$ in the blood of B1046. These data may reflect normal biological 
variability or perhaps a radiation dose effect since B806 and B1046 received 3-4 times higher doses of $20 \mathrm{Po}$ than did the other two animals. Another possibility for the differences observed in early Po retention is the relative amounts of the administered dose which were accidentally injected intramuscularly.

The clearance of Po from the blood may be more rapid in the baboon than in the tamarin. However, the longer retention half-time measured in tamarin blood (37 days) is based on too few samples to warrant a conclusive comparison. Nevertheless, the blood Po retention half-time differences between the species appear to be reflected in the urinary excretion half-time differences. The initial rapid phase for both species appears similar, with the blood Po level falling to approximately $20 \%$ of the injected dose in the tamarin and to $11-22 \%$ in the baboon.

\subsubsection{Tissue Distribution and Retention}

Polonium has often been described as a soft: tissue seeker which distributes throughout the whole body (Fink 1950; Spoerl and Anthony 1956; Stannard 1964a; ICRP 1979). For the most part, the baboon data support this generalized description of ${ }^{210} \mathrm{Po}$ distribution.

The tissue ${ }^{20} \mathrm{Po}$ distribution in the baboon was generally similar to distribution data reported in other species (especially the rat). Liver, kidney, and spleen were the tissues with the greatest ${ }^{20} \mathrm{Po}$ concentrations. However, the spleen ${ }^{20} \mathrm{Po}$ content was much lower in the baboon than in the rat and somewhat lower than in the mouse on a percent injected dose per organ basis (Stannard and Smith 1964). Two factors may have contributed to this difference: 1. The injection solution administered to the baboon was free of Po aggregates whereas the Po chloride solutions used in previous metabolic studies in other species did consist largely of Po aggregates. The spleen (as well as other RES tissues) 
would be expected to remove aggregates from the bloodstream. An injection solution free of aggregates was essential to best approximate the metabolic behavior of systemic Po following occupational exposure. 2. To a lesser extent, the baboon tissue data are "blood-free" measurements. Subtracting the residual blood 210 Po from the spleen assays. resulted in an approximate 25\% reduction in the measured spleen ${ }^{20}$ Po content.

The excretion rate of ${ }^{20} \mathrm{Po}$ in feces is almost identical to the rate of loss of $210 \mathrm{Po}$ from the liver, with half-time estimates of 14.4 days and 15.4 days, respectively. These kinetics support the assumption that the entire liver 210Po content is excreted in the feces via the biliary pathway. This suggests that a significant amount of Po is recycled to the liver by the circulatory system since a total of $55 \%$ of the administered dose is excreted in baboon feces compared to the only $30 \%$ of the administered dose initially found in the liver.

Retention of ${ }^{20} \mathrm{Po}$ in various baboon tissues exhibited half-times ranging from 15-50 days. In general, the tissue retention kinetics observed in the baboon were similar to the other species studied previously, especially the rat. Differences in tissue processing, injection solution composition, and dosage levels make a more rigorous comparison of distribution and retention difficult to quantify.

\subsubsection{Residual Blood}

Residual blood Po contributed significantly to the organ Po measurement of some organs under certain circumstances. The measurement of red blood cells labeled with ${ }^{s 1} \mathrm{Cr}$ revealed that significant amounts of activity were added to the gross organ Po measurements of the spleen, lungs, heart, skeletal muscle, and bone marrow. The time from exposure to sacrifice was most important, as the amount of blood-borne Po was 
greatest when the blood Po concentration was still high. The completeness of the exsanguination procedure, the route of administration, and the chemical form of Po also influence the relative contribution of blood-borne Po to the total organ Po content.

Morrow et al. (1964b) accounted for the amount of blood-borne Po in cat tissue samples by comparing the blood volume recovered to reported organ blood volumes and estimating the quantity of blood remaining in each sample. The authors concluded that addition of the blood-borne Po to the blood-free tissue Po content seven hours after intravenous administration of Po citrate would add $66 \%$ to the spleen, $83 \%$ to the liver, $72 \%$ to the lung, and $49 \%$ to the kidney.

Thomas and Stannard (1964c) estimated that blood-borne Po in rat organs following intratracheal administration when blood Po is highest relative to total Po (day 62) accounts for decreases of $10.2 \%$ in spleen, $37.5 \%$ in liver, and $5.3 \%$ in kidneys. They assumed removal of only one-third total blood volume at sacrifice. 
TABLE 4.1 EXCRETION OF PO BY NON-HUMAN PRIMATES

\begin{tabular}{cccc}
\hline \hline Species & $\begin{array}{c}\text { Study } \\
\text { Period } \\
\text { (days) }\end{array}$ & $\begin{array}{c}\text { Biological } \\
\text { Half-time } \\
\text { (days } \pm \mathrm{se})\end{array}$ & $\begin{array}{c}\text { Excretion fraction } \\
( \pm \mathrm{se})\end{array}$ \\
\hline Tamarin: & & & \\
Urine & 203 & $45.2 \pm 2.1$ & $0.20 \pm 0.03$ \\
Feces & 203 & $54.3 \pm 3.9$ & $0.69 \pm 0.29$ \\
\hline Baboon: & & & \\
Urine & 91 & $15.6 \pm 1.5$ & $0.38 \pm 0.04$ \\
Feces & 91 & $14.4 \pm 2.5$ & $0.55 \pm 0.11$ \\
\hline
\end{tabular}


TABLE 4.2 MATERIAL BALANCE OF INJECTED PO

\begin{tabular}{lccccc}
\hline \hline \multicolumn{5}{c}{ Percent Injected Dose $( \pm 1 \mathrm{sd})$} \\
\hline Sacrifice & $\mathrm{B} 1054$ & $\mathrm{~B} 156$ & $\mathrm{~B} 1060$ & $\mathrm{~B} 1046$ & $\mathrm{~B} 806$ \\
Time (days) & 1 & 7 & 14 & 30 & 91 \\
\hline Feces & 0.4 & $26.7 \mathrm{z}$ & 22.4 & 41.6 & $54^{\mathrm{b}}$ \\
& \pm 0.01 & \pm 0.3 & \pm 0.3 & \pm 0.2 & \pm 0.2 \\
Urine & 1.0 & 13.3 & 17.2 & 25.1 & $36^{\mathrm{b}}$ \\
& \pm 0.1 & \pm 0.1 & \pm 0.1 & \pm 0.1 & \pm 0.1 \\
Blood & 20.5 & 5.7 & 4.3 & 3.7 & 0.6 \\
& \pm 0.5 & \pm 0.1 & \pm 0.1 & \pm 0.04 & \pm 0.02 \\
Soft Tissues & 63.8 & $35.1 \mathrm{c}$ & $27 . \mathrm{c}^{\mathrm{c}}$ & $18.6 \mathrm{c}$ & $2.4 \mathrm{c}$ \\
& \pm 1.2 & \pm 0.6 & \pm 0.3 & \pm 0.1 & \pm 0.03 \\
Muscled & 6.6 & 8.2 & 6.4 & 8.7 & 1.0 \\
& \pm 0.5 & \pm 0.4 & \pm 0.2 & \pm 0.1 & \pm 0.09 \\
Pelt & 5.2 & 6.6 & 6.9 & $105 \mathrm{5}$ & 5.6 \\
& \pm 0.4 & \pm 0.4 & \pm 0.2 & 4.1 & \pm 0.5 \\
Skeleton & & 5.8 & 5.7 & 4.8 & 1.0 \\
& \pm 0.3 & \pm 0.3 & \pm 0.1 & \pm 0.04 & \pm 0.06 \\
\hline \hline TOTAL & 102 & 101 & 89 & 102 & 101 \\
& \pm 1.4 & \pm 0.9 & \pm 0.6 & \pm 0.4 & \pm 0.6 \\
\hline \hline
\end{tabular}

- Day 4 sample was lost. Polonium-210 content was estimated.

b Polonium content of some samples from day 60-80 were estimated.

- Polonium content of large intestine (and contents) was estimated.

d Value estimated from $\% \mathrm{ID} / \mathrm{gm}$ (mean of 3 samples) * gm (total)

- Entire skeleton of B1046 was analyzed.

Other values estimated:

Skeletal ${ }^{20} \mathrm{Po}=$ Femur ${ }^{20} \mathrm{Po}$ content $/ 0.0329$

Right femur of B1046 constituted 3.29\% of the skeletal $210 \mathrm{Po}$ burden. 
TABLE 4.3 BABOON ORGAN AND TISSUE PO CONTENT

\begin{tabular}{|c|c|c|c|c|c|}
\hline \multirow[b]{2}{*}{$\begin{array}{l}\text { Baboon \# } \\
\text { Days on Study } \\
\text { Tissue }\end{array}$} & \multicolumn{5}{|c|}{ Percent injected dose/organ or tissue } \\
\hline & $\underset{1}{\mathrm{~B} 1054}$ & $\begin{array}{c}\text { B156 } \\
7\end{array}$ & $\begin{array}{l}\text { B1060 } \\
14\end{array}$ & $\begin{array}{l}\text { B1046 } \\
30\end{array}$ & $\begin{array}{l}\text { B806 } \\
91\end{array}$ \\
\hline $\begin{array}{l}\text { Blood } \\
\text { Liver } \\
\text { Kidney } \\
\text { Spleen } \\
\text { Lung } \\
\text { Ovary } \\
\text { Thyroid } \\
\text { Adrenal Gland } \\
\text { Pancreas } \\
\text { Brain } \\
\text { GI tractb } \\
\text { Muscled } \\
\text { Skeleton }^{\circ} \\
\text { Peltd }\end{array}$ & $\begin{array}{l}20.5 \\
33.2 \\
7.2 \\
0.95 \\
1.8 \\
0.03 \\
0.09 \\
0.10 \\
0.30 \\
0.06 \\
18.8 \\
6.6 \\
4.8 \\
5.2 \\
\end{array}$ & $\begin{array}{l}5.6 \\
19.3 \\
4.4 \\
0.40 \\
0.78 \\
0.03 \\
0.01 \\
0.02 \\
0.24 \\
0.29 \\
8.3^{c} \\
8.2 \\
5.3 \\
6.6 \\
\end{array}$ & $\begin{array}{l}4.3 \\
15.3 \\
4.8 \\
0.39 \\
0.42 \\
0.01 \\
0.003 \\
0.03 \\
0.17 \\
\overline{5.1} \\
6.4 \\
4.8 \\
6.9\end{array}$ & $\begin{array}{l}3.7 \\
6.3 \\
4.3 \\
0.24 \\
0.75 \\
0.04 \\
0.01 \\
-.20 \\
0.20 \\
0.55 \\
4.6 \\
8.7 \\
4.1 \\
- \\
\end{array}$ & $\begin{array}{l}0.59 \\
0.48 \\
0.57 \\
0.05 \\
0.22 \\
0.01 \\
0.002 \\
0.004 \\
0.02 \\
0.28 \\
0.7 \mathrm{c} \\
1.0 \\
1.0 \\
5.6 \\
\end{array}$ \\
\hline Peltd & \multicolumn{5}{|c|}{ Percent injected dose/gm } \\
\hline $\begin{array}{l}\text { Blood } \\
\text { Liver } \\
\text { Kidney } \\
\text { Spleen } \\
\text { Lung } \\
\text { Ovary } \\
\text { Thyroid } \\
\text { Adrenal Gland } \\
\text { Pancreas } \\
\text { Brain } \\
\text { GI tract } \\
\text { Muscled } \\
\text { Skeletone } \\
\text { Pelt }^{\mathrm{d}}\end{array}$ & $\begin{array}{l}0.027 \\
0.105 \\
0.129 \\
0.035 \\
0.015 \\
0.011 \\
0.073 \\
0.039 \\
0.018 \\
0.0005 \\
-\overline{0} \\
0.002 \\
0.002 \\
0.005\end{array}$ & $\begin{array}{l}0.007 \\
0.105 \\
0.103 \\
0.025 \\
0.009 \\
0.015 \\
0.008 \\
0.011 \\
0.018 \\
0.002 \\
-- \\
0.002 \\
0.002 \\
0.005\end{array}$ & $\begin{array}{l}0.004 \\
0.059 \\
0.082 \\
0.018 \\
0.006 \\
0.005 \\
0.004 \\
0.010 \\
0.008 \\
-- \\
-- \\
0.0007 \\
0.002 \\
0.003\end{array}$ & $\begin{array}{l}0.004 \\
0.026 \\
0.083 \\
0.021 \\
0.008 \\
0.008 \\
0.003 \\
-- \\
0.011 \\
0.003 \\
-- \\
0.001 \\
0.002 \\
-- \\
\end{array}$ & $\begin{array}{l}0.0008 \\
0.003 \\
0.014 \\
0.003 \\
0.002 \\
0.003 \\
0.002 \\
0.001 \\
0.001 \\
0.002 \\
-.002 \\
0.0002 \\
0.0003 \\
0.004 \\
\end{array}$ \\
\hline
\end{tabular}

2-10\% relative range of errors

b Sum of stomach, small and large intestines (with contents).

- Large intestine 210 Po content was estimated.

d Value estimated from \%ID/gm (mean of 3 samples) * gm (total)

- Entire skeleton of B1046 was analyzed. Other values estimated:

Right femur of B1046 constituted 3.29\% of the skeletal 210 Po burden.

Skeletal ${ }^{210} \mathrm{Po}=$ Right femur ${ }^{20} \mathrm{Po}$ content $/ 0.0329$ 
TABLE 4.4 PERCENT OF PO BODY CONTENT IN BABOON TISSUES

\begin{tabular}{|c|c|c|c|c|c|}
\hline \multirow[b]{2}{*}{$\begin{array}{l}\text { Baboon \# } \\
\text { Days on Study } \\
\text { Tissue }\end{array}$} & \multicolumn{5}{|c|}{ Percent body content/organ or tissue } \\
\hline & $\underset{1}{\mathrm{~B} 1054}$ & $\begin{array}{c}\mathrm{B} 156 \\
7\end{array}$ & $\begin{array}{l}\text { B1060 } \\
14\end{array}$ & $\begin{array}{l}\text { B1046 } \\
30\end{array}$ & $\begin{array}{l}\text { B806 } \\
91\end{array}$ \\
\hline $\begin{array}{l}\text { Blood } \\
\text { Liver } \\
\text { Kidney } \\
\text { Spleen } \\
\text { Lung } \\
\text { Ovary } \\
\text { Thyroid } \\
\text { Adrenal Gland } \\
\text { Pancreas } \\
\text { Brain } \\
\text { GI tract } \\
\text { Muscled } \\
\text { Skeleton }^{\text {e }} \\
\text { Pelt }\end{array}$ & $\begin{array}{l}20.3 \\
32.7 \\
7.1 \\
0.9 \\
1.8 \\
0.03 \\
0.09 \\
0.10 \\
0.3 \\
0.06 \\
18.5 \\
6.5 \\
4.7 \\
5.1\end{array}$ & $\begin{array}{l}9.2 \\
31.4 \\
7.1 \\
0.6 \\
1.3 \\
0.05 \\
0.02 \\
0.04 \\
0.4 \\
0.5 \\
13.5 \mathrm{c} \\
13.4 \\
8.5 \\
10.8\end{array}$ & $\begin{array}{l}8.7 \\
31.0 \\
9.8 \\
0.8 \\
0.8 \\
0.03 \\
0.01 \\
0.06 \\
0.4 \\
-\overline{10} \\
12.8 \\
8.9 \\
14.1\end{array}$ & $\begin{array}{l}10.3 \\
17.4 \\
12.0 \\
0.6 \\
1.2 \\
0.17 \\
0.01 \\
-. \\
0.5 \\
1.4 \\
12.7 \\
24.1 \\
11.4 \\
-\end{array}$ & $\begin{array}{l}5.5 \\
4.5 \\
5.3 \\
0.4 \\
2.1 \\
0.07 \\
0.02 \\
0.04 \\
0.2 \\
2.6 \\
6.4 c \\
9.7 \\
8.9 \\
53.0\end{array}$ \\
\hline & \multicolumn{5}{|c|}{ Percent body content/gm } \\
\hline $\begin{array}{l}\text { Blood } \\
\text { Liver } \\
\text { Kidney } \\
\text { Spleen } \\
\text { Lung } \\
\text { Ovary } \\
\text { Thyroid } \\
\text { Adrenal Gland } \\
\text { Pancreas } \\
\text { Brain } \\
\text { GI tract } \\
\text { Muscle } \\
\text { Skeleton } \\
\text { Pelt' }\end{array}$ & $\begin{array}{l}0.03 \\
0.11 \\
0.13 \\
0.03 \\
0.01 \\
0.01 \\
0.07 \\
0.04 \\
0.02 \\
0.0005 \\
-- \\
0.002 \\
0.002 \\
0.005\end{array}$ & $\begin{array}{l}0.01 \\
0.17 \\
0.17 \\
0.04 \\
0.01 \\
0.02 \\
0.01 \\
0.02 \\
0.03 \\
0.003 \\
-- \\
0.003 \\
0.003 \\
0.008\end{array}$ & $\begin{array}{l}0.01 \\
0.12 \\
0.17 \\
0.04 \\
0.01 \\
0.01 \\
0.01 \\
0.02 \\
0.02 \\
-- \\
\overline{0.001} \\
0.003 \\
0.01\end{array}$ & $\begin{array}{l}0.01 \\
0.07 \\
0.23 \\
0.06 \\
0.02 \\
0.04 \\
0.01 \\
-- \\
0.03 \\
0.01 \\
-- \\
0.004 \\
0.005 \\
--\end{array}$ & $\begin{array}{l}0.007 \\
0.02 \\
0.13 \\
0.03 \\
0.02 \\
0.03 \\
0.03 \\
0.01 \\
0.01 \\
0.02 \\
-.001 \\
0.001 \\
0.004\end{array}$ \\
\hline
\end{tabular}

2-10\% relative range of errors

b Sum of stomach, small and large intestines (with contents).

- Large intestine 2000 content was estimated.

d Value estimated from \% ID/gm (mean of 3 samples) * gm (total)

- Entire skeleton of B1046 was analyzed. Other values estimated:

Right femur of B1046 constituted 3.29\% of the skeletal 210 Po burden.

Skeletal ${ }^{20} \mathrm{Po}=$ Right femur ${ }^{210} \mathrm{Po}$ content $/ 0.0329$ 
TABLE 4.5 DISTRIBUTION OF SYSTEMIC PO IN • SELECTED ORGANS OF THE BABOON

\begin{tabular}{lccc}
\hline \hline Organ & $\begin{array}{c}\text { Partition } \\
\text { Coefficient } \\
\pm \text { se }\end{array}$ & $\begin{array}{c}\text { Biological } \\
\text { Half-time } \\
\text { (days } \pm \mathrm{se} \text { ) }\end{array}$ & $\begin{array}{c}\mathrm{r}^{2} \text { of the } \\
\text { regression }\end{array}$ \\
\hline Liver & $0.29 \pm .01$ & $15.4 \pm 0.6$ & 0.99 \\
Kidneys & $0.07 \pm .01$ & $24.5 \pm 3.0$ & 0.95 \\
Spleen & $0.006 \pm .002$ & $24.9 \pm 3.0$ & 0.95 \\
Pancreas & $3 \mathrm{E}-3 \pm 4 \mathrm{E}-4$ & $24.7 \pm 2.2$ & 0.95 \\
Adrenal & $5 \mathrm{E}-4 \pm 6 \mathrm{E}-6$ & $25.2 \pm 6.3$ & 0.83 \\
Gland & & & \\
Skeleton & $0.06 \pm 0.003$ & $33.8 \pm 2.7$ & 0.97 \\
Lungs & $0.009 \pm .005$ & $44.9 \pm 18.0$ & 0.66 \\
Ovaries & $3 \mathrm{E}-4 \pm 2 \mathrm{E}-5$ & $48.2 \pm 22.8$ & 0.61 \\
Thyroid & $7 \mathrm{E}-5 \pm 6 \mathrm{E}-6$ & $49.5 \pm 31.2$ & 0.56 \\
\hline \hline
\end{tabular}


TABLE 4.6 ${ }^{51} \mathrm{Cr}$ BLOOD LABELING RESULTS

\begin{tabular}{lccc}
\hline \hline Baboon & $\begin{array}{c}\text { Body } \\
\text { Weight } \\
(\mathrm{kg})\end{array}$ & $\begin{array}{c}{ }^{\mathrm{s}} \mathrm{Cr} \text { Blood Concentration } \\
(\mathrm{Bq} / \mathrm{ml} \pm \text { sd) }\end{array}$ & $\begin{array}{c}\text { Total Blood Vol. } \\
(\mathrm{ml} \pm \mathrm{sd})\end{array}$ \\
\hline B1054 & 10.1 & $0.59 \pm 0.10$ & $749.8 \pm 45.5$ \\
B156 & 11.0 & $3.96 \pm 0.42$ & $785.1 \pm 29.1$ \\
B1060 & 16.6 & $0.70 \pm 0.06$ & 1162. \\
B1046 & 13.0 & $1.98 \pm 0.02$ & $970.1 \pm 6.4$ \\
B806 & 13.0 & $6.06 \pm 0.62$ & $782.1 \pm 32.4$ \\
\hline \hline
\end{tabular}

- volume estimated to be $7 \%$ of body weight; majority of the activity in the syringe did not enter bloodstream 
TABLE 4.7 BABOON ORGAN WEIGHTS AND RESIDUAL BLOOD CONCENTRATION

\begin{tabular}{lccc}
\hline \hline Organ & $\mathrm{N}$ & $\begin{array}{c}\text { Weight } \\
(\mathrm{g} \pm \mathrm{sd})\end{array}$ & $\begin{array}{c}\text { Residual Blood } \\
(\mathrm{mL} / \mathrm{g} \pm \mathrm{sd})\end{array}$ \\
\hline Liver & 5 & $241.22 \pm 46.11$ & $0.10 \pm 0.04$ \\
Kidneys & 5 & $50.10 \pm 8.31$ & $0.11 \pm 0.02$ \\
Spleen & 4 & $17.08 \pm 7.20$ & $0.51 \pm 0.19$ \\
Lungs & 5 & $94.55 \pm 19.74$ & $0.23 \pm 0.05$ \\
Heart & 5 & $54.42 \pm 6.17$ & $0.05 \pm 0.02$ \\
Brain & 4 & $143.50+19.51$ & $0.01 \pm 0.00$ \\
Pancreas & 5 & $17.70 \pm 2.77$ & $0.03 \pm 0.02$ \\
Adrenal & 4 & $2.68+0.42$ & $0.19 \pm 0.11$ \\
Muscle & 21 & -- & $0.01 \pm 0.00$ \\
Bone-Femur & 3 & $87.48 \pm 5.20$ & $0.01 \pm 0.01$ \\
Bone Marrow & 19 &.- .7 & $0.06 \pm 0.09$ \\
Pelt & 4 & $1229.7 \pm 92.3$ & $0.01 \pm 0.00$ \\
\hline \hline
\end{tabular}


TABLE 4.8 RESIDUAL BLOOD 20PO CONTRIBUTION TO VARIOUS TISSUES

\begin{tabular}{|c|c|c|c|c|}
\hline Organ & $\begin{array}{l}\text { Days Post } \\
\text { Injection }\end{array}$ & $\begin{array}{l}\text { Percent ID } \\
\text { (Gross) }\end{array}$ & $\begin{array}{l}\text { Percent ID } \\
\text { (Corrected) }\end{array}$ & $\begin{array}{c}\text { Percent } \\
\text { Difference }\end{array}$ \\
\hline Liver & $\begin{array}{c}1 \\
7 \\
14 \\
30 \\
91 \\
\end{array}$ & $\begin{array}{c}33.9 \\
19.4 \\
15.4 \\
6.4 \\
0.5 \\
\end{array}$ & $\begin{array}{l}33.2 \\
19.3 \\
15.3 \\
6.3 \\
0.5 \\
\end{array}$ & $\begin{array}{l}2.1 \\
0.6 \\
1.1 \\
1.3 \\
2.7 \\
\end{array}$ \\
\hline Kidneys & $\begin{array}{c}1 \\
7 \\
14 \\
30 \\
91 \\
\end{array}$ & $\begin{array}{l}7.4 \\
4.4 \\
4.9 \\
4.4 \\
0.6\end{array}$ & $\begin{array}{l}7.2 \\
4.4 \\
4.8 \\
4.3 \\
0.6 \\
\end{array}$ & $\begin{array}{l}2.6 \\
0.7 \\
0.5 \\
0.7 \\
0.7 \\
\end{array}$ \\
\hline Spleen & $\begin{array}{c}1 \\
7 \\
14 \\
30 \\
91 \\
\end{array}$ & $\begin{array}{c}1.2 \\
0.5 \\
0.4 \\
0.3 \\
0.05\end{array}$ & $\begin{array}{c}0.9 \\
0.4 \\
0.4 \\
0.2 \\
0.05 \\
\end{array}$ & $\begin{array}{l}23.5 \\
16.9 \\
11.4 \\
13.1 \\
10.4\end{array}$ \\
\hline Lungs & $\begin{array}{c}1 \\
7 \\
14 \\
30 \\
91 \\
\end{array}$ & $\begin{array}{l}2.3 \\
0.9 \\
0.5 \\
0.8 \\
0.2 \\
\end{array}$ & $\begin{array}{l}1.8 \\
0.8 \\
0.4 \\
0.7 \\
0.2 \\
\end{array}$ & $\begin{array}{c}28.6 \\
20.9 \\
17.3 \\
12.2 \\
7.3 \\
\end{array}$ \\
\hline Heart & $\begin{array}{c}1 \\
7 \\
14 \\
30 \\
91\end{array}$ & $\begin{array}{c}0.6 \\
0.4 \\
0.1 \\
0.2 \\
0.06\end{array}$ & $\begin{array}{c}0.4 \\
0.3 \\
0.1 \\
0.2 \\
0.05\end{array}$ & $\begin{array}{c}36.0 \\
5.4 \\
4.1 \\
6.6 \\
10.0\end{array}$ \\
\hline $\begin{array}{l}\text { Bone } \\
\text { Marrow: }\end{array}$ & $\begin{array}{c}1 \\
7 \\
14 \\
30 \\
91\end{array}$ & $\begin{array}{l}0.005 \\
0.004 \\
0.014 \\
0.024 \\
0.002\end{array}$ & $\begin{array}{l}0.002 \\
0.003 \\
0.013 \\
0.022 \\
0.002 \\
\end{array}$ & $\begin{array}{c}125.4 \\
28.4 \\
6.3 \\
9.0 \\
7.0 \\
\end{array}$ \\
\hline
\end{tabular}

- Bone marrow extracted from right femur. Considerable variation in sample sizes. 
Figure 4.1 Tamarin Urinary 20Po Excretion

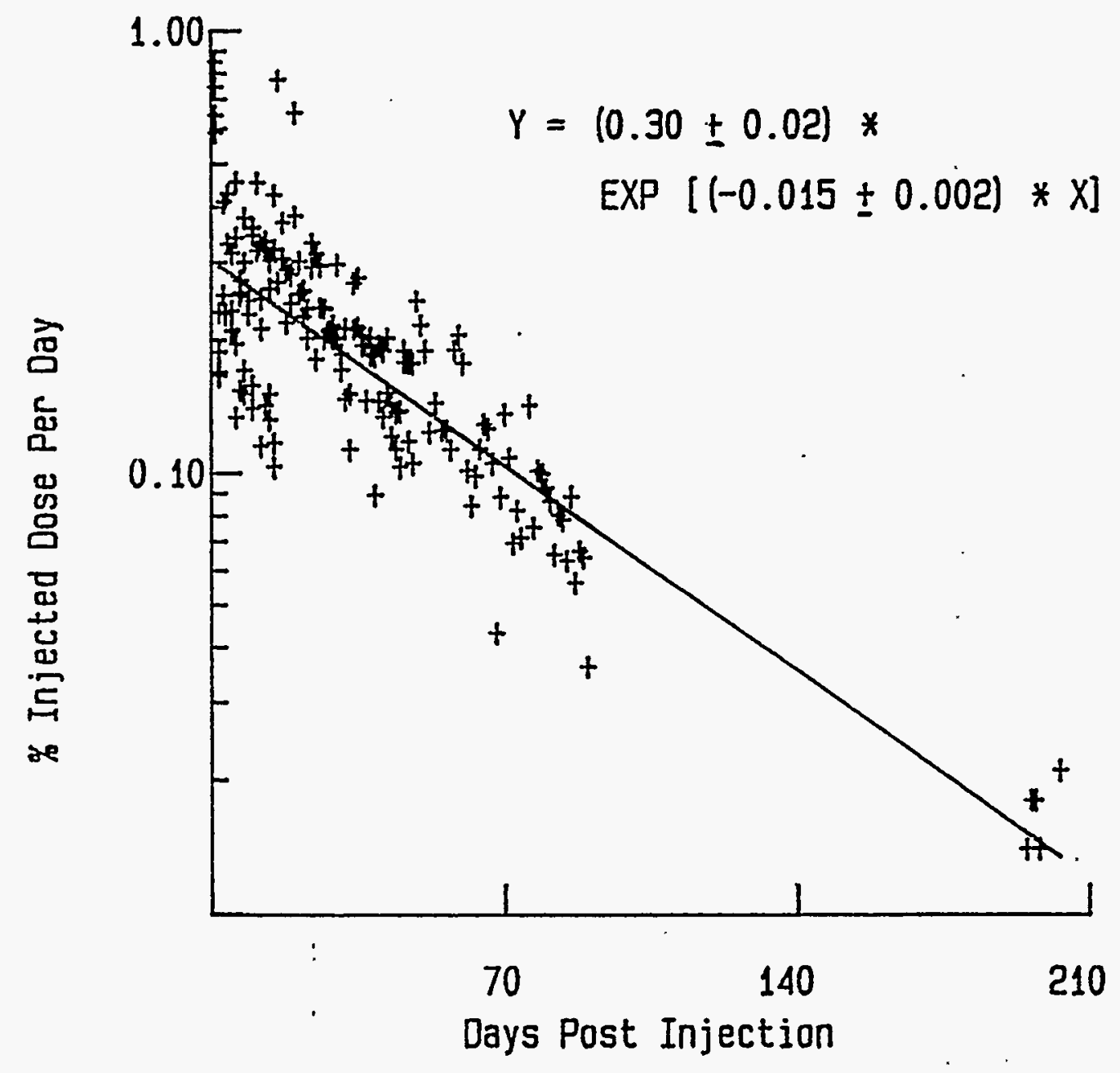


Figure 4.2 Tamarin 504 Fecal 20Po Excretion

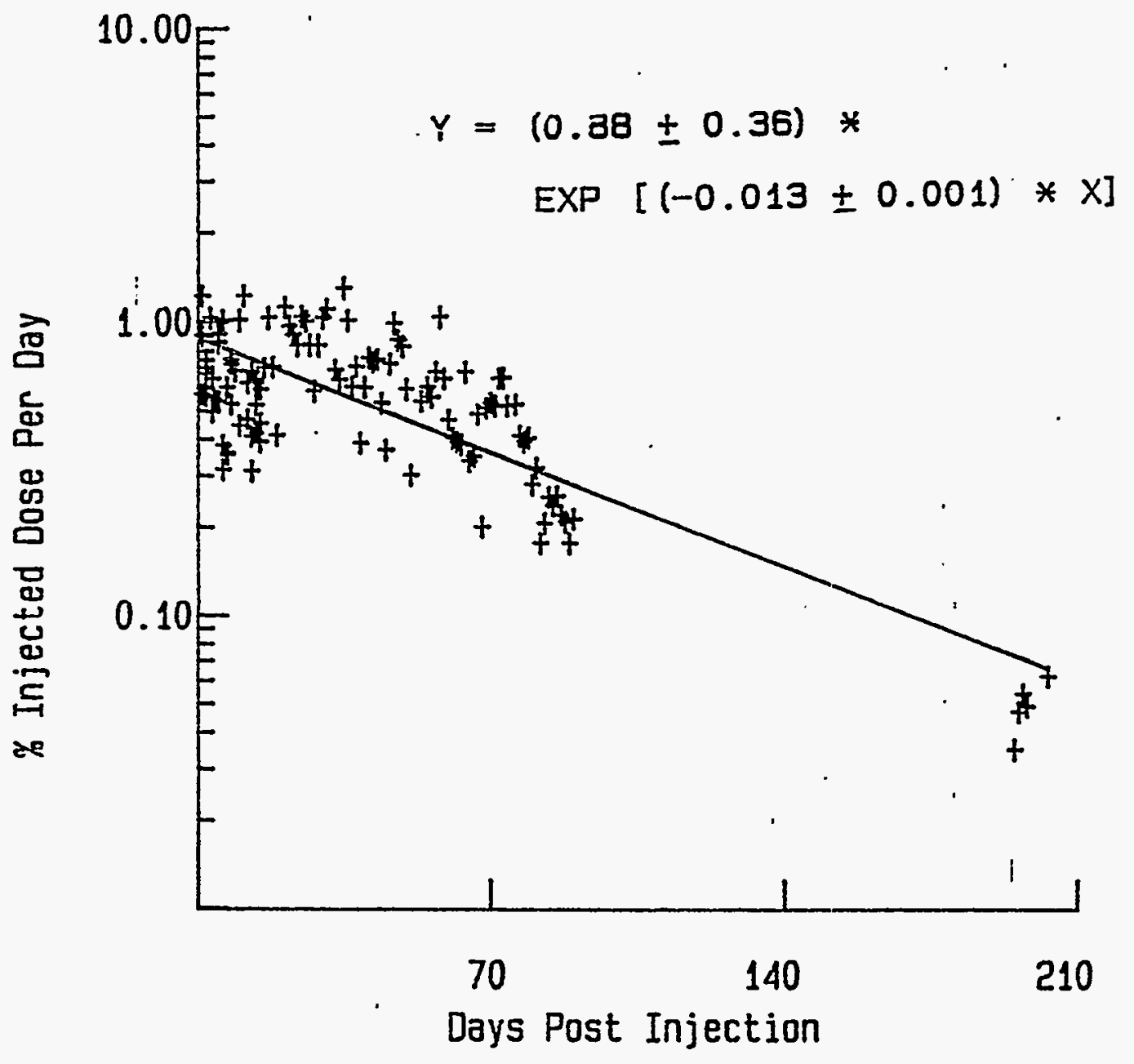


Figure 4.3 Baboon Urinary 20Po Excretion

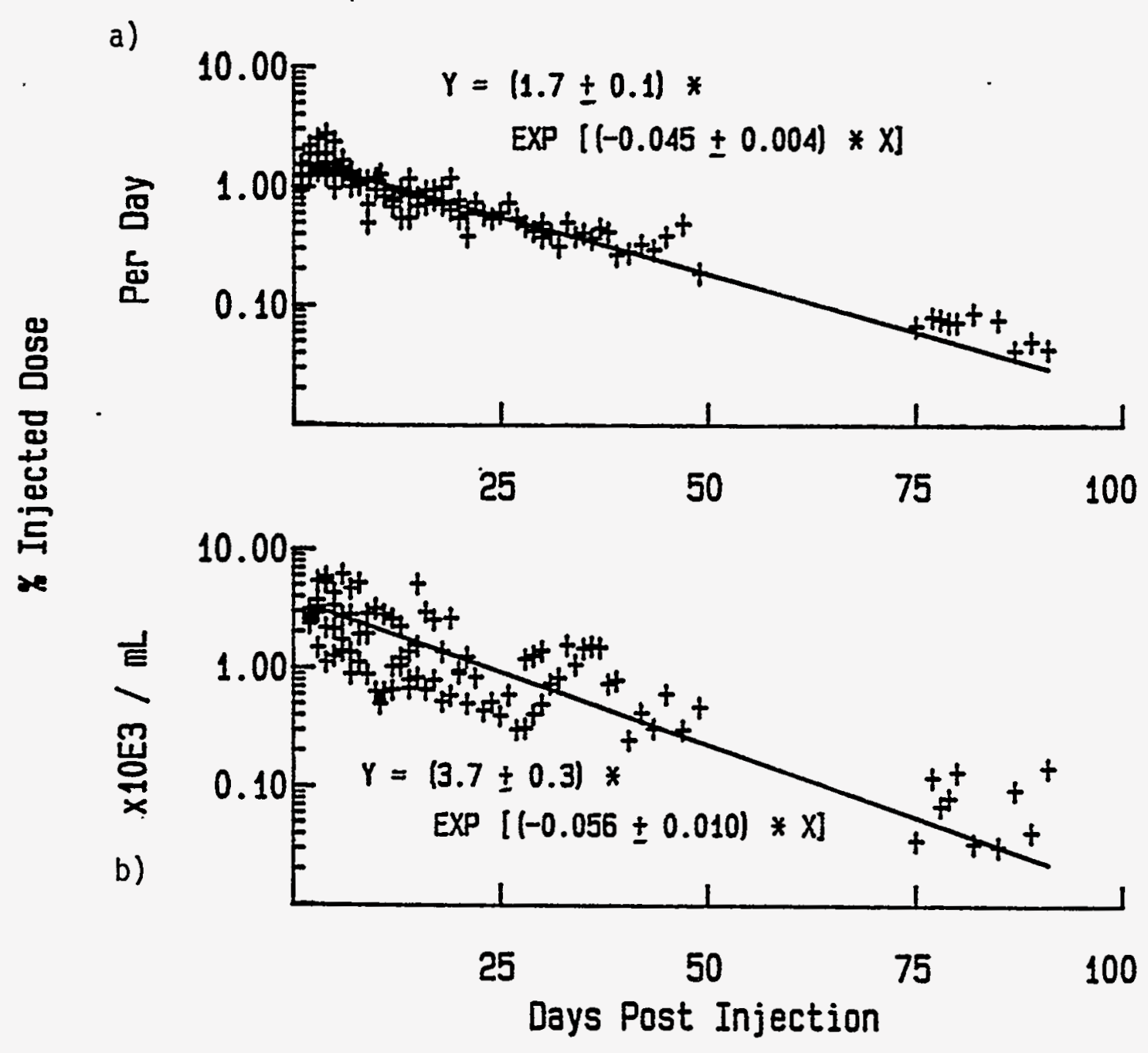


Figure 4.4 Baboon Fecal 20Po Excretion

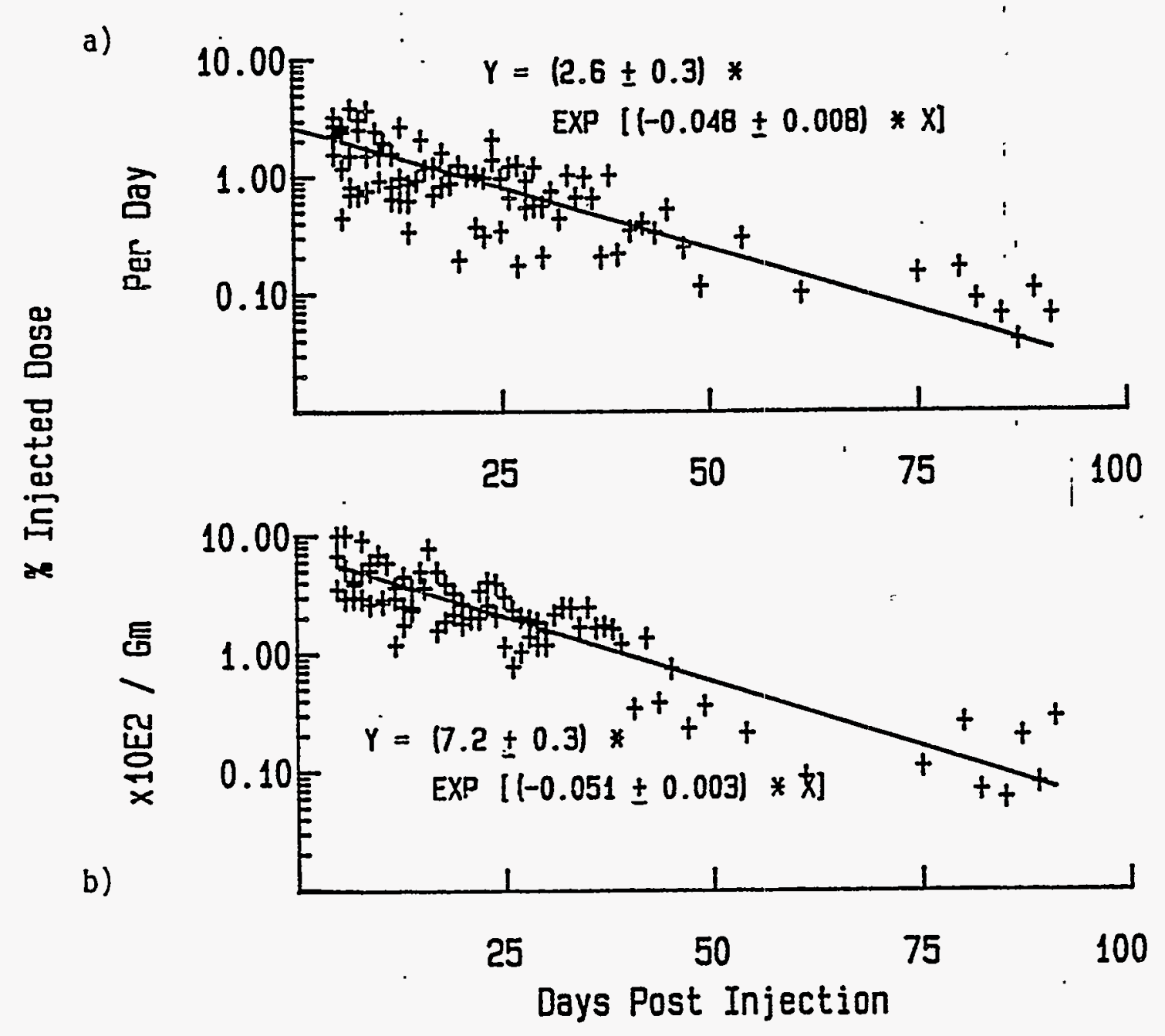


Figure 4.5 Tamarin Blood 210Po Retention

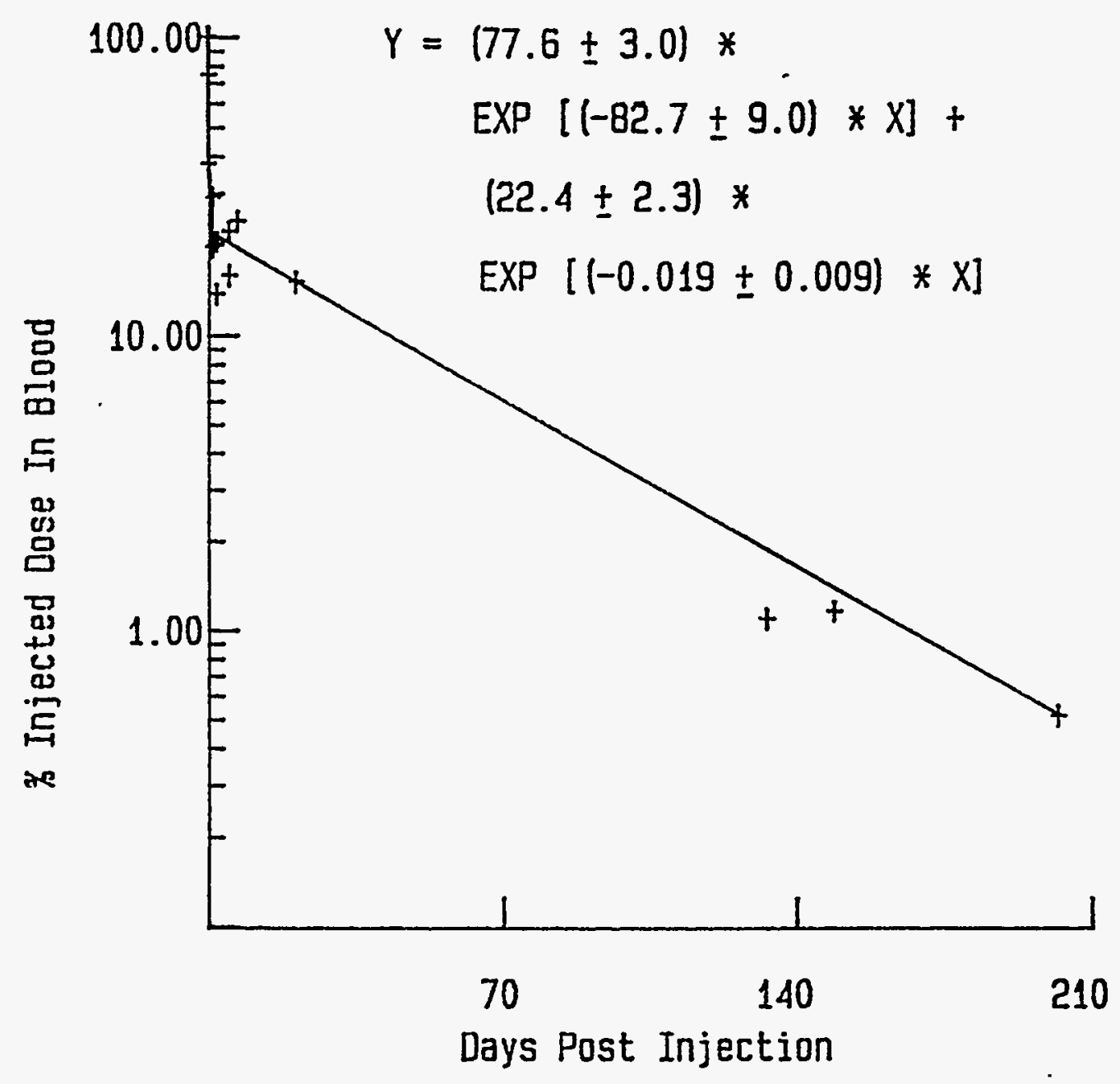


Figure 4.6 Baboon B156, B1060 and B1046 20Po Whole Blood Rètention

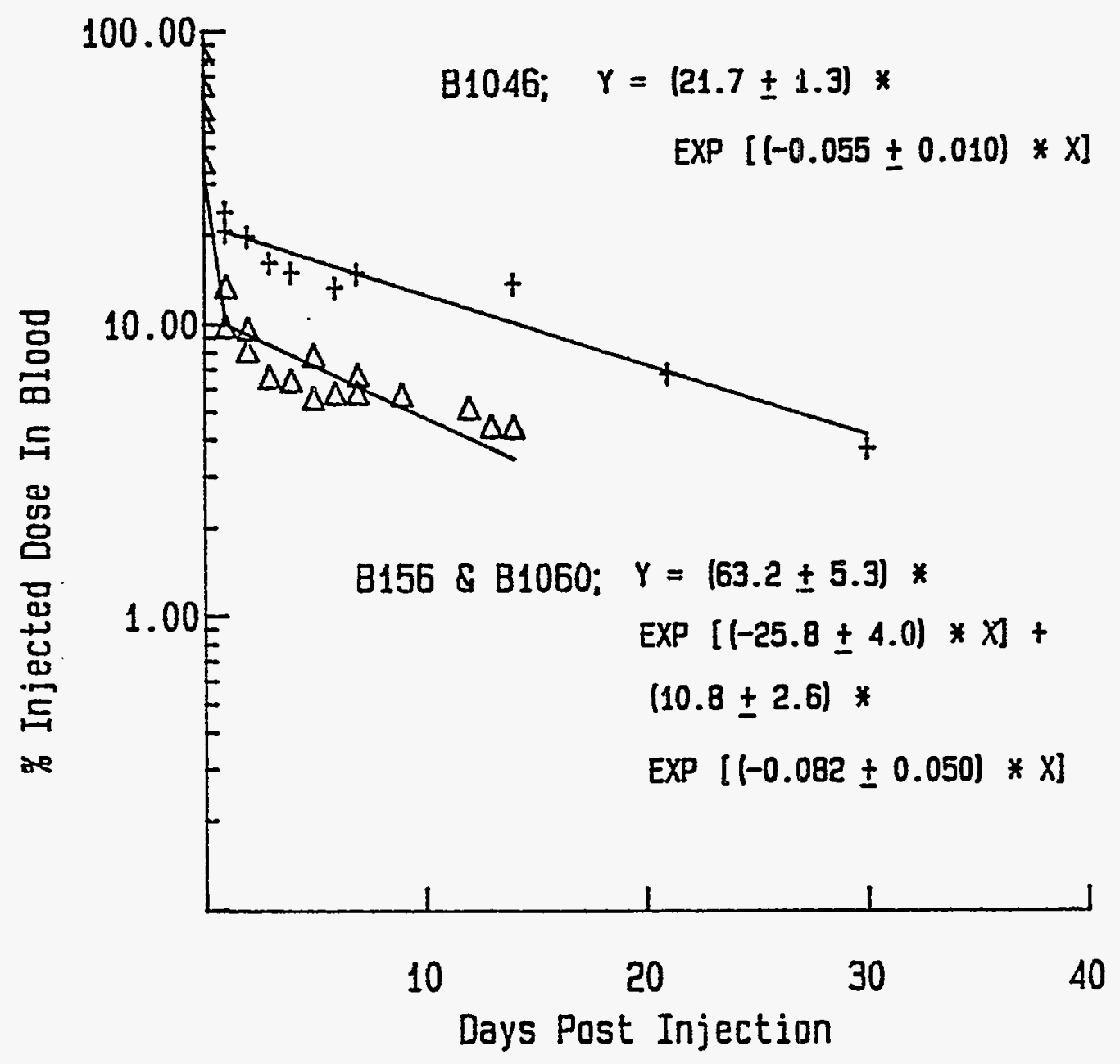


Figure 4.7 Baboon B806 210Po Blood Retention

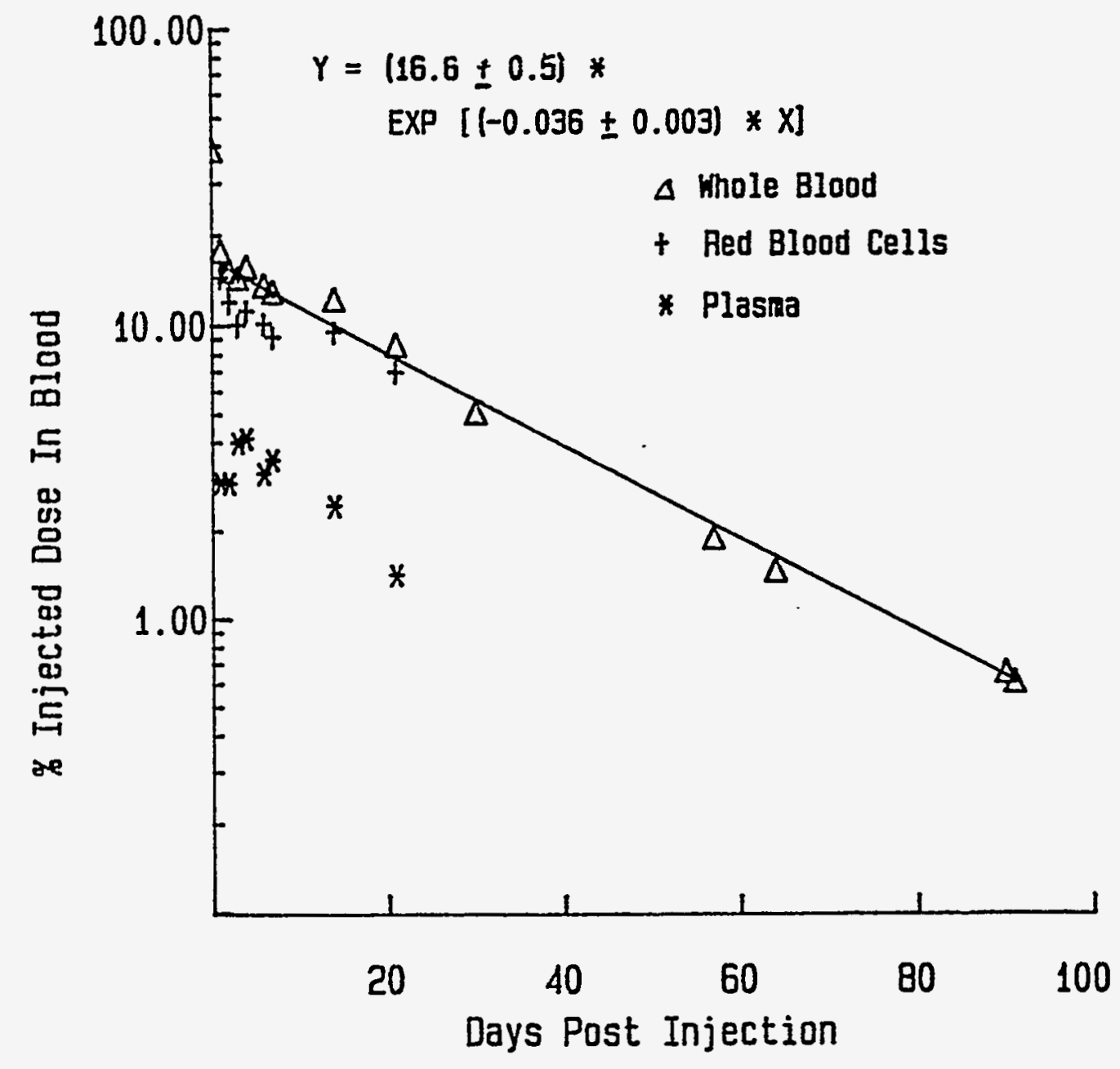


Fig. 4.8 Polonium-210 Retention in the Liver and Kidney Following Serial Sacrifice of Five Adult Female Baboons

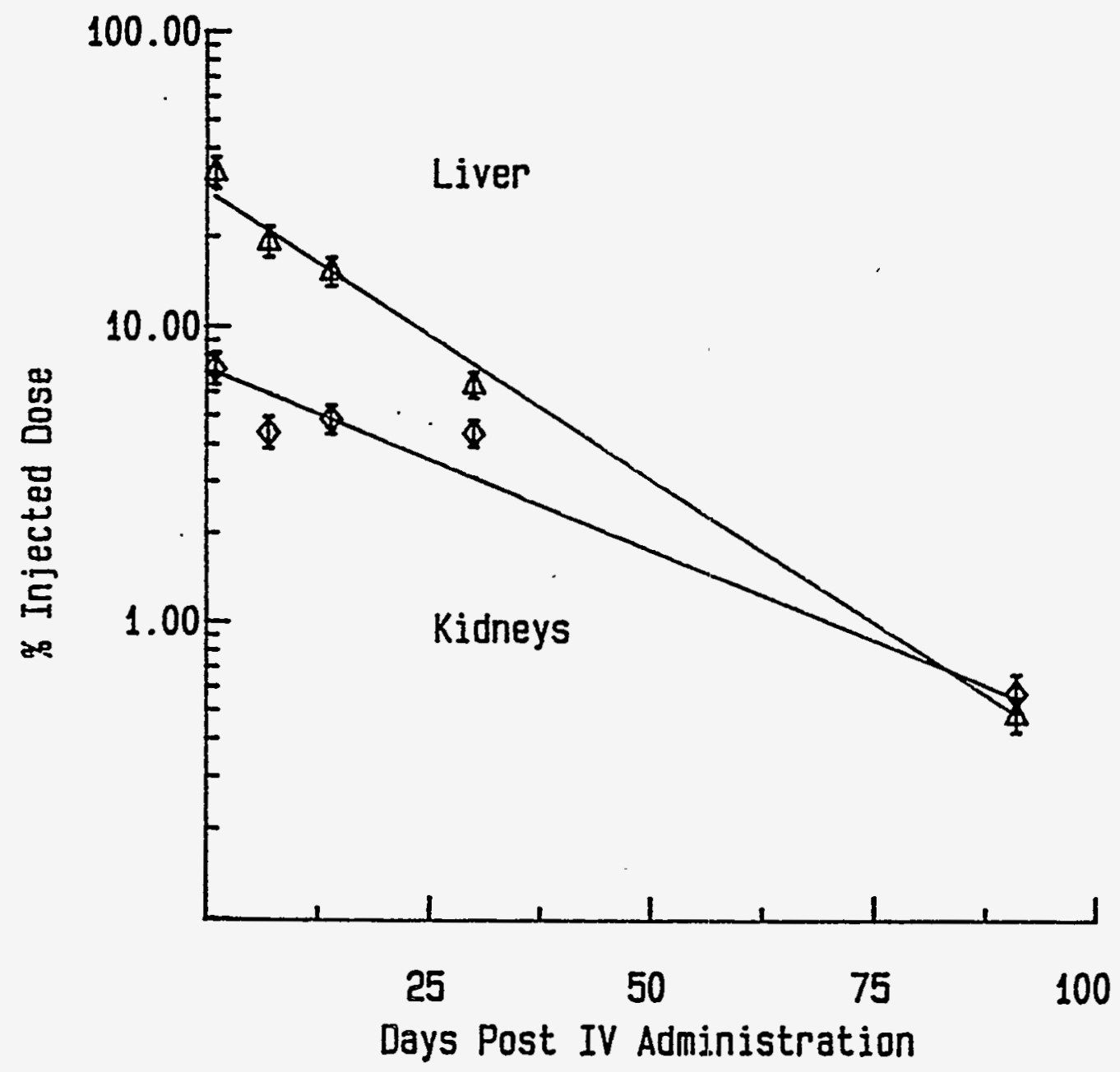


Fig. 4.9 Polonium-210 Retention in the Spleen, Adrenal Gland, and Pancreas Following Serial Sacrifice of Five Adult Female Baboons

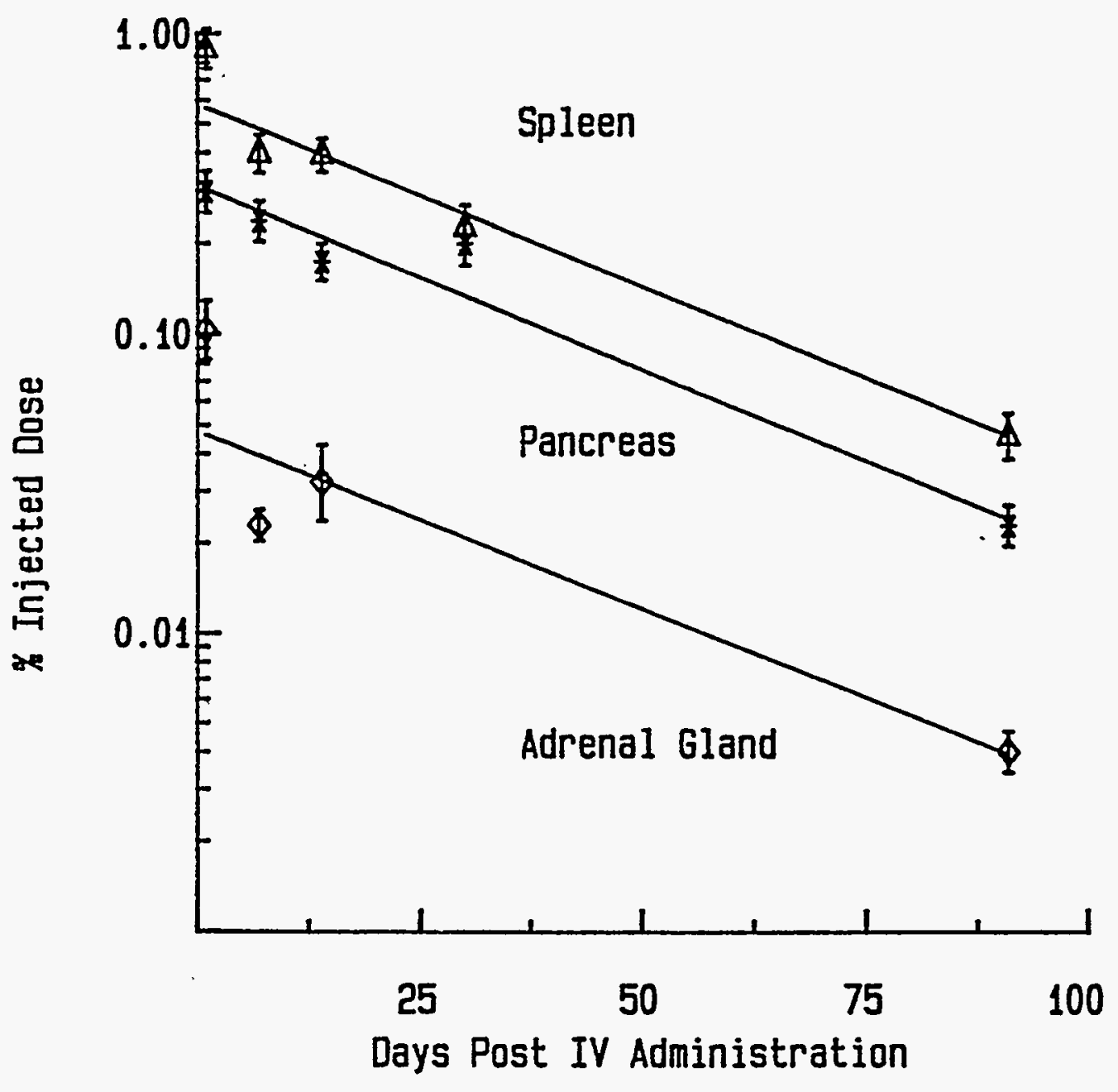


Fig. 4.10 Polonium-210 Retention in the Thyroid and Ovaries Following Serial Sacrifice of Five Adult Female Baboons

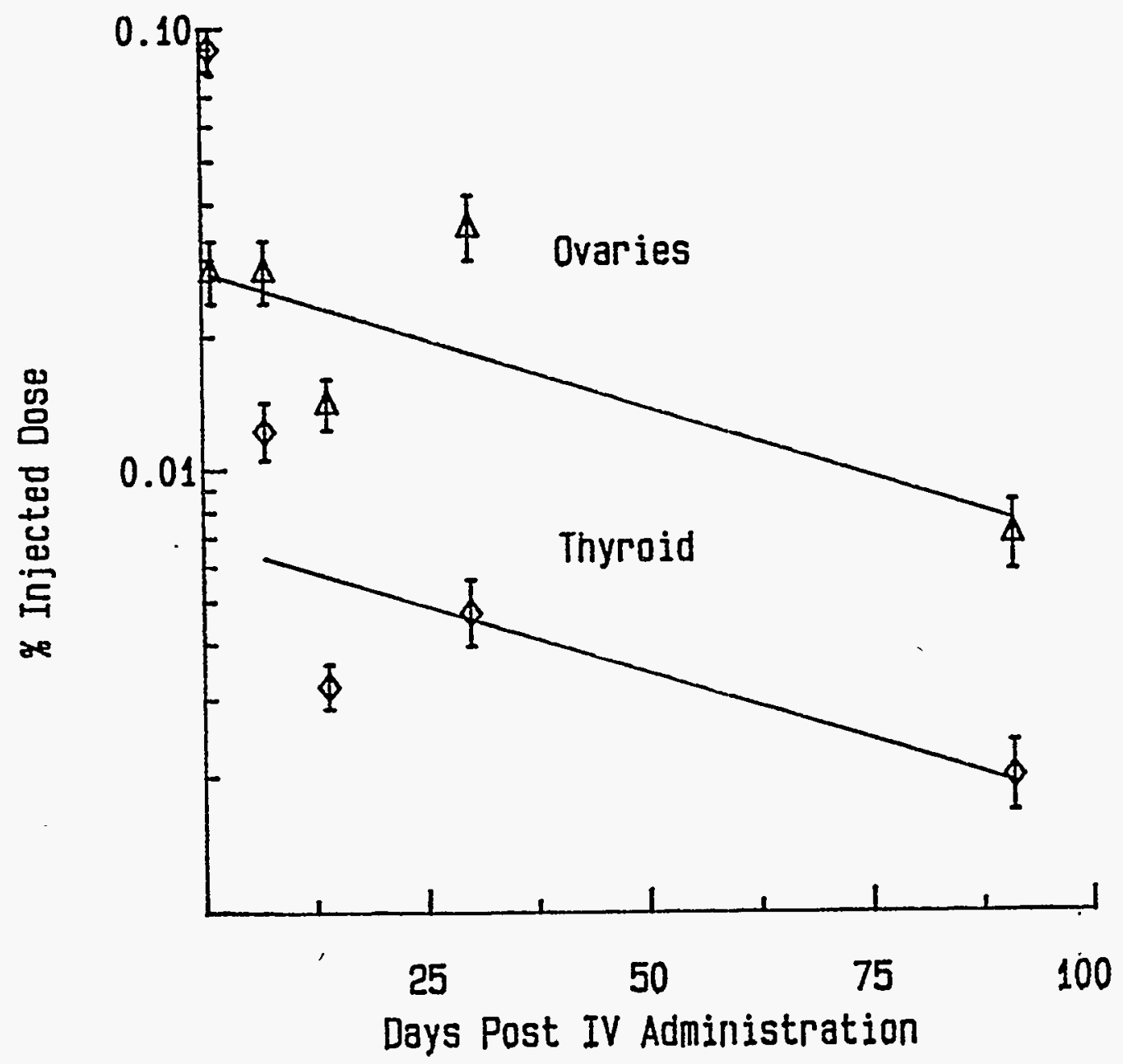

84 
Fig. 4.11 Polonium-210 Retention in the Lungs and Skeleton Following Serial Sacrifice of Five Adult Female Baboons

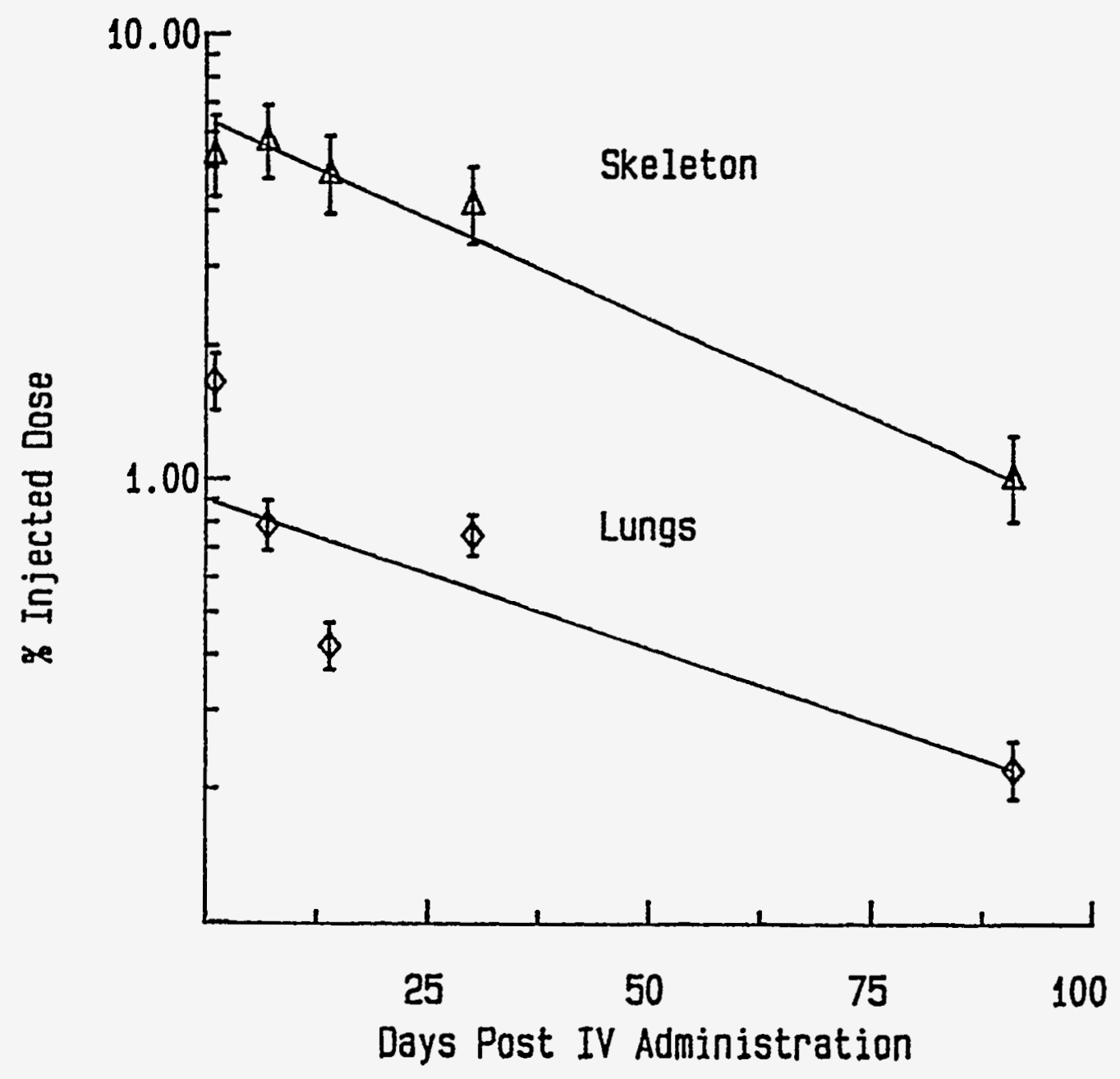


Fig. 4.12 Relative Concentration of 20 Po In Several Tissues Following Serial Sacrifice of Five Adult Female Baboons

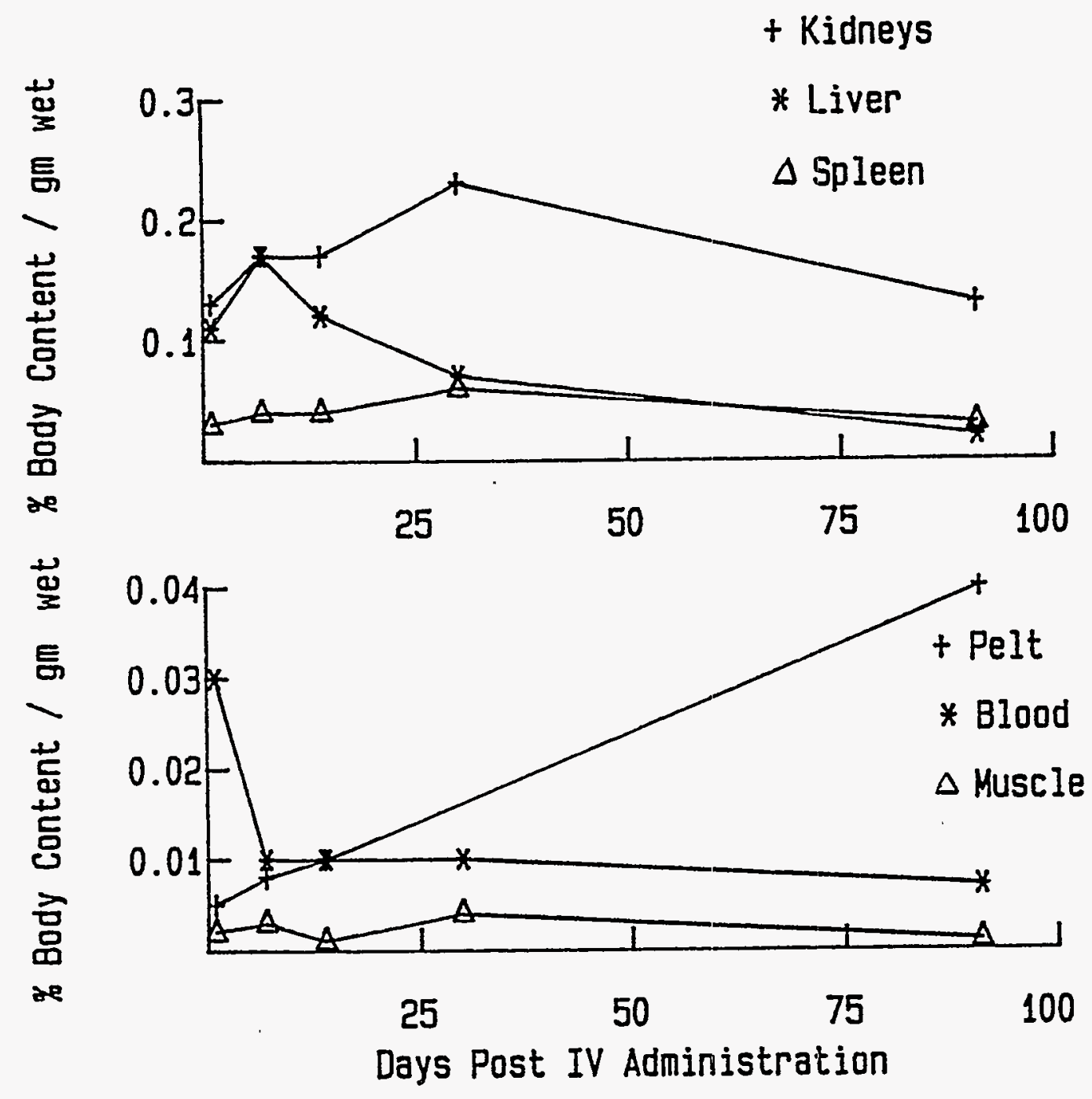




\section{Mound Laboratory Po Urinalysis Monitoring}

Early work done at the Dayton, Ohio facility of the Dayton Project showed that Po is excreted in measurable quantities via the urine and feces (Silverman 1944). As part of the health physics program at Dayton and later continued at the Mound Laboratory, workers submitted urine samples at intervals averaging one time per week. The Po concentration of the samples was determined radiochemically and compared to an established tolerance limit which was set at 8 and later 12 counts per minute per $50 \mathrm{~mL}$ of urine (Spoerl 1950; Meyer 1956). Workers whose urine Po levels were confirmed to be in excess of the limit were removed from potentially contaminated work areas. The worker returned to his normal job activities when his urine Po level dropped beneath the tolerance limit. Polonium was processed at Mound until the 1970 s.

The procedure used at Mound to monitor Po exposure was as follows (Steinberg 1946; Spoerl 1950; Meyer 1956): Weekly spot urine specimens were submitted at the plant in a "clean room" on the morning of the first day of the work week. Samples were collected in Sealright paper cartons and assayed within a few hours of sample collection. After thorough shaking, a $50 \mathrm{~mL}$ aliquot was acidified to $1 N$ with $10 \mathrm{~mL}$ of $6 \mathrm{~N} \mathrm{HCl}$ in a waxed paper cup. A Cu disc ( $2.54 \mathrm{~cm}$ diameter, 16 gauge thickness) was suspended in the urine on a glass hook through a $0.24 \mathrm{~cm}$ diameter hole bored near the edge of the $\mathrm{Cu}$. A glass paddle stirred the solution for 2 hours at $150-700 \mathrm{rpm}$. The disc was then removed, rinsed with water and air dried prior to counting in parallel plate alpha particle counters. Both sides of the disc were counted for 20 minutes each. The sum of the counts on both sides is a measure of the total Po deposited on the disc.

In 1964, the procedure was altered slightly to increase the sensitivity of the assay (Sheehan 1964b). The volume of the sample analyzed was changed from $50 \mathrm{~mL}$ to 100 
$\mathrm{mL}$ and the geometry of the plating cell was changed such that only one surface of the $\mathrm{Cu}$ disc was used for plating Po. These changes resulted in more statistically valid results while retaining the 20 minute counting time.

There has been little change in the procedure for analyzing ${ }^{20} \mathrm{Po}$ in urine over the past several decades (Fink 1950; Spoerl 1950; Meyer 1956; Hursh 1958; Sheehan 1964). The current procedure most typically utilized is described in the EML Procedures Manual (EML 1983) and is almost identical to the procedure described above, the main difference being the use of $\mathrm{Ni}$ planchettes rather than $\mathrm{Cu}$ ones for $20 \mathrm{Po}$ deposition.

Spontaneous deposition of ${ }^{20} \mathrm{Po}$ on $\mathrm{Cu}, \mathrm{Ni}$, and $\mathrm{Ag}$ has been reported in the literature (Fink 1950; Helmkamp et al. 1979). Researchers have drawn inconsistent conclusions concerning the metal conducive to the most efficient $210 \mathrm{Po}$ recovery. For example, Bale et al. (1975) noted that $\mathrm{Ag}$ had been the metal of choice for most investigators, and that $\mathrm{Cu}$ resulted in lower recoveries than either $\mathrm{Ag}$ or $\mathrm{Ni}$. In contrast, a comparison of the ${ }^{20} \mathrm{Po}$ recovery on $\mathrm{Cu}$ vs. Ag discs when deposited out of urine showed that $\mathrm{Cu}$ extracted a significantly greater amount of activity than did Ag (Spoerl 1950). Loose Ni filings removed $20 \mathrm{Po}$ from large volumes (approximately $1 \overline{\mathrm{L}}$ ) of acidified urine solutions with the same efficiency as $\mathrm{Ag}$ filings, and $210 \mathrm{Po}$ deposition onto $\mathrm{Cu}$ and $\mathrm{Ag}$ foils were comparable (Fink 1950). A technique requiring ${ }^{210}$ Po deposition on a relatively small metal disc for autoradiographic analysis of environmental samples utilized $\mathrm{Ni}$ rather than $\mathrm{Ag}$ since the former are inexpensive enough to discard after one use (Taylor et al. 1964).

The recovery of ${ }^{20} \mathrm{Po}$ deposited directly out of urine onto $\mathrm{Cu}$ was studied extensively (Spoerl 1950). Blank urine samples (i.e., urine samples from unexposed persons) were spiked with known amounts of 210Po and plated under standard conditions 
(1N HCl for 2 hours). The recoveries measured were normally distributed, with a mean recovery of $86.1 \pm 11.9 \%$ for urine with ${ }^{20} \mathrm{Po}$ levels at count rates of less than 200 counts per minute per $50 \mathrm{~mL}$ sample.

The mean $86.1 \%$ recovery to quantitate the actual $210 \mathrm{Po}$ content of a urine sample implies that tracer Po added to a blank urine sample deposits onto a suitable metal disc with the same efficiency as metabolized Po (i.e., Po which has first been filtered out of the blood by the kidneys and is possibly bound to protein or other metabolic product before being excreted). This assumption was tested by comparing the published historical method of analyzing ${ }^{210} \mathrm{Po}$ in urine (referred to here as the unashed/untraced method) with the procedure utilized in this research, which incorporates the addition of ${ }^{203} \mathrm{Po}$ tracer and the complete chemical digestion of the urine sample by $\mathrm{HNO}_{3}$ prior to deposition of Po onto a Ni disc (referred to here as the ashed/traced method).

\subsection{Duplication of the Mound Laboratory Procedure}

Table 5.1 identifies the differences between the historical unashed/untraced procedures; the reconstructed historical method utilized in this research, and the EML methodology previously described (EML 1983). A picture of the plating apparatus used at NYUMC appears in Fig. 5.1. After the $\mathrm{Cu}$ disc was dried, both sides were counted separately in a conventional gas flow proportional counter.

In the initial part of the study, the recovery of Po added to blank aqueous solutions and raw urine from unexposed humans and non-human primates was determined. This was an attempt to validate the recovery values measured by Spoerl and reported by Meyer (Spoerl 1950; Meyer 1956). Average plating recoveries for the unashed/untraced procedure are given in Table 5.2. At three concentrations of Po activity in human urine ranging from $0.06-0.66 \mathrm{~Bq} / \mathrm{mL}(3.3-33 \mathrm{~Bq}$ total), a mean recovery of $80.4 \pm 3.4 \%$ was 
determined. Recovery of ${ }^{208} \mathrm{Po}$ from two baboon urine samples spiked with approximately $0.38 \mathrm{~Bq} / \mathrm{mL}$ (19 Bq total) was $84.5 \pm 1.6 \%$. Recovery of $208 \mathrm{Po}$ which had been added to $1 N \mathrm{HCl}(1.3 \mathrm{~Bq} / \mathrm{ml}, 65 \mathrm{~Bq}$ total) was not significantly different from the spiked urine recoveries, with the average of three measurements equal to $83.4 \pm 1.6 \%$. Combining the urine and acid solution recovery data yield an average recovery of $81.7 \pm 3.2 \%$, a value similar to the $86.1 \pm 11.9 \%$ value determined at Mound Laboratory (Spoerl 1950; Meyer 1956). It is interesting to note that the recoveries measured did not decrease when the count rate exceeded $200 \mathrm{cpm}$ (approximately $400 \mathrm{dpm}$ ) in a $50 \mathrm{~mL}$ sample, as reported by Spoerl (1950). A possible explanation for this difference is that the alpha proportional counters used in the 1940s would often "lock up" (i.e., exceed the number changing capacity of the mechanical meters thereby causing them to become nonfunctional) when counting relatively high activity samples.

\subsubsection{Ashed vs. Únashed Urine}

\section{Methods}

Urine samples collected from four of the baboons and three of the tamarins injected with approximately $18.5 \mathrm{~Bq}(0.5 \mathrm{uCi}) / \mathrm{kg}$ of non-colloidal $20 \mathrm{Po}$ citrate were obtained to compare the unashed/untraced and ashed/traced ${ }^{20} \mathrm{Po}$ analysis methods. Although the majority of the samples were collected during the first month post injection, ten baboon samples were collected beyond 50 days post injection. Duplicate $50 \mathrm{~mL}$ aliquots were prepared from each sample. The average recovery of $81.7 \%$ was used to calculate the ${ }^{20} \mathrm{Po}$ activity in the aliquot processed by the unashed/untraced procedure.

The ashed/traced procedure used for the analysis of environmental samples requires a four hour Po deposition period in a plating cell placed in an $80^{\circ} \mathrm{C}$ water bath. Tests showed that the water bath was not necessary for quantitative deposition of Po. 
Duplicate aliquots from eight baboon urine samples were analyzed with both the original EMI method and the modified NYUMC method, which eliminated the water bath heating of the plating cells during spontaneous deposition. Samples processed by the original EML method with the water bath were plated for two hours. Samples processed at room temperature with the NYUMC method (Appendix A) were plated for periods of either two or three hours to determine whether the longer period was necessary. The results of these studies are presented in Table 5.3.

Recovery was greatest when the water bath was used, resulting in a mean value of $77.5 \pm 3.5 \%$ for the eight samples. The average recovery determined for room temperature plating was $62.8 \pm 11.7 \%$ for the two hour plating period and $72.5 \pm 11.0 \%$ for the three hour period. These recovery values were sufficiently high to enable subsequent deposition of Po to be conducted without the use of a water bath.

\section{Results of Comparison}

The mean ${ }^{208} \mathrm{Po}$ radiochemical recoveries for 67 ashed/traced baboon urine samples and 17 ashed/traced tamarin urine samples were $83 \pm 18 \%$ and $81 \pm 16 \%$, respectively. However, there were a few recovery values as low as 40-50\%. Using a tracer to directly determine the recovery for each sample is preferable to the use of an average recovery because it provides greater accuracy and minimizes the uncertainty in the result.

As shown in Fig. 5.2, the ashed/traced analysis method results in recovery of more 210Po from the baboon urine than does the historical unashed/untraced procedure. Therefore, human monitoring data resulting from an historical unashed/untraced method may significantly underestimate the quantity of Po in urine. The ratio of the ashed/traced values to the unashed/untraced values is shown as a function of time in Fig. 5.3. The following temporal relationship, or "correction function," described the change in the ratio starting with data on the second day post injection: 
$\mathrm{CF}(\mathrm{t})=10.47 \cdot \operatorname{EXP}[-0.0086 \cdot \mathrm{t}]$

Eq. 5.1

where,

$\mathrm{CF}(\mathrm{t})=\quad$ Ratio of the \% Injected dose in urine per day

[ashed method/unashed method]

$t=\quad$ days post injection

Polonium-210 urinalysis results and excretion functions determined for the baboon -from both the ashed/traced and unashed/untraced methods are presented in Fig. 5.2. Urinary excretion is best described by single compartment exponential kinetics. The magnitude of urinary $200 \mathrm{Po}$ excretion is much greater and the kinetics somewhat more rapid (biological half-time of $14.8 \pm 0.4$ days vs. $19.2 \pm 1.1$ days) when data from the ashed/traced method (upper curve in Fig. 5.2) are utilized in metabolic modeling compared to data from the unashed/untraced method (lower curve in Fig. 5.2).

Recoveries of ${ }^{20} \mathrm{Po}$ from tamarin urine were also greater when the ashed/traced method was used, although not to the same degree as was observed in the baboon urines. Unlike the baboon data, the ratio of the ashed/traced values to the unashed/untraced values for the tamarin data was relatively constant after the second day post injection, with a mean ratio of $3.5 \pm 0.8$ (Fig. 5.4).

Results of the urinary ${ }^{20} \mathrm{Po}$ excretion obtained with the unashed/untraced methodology in the non-human primate were compared to the data obtained after the clinical administration of $20 \mathrm{Po}$ to human subjects reported by Fink (1950) discussed in Section 2.2.4. The ${ }^{20} \mathrm{Po}$ contents of the human urine samples were determined via a procedure similar to the unashed/untraced procedure used at Mound. The urinary excretion curves determined by least squares regression to the daily ${ }^{210} \mathrm{Po}$. urinary data for three of the patients (patient \#2 died only six days following the administration of $\mathrm{Po}$ ) are shown in Fig. 5.5, along with the non-human primate urine data generated with the unashed/un- 
traced procedure. The estimates of urinary ${ }^{210} \mathrm{Po}$ excretion in both species of non-human primates are similar to humans whose urinary ${ }^{210} \mathrm{Po}$ had been analyzed by the same method.

\subsubsection{Dosimetric And Other Implications}

Differences in 210 Po content between duplicate aliquots of urine prepared from the same sample and processed separately with the ashed/traced and unashed/untraced procedures, respectively, reflect differences in the recovery of metabolized 20 Po based on whether the sample was wet ashed prior to spontaneous deposition. Given its tendency for binding to globin and plasma proteins in the blood (Campbell and Talley 1954; Thomas 1955; Thomas 1964), Po atoms will most likely be bound to proteins in the urine. It can be hypothesized that deposition of metabolized ${ }^{200} \mathrm{Po}$ out of raw urine is not as efficient a process as it is for the nuclide in an uncombined state (i.e., following wet ashing of urine containing metabolized ${ }^{210} \mathrm{Po}$ ). When urine is chemically processed (i.e., wet ashed), the matrix is destroyed and the availability of the Po for spontaneous deposition is presumably maximized.

The difference in the ratio of deposition efficiency between the two radiochemical procedures for the two species of non-human primates can be explained by the fact that no difference was seen when the samples were not ashed but a noticeable difference was observed when the samples were ashed.

A similar experiment reported in the literature was performed to compare deposition efficiency between ashed and unashed rat urine following intravenous administration of a ${ }^{210} \mathrm{Po}$ chloride solution (Black 1956). As with the non-human primates in the current study, more ${ }^{20} \mathrm{Po}$ was recovered in samples which were wet ashed prior to plating. However, the magnitude of the differences between the two procedures was 
much less than that observed with either the baboon or the tamarin. The activity deposited from the unashed aliquot of a rat urine sample had $83 \%$ of the activity deposited from the ashed aliquot of the same sample. Nevertheless, while the author was attempting to answer the same question as in the present investigation, i.e., whether metabolized Po was complexed with constituents in the urine causing a reduction in plating efficiency, the only urine samples assayed were collected "several weeks" post injection. Based on the time dependence of the correction function fit to the baboon urine data, it is possible that the rat urine sample chosen for the radiochemical comparison was not sufficient to accurately characterize the magnitude and/or temporal nature of the plating efficiency differences. It should also be noted that the ${ }^{20} \mathrm{Po}$ in the rat urine was plated out of a $0.5 \mathrm{~N} \mathrm{HCl}$ acid solution while the non-human primate urines used in the current study were plated out of a $1 \mathrm{~N} \mathrm{HCl}$ acid solution.

The difference between sample results processed by the ashed/traced and unashed/untraced methods was not nearly as great as expected when baboon urine collected on the first day post injection was analyzed. The average ratio of the ashed/traced to unashed/untraced data was only 2.4 compared to values ranging from 6-10 for all post day-one samples. These results could be explained by a greater percentage of the ${ }^{20} \mathrm{Po}$ being available for deposition from the unashed aliquots taken from the day-one urine samples than from subsequent samples. It appears that the mechanism responsible for restricting ${ }^{20} \mathrm{Po}$ deposition from a direct plating procedure in urine does not fully manifest itself during the first 24 hours post exposure, but is established within a 24 to 48 hour period following intravenous introduction of $20 \mathrm{Po}$. The availability of proteins to complex with $P o$ is probably insufficient immediately following uptake so that more "unbound" Po is excreted on day-one. Thereafter, Po in 
the transfer compartment and that recycled from other organs and soft tissue has had adequate time to bind with available proteins, making wet ashing of urine necessary for efficient extraction of Po during spontaneous deposition. .

The reduced availability for spōntaneous deposition of metabolized 210Po was observed to a lesser degree in tamarin urine. The ratio of the ashed/traced to unashed/untraced data from samples collected during the first two days post exposure ranged from 1.1-2.0, compared to the mean factor of 3.5 for all other samples.

A similar phenomenon has been seen in human urine (Sedlet and Robinson 1971). Only a small fraction of the metabolized Po present in urine could be deposited directly from the raw urine of seven individuals who had inhaled neutron-irradiated ${ }^{20} \mathrm{Bi}$. A similar result has also been observed in the blood of rats, i.e., a direct assay method gives a significantly lower Po recovery than after a chemical digestion pretreatment method (Davis 1950b).

It can be concluded, therefore, that evaluation of body burden based on 2roPo urinary excretion may be underestimated if it was plated directly out of unashed urine. Effect of Recovery on the Urinary Excretion Fraction

The urinary excretion fraction relates urinary excretion to total excretion and thus to systemic body burden. The existing metabolic models for Po include a urinary excretion fraction of 0.1 (ICRP 1968; Jackson and Dolphin 1966). More recently, Bernard (1979) estimated a fecal-to-urine excretion ratio of 9 for systemic Po following intravenous injection, corresponding to a urinary excretion fraction of 0.1 . However, when urinary ${ }_{210}$ Po content was determined via the ashed/traced method in two species of non-human primates, a considerably greater percentage of the administered dose was detected. These 
studies (discussed in the previous section) resulted in estimated urinary $210 \mathrm{Po}$ excretion fractions of $0.38 \pm 0.04$ and $0.20 \pm 0.01$ for the baboon and the tamarin, respectively. The fecal-to-urine Po ratio was 1.5 for the baboon and 3.5 for the tamarin.

Re-evaluation of ${ }^{20}$ Po excretion data presented by Fink (1950) suggests that a 0.1 urinary excretion fraction for humans may be too low. Of the four individuals receiving intravenous administration of $20 \mathrm{Po}$ chloride, sufficient data exist to permit an estimation of total 210Po excretion for one patient. Urinary and fecal 210Po excretion parameters were determined for patient \#3 by performing a least squares regression on the provided 210Po excretion data. The resultant 210Po excretion curves appear as single exponential models in Fig. 5.6. Based on integration of the urinary and fecal excretion functions, estimates of $54 \%$ and $5 \%$ of the administered dose were excreted via the feces and urine (out to infinity), respectively. The data, as found in the literature, fail to account for approximately $40 \%$ of the administered dose, which could be explained if the correction function describing the ratio of the ashed/traced to unashed/untraced deposition efficiencies for baboon urine is applied. Doing so increases the total urinary ${ }^{210} \mathrm{Po}$ output to an estimated $35 \%$ and accounts for the majority of the previously undetected percentage of the administered dose (Fig. 5.7).

Breuer and Clemente (1979) developed a mathematical model to describe the metabolic behavior of $\mathrm{Po}$ based on the ${ }^{210} \mathrm{~Pb}$ and ${ }^{210} \mathrm{Po}$ intake, excretion, and body burden data reported for the general Italian population. While they were most interested in predicting lung exposure to radon progeny from urinary excretion of the two nuclides, the authors calculated that for any systemic input of Po, the urinary excretion fraction is equal to 0.36 , a value in good agreement with the $0.38 \pm 0.04$ measured in the baboon. 


\subsubsection{Summary}

The historically important technique of analyzing ${ }^{20} \mathrm{Po}$ in urine has been investigated. The recovery value used as part of the routine health monitoring program at Mound Laboratory was based on the incorrect assumption that metabolized Po is plated by spontaneous deposition with the same efficiency as tracer Po added to blank urine samples. Duplicate aliquots of urine samples collected from non-human primates were analyzed by an ashed/traced method and an unashed/untraced method similar to that used routinely in the past at Mound. The ${ }^{20} \mathrm{Po}$ deposition recovery was significantly lower when the nuclide was analyzed with the unashed/untraced method than after preparation by the ashed/traced technique.

\subsection{Systemic Dosimetry Model for Po}

\subsubsection{ICRP And Other Models}

A prospective current metabolic model for Po is described by the ICRP (1979). The model references the human excretion data summarized by Jackson and Dolphin (1966) and the animal data reported by Fink (1950) and Smith et al. (1961). Whole body retention is described by the following function:

$\mathrm{R}(\mathrm{t})=\operatorname{EXP}[(-\ln (2) / 50) \cdot \mathrm{t}] \quad$ Eq. 5.2 where, $\mathrm{t}=$ days post injection.

Organ partition coefficients of 0.1 are assumed for the liver, kidney, and spleen and 0.7 for all other tissues combined. Polonium is retained in all tissues with a biological half-time of 50 days. 
The metabolic model presented by Bernard (1979) is similar to that of the ICRP. Citing the human clinical data of Fink (1950) and the metabolic studies conducted at the University of Rochester (summarized in Section 2 of this report), Bernard described a model whereby Po deposits preferentially in the tissues of the reticuloendothelial system (RES). Consistent with the ICRP model, the partition coefficients to liver, kidney, and spleen are each 0.1. Distribution is uniform throughout all other tissues at a concentration 10 times less than in the RES tissues. Exceptions are muscle, bone, and testes with one-tenth the average tissue Po concentration. Retention of Po in the tissues is described by two phase kinetics, with the majority of the radionuclide clearing with a 50 day biological half-time. The uptake from the GI tract to the blood ( $f_{1}$ value) is 0.1 , and as stated in the previous section, the fecal-to-urine excretion ratio is equal to 9.

The characterization of Po distribution and excretion in the published metabolic models have both similarities and differences. with that observed in the non-human primates of this study. The tissue concentration pattern described by Bernard was, for the most part, demonstrated in the baboon, with the primary exception being the lower $20 \mathrm{Po}$ concentration in the baboon spleen. However, retention and excretion half-times were consistently more rapid in the baboon. In addition, a major difference was found in the fecal-to-urine excretion ratio, which was found to be equal to 1.5 and 3.5 for the two species of non-human primates.

\subsubsection{The NYUMC Model}

Evaluation of Po urinalysis data for individual members of the "former Mound Laboratory employee group" indicate that the time sequence of exposure to the radionuclide varied extensively as would be expected in an industrial situation. (Appendix $\mathrm{E}$ consists of a number of sample plots of worker urinary Po excretion.) No 
consistent Po excretion pattern was apparent among the workforce. Observed Po urinary excretion as well as the excretion rate kinetics were different from worker to worker, more indicative of the dynamics associated with monitoring workers than actual Po biokinetics.

The variability of Po excretion patterns observed among the Mound workforce is not considered unusual, in light of the many metallurgical and chemical processes then in effect which contributed varying amounts of Po aerosols to which the workers were exposed. Since the vast majority of the exposures were estimated to occur via the inhalation pathway (Garner 1986), the urinary Po excretion was influenced not only by the rate of Po clearance from blood to urine, but also by the rate of Po absorption into the bloodstream from both the lung and the gastrointestinal tract (following ingestion as a result of lung clearance via the mucociliary escalator).

A model has been developed to estimate the systemic radiological dose equivalent to members of the Mound Po workforce based on their past Po urinalysis data. The model utilizes the Po metabolic parameters determined here in studies with the adult female baboon. The tamarin urinary excretion data was not combined with the baboon data due to the species differences observed; covariant analysis of the data sets indicated significant differences between the two. The existing body of literature establishing physiologic and metabolic similarities between the baboon and human was an additional contributing factor in the exclusive selection of the baboon data for the model.

The model works equally well on any pattern of urinary Po excretion; it is applicable to both acute and chronic exposure conditions. Mathematically, the model is based on the single exponential baboon urinary excretion function (13.7 day effective half-time) and single exponential baboon tissue retention functions. Dose equivalent is calculated from the following equation (Eq. 5.3): 
$\mathrm{H}_{\mathrm{j}}=\mathrm{K} * \mathrm{SEE} * \sum_{\mathrm{i}=1}^{\mathrm{n}} \mathrm{I}_{\mathrm{i}} * \int_{0}^{\infty} \frac{\mathrm{F}_{\mathrm{u}}(\mathrm{t})}{\mathrm{f}_{\mathrm{u}}} * \mathrm{f}_{\mathrm{j}} \int_{0}^{50}{ }_{\mathrm{F}}(\mathrm{t})$

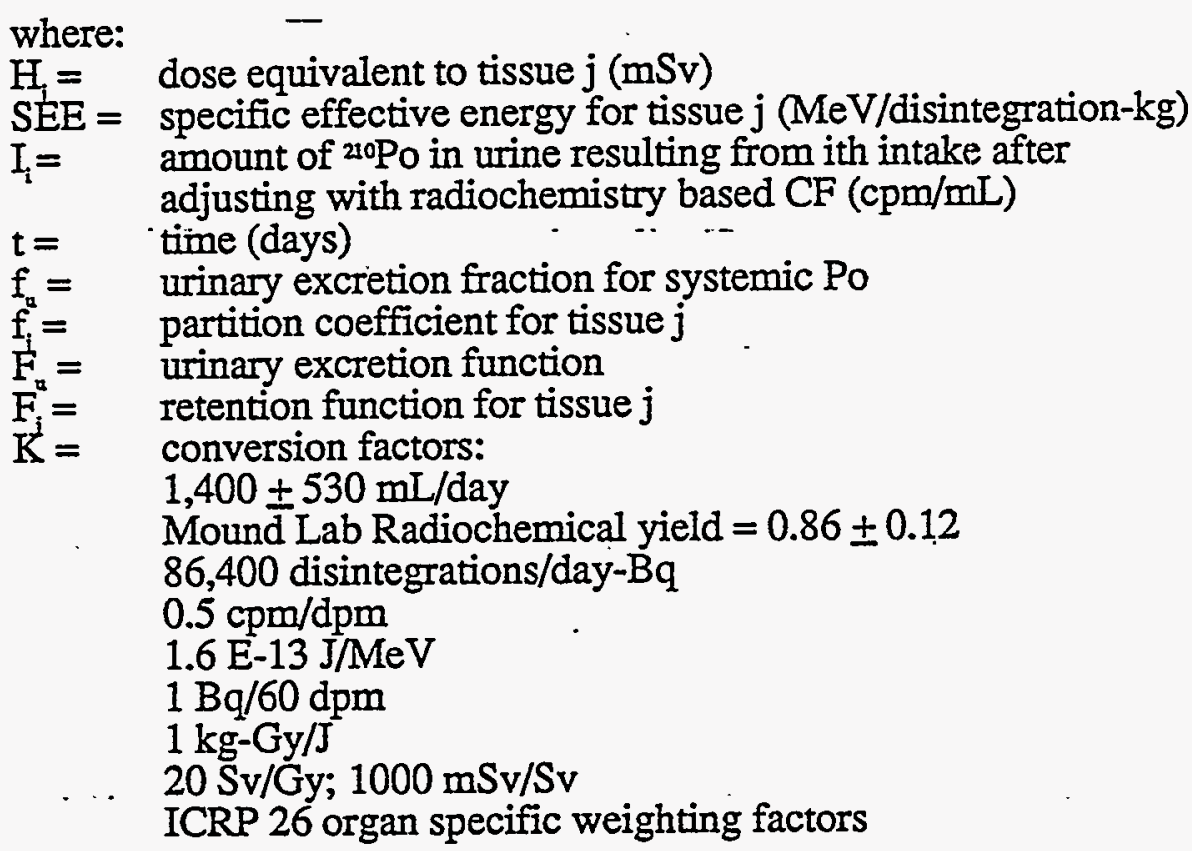

It should be noted that the model estimates dose equivalent values on a gross organ basis.

-- The actual microdosimetric distribution within any specific tissue (e.g., based on cell type or function) may differ from the gross organ estimate. However as pointed out in Section 2.2.2, autoradiographic studies on the cat and rat have shown that the distribution of nonaggregated $\mathrm{Po}$ is the same in several tissues irrespective of the route of administration, dosage level, and physicochemical form.

A Fortran program named Omdos has been written to convert an individual's records from the Mound Laboratory urinary Po data base into a format accessible for dosimetry calculations. The output file from Omdos is used in the Fortran program Dose, which estimates the systemic dose equivalent from the Po bioassay data. The user is asked for a worker case number. Sample dates are converted initially to Julian days and 
then to Arabic numerals, with day 0 assigned to the first sample. A column labelled "days post first sample" is written to a new file along with the sample Po count rate, expressed as counts per minute per $\mathrm{mL}$ urine.

There are a number of data entries resident on the Mound data base that need to be rejected as described in internal Mound memorandum. These are indicated by entries of "." in the sample description column of the data base. The inclusion of these in the data sets would adversely affect the testing of the data for outliers, which is described below. Therefore at the outset, Omdos rewrites the data set excluding the aforementioned entries. For other sample data, the symbol "*" appears in the description column indicating that a change in sample volume from 50 to $100 \mathrm{~mL}$ may be warranted depending on the date of sample collection. These changes are also made by Omdos.

Historical records indicate that some urine samples analyzed at Mound were externally contaminated. Visual inspection of some data show an occasional sample with Po levels two to three orders of magnitude greater than follow-up samples taken later in the same day or during the ensuing days. A significant intake is reflected by a proportional increase in urine Po content. But for a sample Po count rate to be truly reflective of an intake, the ensuing sample must have a predictable Po level based on expected excretion rates of Po. For example, biological considerations dictate that an accurate urinary Po measurement simply cannot be on the order of $1000 \mathrm{cpm} / \mathrm{mL}$ on day 1 and $0-1 \mathrm{cpm} / \mathrm{mL}$ on day 3 .

Omdos takes the first value and predicts urinary Po excretion from that point in time based on the urinary biokinetics for non-human primates determined in this research. Likewise, the uncertainty associated with each predicted point is known from the regression statistics; consequently, the range of a predicted value can be described within a confidence interval. Similarly, for each value, an error term (based on counting 
statistics) and distribution about the mean can be calculated. A Students t-test made using the second measured excretion value and the associated predicted value is performed to determine two factors. ${ }^{6}$ The first is whether or not the intake represented by the first value is real or should be eliminated as a false positive? And secondly, does the second value represent an additional intake, or does it reflect predicted clearance resulting from the most recent intake? In Omdos, the former question is addressed. The maximum estimate of the $95 \%$ confidence interval describing the second value is compared to the minimum predicted estimate of the $95 \%$ confidence interval at that time. Failure of the $t$-test where $t$ is negative (i.e., the measured value is less than the predicted value) is the criterion for deleting the potential intake point from the data set as a "high side" outlier. Omdos continues to check all data points for outliers.

It was decided not to incorporate an analagous procedure in the algorithm to - eliminate "low side" outliers. Integrating the urinary excretion function beginning with a data point identified as a statistically significant intake will not be affected by any such subsequent outliers. If an inaccurate low data point is used in a t-test to eliminate a potential intake point, the quantitative effect on the dosimetry calculation will be minimal because the increased Po output in urine would have been measured in the next sample submitted by the worker. "High" level samples were usually followed up within a few days; often, a duplicate, same day sample was submitted. In addition, due to the reduction in Po plating efficiency resulting from deposition out of freshly voided unashed urine, it is possible that some samples will not record more than a few counts during the 20 minute count time utilized at Mound Laboratory.

6 After a relatively high urine 20 Po measurement, duplicate samples were often collected and analyzed on the same day. When the second data point on the data base was taken from the same day as the first data point, Omdos advances to the next data point for use in the $\mathrm{t}$-test. 
Finally, Omdos checks the remaining data set for multiple same-day entries. Where these occur, the mean count rate is calculated and written to the output data file.

Program Dose uses the data file prepared by Omdos. In the first section of the algorithm, a search of the data file is made to determine all data which can be statistically shown to represent systemic uptake of Po. As was done in the outlier testing in Omdos, a predicted curve (and associated error based on the t-distribution) is generated from the first intake point ${ }^{7}$ based on the urinary excretion function for Po that was determined in the baboon.

The minimum of the $95 \%$ confidence interval describing all subsequent data (error bands for the measured data are based on counting statistics) are compared to the corresponding maximum predicted value based on the $95 \%$ confidence interval resulting from the initial intake event. This is synonymous with a t-test. The procedure continues until failure of the $t$-test occurs where $t$ is positive (i.e., the data point, or measured value is greater than the predicted value), signifying that the data point tested represents the occurrence of an additional Po intake. Biologically, the systemic input of Po may represent either Po passing across the lung epithelium, through the wall of the small intestine, or an additional occupational exposure.

In the next section of the program, Dose applies the "correction function" which describes the ashed/traced to unashed/untraced spontaneous deposition recovery ratio to the intake points (Eq. 5.1). The first intake point is multiplied by a correction factor of $10.0(\mathrm{CF}(\mathrm{t})$, where $\mathrm{t}=5$ days post exposure). Application of the $\mathrm{CF}$ begin with days post

7 To start the procedure, the first positive data point is assumed to represent the first intake. 
exposure equal to 5 because urine samples were usually submitted on Monday morning at Mound. The bioassay measurement thus reflected potential intakes which had occurred from 3 to 7 days earlier.

The $C F$ is then applied to all remaining intake points. The days post exposure for a new intake is set equal to 5 if the Po excreted at that time is entirely due to the new intake. However, the Po being excreted at that point in time may be influenced by one or more previous intakes, depending on that individuals's exposure history. Therefore, prior to application of the $\mathrm{CF}$, the intake point is segmented into portions based on the predicted Po excretion from prior intakes. For example, if:

$3 \mathrm{x}=$ the amount of Po in urine resulting from a

statistically significant intake

$1 \mathrm{x}=$ the predicted amount of Po excretion based on the previous intake

$t_{1}=\quad$ the time of the previous intake (days post first sample)

$t_{2}=$ the time of the new intake (days post first sample)

then:

$3 x-x=2 x=$ the portion of the measurement attributable to the new intake.

- The $\mathrm{CF}$ is applied.to give the new adjusted intake point-as follows:

\begin{tabular}{|c|c|c|}
\hline Portion magnitude & Source & Time post intake- \\
\hline $2 x$ & $\begin{array}{l}\text { new } \\
\text { intake }\end{array}$ & 5 days \\
\hline $\mathrm{x}$ & $\begin{array}{l}\text { previous } \\
\text { intake }\end{array}$ & $t_{2}-t_{1}$ \\
\hline
\end{tabular}

Therefore, the adjusted intake point $=[2 \mathrm{x} * 10.0]+[\mathrm{x} * \mathrm{CF}(\mathrm{t})]$.

By integrating the urinary excretion function, the quantity $Q$, or time integral of internal contamination (ICRP 1968), can be calculated (Eq. 5.4): 


$$
Q=\sum_{j=1}^{n} \int_{0}^{\infty} \Gamma_{j}^{\infty} * \exp \left(-\lambda_{u} * t\right)
$$

where,

$I_{j}=\quad$ adjusted amount of $210 \mathrm{Po}$ in urine resulting from

. the jth intake

$t=$ time (days)

$\lambda_{\mathrm{u}}=$ effective clearance rate of Po from urine (day-1)

Dose performs this calculation by applying the baboon urinary excretion function for systemic Po to the adjusted intake data. The contribution to $Q$ due to each intake is summed to determine the total $Q$ for the entire series of measurements.

The program calculates organ specific dose equivalents by multiplying $Q$ by the proper constants, metabolic parameters, conversion factors, and weighting factors as recommended in ICRP 26 (1977). The individual dose equivalents are summed to determine the total systemic dose equivalent. The ICRP dosimetric methodology assigns weighting factors to the gonads, skeleton, bone marrow, lungs, and thyroid. The liver, kidney, spleen, adrenal gland, and pancreas are the five remaining organs with-the greatest Po concentrations and are therefore assigned a weighting factor of 0.06 .-

The metabolic parameters utilized are the organ partition coefficients and effective retention half-times determined in the adult female baboon (Table 4.5).8 Some of the parameters have been summarized along with previously published parameters in Table 5.4. The model is applied, however, to a data base corresponding mostly to males. A study of sex differences in the metabolism of Po in rats supported the supposition that the use of metabolic parameters determined in the female might reasonably be applied to the

8 The retention half-times in Table 4.5 reflect biological processes only. These have been adjusted so that the dosimetry algorithm uses the effective half-times. 
male of the species (Stannard and Angell 1956). That is both excretion and tissue retention rates were not significantly dependent on sex, although the partition coefficients for the kidney and spleen were slightly higher for females. If this difference is also a fact for primates, then use of the partition coefficient determined in the female would be dosimetrically conservative.

The assumption that the 200 partition coefficient and retention time for ovaries is the same as for testes was found to be inaccurate in rats (Stannard and Angell 1956). Initial Po concentration in the ovaries was much greater than that in the testes. However, the loss of Po from the testes occurred at a slower rate such that Po concentration in the two gonadal tissues was equal at approximately 90 days post intravenous administration. Since the total radiation dose to the ovaries exceeded that to the testes, use of the metabolic parameters determined for the female gonads results in conservative dose estimates (as is the case for the kidney and spleen). when applied to males.

Throughout the entire algorithm, standard statistical error propagation techniques are followed whenever variables are multiplied, divided, added or subtracted. For example:

$$
\begin{aligned}
& (A \pm a) *(B \pm b)=A * B \pm(A * B)^{*}\left[(a / A)^{2}+(b / B)^{2}\right]^{1 / 2} \\
& (A \pm a) /(B \pm b)=A / B \pm(A / B) *\left[(a / A)^{2}+(b / B)^{2}\right]^{1 / 2} \\
& (A \pm a)+(B \pm b)=A+B \pm\left[a^{2}+b^{2}\right]^{1 / 2} \\
& (A \pm a)-(B \pm b)=A-B \pm\left[a^{2}+b^{2}\right]^{3 / 2}
\end{aligned}
$$

Sources of error with their approximate range and the basis for their estimation, are given in Table 5.5.

The algorithm was checked for accuracy as it was developed. During program execution, key variables (e.g., intake point values, quantity of systemic Po, etc.) were 
written to the terminal screen as they were calculated. Hand calculations made prior to program execution were compared with these variables as a means of assuring that the algorithm was in fact processing the data correctly.

The source codes for Omdos, Dose, and Mndose, the dBase III+ batch file which accesses Omdos and Dose, are listed in Appendix $\mathrm{F}$ along with instructions for their use. Sample dosimetry output tables appear in Appendix G.

\subsubsection{Model Validation}

The dosimetry model is constructed in part by applying the biokinetics which describe excretion of $\mathrm{Po}$ in the urine of non-human primates. The metabolic parameters utilized were determined following intravenous administration of Po whereas the occupational exposure of workers occurred primarily due to inhalation exposure. A biokinetic parameter used in the model (i.e., half-time of Po in urine following intravenous injection) is a measure of a different physiological phenomenon than is the half-time following regression of an excretion model to a set of worker bioassay data. After intravenous administration to the baboon, the entire intake is deposited in the bloodstream (i.e., within the systemic compartment). But following ${ }^{20}$ Po inhalation exposure of a worker, the systemic deposition is controlled by the retention of the radionuclide in an external organ (e.g., the lung). Therefore, the biokinetics for Po in urine predicted by the model should not be the same as the half-time resulting from a regression performed directly on the health monitoring data.

While an intake resulting in an elevated urine Po count rate may be of an acute nature, the absorption of Po into the systemic compartment is invariably a temporal 
process. For this reason, the occupational exposure episodes are more accurately classified as "chronic" systemic exposures resulting from one or more acute intakes which had occurred during the previous work week.

When a urinary Po sample count exceeded the pre-set tolerance limit of 8 or $12 \mathrm{cpm}$ per $50 \mathrm{~mL}$ of urine, the standard procedure at Mound Laboratory called for the individual to be moved to a relatively "Po free" location. Another single void sample was usually assayed to confirm the presence of an elevated urinary Po content. An accelerated schedule of urinalyses continued until excretion of the radionuclide dropped to an acceptable level.

From the Mound Po bioassay data base a subse: of approximately 200 cases was initially identified consisting of individuals with urinary Po levels which clearly exceeded the tolerance limit. However, after removing outliers and examining the clearance pattern for Po in urine, the number of episodes in which the worker was moved to avoid further possible exposure was reduced to 54 .

A test of the model must first consider the movement of Po through the compartments shown in Fig. $\ddot{5.8}$. First, the absorption of Po from the pulmonary region into the bloodstream is calculated as a function of time through use of the ICRP 30 lung and gastrointestinal retention models (Figs. 5.9 and 5.10). Direct absorption occurs from lung compartments a, c, e, and i (through h). Retained Po clears from compartments b, d, $d$ (through $f$ ), and $d$ (through $g$ ) into the stomach, through which a fraction (the $f_{1}$ value) gains entrance into the bloodstream via absorption through the small intestine. The contribution of Po from each compartment into the blood and from the blood to urine is shown in Table 5.6. 
The $f_{1}$ value for Po. is given in ICRP 30 as 0.1 . However, $f_{1}$ values reported in the literature indicate that a value of 0.05 may be more accurate. Studies in the rat (Silberstein et al. 1950a; Stannard 1954; Stannard and Angell 1956; Spoerl and Anthony 1956; Stannard 1964a) consistently determined that the $f_{1}$ value ranged from 0.03-0.05. The $f_{1}$ of a human subject who had ingested Po may have reached 0.1 , but the estimate was largely conjectural and may have been considerably less, according to the authors (Silberstein et al. 1950b). Based on the conclusions of these studies, the value chosen for use in the model validation calculations was 0.05 .

Having established the temporal input of Po from the lung and GI tract into the systemic compartment based on ICRP 30 models, the baboon model describing the rate of urinary excretion of systemic Po is applied. The entire biokinetic model (i.e., including lung and gi tract Po clearance into blood and into urine) predicts that Po is excreted into the urine with a 28.0 day half-time. The average half-time detemined via least squares regression analyses for the 54 occupational exposure episodes is $38.1 \pm 15.9$ days. These data reflect the kinetics expected for a Class W substance clearing from the lungs (ICRP 1979). However, the most accurate description of this parameter must also incorporate the CF described in Section 5.1.1. Application of the $\mathrm{CF}$ to the human data reduces the average effective half-time of Po in the urine to $25.9 \pm 10.8$ days, a value in excellent agreement with the 28.0 days predicted by the model. 
TABLE 5.1 UNASHED/UNTRACED PROCEDURE COMPARISON FOR PO DEPOSITION

\begin{tabular}{|c|c|c|c|}
\hline Procedure: & Meyer 1956 & NYUMC'1989 & EML2 $^{2} 1983$ \\
\hline Sample: & $\begin{array}{l}\text { weekly } \\
\text { spot specimen }\end{array}$ & $\begin{array}{l}\text { daily } \\
24 \mathrm{~h} \text { sample }\end{array}$ & unspecified \\
\hline Solution & $1 N \mathrm{HCl}$ & $1 N \mathrm{HCl}$ & $1 N \mathrm{HCl}$ \\
\hline Plating: & $\begin{array}{l}50 \mathrm{~mL} \\
\text { wax paper cup } \\
\text { room temperature } \\
16 \text {-gauge } \mathrm{Cu} \\
2.54 \mathrm{~cm} \text { diameter } \\
2 \mathrm{~h} \text { plate time } \\
\text { water rinse }\end{array}$ & $\begin{array}{l}50 \mathrm{~g} \\
\text { plastic cup } \\
\text { room temperature } \\
\text { 8-gauge Cu } \\
2.54 \mathrm{~cm} \text { diameter } \\
3 \mathrm{~h} \text { plate time } \\
\text { ethanol rinse }\end{array}$ & $\begin{array}{l}100 \mathrm{~mL} \\
250 \mathrm{~mL} \text { beaker in } \\
55^{\circ} \mathrm{C} \text { water bath } \\
0.64 \mathrm{~mm} \mathrm{Ni} \\
2.22 \mathrm{~cm} \text { diameter } \\
2.5 \mathrm{~h} \text { plate time } \\
\text { water rinse }\end{array}$ \\
\hline $\begin{array}{l}\text { Deposition } \\
\text { Recovery: }\end{array}$ & $\begin{array}{l}86 \pm 12 \% \\
\text { (limit tested: } \\
\text { approx. } 6.7 \mathrm{~Bq} \text { ) }\end{array}$ & $\begin{array}{l}82 \pm 3 \% \\
\text { (limit tested: } \\
70 \mathrm{~Bq} \text { ) }\end{array}$ & $70 \%$ \\
\hline
\end{tabular}

${ }^{1}$ NYUMC=New York University Medical Center

${ }^{2}$ EMI $=$ Department of Energy Environmental Measurements Laboratory 
TABLE 5.2 SUMMARY OF UNMETABOLIZED PO RECOVERIES

\begin{tabular}{lcccc}
\hline Sample Type & $\begin{array}{c}\text { 2880 } \\
\text { Tracer } \\
\left(\mathrm{Bq} \mathrm{mL}^{-1}\right)\end{array}$ & $\begin{array}{c}\text { \# of } \\
\mathrm{Cu} \\
\text { Plates }\end{array}$ & $\begin{array}{c}\text { Mean Percent } \\
\text { Recovery } \\
\pm \mathrm{sd}\end{array}$ & $\begin{array}{c}\text { Recovery } \\
\text { Range } \\
\text { low high }\end{array}$ \\
\hline Human urine & $0.06 \pm 0.00$ & 4 & $78.6 \pm 3.3$ & 75.482 .8 \\
Human urine & $0.27 \pm 0.00$ & 2 & $80.6 \pm 2.2$ & 79.082 .1 \\
Human urine & $0.66 \pm 0.01$ & 2 & $84.1 \pm 0.9$ & 83.484 .7 \\
Baboon urine & $0.38 \pm 0.01$ & 2 & $84.5 \pm 1.6$ & 83.385 .7 \\
\hline mean recovery & & 10 & $81.2 \pm 3.5$ & \\
\hline Acid solution & $1.30 \pm 0.04$ & 3 & $83.4 \pm 1.6$ & 81.584 .4 \\
\hline All samples & & 13 & $81.7 \pm 3.2$ & \\
\hline Spoerl 1950 & & $86.1 \pm 11.9$ & \\
\hline
\end{tabular}

TABLE 5.3 THE EFFECT OF A WATER BATH ON PO RECOVERY*

\begin{tabular}{cccc}
\hline \hline $\begin{array}{c}\text { Deposition } \\
\text { Condition }\end{array}$ & $\begin{array}{c}\text { Plate } \\
\text { Time } \\
\text { (hours) }\end{array}$ & $\mathrm{N}$ & $\begin{array}{c}\text { Recovery } \\
(\% \pm \mathrm{sd})\end{array}$ \\
\hline Water Bath & 2 & 8 & $77.5 \pm 3.5$ \\
Room Temp. & 2 & 4 & $62.8 \pm 11.7$ \\
Room Temp. & 3 & 4 & $\mathbf{7 2 . 5} \pm 11.0$ \\
\hline \hline
\end{tabular}

-(Comparison of Po deposition recovery results from urine samples plated in an $80^{\circ} \mathrm{C}$ water bath and at room temperature). 
TABLE 5.4 METABOLIC PARAMETERS FOR SYSTEMIC PO

\begin{tabular}{|c|c|c|c|c|}
\hline \multirow[b]{2}{*}{ Parameter } & \multicolumn{4}{|c|}{ Model } \\
\hline & $\begin{array}{c}\text { NYUMC } \\
1989\end{array}$ & $\begin{array}{l}\text { ICRP } \\
1979\end{array}$ & $\begin{array}{c}\text { Bernard } \\
1979\end{array}$ & $\begin{array}{c}\text { Breuer and } \\
\text { Clemente } 1979\end{array}$ \\
\hline $\begin{array}{l}\text { Biological } \\
\text { Retention }\end{array}$ & $\begin{array}{l}15-50 \\
\text { days }^{1}\end{array}$ & $\begin{array}{c}50 \\
\text { days }\end{array}$ & $\begin{array}{l}50 \\
\text { days }\end{array}$ & $\begin{array}{l}50 \text { days; } \\
400 \text { days }\end{array}$ \\
\hline $\begin{array}{l}\text { Absorbed } \\
\text { Fraction }\left(f_{1}\right)\end{array}$ & - & 0.1 & 0.1 & 0.25 \\
\hline $\begin{array}{l}\text { Urinary Excretion } \\
\text { Fraction }\left(f_{n}\right)\end{array}$ & 0.38 & 0.1 & 0.1 & 0.36 \\
\hline $\begin{array}{rr}\text { Partition Coef.: } & \begin{array}{r}\text { Liver } \\
\text { Kidney } \\
\text { Spleen }\end{array} \\
\end{array}$ & $\begin{array}{c}0.29 \\
0.07 \\
0.006\end{array}$ & $\begin{array}{l}0.1 \\
0.1 \\
0.1\end{array}$ & $\begin{array}{l}0.1 \\
0.1 \\
0.1\end{array}$ & $\begin{array}{l}-- \\
-- \\
-- \\
\end{array}$ \\
\hline
\end{tabular}

${ }^{1}$ Range of retention times for individual organs 
TABLE 5.5 SOURCES OF ERROR IN PROGRAM DOSE

\begin{tabular}{|c|c|c|}
\hline Source of Error & $\begin{array}{c}\text { Relative } \\
\text { Range (\%) }\end{array}$ & Basis for Propagation \\
\hline Urine ${ }^{210} \mathrm{Po}$ measurement & $1-50$ & counting statistics \\
\hline CF regression & $25-40$ & $\begin{array}{l}\text { regression error about least } \\
\text { squares line }\end{array}$ \\
\hline $\begin{array}{l}\text { Baboon urinary excretion } \\
\text { curve }\end{array}$ & $5-15$ & $\begin{array}{l}\text { regression error about least } \\
\text { squares line }\end{array}$ \\
\hline $\begin{array}{l}\text { Reference man: } \\
\text { daily urine output } \\
\text { organ weights }\end{array}$ & $\begin{array}{c}38 \\
6-33\end{array}$ & $\begin{array}{l}\text { ICRP } 23 \text { and Snedecor (1956) } \\
\text { ICRP } 23 \text { and Snedecor (1956) }\end{array}$ \\
\hline $\begin{array}{l}\text { Metabolic parameters: } \\
\text { a) organ partition coef. } \\
\text { b) clearance half-times } \\
\text { c) urinary excretion fraction }\end{array}$ & $\begin{array}{c}3-56 \\
4-63 \\
11\end{array}$ & $\begin{array}{l}\text { parameter errors from least } \\
\text { squares regressions performed on } \\
\text { baboon data }\end{array}$ \\
\hline
\end{tabular}


TABLE 5.6 ICRP 30 LUNG COMPARTMENT CONTRIBUTIONS TO SYSTEMIC UPTAKE OF PO AND SUBSEQUENT URINARY EXCRETION FOLLOWING AN ACUTE INHALATORY INTAKE ${ }^{1}$

\begin{tabular}{ll}
\hline \hline Compartment & Fraction of Intake (Q) \\
\hline
\end{tabular}

Lung->Blood

$\begin{array}{ll}\text { a } & 0.03 \\ \text { c } & 0.04 \\ \text { e } & 0.0375 \cdot\left(1-\exp \left(-0.0189 \cdot t^{*}\right)\right) \\ \text { ough h } & 0.0125 \cdot(1-\exp (-0.0189 \cdot t))^{2}\end{array}$

Lung $\rightarrow$ $>$ GI

$0.27 \cdot(1-\exp (-1.7379 \cdot \mathrm{t}))$

d through $f$

$0.04 \cdot(1-\exp (-3.4707 \cdot t))$

$\mathrm{d}$ through $\mathrm{g}$

$0.10 \cdot(1-\exp (-0.6981 \cdot t)) \cdot(1-\exp (-3.4707 \cdot t))$

$0.10 \cdot(1-\exp (-0.6981 \cdot t)) \cdot(1-\exp (-3.4707 \cdot t))$

GI->Blood**

$$
\begin{aligned}
& \sum_{\mathrm{i}=1}^{4} \mathrm{GI} *(1-\exp [-24 * \mathrm{t}]) \\
& * \mathrm{f}_{1} *(1-\exp [-0.3161 * \mathrm{t}])
\end{aligned}
$$

Urine+

$$
\left(\mathrm{Q}_{\mathrm{pulm}}+\mathrm{Q}_{\mathrm{GI}}\right) \cdot(1-\exp (-0.0495 \cdot t))
$$

Polonium assumed to be $100 \%$ Class W; rates include radioactive decay; transfer rates between compartments taken from ICRP 30 models

- days

. $\mathrm{f}_{1}=0.05$

+ effective urinary Po excretion rate $=0.0495$ days $^{-1}$ 
Fig. 5.1 Apparatus utilized for the NYUMC unashed/untraced method of spontaneous deposition of Po.

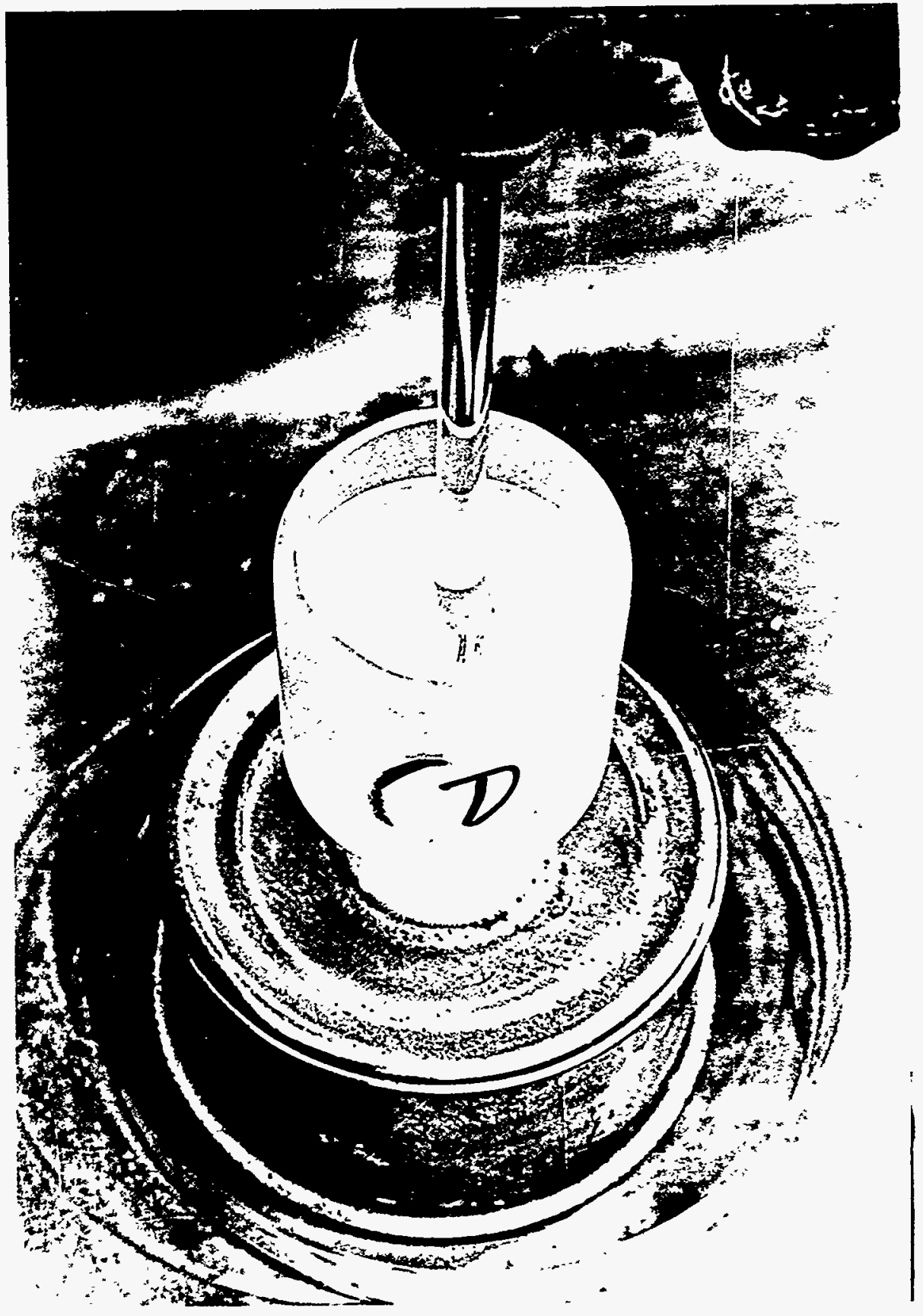


Fig. 5.2 Urinary ${ }^{20}$ Po excretion determined from split samples using two radiochemical procedures following intravenous administration of $210 \mathrm{Po}$ citrate in the adult female baboon.

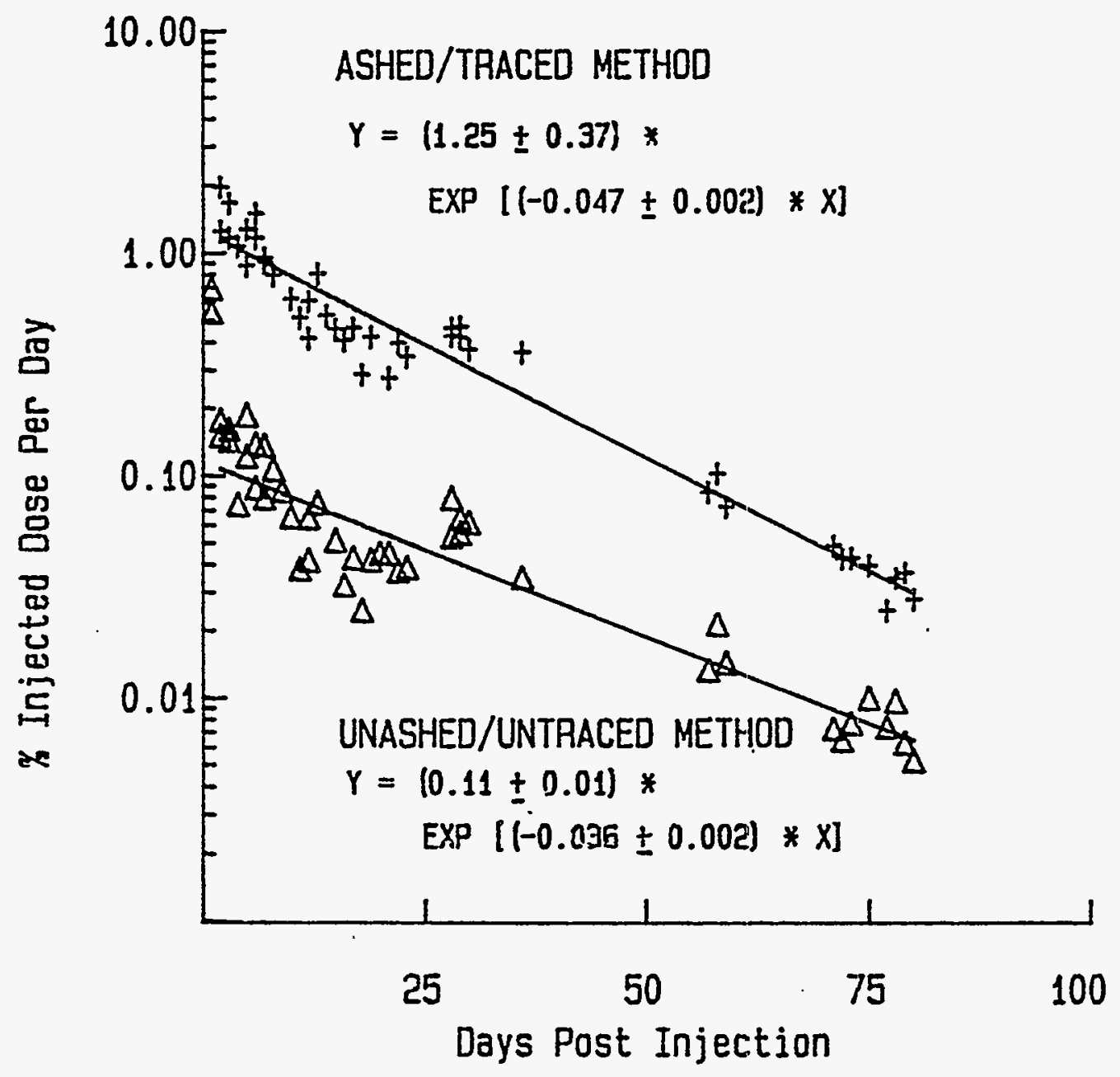

all data points have relative standard deviation $<10 \%$ 
Fig. 5.3 Temporal relationship resulting from the linear regression of the natural $\log$ of the ratio of ashed/traced to unashed/untraced baboon urine $210 \mathrm{Po}$ data on days post injection (day one samples not included in the regression).

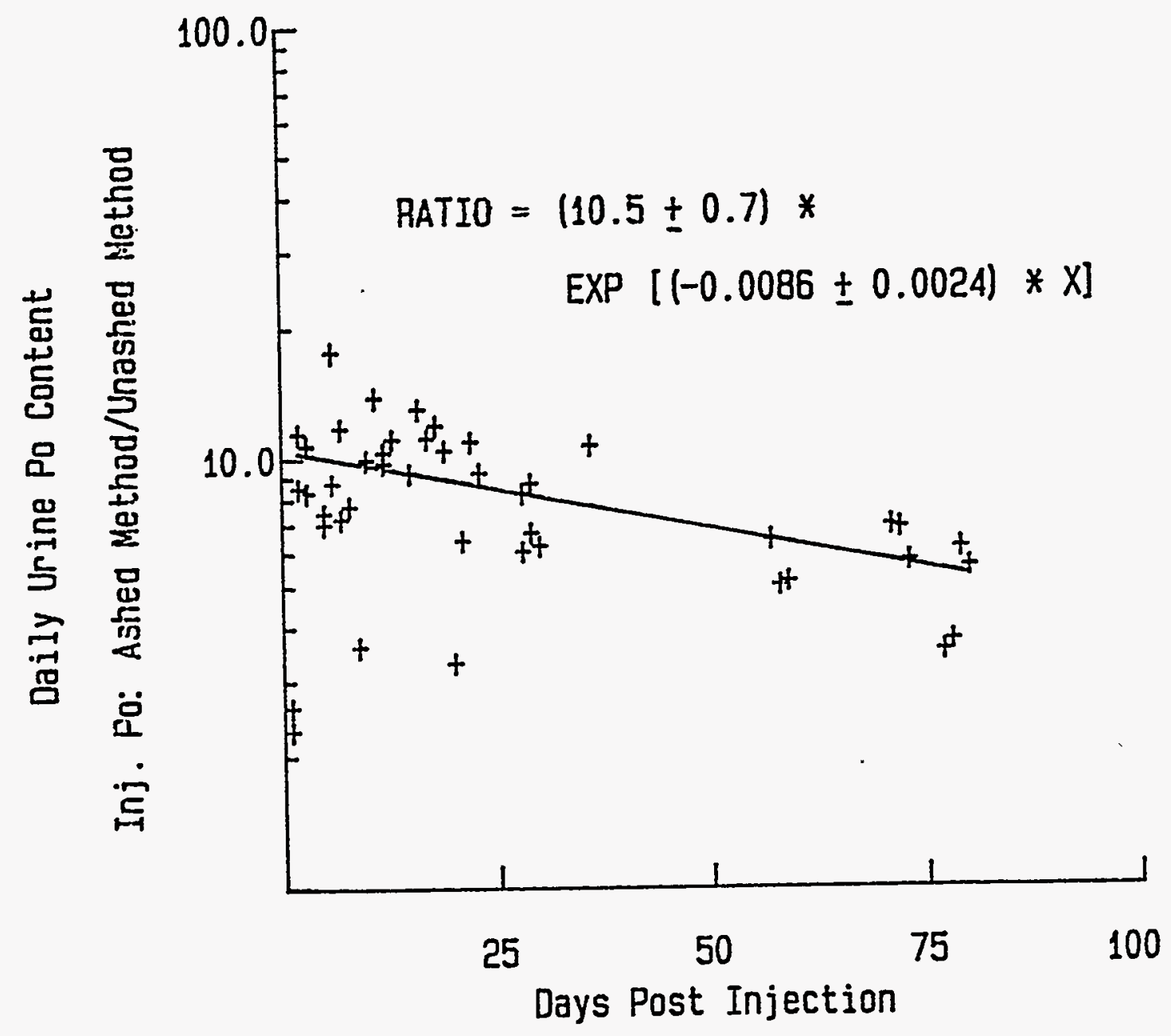


Daily Urine Pó Content

Inj. Po: Ashed Method/Unashed Methad

装
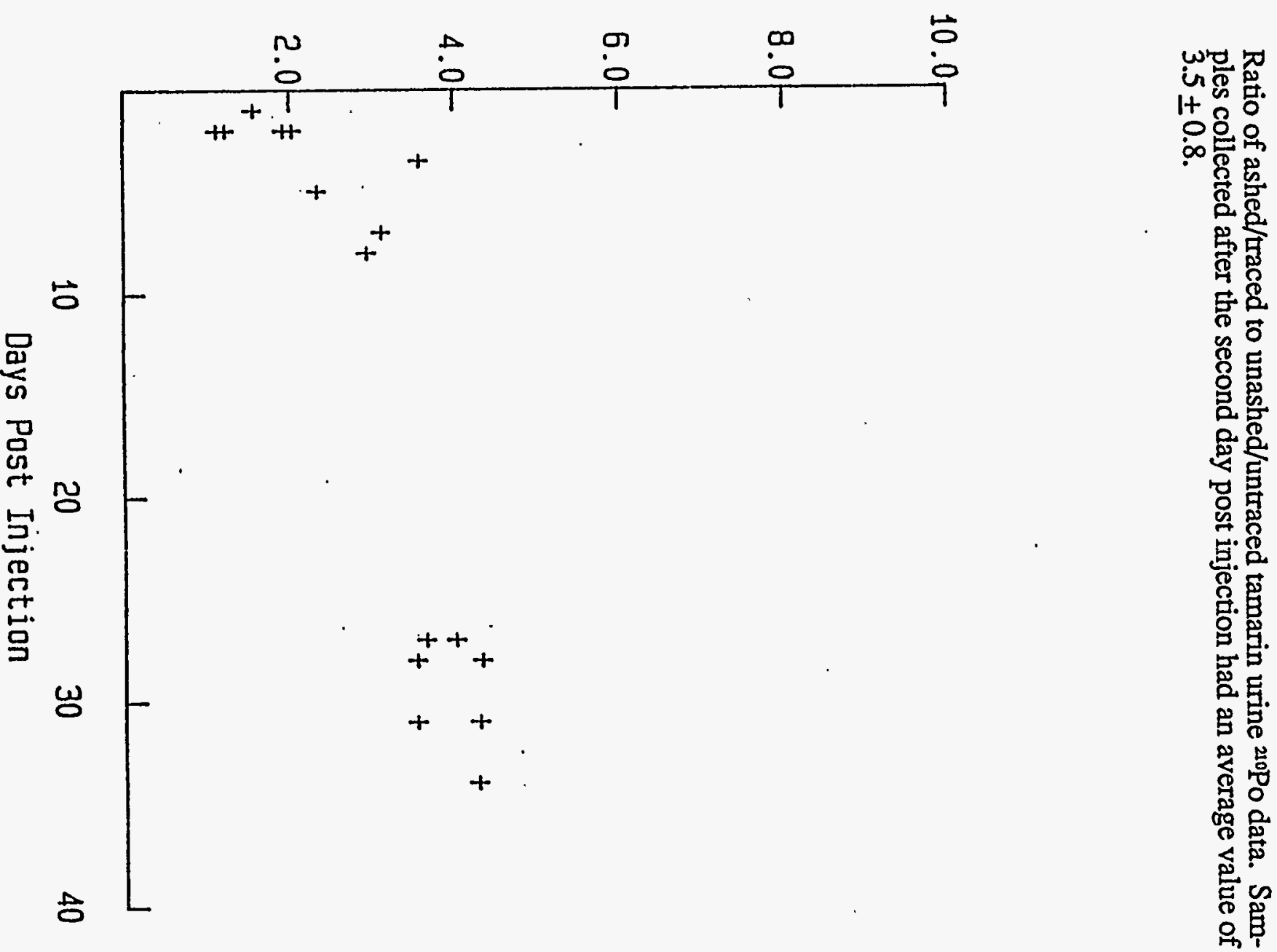
Fig. 5.5 Urinary 2000 excretion curves regressed to data presented by Fink (1950) for three humans compared to the unashed/untraced data from both species of non-human primates. The human data were also generated with an unashed/untraced procedure.

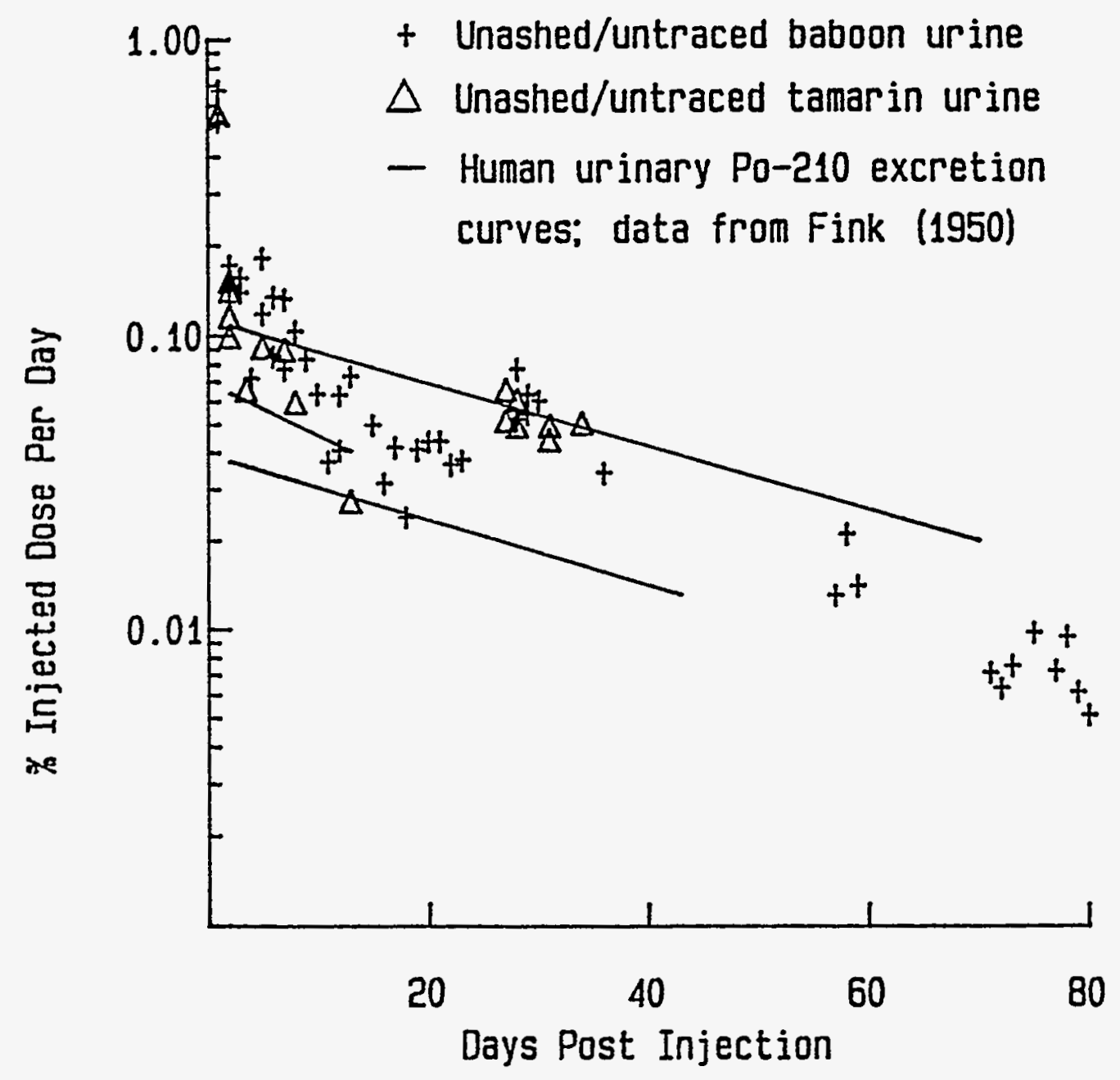


Fig. 5.6 Fitted curves, data, and excretion functions for a human injected with $210 \mathrm{Po}$ chloride (data from Fink 1950). Integration of the functions show that $54 \%$ and $5 \%$ of the administered dose are excreted via the fecal and urinary routes out to infinity, respectively.

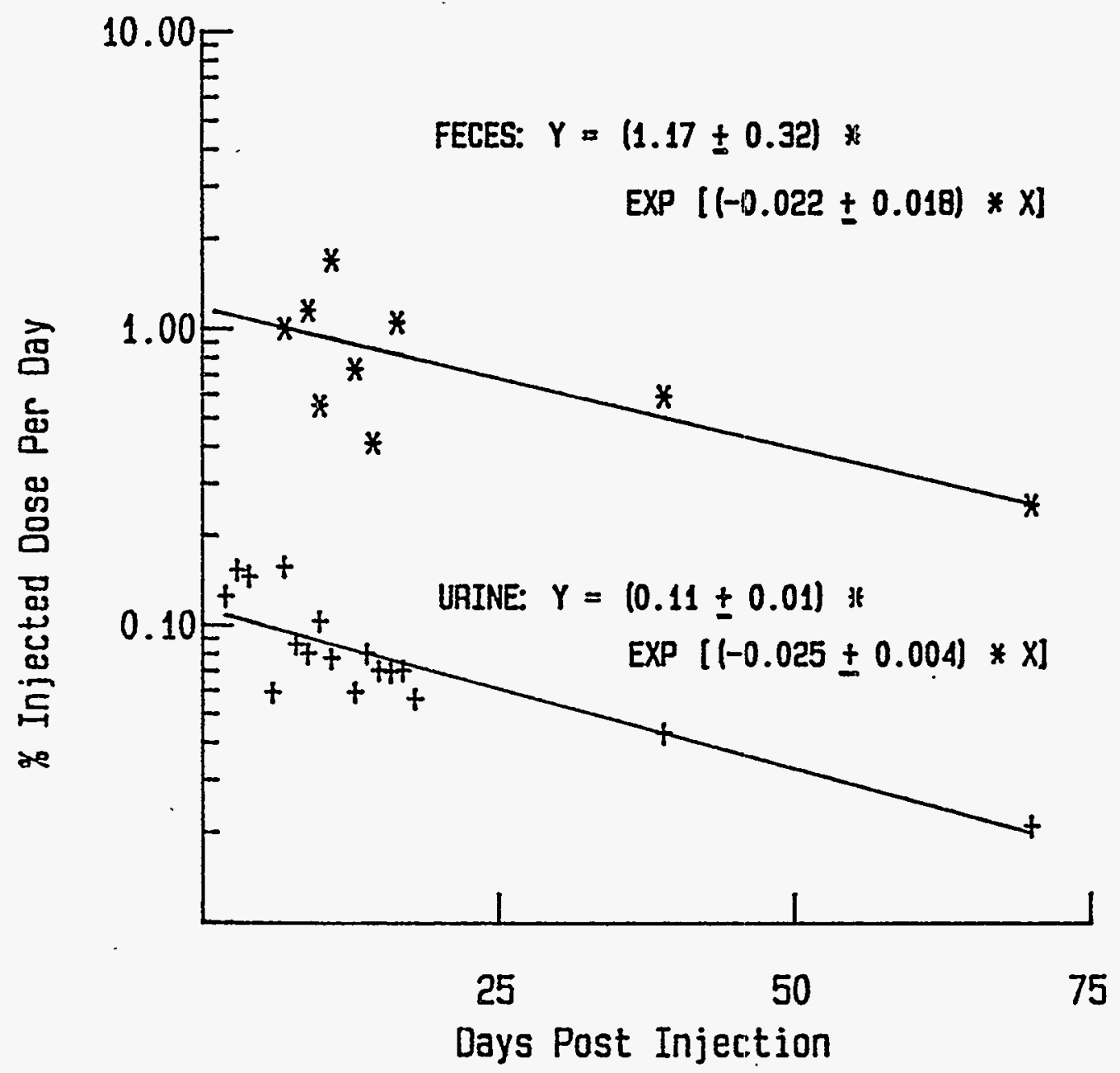


Fig. 5.7 Adjusted urinary excretion of $20 \mathrm{Po}$ for a human injected with $210 \mathrm{Po}$ chloride. The urinary Po data has been adjusted to account for the ratio of ashed/traced to unashed/untraced deposition efficiencies observed in baboon urine. The total 210 Po urinary output increases from $5 \%$ based on the original data (lower curve) to $35 \%$ of the administered dose.

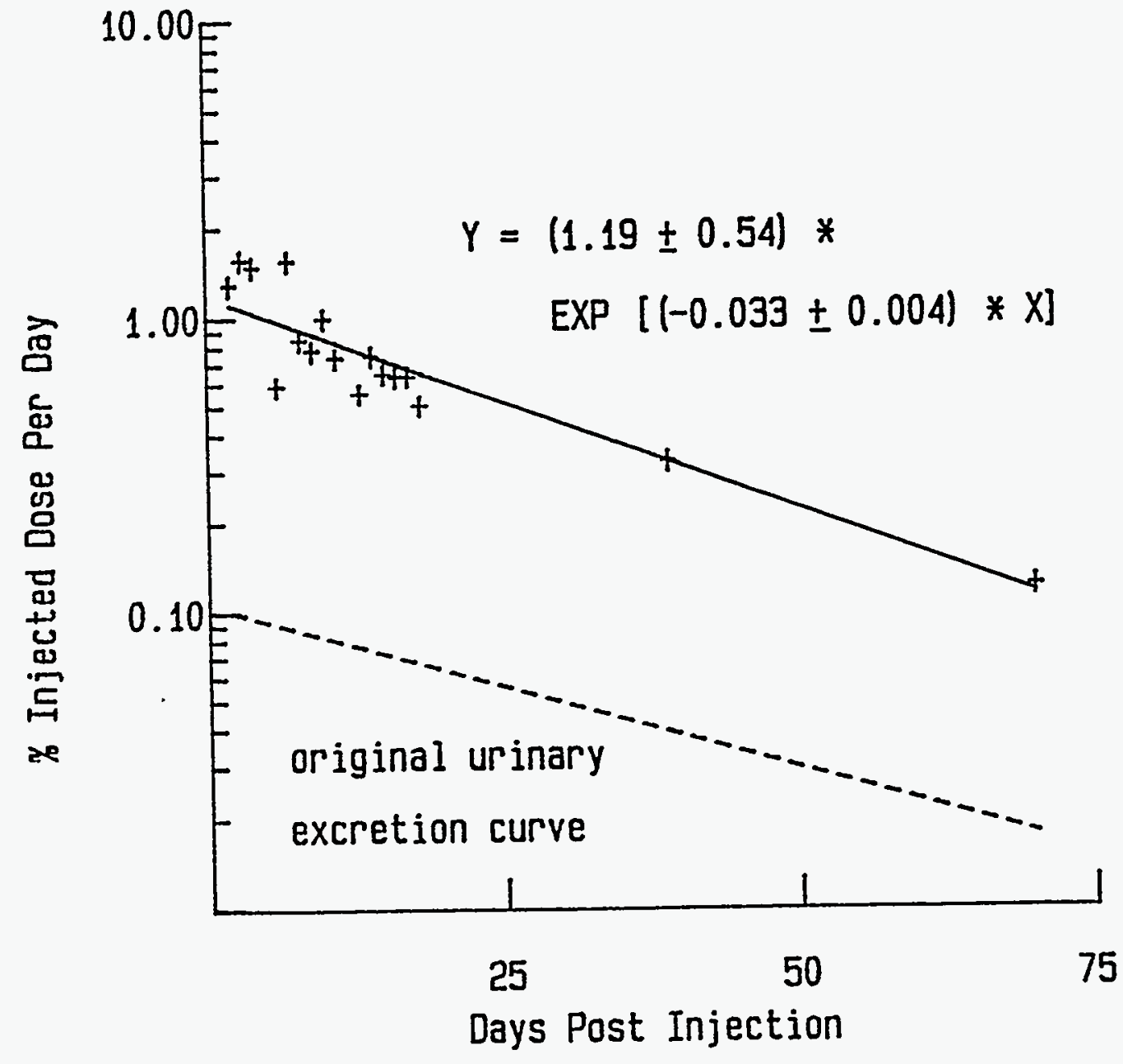


Fig. 5.8 Schematic of material transfer following deposition in the lung

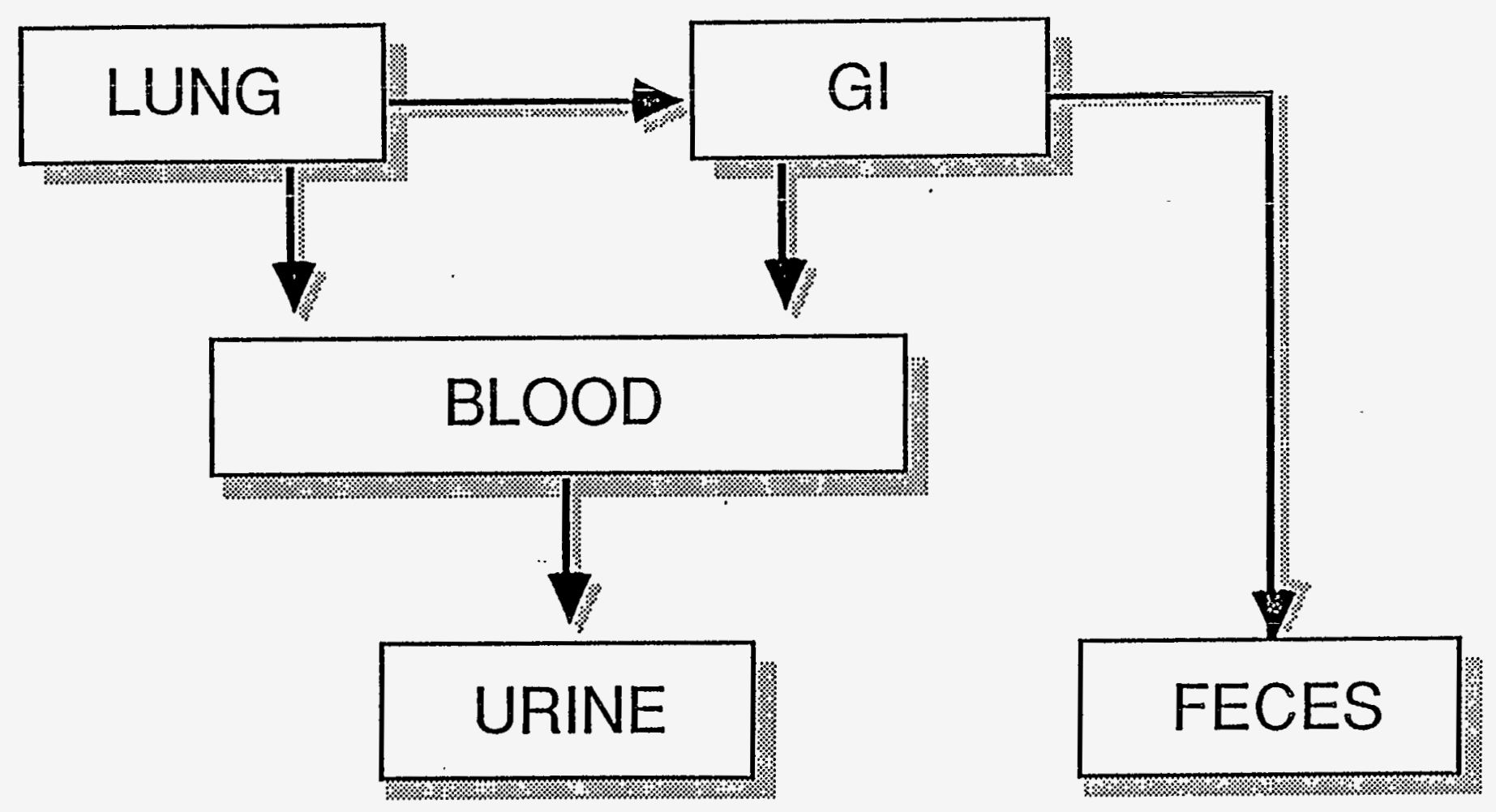


Fig. 5.9 The ICRP 30 Lung Model

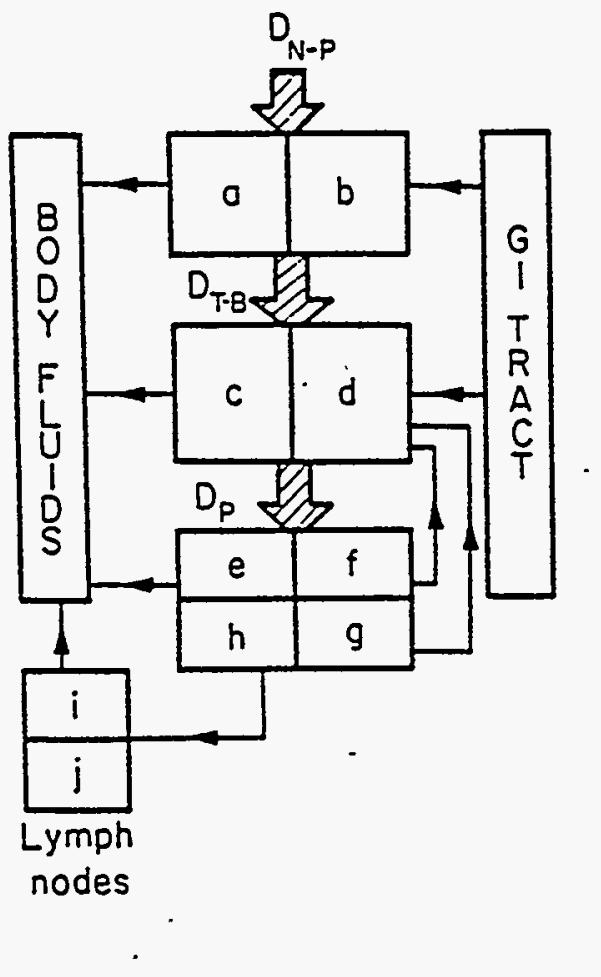


Fig. 5.10 The ICRP 30 GI Model

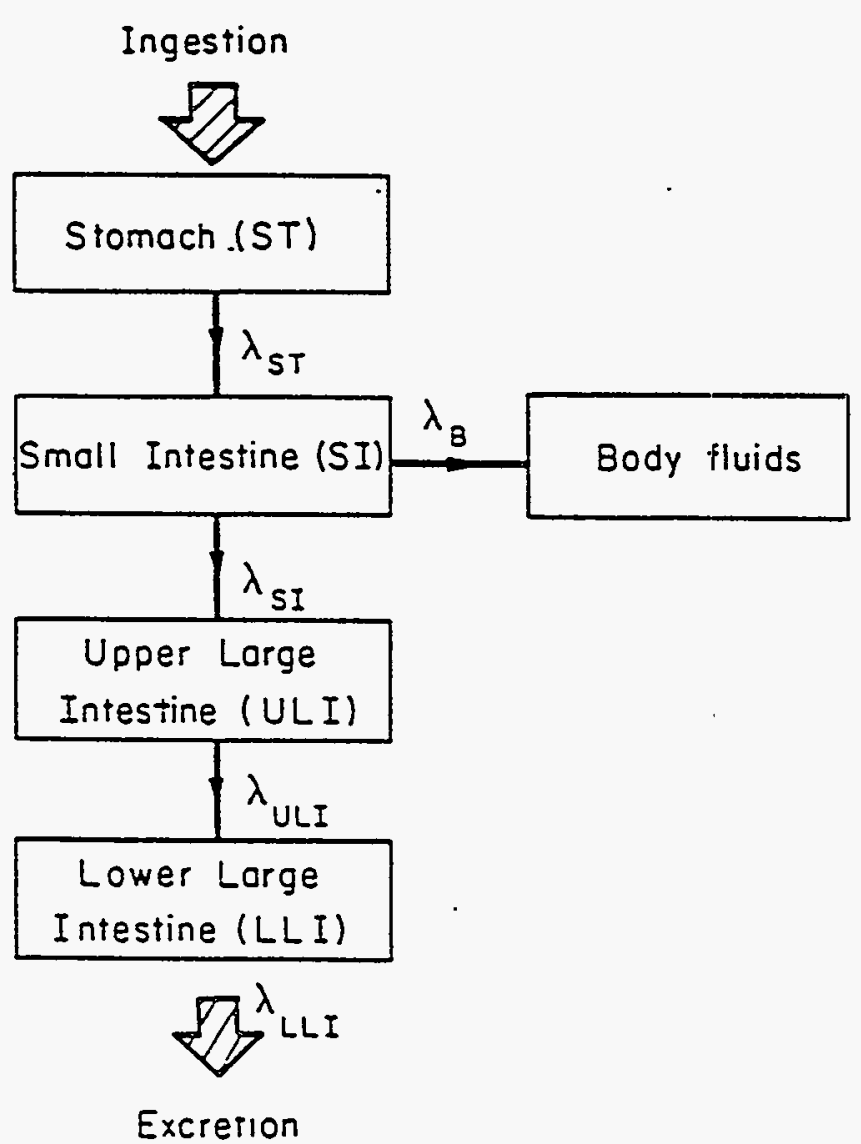




\section{Summary of Significant Findings}

The characterization of Po metabolism in non-human primates revealed the following:

- The radiochemical deposition efficiency of metabolized ${ }^{20} \mathrm{Po}$ is significantly lower when spontaneously deposited from fresh (unashed) urine compared to urine which has been wet ashed in $\mathrm{HNO}_{3}$.

- The Po excretion rate is more rapid than the rates in the literature for non-primate species and in the ICRP 30 metabolic model.

- The urinary excretion fraction for Po is greater than the 0.1 value in the ICRP 30 metabolic model, with measured values of approximately 0.2 and 0.4 in the tamarin and baboon, respectively.

- Polonium distributes throughout the soft tissues. However, organ partition coefficients were not equal for the liver, kidney, and spleen as would be predicted by the ICRP 30 metabolic model.

- Considerably less ${ }^{20}$ Po than expected deposits initially in the spleen. This distribution is most likely the result of using an injection solution free of aggregates.

- The 210 Po content of residual blood contributes significantly to the in vitro organ Po measurement of some organs (especially spleen and lung) under certain circumstances. 
Evaluation of human urine Po data collected during the Manhattan Project led to the following:

- Re-evaluation of data collected following the clinical administration of $210 \mathrm{Po}$ to humans by Fink (1950) suggest that the failure to wet ash urine prior to spontaneous deposition assay caused a decrease in the deposition efficiency of a similar magnitude as that measured in baboons as part of this research. Adjusting the human data to account for the quantitative effect of wet ashing urine on deposition efficiency results in good agreement between the urinary excretion parameters derived from the human and baboon data.

- A model has been developed to retrospectively estimate organ specific systemic radiological dose equivalent values to workers at Mound Laboratory based on their past Po urinalysis data. The model incorporates statistical testing to determine data reflective of significant Po intakes. Metabolic parameters determined in the baboon are utilized in the dosimetry calculations.

- Inclusion of lung retention parameters to the model (using an existing lung model or preferably new data based on ${ }^{-20} \overline{\mathrm{P}} \mathrm{O}$ inhalation exposure of non-human primates) could be easily accomplished. This would enable estimation of the effective dose equivalent. 


\section{APPENDICES}

\section{APPENDIX A. Radiochemical Procedures For Determination of $20 \mathrm{Po}$ In Bioassay. Samples}

\section{BIOASSAY PROCEDURE FOR PO IN URINE}

$50-\mathrm{ml}$ representative aliquot from $24 \mathrm{hr}$. urine sample

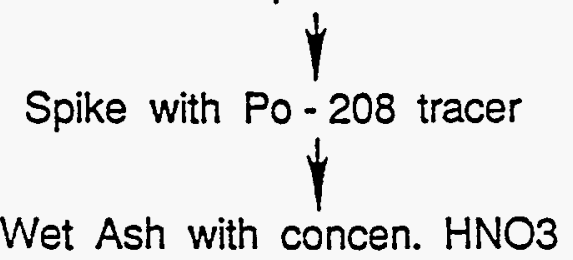

Dissolve ashed sample in $100-\mathrm{ml}$ of $1 \mathrm{~N} \mathrm{HCL}$

Transfer $10-\mathrm{ml}$ aliquot to nickel plating cell

Add $1-\mathrm{ml}$ sat. ascorbic acid solution

Adjust to $20-\mathrm{ml}$ with $1 \mathrm{~N} \mathrm{HCL}$

Stir for $3 \mathrm{hrs}$ at room temp.

Remove disc and rinse with ethanol

Count disc on an alpha spectrometer to resolve Po- 208 and Po- 210 


\section{BIOASSAY PROCEDURE FOR PO IN FECES}

24-hr. Tamarin feces

( 4 - 30g. wet wt.)<smiles>[13CH2][Te]</smiles>

Dry in convection oven

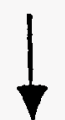

(2 - 15g. wet wt.)<smiles>[13CH3]</smiles>

Wet ash entire sample with concen. $\mathrm{HNO}_{3}+\mathrm{HClO}_{4}$

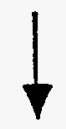

Take to Volume of $100-\mathrm{ml}$ in dilute $\mathrm{HNO}_{3}$

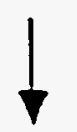

Remove a $10-\mathrm{ml}$ aliquot, spike with Po-208 tracer, reduce to dryness, convert to chloride $(1 \mathrm{~N} \mathrm{HCl})$ and plate 24-hr. Baboon feces

( 10 - 300g. wet wt. )

@ $100^{\circ} \mathrm{F}$ for 2 -3days

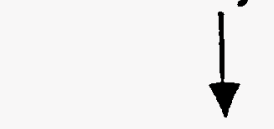

( 5 - 150g. wet wt.)

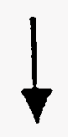

Homogenize dried feces in a screw-top container using a Spex Ball Mill Shaker.<smiles>[3H][13CH3]</smiles>

Wet ash $10 \%$ of sample with concen. $\mathrm{HNO}_{3}+\mathrm{HClO}_{4}$

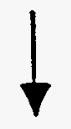

Take to Volume of $100-\mathrm{ml}$ in dilute $\mathrm{HNO}_{3}$ 


\section{BIOASSAY PROCEDURE FOR PO IN BLOOD}

Draw two (2) 5 - $10 \mathrm{ml}$. Whole Blood Samples

into vacutainer tubes contain. heparin or ACD

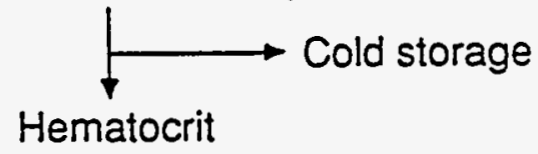

1

Centrifuge @ 2000 rpm for 10 min.

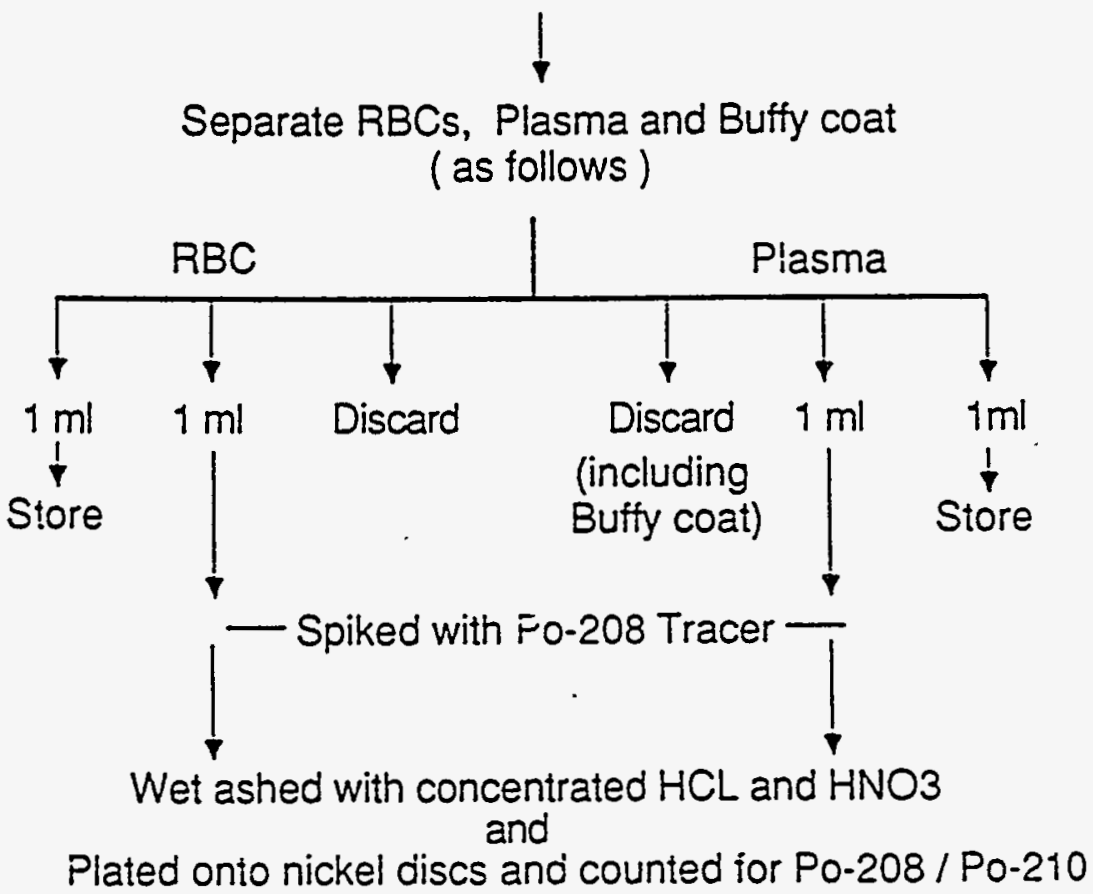




\section{APPENDIX B. Preparation of ${ }^{\mathrm{C}} \mathrm{Cr}$-labeled Erythrocytes}

1. Draw a $5 \mathrm{~mL}$ whole blood sample into a vacutainer containing $0.75 \mathrm{~mL}$ of acid citrate dextrose (ACD) solution.

2. Centrifuge @ 2000 rpm for 5 minutes @ 4․

3. Remove serum and buffy coat.

4. Wash RBCs three times with physiologic saline (PS), $0.9 \% \mathrm{NaCl}$.

5. Add dropwise $0.37-0.74 \mathrm{kBq}(10-20 \mathrm{uCi})$ of sterile sodium ${ }^{51} \mathrm{Cr}$ per $\mathrm{mL} \mathrm{RBC}$ with mixing.

6. Incubate mixture with mixing for 30 minutes @ $37^{\circ} \mathrm{C}$.

7. Wash ${ }^{51} \mathrm{Cr}-\mathrm{RBC}$ with PS.

8. Resuspend in 5-10 mL culture medium (90\% RPMI-1640, 10\% Bovine Serum, $1 \%$ Penn/Strep.)

9. Refrigerate overnight @ $4^{\circ} \mathrm{C}$.

10. Centrifuge @ 2000 rpm for 5 minutes @ 4ㄷ

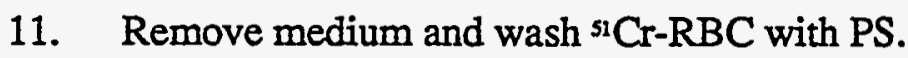

12. Resuspend ${ }^{\mathrm{SI}} \mathrm{Cr}-\mathrm{RBC}$ in approximately $10 \mathrm{~mL} \mathrm{PS}$.

13. Inject (iv) cells.

14. Allow labeled RBC solution to circulate in vivo for 5-10 minutes prior to sacrifice by exsanguination.

- Modified from Frank et al. (1979) 


\section{APPENDIX C. Preparation of ${ }^{210}$ Po Citrate Solution for Intravenous Administra- tion to Non-human Primates}

(1) Withdraw $\sim 0.5 \mathrm{cc}$ of ${ }^{210} \mathrm{Po}$ stock soln. ( $2 \mathrm{~N} \mathrm{HCL}$ ) into a $1 \mathrm{cc}$ tuberculin syringe.

(2) Transfer Po solution into a pre-weighed $30 \mathrm{~mL}$ polypropylene bottle and obtain the solution weight.

(3) Add $\sim 9.5 \mathrm{~mL}$ of $0.1 M \mathrm{Na}$ citrate solution slowly with mixing (in $0.1 \mathrm{~mL}$ aliquots).

(4) Re-weigh bottle to determine the amount of citrate added.

(5) Wait 15-20 minutes to complete reaction.

(6) Draw off an aliquot. Calibrate solution and test $\mathrm{pH}$ with short-range indicator paper (solution $\mathrm{pH} 4-5$ ).

(7) Draw up solution into a 35 cc syringe with a Leur-lock neck.

(8) Attach a 0.22 uM Swinex (Millipore) filter and collect filtered solution in a pre-weighed $30 \mathrm{~mL}$ PP bottle. Weigh.

(9) Test $\mathrm{pH}$ (4-5) with short-range paper and calibrate an aliquot of the solution.

(10) Compare solution activity concentrations before and after filtration to determine filterability.

Final administration solution is $100 \%$ ultrafilterable (0.22 uM) with $\mathrm{pH}$ 4-5 and 0.1 $M \mathrm{Na}$ citrate. 
APPENDIX D. Po Excretion Data In Non-human Primates TAMARIN

\begin{tabular}{|c|c|c|c|}
\hline $\begin{array}{c}\text { Tamarin } \\
\#\end{array}$ & $\begin{array}{c}\text { Days Post } \\
\text { Administration }\end{array}$ & $\begin{array}{c}\text { \% Injected } \\
\text { Dose Excreted } \\
\text { In Urine d-1* }\end{array}$ & $\begin{array}{c}\% \text { Injected } \\
\text { Dose Excreted } \\
\times 10 \mathrm{E} 3 \\
\mathrm{~mL}^{-1} \mathrm{~d}^{-1^{*}} \\
\end{array}$ \\
\hline T500 & 1 & .643 & 6.298 \\
\hline T500 & 2 & .231 & 2.179 \\
\hline T500 & 3 & .253 & 2.014 \\
\hline T500 & 4 & .330 & 2.161 \\
\hline T500 & 5 & .233 & 2.031 \\
\hline T500 & 6 & .341 & 2.376 \\
\hline T500 & 7 & .252 & 2.437 \\
\hline T500 & 8 & .299 & 1.709 \\
\hline T500 & 9 & .229 & 1.363 \\
\hline T500 & 10 & 345 & 3.317 \\
\hline T500 & 11 & .318 & 1.861 \\
\hline T500 & 12 & .248 & 5.188 \\
\hline T500 & 13 & .334 & 1.776 \\
\hline T500 & 14 & .261 & 1.602 \\
\hline T500 & 15 & 320 & 1.698 \\
\hline T500 & 16 & .270 & 7.337 \\
\hline T500 & 17 & .305 & 1.836 \\
\hline T500 & 18 & .219 & 3.411 \\
\hline T500 & 19 & .242 & 2.840 \\
\hline T500 & 20 & .381 & 2.389 \\
\hline T500 & 21 & .301 & 2.339 \\
\hline T500 & 22 & .226 & 1.894 \\
\hline T500 & 23 & .202 & 1.872 \\
\hline T500 & 24 & .292 & 2.086 \\
\hline T500 & 25 & .181 & 1.759 \\
\hline T500 & 26 & .237 & 2.114 \\
\hline T500 & 27 & .202 & 2.174 \\
\hline T500 & 28 & 209 & 2.105 \\
\hline T500 & 29 & .216 & 2.703 \\
\hline T500 & 30 & .202 & 1.443 \\
\hline T500 & 31 & .186 & 1.513 \\
\hline T500 & 32 & .147 & 1.574 \\
\hline T500 & 33 & 151 & 2.658 \\
\hline T500 & 34 & .211 & 2.116 \\
\hline T500 & 35 & .213 & 2.669 \\
\hline T500 & 36 & .194 & 1.952 \\
\hline T500 & 37 & .146 & 1.597 \\
\hline T500 & 38 & .202 & 2.428 \\
\hline T500 & 39 & .183 & 1.889 \\
\hline T500 & 40 & .194 & 1.948 \\
\hline T500 & 41 & .134 & 1.971 \\
\hline T500 & 42 & .152 & 1.867 \\
\hline T500 & 43 & .142 & 2.152 \\
\hline
\end{tabular}




\begin{tabular}{|c|c|c|c|}
\hline $\begin{array}{c}\text { Tamarin } \\
\#\end{array}$ & $\begin{array}{c}\text { Days Post } \\
\text { Administration }\end{array}$ & $\begin{array}{c}\% \text { Injected } \\
\text { Dose Excreted } \\
\text { In Urine d-1* }\end{array}$ & $\begin{array}{c}\text { \% Injected } \\
\text { Dose Excreted } \\
\times 10 \mathrm{E} 3 \\
\mathrm{~mL}^{-1} \mathrm{~d}^{-1 *} \\
\end{array}$ \\
\hline $\begin{array}{l}\text { T500 } \\
\text { T500 } \\
\text { T500 } \\
\text { T500 } \\
\text { T500 } \\
\text { T504 } \\
\text { T504 } \\
\text { T504 } \\
\text { T504 } \\
\text { T504 } \\
\text { T504 } \\
\text { T504 } \\
\text { T504 } \\
\text { T504 } \\
\text { T504 } \\
\text { T504 } \\
\text { T504 } \\
\text { T504 } \\
\text { T504 } \\
\text { T504 } \\
\text { T504 } \\
\text { T504 } \\
\text { T504 } \\
\text { T504 } \\
\text { T504 } \\
\text { T504 } \\
\text { T504 } \\
\text { T504 } \\
\text { T504 } \\
\text { T504 } \\
\text { T504 } \\
\text { T504 } \\
\text { T504 } \\
\text { T504 } \\
\text { T504 } \\
\text { T504 } \\
\text { T504 } \\
\text { T504 } \\
\text { T504 } \\
\text { T504 } \\
\text { T504 } \\
\text { T504 } \\
\text { T504 } \\
\text { T504 } \\
\text { T504 }\end{array}$ & $\begin{array}{c}44 \\
45 \\
46 \\
47 \\
48 \\
1 \\
2 \\
3 \\
4 \\
5 \\
6 \\
7 \\
8 \\
9 \\
10 \\
11 \\
12 \\
13 \\
14 \\
15 \\
16 \\
17 \\
18 \\
19 \\
20 \\
21 \\
22 \\
23 \\
24 \\
25 \\
26 \\
27 \\
28 \\
29 \\
30 \\
31 \\
32 \\
33 \\
34 \\
35 \\
36 \\
37 \\
38 \\
39 \\
40\end{array}$ & $\begin{array}{l}.113 \\
.138 \\
.189 \\
.118 \\
.105 \\
.585 \\
.188 \\
.409 \\
.427 \\
.314 \\
.454 \\
.256 \\
.377 \\
.246 \\
.359 \\
.453 \\
.325 \\
.321 \\
.301 \\
.425 \\
.771 \\
.369 \\
.288 \\
.281 \\
.650 \\
.254 \\
.258 \\
.235 \\
.332 \\
.313 \\
.294 \\
.235 \\
.210 \\
.201 \\
.296 \\
.171 \\
.212 \\
.113 \\
.269 \\
.276 \\
.205 \\
.194 \\
.185 \\
.089 \\
.145\end{array}$ & $\begin{array}{l}2.112 \\
2.396 \\
3.500 \\
3.226 \\
5.438 \\
1.364 \\
7.529 \\
5.013 \\
8.099 \\
4.443 \\
3.783 \\
4.263 \\
3.721 \\
5.417 \\
3.586 \\
3.485 \\
4.198 \\
3.273 \\
2.846 \\
3.261 \\
3.664 \\
7.442 \\
2.445 \\
3.307 \\
3.226 \\
6.660 \\
4.387 \\
3.603 \\
3.028 \\
3.656 \\
3.340 \\
2.637 \\
2.450 \\
2.349 \\
3.083 \\
2.418 \\
2.140 \\
4.501 \\
5.000 \\
4.891 \\
3.489 \\
3.015 \\
2.853 \\
1.784 \\
2.673\end{array}$ \\
\hline
\end{tabular}




\begin{tabular}{|c|c|c|c|}
\hline $\begin{array}{c}\text { Tamarin } \\
\#\end{array}$ & $\begin{array}{c}\text { Days Post } \\
\text { Administration }\end{array}$ & $\begin{array}{c}\% \text { Injected } \\
\text { Dose Excreted } \\
\text { In Urine } \mathrm{d}^{-1^{\circ}}\end{array}$ & $\begin{array}{c}\% \text { Injected } \\
\text { Dose Excreted } \\
\text { x 10E3 } \\
\mathrm{mL}^{-1} \mathrm{~d}^{-1} \\
\end{array}$ \\
\hline T504 & 41 & .189 & 3.326 \\
\hline T504 & 42 & .202 & 3.533 \\
\hline T504 & 43 & .121 & 2.894 \\
\hline T504 & 44 & .137 & 3.591 \\
\hline T504 & 45 & .103 & 4.492 \\
\hline T504 & 46 & .178 & 3.270 \\
\hline T504 & 47 & .177 & 3.812 \\
\hline T504 & 48 & .177 & 3.882 \\
\hline T504 & 49 & .245 & 3.734 \\
\hline T504 & 50 & .216 & 2.526 \\
\hline T504 & 51 & .189 & 2.441 \\
\hline T504 & 52 & .124 & 3.005 \\
\hline T504 & 53.5 & .144 & 2.952 \\
\hline T504 & 55 & .125 & 1.502 \\
\hline T504 & 56 & .125 & 4.480 \\
\hline T504 & 57 & .113 & 5.081 \\
\hline T504 & 58 & .190 & 6.141 \\
\hline T504 & 59 & .205 & 3.800 \\
\hline T504 & 60 & .177 & 3.417 \\
\hline T504 & 61 & .101 & 2.818 \\
\hline T504 & 62 & .084 & 2.886 \\
\hline T504 & 63 & .098 & 2.044 \\
\hline T504 & 64 & .113 & 2.284 \\
\hline T504 & 65 & .129 & 3.038 \\
\hline T504 & 66 & .126 & 2.959 \\
\hline T504 & 67 & .105 & 1.883 \\
\hline T504 & 68 & .043 & 2.126 \\
\hline T504 & 69 & .088 & 3.945 \\
\hline T504 & 70 & .136 & 3.667 \\
\hline T504 & 71 & .108 & 2.523 \\
\hline T504 & 72 & .069 & 1.545 \\
\hline T504 & 73 & .082 & 1.700 \\
\hline T504 & 74 & .071 & 1.592 \\
\hline T504 & 75 & .010 & 1.277 \\
\hline T504 & 76 & .142 & .2513 \\
\hline T504 & 77 & .075 & 3.568 \\
\hline T504 & 78 & .101 & 2.095 \\
\hline T504 & 79 & .099 & 1.836 \\
\hline T504 & 80 & .092 & 2.152 \\
\hline T504 & 81 & .086 & 1.190 \\
\hline T504 & 82 & .065 & 1.286 \\
\hline T504 & 83 & .080 & 1.952 \\
\hline T504 & 84 & .078 & 1.790 \\
\hline T504 & 85 & .063 & 1.320 \\
\hline T504 & 86 & .088 & 1.755 \\
\hline
\end{tabular}




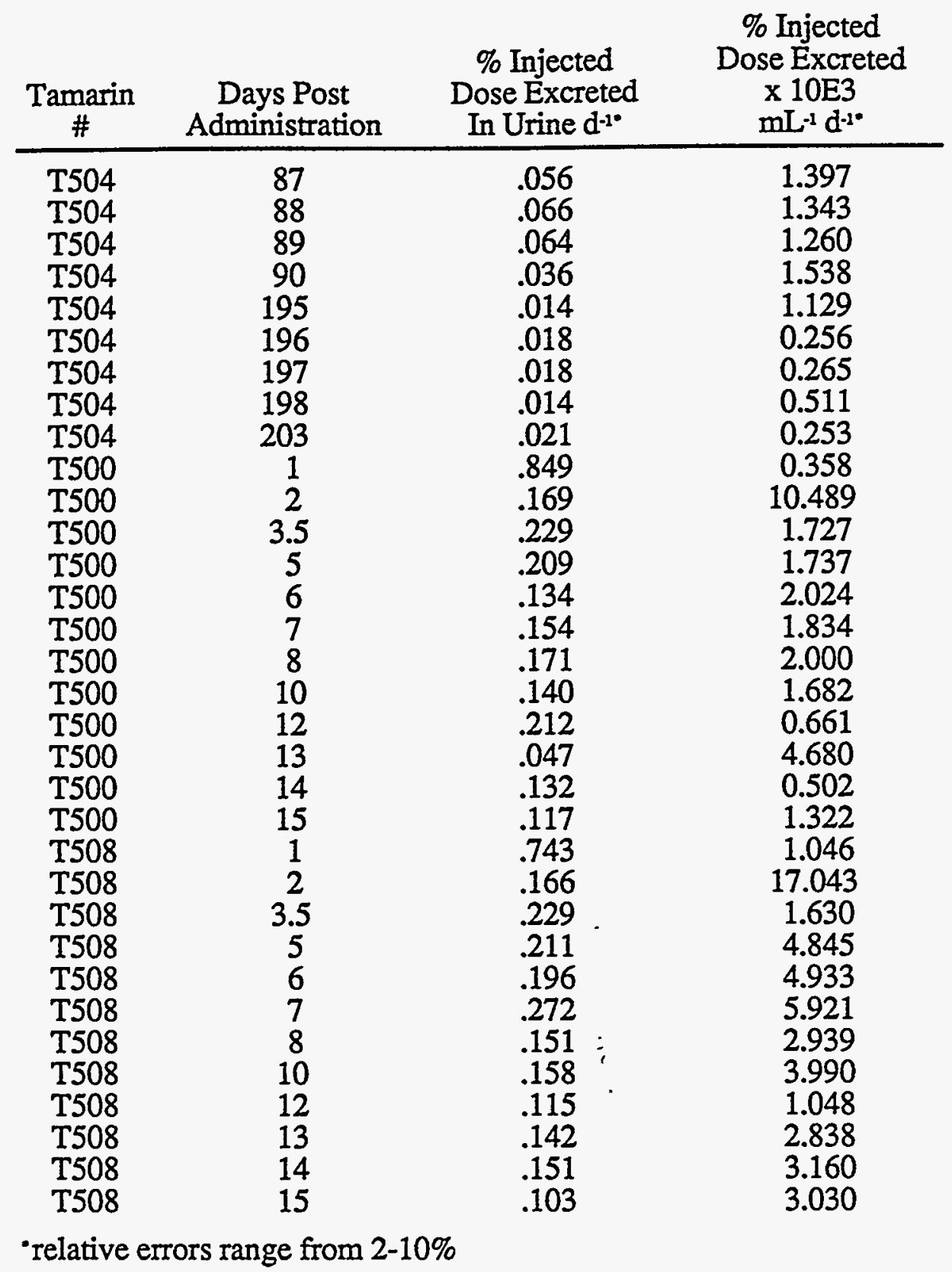




\begin{tabular}{|c|c|c|c|}
\hline$\underset{\#}{\text { Tamarin }}$ & $\begin{array}{c}\text { Days Post } \\
\text { Administration }\end{array}$ & $\begin{array}{c}\% \text { Injected } \\
\text { Dose Excreted } \\
\text { In Feces d-1* }\end{array}$ & $\begin{array}{c}\text { \% Injected } \\
\text { Dose Excreted } \\
\times 10 \mathrm{E} 2 \\
\mathrm{~g}^{-1} \mathrm{~d}^{-1^{*}}\end{array}$ \\
\hline T504 & 1 & 0.568 & 14.190 \\
\hline T504 & 2 & 0.667 & 10.588 \\
\hline T504 & 3 & 1.031 & 12.886 \\
\hline T504 & 4 & 0.543 & 3.332 \\
\hline T504 & 5 & 0.535 & 3.996 \\
\hline T504 & 6 & 1.011 & 5.053 \\
\hline T504 & 7 & 0.599 & 4.684 \\
\hline T504 & 8 & 0.745 & 9.315 \\
\hline T504 & 9 & 0.680 & 2.178 \\
\hline T504 & 10 & 1.015 & 5.835 \\
\hline T504 & 11 & 1.227 & 8.293 \\
\hline $\mathrm{T} 504$ & 12 & 0.620 & 5.001 \\
\hline T504 & 13 & 0.675 & 4.625 \\
\hline $\mathrm{T} 504$ & 14 & 0.624 & 4.520 \\
\hline T504 & 15 & 0.589 & 3.982 \\
\hline T504 & 16 & 0.699 & 6.359 \\
\hline T504 & 17 & 1.034 & 6.155 \\
\hline T504 & 18 & 0.702 & 10.972 \\
\hline T504 & 19 & 0.412 & 3.298 \\
\hline T504 & 20 & 0.092 & 0.694 \\
\hline T504 & 21 & 1.124 & 10.310 \\
\hline T504 & 22 & 0.969 & 14.460 \\
\hline T504 & 23 & 0.908 & 7.264 \\
\hline T504 & 24 & 0.834 & 8.421 \\
\hline T504 & 25 & 1.046 & 7.068 \\
\hline T504 & 26 & 1.005 & 5.911 \\
\hline T504 & 27 & 0.836 & 6.014 \\
\hline $\mathrm{T} 504$ & 28 & 0.583 & 4.860 \\
\hline T504 & 29 & 0.833 & 15.427 \\
\hline T504 & 30 & 1.035 & 5.783 \\
\hline T504 & 31 & 1.105 & 9.867 \\
\hline T504 & 33 & 0.686 & 5.968 \\
\hline T504 & 34 & 0.638 & 3.799 \\
\hline T504 & 35 & 1.305 & 9.959 \\
\hline T504 & 36 & 1.014 & 6.001 \\
\hline T504 & 37 & 0.603 & 5.687 \\
\hline T504 & 38 & 0.706 & 4.413 \\
\hline T504 & 39 & 0.387 & 5.687 \\
\hline T504 & 40 & 0.599 & 6.888 \\
\hline T504 & 41 & 0.756 & 7.136 \\
\hline T504 & 42 & 0.735 & 7.899 \\
\hline T504 & 43 & 0.747 & 6.789 \\
\hline T504 & 44 & 0.531 & 7.702 \\
\hline T504 & 45 & 0.367 & 11.484 \\
\hline
\end{tabular}




\begin{tabular}{|c|c|c|c|}
\hline$\underset{\#}{\text { Tamarin }}$ & $\begin{array}{c}\text { Days Post } \\
\text { Administration }\end{array}$ & $\begin{array}{c}\% \text { Injected } \\
\text { Dose Excreted } \\
\text { In Feces d-1* }\end{array}$ & $\begin{array}{c}\text { \% Injected } \\
\text { Dose Excreted } \\
\times 10 \mathrm{E} 2 \\
\mathrm{~g}^{-1} \mathrm{~d}^{-1^{*}} \\
\end{array}$ \\
\hline T504 & 46 & 0.723 & 5.199 \\
\hline T504 & 47 & 0.992 & 7.940 \\
\hline T504 & 48 & 0.870 & 6.848 \\
\hline T504 & 49 & 0.828 & 5.749 \\
\hline T504 & 50 & 0.592 & 3.697 \\
\hline T504 & 51 & 0.301 & 1.749 \\
\hline T504 & 53.5 & 0.538 & 2.626 \\
\hline T504 & 55 & 0.602 & 3.837 \\
\hline T504 & 56 & 0.557 & 6.050 \\
\hline T504 & 57 & 0.677 & 7.443 \\
\hline T504 & 58 & 1.043 & 6.062 \\
\hline T504 & 59 & 0.643 & 3.652 \\
\hline T504 & 60 & 0.465 & 2.434 \\
\hline T504 & 61 & 0.403 & 3.124 \\
\hline T504 & 62 & 0.390 & 6.502 \\
\hline T504 & 63 & 0.383 & 4.073 \\
\hline T504 & 64 & 0.678 & 5.427 \\
\hline T504 & 65 & 0.337 & 2.408 \\
\hline T504 & 66 & 0.350 & 3.094 \\
\hline T504 & 67 & 0.488 & 4.878 \\
\hline T504 & 68 & 0.201 & 5.033 \\
\hline T504 & 69 & 0.511 & 14.195 \\
\hline T504 & 70 & 0.532 & 3.095 \\
\hline T504 & 71 & 0.520 & 1.683 \\
\hline T504 & 72 & 0.644 & 6.779 \\
\hline T504 & 73 & 0.648 & 2.064 \\
\hline T504 & 74 & 0.519 & 2.610 \\
\hline T504 & 75 & 0.075 & 3.752 \\
\hline T504 & 76 & 0.525 & 4.011 \\
\hline T504 & 77 & 0.410 & 7.454 \\
\hline T504 & 78 & 0.392 & 2.990 \\
\hline T504 & 79 & 0.404 & 2.022 \\
\hline T504 & 80 & 0.281 & 0.954 \\
\hline T504 & 81 & 0.319 & 1.151 \\
\hline T504 & 82 & 0.177 & 1.024 \\
\hline T504 & 83 & 0.207 & 1.627 \\
\hline T504 & 84 & 0.254 & 1.590 \\
\hline T504 & 85 & 0.237 & 1.625 \\
\hline T504 & 86 & 0.256 & 1.550 \\
\hline T504 & 87 & 0.221 & 2.141 \\
\hline T504 & 88 & 0.209 & 1.367 \\
\hline T504 & 89 & 0.177 & 1.290 \\
\hline T504 & 90 & 0.214 & 13.398 \\
\hline
\end{tabular}




\begin{tabular}{|c|c|c|c|}
\hline $\begin{array}{c}\text { Tamarin } \\
\#\end{array}$ & $\begin{array}{c}\text { Days Post } \\
\text { Administration }\end{array}$ & $\begin{array}{c}\% \text { Injected } \\
\text { Dose Excreted } \\
\text { In Feces d } \mathrm{d}^{-1 *} \\
\end{array}$ & $\begin{array}{c}\text { \% Injected } \\
\text { Dose Excreted } \\
\times 10 \mathrm{E} 2 \\
\mathrm{~g}^{-1} \mathrm{~d}^{-1{ }^{\bullet}} \\
\end{array}$ \\
\hline T504 & 195 & 0.035 & 0.291 \\
\hline T504 & 196 & 0.047 & 0.243 \\
\hline T504 & 197 & 0.054 & 0.349 \\
\hline T504 & 198 & 0.049 & 0.718 \\
\hline T504 & 203 & 0.062 & 1.034 \\
\hline T500 & 1 & 0.898 & \\
\hline T500 & 2 & 0.740 & \\
\hline T500 & 3.5 & 0.494 & \\
\hline T500 & 5 & 0.851 & \\
\hline T500 & 6 & 0.379 & \\
\hline T500 & 7 & 0.357 & \\
\hline T500 & 8 & 0.525 & \\
\hline T500 & 10 & 0.311 & \\
\hline T500 & 12 & 0.041 & \\
\hline T500 & 13 & 0.311 & \\
\hline $\mathrm{T} 500$ & 14 & 0.523 & \\
\hline T500 & 15 & 0.391 & \\
\hline T508 & 1 & 1.223 & \\
\hline T508 & 2 & 0.559 & \\
\hline T508 & 3.5 & 0.640 & \\
\hline T508 & 5 & 0.909 & \\
\hline T508 & 6 & 0.314 & \\
\hline T508 & 7 & 0.353 & \\
\hline T508 & 8 & 0.718 & \\
\hline T508 & 10 & 0.444 & \\
\hline T508 & 12 & 0.466 & \\
\hline T508 & 13 & 0.407 & \\
\hline T508 & 14 & 0.418 & \\
\hline T508 & 15 & 0.452 & \\
\hline
\end{tabular}




\section{BABOON}

\begin{tabular}{|c|c|c|c|}
\hline $\begin{array}{l}\text { Baboon } \\
\quad \#\end{array}$ & $\begin{array}{c}\text { Days Post } \\
\text { Administration }\end{array}$ & $\begin{array}{c}\text { \% Injected } \\
\text { Dose Excreted } \\
\text { In Urine } \mathrm{d}^{-1^{*}}\end{array}$ & $\begin{array}{c}\text { \% Injected } \\
\text { Dose Excreted } \\
\times 10 \mathrm{E} 3 \\
\mathrm{~mL}^{-1} \mathrm{~d}^{-1^{-}}\end{array}$ \\
\hline B1054 & 1 & 0.918 & 3.586 \\
\hline B156 & 1 & 1.212 & 2.166 \\
\hline B156 & 2 & 1.854 & 3.727 \\
\hline B156 & 3 & 2.470 & 3.750 \\
\hline B156 & 4 & 2.705 & 2.204 \\
\hline B156 & 5 & 2.328 & 3.858 \\
\hline B156 & 6 & 1.448 & 3.281 \\
\hline B156 & 7 & 1.315 & 3.525 \\
\hline B1060 & 1 & 1.502 & 2.641 \\
\hline B1060 & 2 & 2.151 & 2.325 \\
\hline B1060 & 3 & 1.832 & 1.466 \\
\hline B1060 & 4 & 1.854 & 1.107 \\
\hline B1060 & $\begin{array}{l}4 \\
5\end{array}$ & 0.965 & 1.253 \\
\hline B1060 & 5 & 0.957 & 1.242 \\
\hline B1060 & 6 & 1.639 & 1.361 \\
\hline B1060 & 7 & 1.072 & 1.038 \\
\hline B1060 & 7 & 0.911 & 0.882 \\
\hline B1060 & 8 & 1.050 & 1.890 \\
\hline B1060 & 9 & 0.473 & 1.790 \\
\hline B1060 & 9 & 0.509 & 1.927 \\
\hline B1060 & 10.5 & 1.263 & 0.495 \\
\hline B1060 & 12 & 0.690 & 0.685 \\
\hline B1060 & 12 & 0.654 & 0.648 \\
\hline B1060 & 13 & 0.884 & 1.038 \\
\hline B1060 & 14 & 0.638 & 0.788 \\
\hline B1060 & 14 & 0.450 & 0.555 \\
\hline B1060 & 15 & 0.225 & 5.080 \\
\hline B1046 & 0.22 & 0.454 & 7.423 \\
\hline B1046 & 1 & 0.793 & 2.359 \\
\hline B1046 & 2 & 1.227 & 3.355 \\
\hline B1046 & 2 & 1.185 & 3.241 \\
\hline B1046 & 3 & 1.453 & $\begin{array}{l}3.640 \\
4070\end{array}$ \\
\hline $\begin{array}{l}\text { B1046 } \\
\text { B1046 }\end{array}$ & $\begin{array}{l}3 \\
4\end{array}$ & $\begin{array}{l}1.625 \\
1.553\end{array}$ & $\begin{array}{l}4.070 \\
5.711\end{array}$ \\
\hline B1046 & 4 & 1.389 & 5.108 \\
\hline B1046 & 5 & 1.521 & 2.510 \\
\hline B1046 & 6 & 1.233 & 1.752 \\
\hline B1046 & 7 & 1.130 & 1.546 \\
\hline B1046 & 8 & 1.132 & 1.116 \\
\hline B1046 & 9 & 1.126 & 0.890 \\
\hline B1046 & 10 & 0.933 & 0.631 \\
\hline B1046 & 11 & 0.936 & 0.616 \\
\hline B1046 & 12 & 0.748 & 1.036 \\
\hline
\end{tabular}


$\%$ Injected

$\%$ Injected

\begin{tabular}{|c|c|c|c|}
\hline $\begin{array}{c}\text { Baboon } \\
\#\end{array}$ & $\begin{array}{c}\text { Days Post } \\
\text { Administration }\end{array}$ & $\begin{array}{l}\text { Dose Excreted } \\
\text { In Urine } \mathrm{d}^{-1^{*}}\end{array}$ & $\begin{array}{l}\mathrm{x} \text { 10E3 } \\
\mathrm{mL}^{-1} \mathrm{~d}^{-1 *}\end{array}$ \\
\hline B1046 & 13 & 0.539 & 1.228 \\
\hline B1046 & 14 & 0.837 & 0.670 \\
\hline B1046 & 15 & 0.813 & 0.831 \\
\hline B1046 & 16 & 0.706 & 0.630 \\
\hline B1046 & 17 & 0.771 & 0.796 \\
\hline B1046 & 18 & 0.703 & 0.528 \\
\hline B1046 & 19 & 0.635 & 0.591 \\
\hline B1046 & 20 & 0.540 & 1.090 \\
\hline B1046 & 21 & 0.378 & 0.507 \\
\hline B1046 & 22 & 0.728 & 0.846 \\
\hline B1046 & 23 & 0.579 & 0.441 \\
\hline B1046 & 24 & 0.538 & 0.521 \\
\hline B1046 & 25 & 0.597 & 0.399 \\
\hline B1046 & 26 & 0.724 & 0.600 \\
\hline B1046 & 27 & 0.540 & 0.305 \\
\hline B1046 & 28 & 0.464 & 0.308 \\
\hline B1046 & 29 & 0.419 & 0.402 \\
\hline B1046 & 30 & 0.372 & 0.489 \\
\hline B806 & 1 & 0.933 & 2.314 \\
\hline B806 & 2 & 1.223 & 3.641 \\
\hline B806 & 3 & 1.339 & 8.968 \\
\hline B806 & 4 & 1.224 & 5.432 \\
\hline B806 & 5 & 1.285 & 6.232 \\
\hline B806 & 6 & 1.353 & 6.208 \\
\hline B806 & 7 & 1.167 & 7.709 \\
\hline B806 & 8 & 1.032 & 10.225 \\
\hline B806 & 9 & 1.135 & 3.8284 \\
\hline B806 & 10 & 1.169 & 4.488 \\
\hline B806 & 11 & 0.821 & 3.261 \\
\hline B806 & 12 & 0.802 & 3.855 \\
\hline B806 & 13 & 0.953 & 2.212 \\
\hline B806 & 14 & 1.157 & 1.375 \\
\hline B806 & 15 & 0.678 & 1.946 \\
\hline B806 & 16 & 0.915 & 4.159 \\
\hline B806 & 17 & 0.934 & 3.014 \\
\hline B806 & 18 & 0.971 & 1.605 \\
\hline B806 & 19 & 1.166 & 3.414 \\
\hline B806 & 20 & 0.759 & 1.075 \\
\hline B806 & 21 & 0.596 & 1.538 \\
\hline B806 & 28 & 0.428 & 1.187 \\
\hline B806 & 29 & 0.469 & 1.269 \\
\hline B806 & 30 & 0.489 & 1.415 \\
\hline B806 & 31 & 0.402 & 0.909 \\
\hline B806 & 32 & 0.309 & 1.130 \\
\hline B806 & 33 & 0.497 & 2.289 \\
\hline
\end{tabular}




\begin{tabular}{cccc}
$\begin{array}{c}\text { Baboon } \\
\text { \# }\end{array}$ & $\begin{array}{c}\text { Days Post } \\
\text { Administration }\end{array}$ & $\begin{array}{c}\text { \% Injected } \\
\text { Dose Excreted } \\
\text { In Urine d-1* }\end{array}$ & $\begin{array}{c}\text { \% Injected } \\
\text { Dose Excreted } \\
\text { x 10E3 } \\
\text { mL-1 }^{-11^{-*}}\end{array}$ \\
\hline B806 & 34 & 0.383 & 1.059 \\
B806 & 35 & 0.404 & 1.993 \\
B806 & 36 & 0.363 & 2.371 \\
B806 & 37 & 0.443 & 2.171 \\
B806 & 38 & 0.410 & 0.905 \\
B806 & 39 & 0.263 & 1.110 \\
B806 & 40.5 & 0.275 & 0.248 \\
B806 & 42 & 0.322 & 0.487 \\
B806 & 43.5 & 0.293 & 0.313 \\
B806 & 45 & 0.383 & 0.605 \\
B806 & 47 & 0.483 & 0.304 \\
B806 & 49 & 0.186 & 0.641 \\
B806 & 75 & 0.067 & 0.036 \\
B806 & 77 & 0.080 & 0.121 \\
B806 & 78 & 0.077 & 0.069 \\
B806 & 79 & 0.072 & 0.081 \\
B806 & 80 & 0.072 & 0.135 \\
B806 & 82 & 0.086 & 0.033 \\
B806 & 85 & 0.076 & 0.031 \\
B806 & 87 & 0.042 & 0.095 \\
B806 & 89 & 0.050 & 0.042 \\
B806 & 91 & 0.043 & 0.147 \\
relative errors range from 2-10\% & &
\end{tabular}




\begin{tabular}{|c|c|c|c|}
\hline $\begin{array}{c}\text { Baboon } \\
\#\end{array}$ & $\begin{array}{c}\text { Days Post } \\
\text { Administration }\end{array}$ & $\begin{array}{c}\% \text { Injected } \\
\text { Dose Excreted } \\
\text { In Feces d-1* }\end{array}$ & $\begin{array}{c}\% \text { Injected } \\
\text { Dose Excreted } \\
\times 10 \mathrm{E} 2 \\
\mathrm{~g}^{-1} \mathrm{~d}^{-1^{*}} \\
\end{array}$ \\
\hline $\begin{array}{c}\text { B1054 } \\
\text { B156 } \\
\text { B156 } \\
\text { B156 } \\
\text { B156 } \\
\text { B156 } \\
\text { B156 } \\
\text { B1060 } \\
\text { B1060 } \\
\text { B1060 } \\
\text { B1060 } \\
\text { B1060 } \\
\text { B1060 } \\
\text { B1060 } \\
\text { B1060 } \\
\text { B1060 } \\
\text { B1060 } \\
\text { B1060 } \\
\text { B1060 } \\
\text { B1060 } \\
\text { B1046 } \\
\text { B1046 } \\
\text { B1046 } \\
\text { B1046 } \\
\text { B1046 } \\
\text { B1046 } \\
\text { B1046 } \\
\text { B1046 } \\
\text { B1046 } \\
\text { B1046 } \\
\text { B1046 } \\
\text { B1046 } \\
\text { B1046 } \\
\text { B1046 } \\
\text { B1046 } \\
\text { B1046 } \\
\text { B1046 } \\
\text { B1046 } \\
\text { B1046 } \\
\text { B1046 } \\
\text { B1046 } \\
\text { B1046 }\end{array}$ & $\begin{array}{c}1 \\
1 \\
2 \\
3 \\
5 \\
6 \\
7 \\
1 \\
2 \\
3 \\
4 \\
5 \\
6 \\
7 \\
8 \\
9 \\
10.5 \\
12 \\
13 \\
14 \\
1 \\
2 \\
3 \\
4 \\
5 \\
6 \\
7 \\
8 \\
9 \\
10.5 \\
12 \\
13 \\
14 \\
15.5 \\
17 \\
18 \\
19 \\
20 \\
21 \\
23 \\
24 \\
25 \\
26 \\
27\end{array}$ & $\begin{array}{r}0.187 \\
0.535 \\
12.000 \\
3.942 \\
3.221 \\
2.651 \\
0.812 \\
0.115 \\
4.431 \\
3.629 \\
2.489 \\
2.696 \\
1.159 \\
1.486 \\
0.696 \\
1.497 \\
0.912 \\
0.818 \\
0.960 \\
0.611 \\
0.017 \\
0.105 \\
0.141 \\
13.373 \\
2.232 \\
0.440 \\
0.689 \\
2.488 \\
3.646 \\
1.540 \\
0.635 \\
0.616 \\
0.333 \\
2.045 \\
0.687 \\
0.816 \\
0.862 \\
0.190 \\
2.030 \\
0.306 \\
2.038 \\
0.338 \\
0.647 \\
0.171\end{array}$ & $\begin{array}{c}0.761 \\
5.351 \\
29.056 \\
26.457 \\
10.192 \\
10.237 \\
4.060 \\
0.454 \\
9.467 \\
16.495 \\
5.710 \\
3.506 \\
2.899 \\
2.971 \\
2.914 \\
2.603 \\
2.835 \\
2.920 \\
2.473 \\
2.315 \\
0.190 \\
0.708 \\
1.487 \\
13.162 \\
6.644 \\
5.179 \\
3.826 \\
4.879 \\
4.994 \\
2.671 \\
1.176 \\
1.741 \\
2.429 \\
3.601 \\
1.568 \\
1.858 \\
2.128 \\
1.780 \\
1.992 \\
2.548 \\
2.086 \\
1.139 \\
0.772 \\
1.033\end{array}$ \\
\hline
\end{tabular}




\begin{tabular}{|c|c|c|c|}
\hline $\begin{array}{c}\text { Baboon } \\
\#\end{array}$ & $\begin{array}{c}\text { Days Post } \\
\text { Administration }\end{array}$ & $\begin{array}{c}\% \text { Injected } \\
\text { Dose Excreted } \\
\text { In Feces d } d^{-1^{*}}\end{array}$ & $\begin{array}{c}\% \text { Injected } \\
\text { Dose Excreted } \\
\text { x 10E2 } \\
\mathrm{g}^{-1} \mathrm{~d}^{-1^{*}} \\
\end{array}$ \\
\hline $\begin{array}{l}\text { B1046 } \\
\text { B1046 } \\
\text { B806 } \\
\text { B806 } \\
\text { B806 } \\
\text { B806 } \\
\text { B806 } \\
\text { B806 } \\
\text { B806 } \\
\text { B806 } \\
\text { B806 } \\
\text { B806 } \\
\text { B806 } \\
\text { B806 } \\
\text { B806 } \\
\text { B806 } \\
\text { B806 } \\
\text { B806 } \\
\text { B806 } \\
\text { B806 } \\
\text { B806 } \\
\text { B806 } \\
\text { B806 } \\
\text { B806 } \\
\text { B806 } \\
\text { B806 } \\
\text { B806 } \\
\text { B806 } \\
\text { B806 } \\
\text { B806 } \\
\text { B806 } \\
\text { B806 } \\
\text { B806 } \\
\text { B806 } \\
\text { B806 } \\
\text { B806 } \\
\text { B806 } \\
\text { B806 } \\
\text { B806 } \\
\text { B806 } \\
\text { B806 } \\
\text { B806 } \\
\text { B806 } \\
\text { B806 }\end{array}$ & $\begin{array}{c}28 \\
30 \\
1 \\
2 \\
3 \\
4 \\
5 \\
6 \\
7 \\
8 \\
9 \\
10 \\
11 \\
12 \\
13 \\
14 \\
15 \\
16 \\
17 \\
18 \\
19 \\
20 \\
22 \\
23 \\
24 \\
25 \\
26 \\
27 \\
28 \\
29 \\
30 \\
31 \\
32 \\
33 \\
34 \\
35 \\
36 \\
37 \\
38 \\
39 \\
40.5 \\
42 \\
43.5 \\
45\end{array}$ & $\begin{array}{l}0.533 \\
1.104 \\
0.033 \\
2.641 \\
3.529 \\
1.143 \\
1.536 \\
2.401 \\
3.806 \\
3.051 \\
0.748 \\
2.401 \\
1.920 \\
1.553 \\
2.656 \\
0.849 \\
0.919 \\
1.139 \\
1.195 \\
1.580 \\
1.033 \\
1.228 \\
0.366 \\
0.964 \\
1.360 \\
0.949 \\
1.191 \\
1.228 \\
0.908 \\
1.181 \\
0.204 \\
0.734 \\
0.431 \\
1.014 \\
0.654 \\
0.976 \\
0.643 \\
0.204 \\
1.013 \\
0.215 \\
0.342 \\
0.396 \\
0.327 \\
0.518\end{array}$ & $\begin{array}{c}1.378 \\
1.175 \\
0.367 \\
7.356 \\
16.724 \\
13.288 \\
15.361 \\
20.525 \\
13.891 \\
9.027 \\
5.795 \\
6.782 \\
5.818 \\
3.638 \\
4.479 \\
3.537 \\
4.939 \\
7.695 \\
4.918 \\
3.883 \\
2.228 \\
2.613 \\
3.392 \\
4.016 \\
3.864 \\
2.994 \\
2.326 \\
2.006 \\
1.932 \\
1.834 \\
1.523 \\
2.133 \\
2.447 \\
2.419 \\
1.661 \\
2.447 \\
1.639 \\
1.696 \\
1.602 \\
1.197 \\
0.674 \\
1.348 \\
0.761 \\
0.740\end{array}$ \\
\hline
\end{tabular}




\begin{tabular}{cccc}
$\begin{array}{c}\text { Baboon } \\
\#\end{array}$ & $\begin{array}{c}\text { Days Post } \\
\text { Administration }\end{array}$ & $\begin{array}{c}\text { \% Injected } \\
\text { Dose Excreted } \\
\text { In Feces d-1* }\end{array}$ & $\begin{array}{c}\text { \% Injected } \\
\text { Dose Excreted } \\
\text { x 10E2 } \\
\mathrm{g}^{-1} \mathrm{~d}^{-1}\end{array}$ \\
\hline B806 & 47 & 0.244 & 0.234 \\
B806 & 49 & 0.114 & 0.360 \\
B806 & 54 & 0.296 & 0.212 \\
B806 & 61 & 0.100 & 0.086 \\
B806 & 75 & 0.149 & 0.108 \\
B806 & 80 & 0.164 & 0.262 \\
B806 & 82 & 0.089 & 0.070 \\
B806 & 85 & 0.066 & 0.056 \\
B806 & 87 & 0.040 & 0.199 \\
B806 & 89 & 0.108 & 0.082 \\
B806 & 91 & 0.066 & 0.291 \\
relative errors range from 2-10\% & &
\end{tabular}


APPENDIX E. Sample Plots of Urinary 200Po Excretion at Mound Laboratory. Original data plotted on bottom curve. Data following removal of outliers plotted on top curve.

\section{CASE 1424 START DATE: $4 / 7 / 1945$}
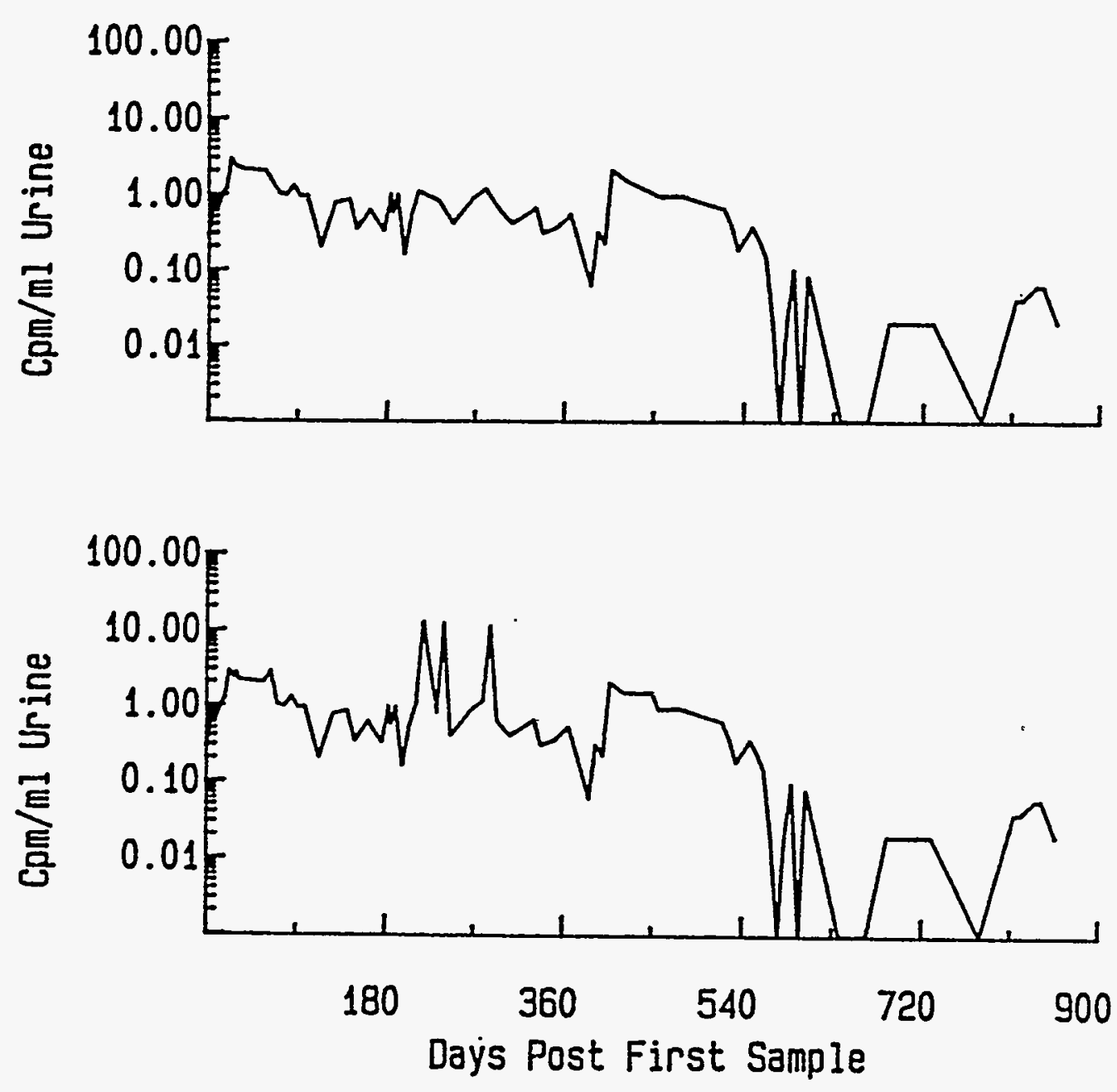
CASE 5604 START DATE: 9/29/1947
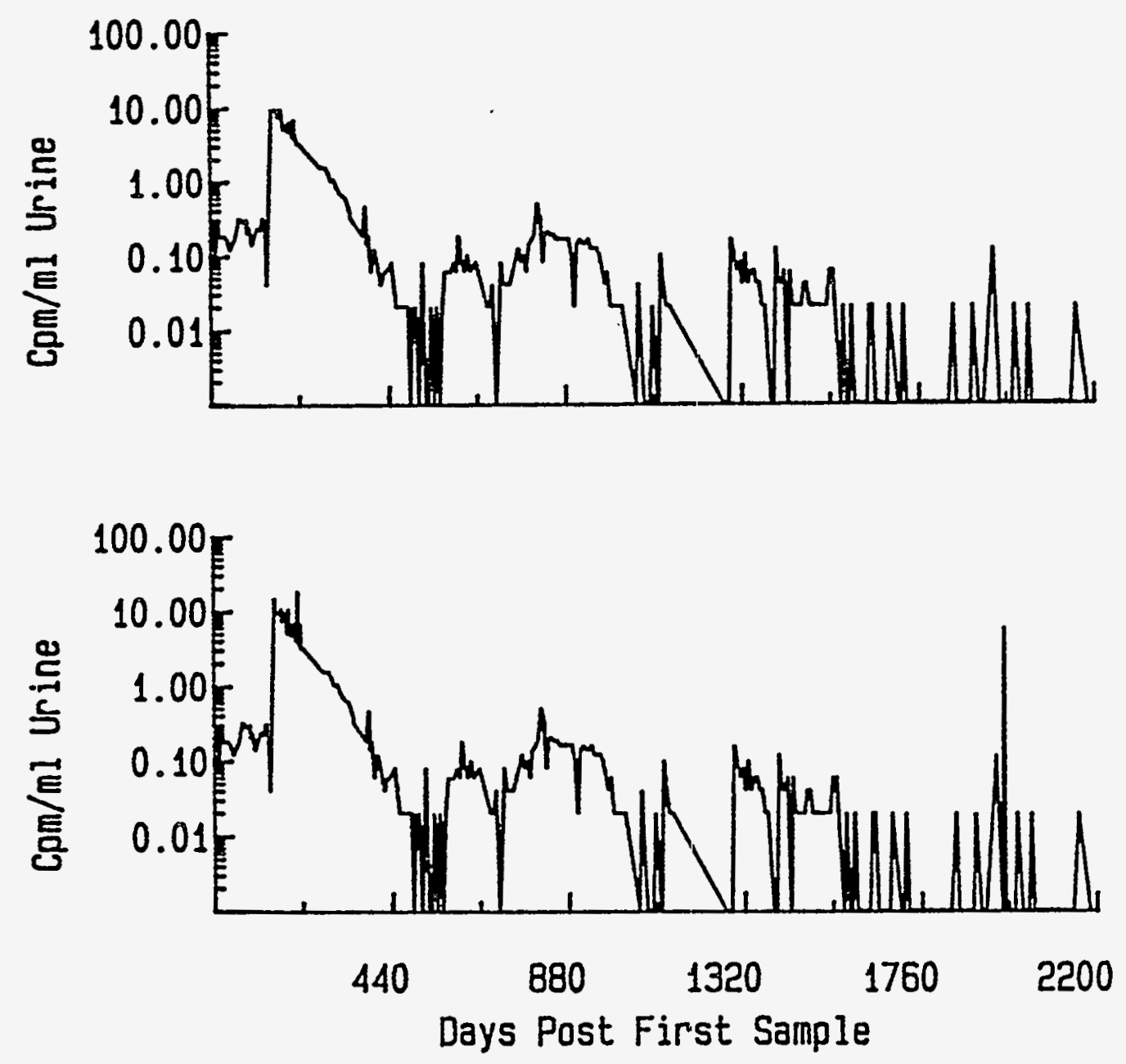


\section{CASE 6175 START DATE: 11/10/1947}
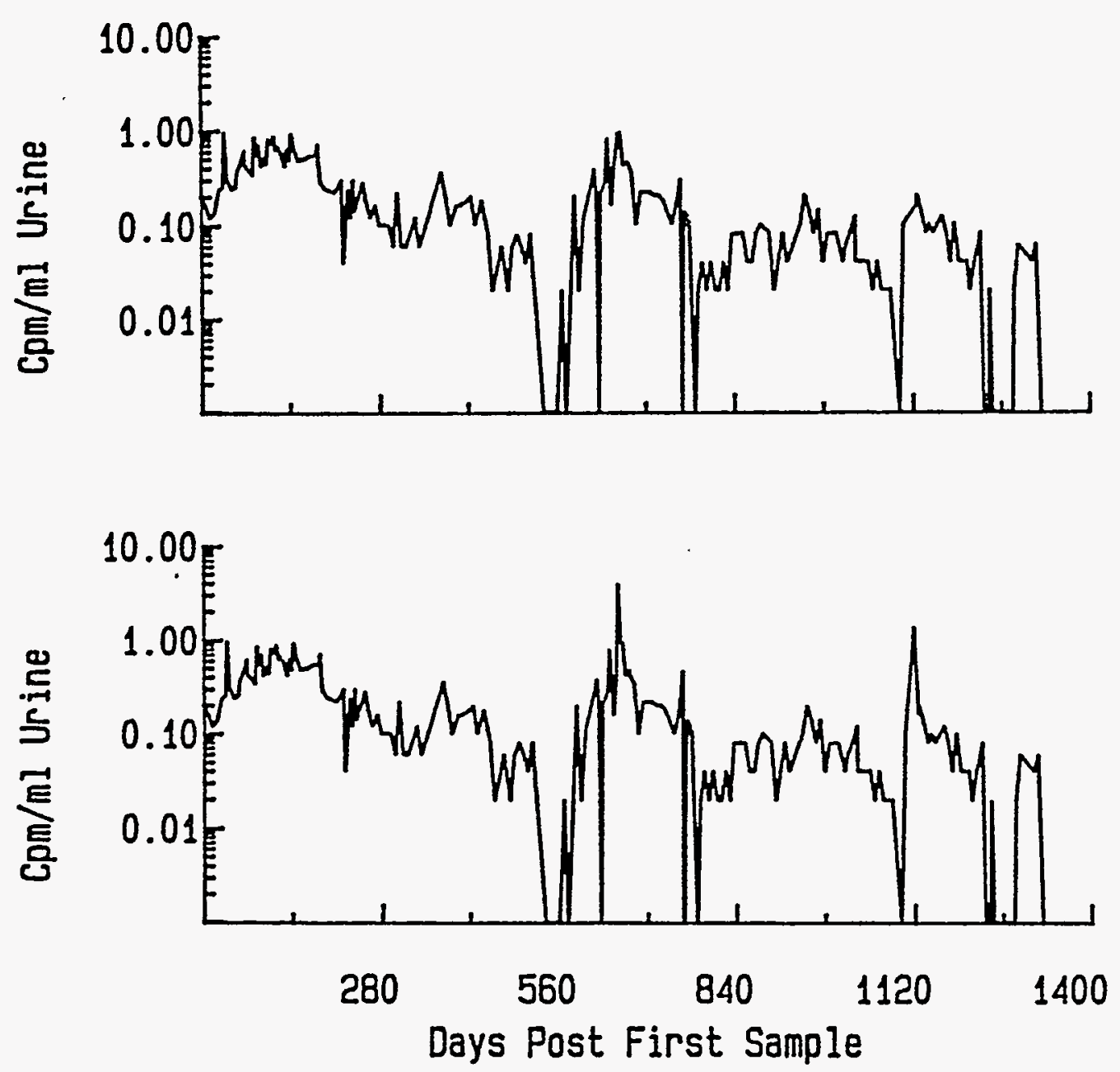
APPENDIX F. Computer Codes Used to Calculate Radiological Dose Based on Urine Bioassay Data and Instructions for Their Use

\section{OMDOS}

c This program operates on data from the urinary Po-210 data base.

c It is part of the batch program run from within dBase III + to

c estimate the whole body dose equivalent incurred by Po

$\mathrm{c}$ workers on an individual basis.

program omdos

character $* 38$ out 30 , title

character*3 $\mathrm{v}(800)$

character*1 qm

character*3 per,star

integer vol(800), month(800),day(800),year(800),case(800)

integer*4 jd(800),dp $(800)$

real cpm(800),cpml(800),ecpm(800)

real forcst( 800$)$,eforcst $(800)$

real newcpm

data qm/"'"/

data per,star/' $0^{\prime},{ }^{\prime} * * *^{\prime} /$

data luncon/0/,lundsk/1/,lunprt/2/

out30='prn'

c

c All records for a specified worker (by ID \#) are read in.

c

open(lundsk,file='a:dp.dat',status='old') 
$\mathrm{i}=1$

15 read(lundsk,10,end=20)case(i),year(i),month(i),day(i),cpm(i),

$1 \mathrm{v}(\mathrm{i})$

10 format(i4,i4,i2,i2,f10.1,a3)

$\operatorname{ecpm}(\mathbf{i})=\operatorname{sqrt}(\operatorname{cpm}(\mathbf{i}) * 20) / 20$

$i=i+1$

go to 15

C

c The date of sample is adjusted.

c Initially, the Julian day value is computed. This is

c followed by normalization to the days post first sample.

C

20 do $30 \mathrm{n}=1, \mathrm{i}-1$

jd(n)=int((year(n)+numdas)*365.25)

$1+(\operatorname{int}((($ month $(\mathrm{n})+1)-(12 *$ numdas $)) * 30.6001))+$ day $(\mathrm{n})$

30 continue

$\mathrm{n} 1=0$

open(lundsk,file='a:data.dat',status='old')

rewind(lundsk)

$\mathrm{n}=\mathrm{n}-1$

c

c There are documented memos indicating that some of the records

c on the data base warrant elimination or adjustment. A period

c in the "comments" column means that the sample was lost or never

c collected. These data points are eliminated. A star indicates 
c that the sample volume should be adjusted from 50 to $100 \mathrm{~mL}$ if c the sample was collected beyond a certain date.

c These corrections are done in the following loop.

c

do $50 \mathrm{k}=1, \mathrm{n}$

$\mathrm{dp}(\mathrm{k})=\mathrm{jd}(\mathrm{k})-\mathrm{jd}(1)$

if(v(k).eq.per)then

$\mathrm{n} 1=\mathrm{n} 1+1$

go to 50

elseif( $(k)$.eq.star)then

if(jd(k).lt.717608)then

$v(k)=0^{\prime}$

else

$\mathrm{v}(\mathrm{k})={ }^{\prime} 100^{\prime}$

endif

endif

if(k.ge.n-1)then

go to 31

endif

c

c In the next portion of the algorithm, the data are tested

$c$ for false positives, which when found are removed from the

c data file. Urinary Po is reflective of the systemic

c Po burden. A datum indicative of a true intake will

$c$ have subsequent data reflecting the elimination of Po 
c at a rate which can be predicted based on studies conducted $\mathrm{c}$ on the elimination of $\mathrm{Po}$ in the adult baboon.

c The t-distribution of the mean predicted value of subsequent data c and the measured data values are compared.

c If the urinary excretion value of the "next" sample is within $c$ the predicted confidence interval, then the point tested is c accepted as represented a true intake.

\section{c}

c In some cases duplicate samples were run on the same date.

c Where these are found, the duplicate sample is skipped and

$c$ the t-test is conducted on the following sample.

c

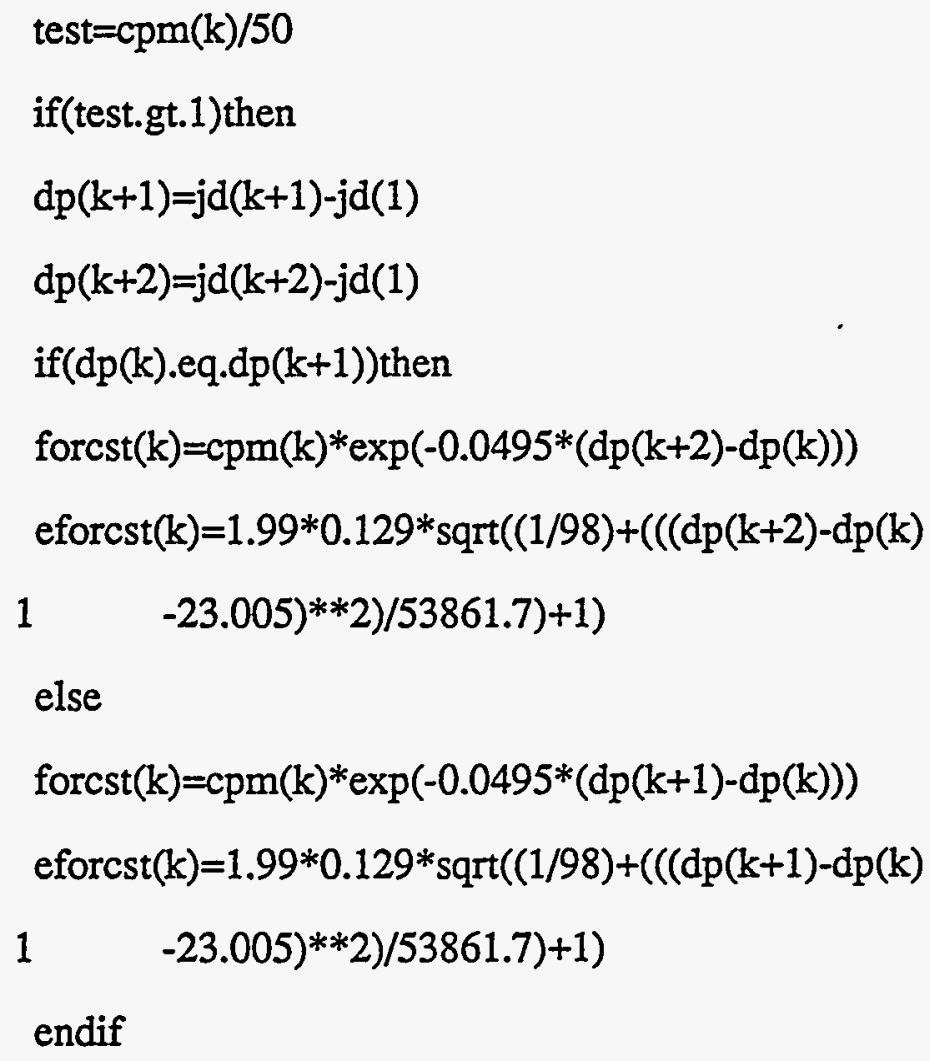


comp=forcst $(k)$-eforcst $(k)$

if $(d p(k) \cdot e q \cdot d p(k+1))$ then

newcpm $=\operatorname{cpm}(k+2)+(2 * \operatorname{ecpm}(k+2))$

if(newcpm.lt.comp)then

$\mathrm{n} 1=\mathrm{n} 1+1$

go to 50

endif

else

newcpm $=\operatorname{cpm}(k+1)+(2 * \operatorname{ecpm}(k+1))$

if(newcpm.lt.comp)then

$\mathrm{n} 1=\mathrm{n} 1+1$

go to 50

endif

endif

endif

31 write(lundsk,60)case(k),dp(k),cpm(k),v(k)

60 format(i4,1x,i6,1x,17.1,1x,a3)

50 continue

close(lundsk)

$\mathrm{n}=\mathrm{n}-\mathrm{n} 1$

c

c The $\mathrm{cpm} / \mathrm{mL}$ are calculated.

c

open(lundsk,file='a:data.dat',status='old')

do $70 \mathrm{i}=1, \mathrm{n}$ 
read(lundsk,80)case(i),dp(i),cpm(i),vol(i)

80 format(i4,1x,i6,1x,f7.1,1x,i3)

$\operatorname{cpml}(i)=\operatorname{cpm}(i) / \operatorname{vol}(i)$

if(vol(i).eq.500)then

$\operatorname{cpml}(\mathbf{i})=\operatorname{cpml}(\mathbf{i}) * 10$

endif

70 continue

c

c The data are written to file dose.dat.

c Where more than one sample exists on the same date, $c$ the average is computed. Only one datum per sample

$c$ date appears on the final data file.

c

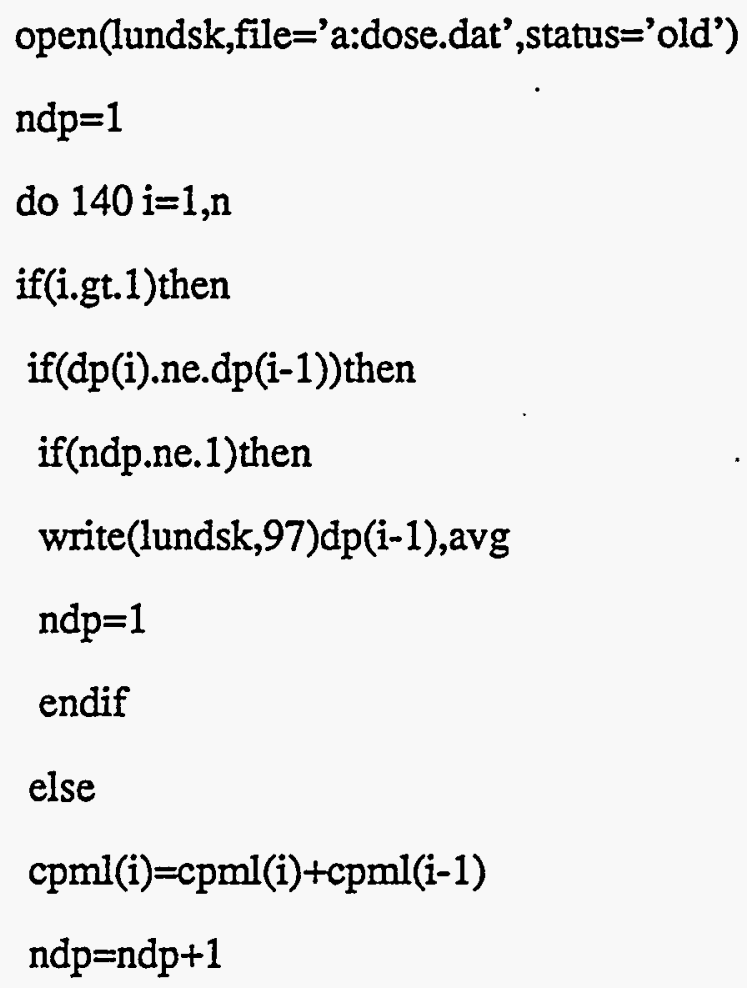




$$
\begin{aligned}
& \text { avg=cpml(i)/ndp } \\
& \text { go to } 140 \\
& \text { endif } \\
& \text { endif }
\end{aligned}
$$

if(i.ne.n)then

if(dp(i).eq.dp(i+1))then

go to 140

endif

endif

write(lundsk,97)dp(i),cpml(i)

97 format(i4,1x,f9.3)

140 continue

close(lundsk)

end

function numdas (month)

dimension month (1500)

numdas $=\operatorname{int}(-1 *(.7+(1 /(\operatorname{month}(\mathrm{n})+1))))$

return

end 


\section{DOSE}

c This program calculates the whole body effective dose c equivalent due to Po-210 based on urinary excretion data.

$c$ The algorithm utilizes the metabolic parameters measured

$\mathrm{c}$ in the adult female baboon following intravenous administration c of Po-210 citrate, references man data (ICRP 23), and the c weighting factors for determining organ specific dose equivalent c values published in ICRP 30 .

c

c

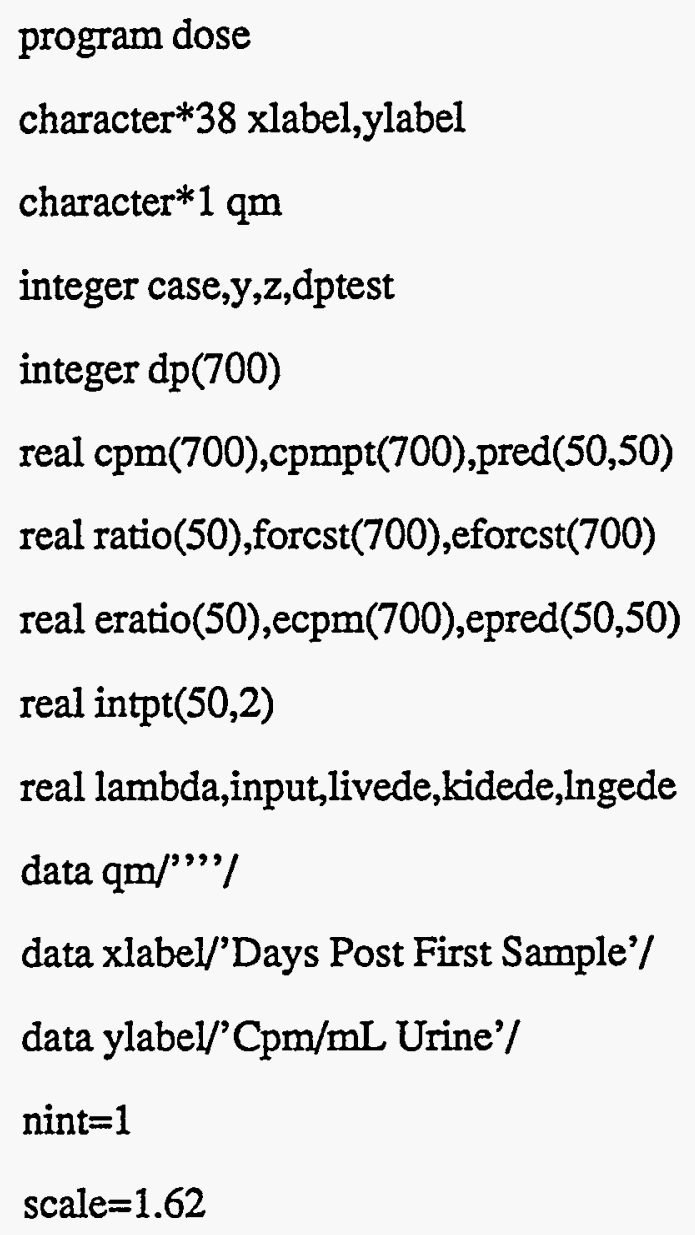


xstart $=0$.

xorigin $=0$.

lambda $=0.0495$

elamb $=0.0048$

write $(*, *)$ 'Case Number:'

$\operatorname{read}(*, 200)$ case

200 format(i4)

$\mathrm{i}=1$

open(1,file='a:dose.dat',status='old')

rewind(1)

c

c Data is read in from a file prepared by program Omdos.

c

$210 \operatorname{read}(1,220$,end=230) dp(i),cpm(i)

220 format(bn,i4,1x,f14.3)

$\mathrm{i}=\mathrm{i}+1$

goto 210

$230 \mathrm{y}=0$

c

c The first data point is assigned to represent the first

c intake of Po-210. A forcasted, or predicted, curve is then

$c$ generated along with the associated error band based on the

c urinary Po-210 clearance measured in the baboon.

c

c The error band about the predicted curve is described 
c by the following formula (Draper and Smith 1978):

c $y=y(x)+-t * S E($ regression $) * \operatorname{sqrt}(1 / n+(((x(i)-x($ avg $) * * 2) / s(x x))+1)$

c

c Where the count rate of the predicted curve falls below

c $0.1 \mathrm{cpm} / \mathrm{mL}$, the forecasting is cut off and set equal to 0.1 .

c

do $235 \mathrm{~m}=1, \mathrm{i}-1$

if(cpm(m).gt.0)then

$\operatorname{intpt}(1,1)=d p(m)$

$\operatorname{intpt}(1,2)=\operatorname{cpm}(\mathrm{m})$

$\operatorname{ecpm}(1)=\operatorname{sqrt}(\operatorname{cpm}(m) * 20) / 20$

goto 236

endif

235 continue

236 do $240 \mathrm{j}=\mathrm{m}+1, \mathrm{i}-1$

if(j.gt.m+1)then

if(forcst(j-1).le.0.1)then

forcst $(j-1)=0.1$

forcst $(j)=0.1$

eforcst $(j)=0.1$

goto 12

endif

endif

forcst $(j)=\operatorname{cpm}(m) * \exp (-1 a m b d a *(d p(j)-d p(m)))$

eforcst $(j)=1.99 * 0.129 * \operatorname{sqrt}((1 / 98)+(((d p(j)-d p(m)-23.005) * * 2)$ 


$$
1 \quad \text { (53861.7)+1) }
$$

240 continue

\section{c}

$\mathrm{c}$ In the following section, the data points reflecting the c occurrence of additional Po-210 intakes are identified. c In iterative fashion, the algorithm proceeds from the c second datum to the last datum performing a test of the $c$ means of the expected urinary excretion level (due to the c most recent prior intake) and the measured urinary excretion $c$ level. The $t$-distribution is utilized for this test.

c

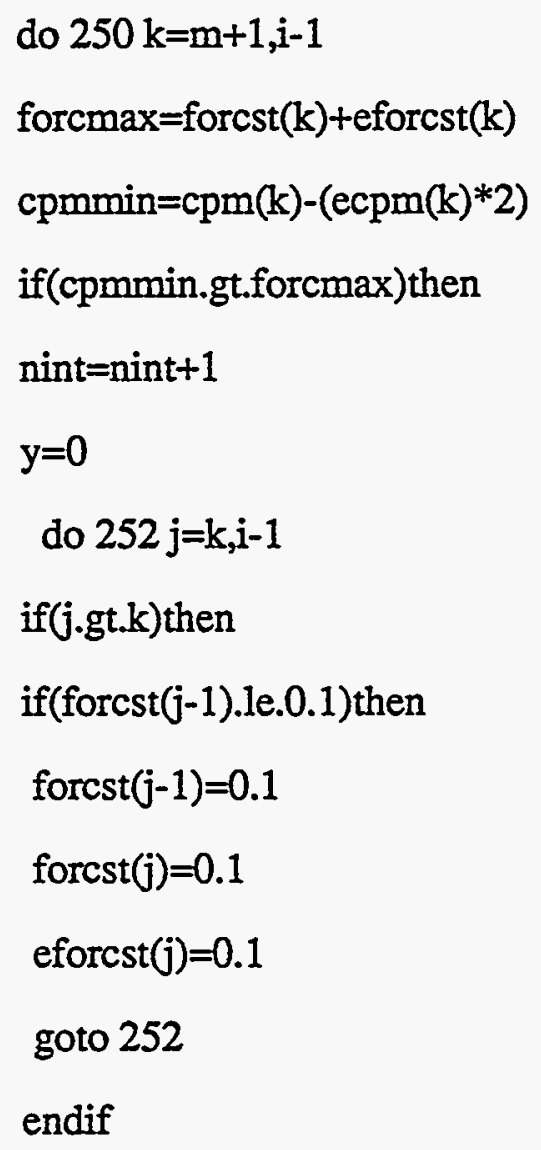


endif

forcst $(j)=c p m(k) * \exp (-\operatorname{lambda} *(d p(j)-d p(k)))$

$\operatorname{eforcst}(j)=1.99 * 0.129 * \operatorname{sqrt}((1 / 98)+(((d p(j)-d p(k)-23.005) * * 2)$

$1 \quad$ (53861.7)+1)

252 continue

intpt(nint, 1$)=d p(k)$

intpt(nint,2)=cpm(k)

ecpm(nint) $=\operatorname{sqrt}($ intpt $($ nint, 2$) * 20) / 20$

endif

250 continue

c

c Significant differences in Po plating efficiency have

$c$ been determined between spontaneous deposition out of raw

c urine (as done in the past) compared to wet ashed urine. .

c The following section adjusts the identified intake points

c by application of the ashed/unashed Correction Function.

c The contribution (if any) of all prior intakes on an intake

c are determined and adjusted by multiplication with the

c proper time dependent CF value.

c

c The first intake is multiplied by the CF value at

c 5 days post intake.

c

ratio $5=10.47 * \exp (-0.0086 * 5)$

ecft5 $=2.021 * 0.193 * \operatorname{sqrt}((0.0238)+(((5-28) * * 2) / 27198)+1)$ 


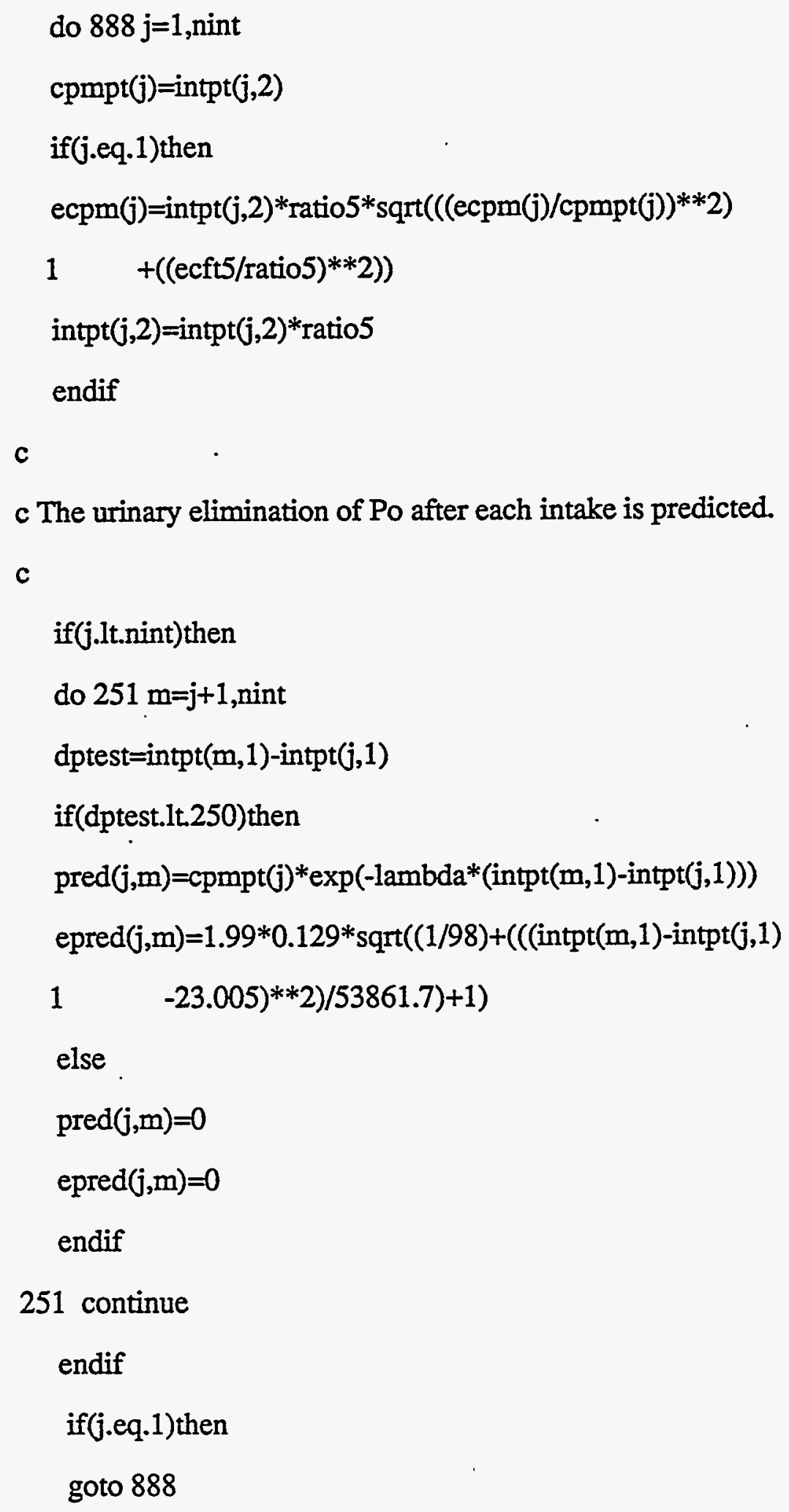

251 continue

endif if(j.eq.1)then goto 888 
endif

c

c The CF values are determined for each intake from all prior intakes.

c CF values less than 1 are set equal to one.

c

$\mathrm{jj}=\mathrm{j}-1$

do $253 n=1, j-1$

if(pred(n,j).gt.0.1)then

$\operatorname{ratio}(n)=10.47 * \exp (-0.0086 *(\operatorname{intpt}(j, 1)-\operatorname{intpt}(n, 1)))$

eratio $(n)=2.021 * 0.193 * \operatorname{sqrt}((1 / 42)+(((\operatorname{intpt}(j, 1)-\operatorname{intpt}(n, 1)$

1

$-28) * * 2)(27198)+1)$

else

$\operatorname{pred}(n, j)=0$

ratio(n) $=1$

endif

if(ratio(n).lt.1)then

$\operatorname{ratio}(n)=1$

endif

253 continue

c

c The magnitude of the intake points are adjusted by

c incorporating the proper CF ratios to the portion

c of each point influenced by prior intakes.

c

cpmcalc $=\operatorname{pred}(1, j) *$ ratio $(1)$ 
ecalc $=0$

if(pred(1,j).gt.0)then

if(ratio(1).gt.1)then

ecalc $=\operatorname{cpmcalc} * \operatorname{sqrt}\left(((\operatorname{epred}(1, \mathrm{j})))^{* * 2} 2\right)+$

$1 \quad(($ eratio(1)/ratio(1))**2))

endif

endif

do $254 n=2, j-1$

cpmcalc $=c$ pmcalc $+\left((\operatorname{pred}(n, j)-\operatorname{pred}(n-1, j)) *_{\text {ratio }}(n)\right)$

$\operatorname{diff}=\operatorname{pred}(n, \mathrm{j})-\operatorname{pred}(\mathrm{n}-1, \mathrm{j})$

if(diff.gt.0)then

errint $=\operatorname{sqrt}(\operatorname{epred}(\mathrm{n}, \mathrm{j}) * * 2+$ epred$(\mathrm{n}-1, \mathrm{j}) * * 2)$

errint $=$ diff*ratio(n)*sqrt(((errint/diff) $* * 2)+$

$1 \quad(($ ratio(n)/ratio(n))**2))

ecalc $=\operatorname{sqrt}($ ecalc $* * 2+e r r i n t * * 2)$

endif

254 continue

c

c That portion of an intake not resulting from a prior intake $c$ is multiplied by the $C F$ at 5 days post intake.

c

$\operatorname{den}=\operatorname{intpt}(j, 2)-\operatorname{pred}(j-1, j)$

if(epred(j-1,j).gt.0)then

$\operatorname{ecpm}(\mathrm{j})=\operatorname{sqrt}(\operatorname{ecpm}(\mathrm{j}) * * 2+\operatorname{epred}(\mathrm{j}-1, \mathrm{j}) * * 2)$

ecpm(j) $=\operatorname{den} *$ ratio $5 * \operatorname{sqrt}(((\operatorname{ecpm}(\mathrm{j}) / \operatorname{den}) * * 2)$ 
$1+(($ ecft5/ratio5)**2))

$\operatorname{ecpm}(j)=s q r t(e c a l c * * 2+e c p m(j) * * 2)$

$\operatorname{intpt}(j, 2)=\operatorname{cpmcalc}+((\operatorname{intpt}(\mathrm{j}, 2)-\operatorname{pred}(\mathrm{j}-1, \mathrm{j})) *$ ratio5)

else

intpt $(\mathbf{j}, 2)=\operatorname{cpmcalc}+\left((\operatorname{intpt}(\mathbf{j}, 2)-\right.$ pred $\left.(\mathrm{j}-1, \mathrm{j})) *{ }_{\text {ratio5 }}\right)$

$\operatorname{ecpm}(j)=\operatorname{intpt}(j, 2) * \operatorname{sqrt}(((\operatorname{ecpm}(j) / \operatorname{cpmpt}(j)) * * 2)$

$1+(($ ecft5/ratio5)**2))

endif

888 continue

c

c The dose equivalent is to be calculated from $Q$, the time

c integral of internal contamination. $Q$ is determined by

$c$ integrating the urinary excretion function (the baboon

c model is used). The integrals from each intake are determined

'c and summed.

C

- $q=\operatorname{intpt}(1,2) /$ lambda

eq=q*sqrt (((ecpm(1)/intpt $(1,2)) * * 2)+(($ elamb/lambda)**2))

do $265 \mathrm{j}=2$, nint

dptest=intpt(j,1)-intpt(j-1,1)

if(dptest.1t.250)then

forcst $(j)=\operatorname{intpt}(j-1,2) * \exp (-\operatorname{lambda}(\operatorname{intpt}(j, 1)-\operatorname{intpt}(j-1,1)))$

eforcst $(j)=$ forcst $(j) * \operatorname{sqrt}(((\operatorname{ecpm}(j-1) / \operatorname{intpt}(j-1,2)) * * 2)$

$1+(\exp (2 *$ lambda $) *($ elamb**2) $))$

iff(forcst $(j) \cdot 1 t .0 .1)$ then 


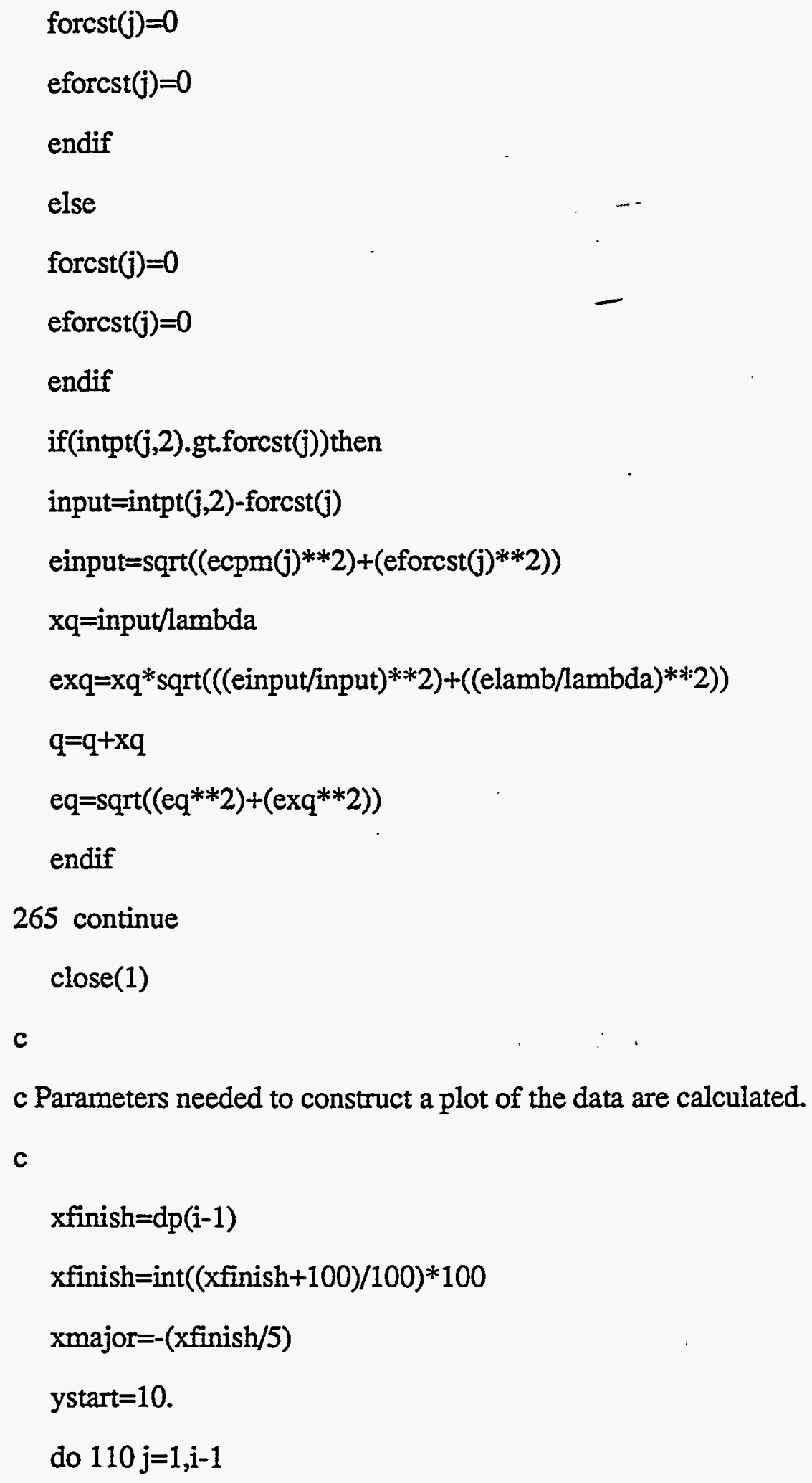


if(cpm(j).lt.ystart)then

$$
\begin{aligned}
& \text { ystart=cpm(j) } \\
& m=j \\
& \text { endif }
\end{aligned}
$$

110 continue

$$
\text { if(ystart.le.0.1)then }
$$$$
\text { ystart }=0.001
$$$$
\text { elseif(ystart.le.1)then }
$$

ystart $=0.01$

else

ystart $=0.1$

endif

ymajor $=10.0$

yorigin=ystart

yfinish $=0$.

do $120 \mathrm{j}=1, \mathrm{i}-\mathrm{i}$

if(cpm(j).gt.yfinish)then

yfinish=cpm(j)

endif

120 continue

$j=0$

130 if(yfinish.ge.1)then

yfinish=yfinish/10.

$j=j+1$

go to 130 
endif

yfinish=int $(y f i n i s h+1) *(10 * * j) * 10$

c

c The variable $\mathrm{q}$ has units $\mathrm{cpm}$-day/mL urine.

c By multiplying by the proper constants,

c clearance half-times, and organ partition coefficients,

c the EDE can be calculated for individual organs.

c These constants are:

c $1400+-530 \mathrm{ml} / \mathrm{day}$

c 86400 dis/day-Bq

c $5.305 \mathrm{MeV} / \mathrm{dis}$

c $1.6 \mathrm{E}-13 \mathrm{~J} / \mathrm{MeV}$

c $1000 \mathrm{mGy} / \mathrm{Gy}$

c dpm/0.5cpm=counter Efficiency

c Bq/60 dpm

c kg-Gy/J

c $1 / f(u) ; f(u)=0.377+-0.040$ based on NYU baboon study

c $1 /$ Unashed deposition recovery; $\mathrm{R}=0.861+-0.119$

c The calculations below utilize ICRP 30 weighting factors

c and a quality factor of 20 to derive EDE in $\mathrm{mSv}$.

c

$c f=1.054342 E-2$

ecf $=c f * \operatorname{sqrt}(((\mathrm{eq} / \mathrm{q}) * * 2)+((530 / 1400) * * 2)+((0.040)$

$\left.\left.10.377)^{* * 2}\right)+\left((0.119 / 0.861)^{* * 2}\right)\right)$

erterm $=((e q / q) * * 2)+((e c f / c f) * * 2)$ 
livede $=\mathrm{q} * 0.286 * \mathrm{cf} * 0.06 * 20 /(0.045 * 1.8)$

eliv $=$ livede*sqrt(erterm $+((0.002 / 0.045) * * 2)+((0.245 /$

$\left.\left.1 \quad 1.8)^{* * 2}\right)+\left((0.01 / 0.286)^{* *} 2\right)\right)$

kidede $=q * 0.072 * c f * 0.06 * 20 /(0.028 * 0.31)$

ekid=kidede*sqrt(erterm $+((0.004 / 0.028) * * 2)+((0.02 /$

$\left.\left.10.31)^{* * 2}\right)+((0.006 / 0.072) * * 2)\right)$

splede $=\mathrm{q} * 0.0058 * \mathrm{cf} * 0.06 * 20 /(0.028 * 0.18)$

espl=splede*sqrt(erterm $+\left((0.004 / 0.028)^{* *} 2\right)+((0.06 /$

$\left.\left.10.18)^{* * 2}\right)+\left((0.0021 / 0.0058)^{* *} 2\right)\right)$

panede $=\mathrm{q} * 0.0031 * \mathrm{cf} * 0.06 * 20 /(0.1 * 0.028)$

epan $=$ panede $*$ sqrt $($ erterm $+((0.004 / 0.028) * * 2)+((0.02)$

$\left.\left.10.1)^{* * 2}\right)+((0.0004 / 0.0031) * * 2)\right)$

adrede $=\mathrm{q} * 0.00048 * \mathrm{cf} * 0.06 * 20 /(0.014 * 0.027)$

eadr $=$ adrede*sqrt(erterm $+((0.008 / 0.027) * * 2)+((0.003 /$

$10.014) * * 2)+((0.00007 / 0.00048) * * 2))$

lngede $=\mathrm{q} * 0.009 * \mathrm{cf} * 0.12 * 20 /(0.47 * 0.0154)$

elng $=$ lngede*sqrt(erterm $+((0.0061 / 0.0154) * * 2)+((0.11 /$

$\left.\left.10.47)^{* * 2}\right)+((0.005 / 0.009) * * 2)\right)$

c

c The assumption has been made that ovary Po retention

$c$ approximates testis Po retention.

c

gonede $=\mathrm{q} * 0.00028 * \mathrm{cf} * 0.25 * 20 /(0.035 * 0.014)$

egon=gonede*sqrt(erterm $+((0.006 / 0.014) * * 2)+((0.007)$

$\left.\left.1 \quad 0.035)^{* * 2}\right)+\left((0.002 / 0.028)^{* * 2}\right)\right)$ 
c Bone surface and red marrow dosimetry done in accordance c with the ICRP 30 recommendations.

$$
\text { bsede }=\mathrm{q} * 0.064 * \mathrm{cf} * 0.03 * 0.25 * 20 /(0.02 * 0.12)
$$

ebs $=$ bsede*sqrt(erterm $+((0.002 / 0.02) * * 2)+((0.03)$

$\left.\left.10.12)^{* * 2}\right)+\left((0.003 / 0.064)^{* * 2}\right)\right)$

- rmede $=q * 0.032 * \mathrm{cf} * 0.12 * 0.5 * 20 /(0.02 * 1.5)$

erm $=$ rmede $*$ sqrt $($ erterm $+((0.002 / 0.02) * * 2)+((0.33 /$

$1 \quad 1.5) * * 2)+((0.0015 / 0.032) * * 2))$

thyede $=\mathrm{q} * 0.000069 * \mathrm{cf} * 0.03 * 20 /(0.014 * 0.02)$

ethy $=$ thyede* $\operatorname{sqrt}($ erterm $+((0.009 / 0.014) * * 2)+((0.008 /$

$1 \quad 0.02) * * 2)+((0.0006 / 0.0069) * * 2))$

wbede $=$ livede+kidede + splede+panede + adrede+lngede +

1 gonede+bsede+rmede+thyede

ewb $=s q r t\left(\right.$ eliv $^{* * 2+e k i d} * * 2+$ esp $1 * * 2+$ epan $* * 2+$ eadr $* * 2+$

1 elng**2+egon $* * 2+$ ebs $* * 2+$ erm $* * 2+$ ethy $* * 2$ )

c

c The results are written to file case.dos on drive a

c

open(2,file='a:case.dos ',status='new')

write $(2,320)$

320 format(' ')

write $(2,330)$ case

330 format('DOSIMETRY REPORT: CASE \# ',i4)

write $(2,320)$

write $(2,340)$ 
340 format('ORGAN',9X,'EFFECTIVE DOSE EQUTVALENT')

write(2,342)

342 format $\left(20 x,{ }^{\prime}(m S v+1 s d)^{\prime}\right)$

write $(2,320)$

write $(2,350)$ livede,eliv

350 format('LIVER',12X,F7.0,1X,'+- ',F7.0)

write $(2,360)$ kidede,ekid

360 format('KIDNEY',11x,f7.0,1x,'+- ',f7.0)

write(2,370)splede,espl

370 format('SPLEEN',11x,f7.0,1x,'+- ',f7.0)

write(2,380)panede,epan

380 format('PANCREAS',9x,f7.0,1x,'+- ',f7.0)

write $(2,390)$ adrede,eadr

390 format('ADRENAL GLAND',4x,f7.0,1x,'+- ',f7.0)

write $(2,400)$ lngede,elng

400 format('SYSTEMIC LUNG',4x,f7.0,1x,'+- ',f7.0)

write $(2,410)$ gonede,egon

410 format('GONADS',11x,f7.0,1x,'+- ',f7.0)

write $(2,420)$ bsede,ebs

420 format('BONE SURFACES',4x,f7.0,1x,'+- ',f7.0)

write $(2,425)$ rmede,erm

425 format('RED MARROW',7x,f7.0,1x,'+- ',f7.0)

write $(2,430)$ thyede, ethy

430 format('THYROID',10x,f7.0,1x,'+- ',f7.0)

write $(2,320)$ 
write $(2,450)$ wbede,ewb

450 format('WHOLE BODY ',F9.0,1x,'+- ',f7.0)

close(2)

c

c A file for plotting the data is written to drive a

C

open(3,file='a:plot.omn ',status='new')

write $(3,91) q m$, case,qm

91 format(a1,18x,'ID\# ',i4,a1)

write(3,92)qm,xlabel,qm

92 format(a1,a38,a1)

write(3,92)qm,ylabel,qm

write $(3,93)$ scale

93 format(f4.2)

write $(3,94) x s t a r t, x f i n i s h, x m a j o r, x o r i g i n$

94 format $(\mathrm{f} 2.0,1 \mathrm{x}, \mathrm{f} 7.0,1 \mathrm{x}, \mathrm{f} 6.0,1 \mathrm{x}, \mathrm{f} 2.0)$

write $(3,95)$ ystart,yfinish,ymajor,yorigin

95 format(f6.3,1x,f9.1,1x,f4.1,1x,f6.3)

$\mathrm{i}=\mathrm{i}-1$

write $(3,96) \mathbf{i}$

96 format(i4)

do $590 \mathrm{j}=1, \mathrm{i}$

write $(3,600) \mathrm{dp}(\mathrm{j}), \mathrm{cpm}(\mathbf{j})$

600 format(i4,1x,f14.3)

590 continue 
write $(3,610)$ nint

610 format(i3)

do $620 \mathrm{j}=1$, nint

write $(3,630)(\operatorname{intpt}(j, m), m=1,2)$

630 format(f5.0;2x,f14.3)

620 continue

end 


\section{MNDOSE}

clear

input "case number" to cn

set index to d:poli

seek cn

set safety off

copy to a:dp.dat rest fields case,date,cpm,volume for case $=c n$ while case $=c n$ sdf

set safety on

run omdos

run dose

filnam $=\operatorname{str}(\mathrm{cn}, 4,0)+"$. dos"

filnam2 $=s t r(c n, 4,0)+" . o m n "$

run ren a:case.dos \&filnam

run ren a:plot.omn \&filnam2 


\section{INSTRUCTIONS}

The urine bioassay data base is put on a hard disk of a PC. The sorted data file is called "pols.dbf." An indexed version of the data file, called "poli.ndx" must also reside on the hard disk. The files dose.exe, omdos.exe, omdos2.exe, mndose.prg, and mndose2.prg are put on the hard disk within the dBase subdirectory. Files "data.dat" and "dose.dat" must appear on a floppy disk in drive a. These are files that will be rewritten during the execution of OMDOSE and DOSE. For the first execution of the job string, the content of data.dat and dose.dat are not important, as long as the files reside on the floppy.

Enter dBase III+ and hit the escape key. This enables the dot prompt. Load the data file by entering "use d:pols" (or c:pols depending on proper drive specification). Enter "do mndose" at the dot prompt to calculate the effective whole body and organ specific systemic dose equivalent values for an individual worker. The user will be asked twice to input a 1-4 digit worker identification number. Enter the number each time and hit the carraige return. When the program is completed, a file with the name "dos" (where is equal to the worker identification number) will reside on the floppy disk in drive a. A file with the name "\#.omn" will also be written to the floppy disk. It can be used to graph the excretion data (without outliers) when utilized with the graphics software package Omniplot. In addition to plotting the time sequence of urinary Po excretion, the intake points used to calculate the time integral of internal contamination (after adjustment with the correction function) are highlighted.

The file "mndose2.prg" is identical to "mndose.prg" with one exception. The mndose2 program uses omdos2.exe instead of omdos.exe. This applies to worker identification numbers $144,2313,3552,4474,5974,6628,8076$, and 9835 . Some data developed for these individuals warrant volume corrections because of some 24-hour 
(rather than spot) sampling. Due to the use of the same coding characters in the original data base for multiple purposes, the portion of the algorithm which makes these corrections could not be included in Omdos. 
APPENDIX G. Sample Dosimetry Output Tables

DOSIMETRY REPORT: CASE \#1424

\begin{tabular}{lc}
\hline \hline ORGAN & $\begin{array}{c}\text { WEIGHTED DOSE EQUTVALENT } \\
(\mathrm{mSv} \pm 1 \mathrm{sd})\end{array}$ \\
\hline LNVER & $85 . \pm 58$. \\
KDNNEY & $188 . \pm 130$. \\
SPLEEN & $26 . \pm 22$. \\
PANCREAS & $25 . \pm 18$. \\
ADRENAL GLAND & $29 . \pm 22$. \\
SYSTEMIC LUNG & $51 . \pm 57$. \\
GONADS & $47 . \pm 38$. \\
BONE SURFACES & $71 . \pm 52$. \\
RED MARROW & $23 . \pm 16$. \\
THYROID & $2 . \pm 2$. \\
\hline TOTAL SYSTEMIC & $548 . \pm 172$. \\
\hline
\end{tabular}

DOSIMETRY REPORT: CASE \#5604

\begin{tabular}{lc}
\hline \hline ORGAN & $\begin{array}{c}\text { WEIGHTED DOSE EQUTVALENT } \\
(\mathrm{mSv} \pm 1 \mathrm{sd})\end{array}$ \\
\hline LIVER & $215 . \pm 159$. \\
KIDNEY & $476 . \pm 357$. \\
SPLEEN & $66 . \pm 59$. \\
PANCREAS & $63 . \pm 49$. \\
ADRENAL GLAND & $72 . \pm 60$. \\
SYSTEMIC LUNG & $129 . \pm 150$. \\
GONADS & $119 . \pm 103$. \\
BONE SURFACES & $180 . \pm 140$. \\
RED MARROW & $58 . \pm 44$. \\
THYROID & $6 . \pm 6$. \\
\hline TOTAL SYSTEMIC & $1384 . \pm 465$. \\
\hline \hline
\end{tabular}


DOSIMETRY REPORT: CASE \#6175

\begin{tabular}{lc}
\hline ORGAN & $\begin{array}{c}\text { WEIGHTED DOSE EQUTVALENT } \\
(\mathrm{mSv} \pm 1 \mathrm{sd})\end{array}$ \\
\hline LIVER & $37 . \pm 47$. \\
KIDNEY & $81 . \pm 104$. \\
SPLEEN & $11 . \pm 15$. \\
PANCREAS & $11 . \pm 14$. \\
ADRENAL GLAND & $12 . \pm 16$. \\
SYSTEMIC LUNG & $22 . \pm 34$. \\
GONADS & $20 . \pm 27$. \\
BONE SURFACES & $31 . \pm 40$. \\
RED MARROW & $10 . \pm 13$. \\
THYROID & $1 . \pm 2$. \\
\hline TOTAL SYSTEMIC & $236 . \pm 132$. \\
\hline \hline
\end{tabular}




\section{REFERENCES}

Altshuler, B. and Pasternack, B. Statistic measures of the lower limit of detection of a radioactivity counter. Health Phys. 9: 293-298; 1963.

Bale, W.F., Helmkamp, R.W., Hrynyszyn, V., and Contreras, M.A. The Determination Of ${ }^{20}$ Po In Urine. Health Phys. 29: 663-671; 1975.

BEIR IV Health Risks Of Radon And Other Internally Deposited Alpha-Emitters Committee on the Biological Effects of Ionizing Radiations, Board on Radiation Effects Research Commission on Life Sciences, National Research Council. National Academy Press. Washington, D.C.; 1988.

Beral, V., Fraser, P., Carpenter, L., Booth, M., Brown, A., and Rose, G. Mortality Of Employees Of The Atomic Weapons Establishment, 1951-1982. B.M.J. 297: 757-770; 1988.

Berke, H.L. and DiPasqua, A.C. Distribution And Excretion Of Polonium-210. VIII. After Inhalation By The Rat. Rad. Res. Supplement 5: 133-147; 1964.

Bernard, S.R. A Metabolic Model For Polonium. Health Phys. 36: 731-732; 1979.

Blair, H.A. The Shortening Of Life Span By A Single. Injection Of Radium, Plutonium Or Polonium. Rad. Res. Supplement 5: 216-227; 1964.

Blanchard, R.L. Concentrations Of ${ }^{20} \mathrm{~Pb}$ And ${ }^{20} \mathrm{Po}$ In Human Soft Tissues. Health Phys. 13: 625-632; 1967.

Breuer, F. and Clemente, G.F. Po-210 Excretion And Radon Exposure. Proceedings of the specialist meeting on personal dosimetry and area monitoring suitable for radon and daughter products. 239-245; Paris, 1979.

Callihan, D. and Ross, D. A Review Of A Polonium Contamination Problem. Oak Ridge National Laboratory, Report ORNL-1381 (Rev.); 1952.

Campbell, J.E. and Talley, L.H. Association Of Polonium-210 With Blood. Proc. Soc. Exptl. Biol. Med. 87: 221-223; 1954.

Casarett, L.J. Distribution And Excretion Of Polonium-210. V. Autoradiographic Study Of Effects Of Route Of Administration On Distribution Of Polonium-210. Rad. Res. Supplement 5: 93-105; 1964a.

Casarett, L.J. Distribution And Excretion Of Polonium-210. IX. Deposition, Retention, And Fate After Inhalation By Nose-only Exposure, With Notes On Mechanics Of Deposition And Clearance And Comparison Of Routes Of Administration. Rad. Res. Supplement 5: 148-165; $1964 \mathrm{~b}$.

Casarett, G.W. Pathology Of Single Intravenous Doses Of Polonium. Rad. Res. Supplement 5: 246-321; 1964c. 
Casarett, G.W. Pathology Of Multiple Intravenous Doses Of Polonium. Rad. Res. Supplement 5: 347-360; 1964d.

Cohen, B.S. The magnitude, lung distribution and significance of the polonoium-210 in inhaled cigarette smoke. Ph.D. Dissertation, New York University Medical Center, 1978.

Cohen, N. and Wrenn, M.E. The Baboon As An Experimental Animal For Metabolic Studies Of Bone-seeking Radionuclides In Man. Medical Primatology. Proc. 3rd Conf. Exp. Med. Surg. Primates. Part III. Lyon; 226-236: 1972.

Cohen, N., Burkhart, W., and LoSasso, T. Curium Excretion Studies In Man Baboon; A Predictive Model. Health Phys. 44: Supplement No. 1: 403-409; 1983.

Cowden, R.N. Histopathological Study of Sprague-Dawley Rats Injected Intravenously With Varying Amounts Of Polonium. Mound Laboratory, Report MLM-761; 1952.

Cowden, R.N. and Zipf, R.E. Hematological And Pathological Studies Of Rats Injected Intravenously With Multiple Doses Of Polonium. Mound Laboratory, Report MLM-626; 1951.

Cowden, R.M., Jolley, W.P. and Zipf, R.L. Hematological And Pathological Studies In Sprague-Dawley Rats Injected Intravenously With Varying Amounts Of Polonium. Mound Laboratory, Report MLM-442; 1950.

Davis, R.K. The $\mathrm{LD}_{\mathrm{s0}}$ (20 days) Of Polonium. Mound Laboratory, Report MLM-474; 1950a.

Davis, R.K. A Direct Assay Of The Polonium Concentration In Blood. Mound Laboratory, Report MLM-525; $1950 \mathrm{~b}$.

Davis, R.K. and Jolley, W.P. Twenty-day $\mathrm{LD}_{s 0}$ Determinations For Different Species Of Laboratory Animals. I. Studies On Dogs. Mound Laboratory, Report MLM-552; 1951.

Davis, R.K., Jolley, W.P., and Lizardi, C. Twenty-day LD $_{30}$ Polonium Determinations For Different Species Of Laboratory Animals. III. Studies On Cats. Mound Laboratory, Report MLM-648; 1952.

Della Rosa, R.J. and Stannard, J.N. Acute Toxicity As A Function Of Route Of Administration. Rad. Res. Supplement 5: 205-215; 1964.

Draper, N. and Smith, H. Applied Regression Analysis, 2nd edition. John Wiley \& Sons, 1981.

Dusan, P., Vajo, V., and Ljiljana, N. Metabolism And Toxicity Of Polonium 210 And $\mathrm{SiO}_{2}$. Final Report, Institute of Occupational and Radiological Health, Belgrade, Jugoslavia; 1977.

Environmental Measurements Laboratory (EML). Radiochemical Determination Of Polonium, in HASL Procedures Manual. 26th ed. HASL-300. New York, E-Po-02-01; 1983. 
Feldman, I. and Saunor, P. Some in vitro Studies Of Polonium-210 Binding By Blood Constituents. Rad. Res. Supplement 5: 40-48; 1964.

Fink, R.M. (ed.) Biological Studies With Polonium, Radium, and Plutonium. Natl. Nucl. Energy Ser. Div. VI-3; 1950.

Finkel, M.P. Relative Biological Effectiveness Of Radium And Other Alpha Emitters In CF No. 1 Female Mice (20394). Proc. Soc. Exp. Biol. Med. 83: 494-498; 1953.

Finkel, M.P., Norris, W.P., Kisieleski, W.E., and Hirsch, G.M. The Toxicity Of Polonium 210 In Mice I. The Thirty Day $\mathrm{LD}_{\mathrm{so}}$, Retention, And Distribution. Am. J. Roentgenology 70: 477-485; 1953.

Foreman, H., Moss, W., and Eustler, B.C. Clinical Experiences With Radioactive Materials. Am. J. Roentgenology 79: 1071-1079; 1958.

Foster, H.L., Small, J.D., and Fox, J.G. (eds.) The Mouse in Biomedical Research Volume III. Academic Press; 1983.

Frank, M.M., Hamburger, M.I., Lawley, T.J., Kimberly, R.P., and Plotz, P.H. Defective Reticuloendothelial System Fe-Receptor Function In Systemic Lupus Erythrematosus. N. Engl. J. Med. 300 (10):518-523; 1979.

Garner, J. Personal communication. December 14, 1986.

Gilbert, K.V. History Of The Dayton project. Monsanto Research Corporation, Mound Laboratory. Miamisburg, Ohio. June, 1969.

Gorham, A.T. Absorption Of Polonium Through Mouse Skin. in Biological Studies With Polonium, Radium, and Plutonium. (Fink, R.M., ed.) Natl. Nucl. Energy Ser. Div. VI-3: 112-114; 1950.

Guskova, A.K. et al. Med. Radiologija 9; 1964 (Cited by Moroz and Parfenov; 1972).

Hall, R.E. and Lilien, D.M. MicroTSP User's Manual Version 5.1. Quantitative Micro Software. Irvine, California; 1987.

Harley, N.H. Personal communication; 1986.

Hill C.R. Polonium-210 In Man. Nature 208: 423-428; 1965.

Holtzman, R.B. Measurement Of The Natural Contents Of $\mathrm{RaD}(210 \mathrm{~Pb})$ And $\mathrm{RaF}(210 \mathrm{Po})$ In Human Bone-estimates Of Whole-body Burdens. Health Phys. 9: 385-400; 1963.

Holtzman, R.B. Natural Levels Of Lead-210, Polonium-210, And Radium-226 In Humans And Biota Of The Arctic. Nature 210: 1094-1097; 1966. 
Holtzman, R.B., Spencer, H., Ilcewicz, F.H., and Kramer L. Variability Of Excretion Rates $\mathrm{Of}{ }^{210 \mathrm{~Pb}}$ And $20 \mathrm{Po}$ Of Humans At Environmental Levels. Tenth Midyear Topical Symposium of the Health Physics Society, Northeastern New York Chapter. October 11-13, 1976, Proceedings of Papers Presented at the Meeting; Rensselaer Polytechnic Institute: $245-257 ; 1976$.

Hursh, J.B. Chemical Methods For Routine Bioassay. United States Atomic Energy Commission, University of Rochester, Report AE-CU-4024; 1958.

International Commission on Radiation Protection, ICRP Publication 10. Evaluation Of Radiation Doses To Body Tissues From Internal Contamination Due To Occupational Exposure. Pergamon Press, Oxford; 1968.

International Commission on Radiation Protection, ICRP Publication 23. Report Of The Task Group On Reference Man. A report prepared by a task group of committee 2 of the ICRP. Pergamon Press, New York; 1974.

International Commission on Radiation Protection, ICRP Publication 26. Recommendations of the Intemational Commission on Radiation Protection. Pergamon Press, Oxford; 1977.

International Commission of Radiological Protection, ICRP Publication 30, Part I. Report of Committee II on Limits for Intakes of Radionuclides by Workers. Pergamon Press, New York: 96-97; 1979.

Ivanyi, P., Gregorova, S., and Mickova, M. Genetic Differences In Thymus, Lymph Node, Testes And Vesicular Gland Weights Among Inbred Mouse Strains. Folia Biol. 18: 81-97; 1972.

Jackson, S. and Dolphin, G.W. The Estimation Of Internal Radiation Dose From Metabolic And Urinary Excretion Data For A Number Of Important Radionuclides. Health Phys. 12: 481-500; 1966.

Jialiu, X., Genyao, Y., Renzhi, W., Benrong, J., Fengwei, Q., and Jiamei, J. Clinical Observations On 4 Cases Internally Contaminated With ${ }^{20} \mathrm{Po}$ And A Follow-up Survey After 15 Years. Zhonghua Fangshe Yixue Yu Fanghu Zazhi (China) 2: 6-11; 1982.

Kimball, C.P. and Fink, R.M. Inhalation Of Volatilized Polonium By Rats. In Biological Studies With Polonium, Radium, And Plutonium. (Fink, R.M., ed.) Natl. Nucl. Energy Ser. Div. VI-3; 1950.

Kozlova, A.V. and Omelianenko, L.M. Acta Med. Sociol. 2; 1963 (Cited by Moroz and Parfenov; 1972).

Ladinskaya, L.A., Parfenov, Y.D., Popov, D.K., and Fedorova, A.V. ${ }^{210} \mathrm{~Pb}$ And ${ }^{210} \mathrm{Po}$ Content In Air, Water, Foodstuffs, And The Human Body. Arch. Environ. Health 27: 254-258; 1973. 
Little, J.B., Grossman, B.N., and O'Toole, W.F. Factors Influencing The Induction Of Lung Cancer In Hamsters By Intratracheal Adminstration Of 210Po. in Radionuclide Carcinogenesis. (Sanders, C.L., Busch, R.H., Ballou, J.E., and Mahlum, D.D., eds.) Proceedings of the Twelfth Annual Hanford Biology Symposium at Richland, Washington, May 10-12, 1972. U.S. Atomic Energy Commission; 1973.

Little, J.B., Kennedy, A.R., and McGandy, R.B. Effect Of Dose Rate On The Induction Of Experimental Lung Cancer In Hamsters By Alpha Radiation. Rad. Res. 103: 293-299; 1985.

Markelov, B.A. et al. Polonium: Materials On Toxicology, Clinical Aspects And Therapy Of Injuries. Medicina, Moscow; 1964 (Cited by Moroz and Parfenov; 1972).

Meyer, H.E. Polonium Determination In Urine, Feces, And Blood. Proceedings of the Second Annual Meeting on Bio-assay and Analytical Chemistry. WASH-736; October 11 and 12, 1956.

Moroz, B.B. and Parfenov, Y.D. Metabolism And Biological Effects Of Polonium-210. Atomic Energy Review 10: 175-232; 1972.

Morrow, P.E., Mehrhof, B.A., Casarett, L.J., and Morken, D.A. An Experimental Study Of Aerosol Deposition In Human Subjects. AMA Arch. Ind. Health. 18: 292-298; 1958.

Morrow, P.E. and Della Rosa, R.J. Distribution And Excretion Of Polonium-210. VII. Fate Of Polonium Colloid After Intratracheal Administration To Rabbits. Rad. Res. Supplement 5: 124-132; 1964.

Morrow, P.E., Della Rosa, R.J., Casarett, L.J. and Miller, G.J. Investigations Of The Colloidal Properties Of Polonium-210 Solutions Using Molecular Filters. Rad. Res. Supplement 5: 1-15; 1964 .

Morrow, P.E., Smith, F.A., Della Rosa, R.J., Casarett, L.J. and Stannard, J.N. Distribution And Excretion Of Polonium-210. II. The Early Fate In Cats. Rad. Res. Supplement 5: 60-66; 1964b.

Naimark, D.H. Acute Exposure To Polonium (medical study of three human cases). Mound Laboratory, Report MLM-67; 1948.

Naimark, D.H. Effective Half-life Of Polonium In The Human. Mound Laboratory, Report MLM-272; 1949.

Neter, J. and Wasserman, W. Applied Linear Statistical Models. Richard D. Irwin, Inc. 1974.

Parfenov, Y.D. Polonium-210 In The Environment And In The Human Organism. Atomic Energy Review 12: 74-143; 1974.

Parfenov, Y.U. and Poluboyarinova, Z.I. Dynamics Of Polonium-210 Exchange In Dogs After A Single Subcutaneous Administration, in Radioactive Isotopes and the Body (Moskalev, Y.I., ed.): 128-135; 1969. 
Pasternack, B.S. and Harley, N.H. Detection limits for radionuclides in the analysis of multi-component gamma ray spectrometer data. Nuclear Instruments and Methods. 91: 533-540; 1971.

Samuels, L.D. Effects Of Polonium-210 On Mouse Ovaries. Int. J. Rad. Biol. 11: 117-129; 1966a.

Samuels, L.D. Depletion Of Mouse Spermatogonia Following Exposure To Polonium-210. Nature 210: 434-435; $1966 \mathrm{~b}$.

Sedlet, J. and Robinson, J.J. Elimination Of Polonium-210 Following Accidental Inhalation Of Neutron-irradiated Bismuth. Health Phys. 21: Abstract P/121, 62; 1971.

Shantyr, V.I. et al. Med. Radiologija 12; 1969 (Cited by Moroz and Parfenov; 1972).

Sheehan, W.E. Effective Half-life Of Polonium. Proceedings of the 10th Annual Bio-assay and Analytical Chemistry Meeting. Ohio; 1964a.

Sheehan, W.E. Polonium Urinalysis Procedure. Proceedings of the 10th Annual Bio-assay and Analytical Chemistry Meeting; Cincinnati, Ohio; $1964 \mathrm{~b}$.

Silberstein, H.E., Minto, W.L. and Fink, R.M. Oral Administration Of Polonium To Rats. in Biological Studies With Polonium, Radium, and Plutonium. (Fink, R.M., ed.) Natl. Nucl. Energy Ser. Div. VI-3; 1950a.

Silberstein, H.E., Valentine, W.N., Minto, W.L., Lawrence, J.S. and Fink, R.M. OraI Administration. in Biological Studies With Polonium, Radium, and Plutonium. (Fink, R.M., ed.) Natl. Nucl. Energy Ser. Div. VI-3; $1950 \mathrm{~b}$.

Silverman, L.B. Excretion Activity Analyses As A Monitor For Postum Exposures. Final Report No. 10, Report MLM-M-1443. Nov. 30, 1944.

Skrable, K.W., Chabot, G.E., French, C.S., LaBone, T.R. Intake Retention Functions And Their Applications To Bioassay And The Estimation Of Internal Radiation Doses. Health Phys. 55: 933-950; 1988.

Smith, F.A., Morrow, P.E., Gibb, F.R., Della Rosa, R.J., Casarett, L.J., Scott, J.K., Morken, D.A. and Stannard, J.N. Distribution And Excretion Studies In Dogs Exposed To An Aerosol Containing Polonium-210. Am. Ind. Hyg. Assoc. J. 22: 201-208; 1961.

Snedecor, G.W. Statistical Methods, Fifth Edition. Iowa State College Press; 1956

Spitz, H. Personal communication. October 1, 1987.

Spoerl, E.S. Urine Assay Procedure At The Mound Laboratory. Mound Laboratory, Report MLM-460; April 14, 1950.

Spoerl, E.S. A Derived Biological Half-life Of Polonium In Humans. MLM-626. Report For Biological Research. 72-76; 1951. 
Spoerl, E. and Anthony, D.S. Biological Research Related To Polonium. in Polonium. United States Atomic Energy Commission Technical Information Service Extension; July, 1956.

Sproul, J.A., Baxter, R.C., and Tuttle, L.W. Some Late Physiological Changes In Rats After Polonium-210 Alpha-particle Irradiation. Rad. Res. Supplement 5: 373-388; 1964.

Stannard, J.N. The Distribution And Excretion Of Orally Administered Polonium In The Rat. University of Rochester Atomic Energy Project, Report UR-299; 1954.

Stannard, J.N. Distribution And Excretion Of Polonium-210. I. Comparison Of Oral And Intravenous Routes In The Rat. Rad. Res. Supplement 5: 49-59; 1964 .

Stannard, J.N. Distribution And Excretion Of Polonium-210. III. Long-term Retention And Distribution In The Rat. Rad. Res. Supplement 5: 67-79; 1964b.

Stannard, J.N. Radioactivity and Health. A History. Prepared for the U.S. Department of Energy, Office of Health and Environmental Research; October, 1988.

Stannard, J.N. and Angell, M.A.K. Possible Sex Influences On The Metabolism Of Polonium-210 In The Rat. University of Rochester, Report UR-427; March 1, 1956.

Stannard, J.N. and Casarett, G.W. Concluding comments on biological effects of alpha-particle emitters in soft tissue as exemplified by experiments with polonium 210 . Rad. Res. Supplement 5: 398-434; 1964.

Stannard, J.N. and Smith, F.A. Distribution And Excretion Of Polonium-210. X. Species Comparison. Rad. Res. Supplement 5: 166-174; 1964.

Stannard, J.N., Blair, H.A., and Baxter, R.C. Mortality, Life Span, And Growth Of Rats With A Maintained Body Burden Of Polonium. Rad. Res. Supplement 5: 228-245; 1964.

Steinberg, G. Low Activity Urine Analysis. Mound Laboratory, Report MLM-M-526; May 2, 1946.

Taylor, M.P., Hibbert, P., and Lambert, B.E. Determination Of Polonium-210 In Urine By Track Counting. Health Phys. 15: 665-669; 1964.

Taylor, N.A. Human Excretion Of 210Po Following Accidental Intake. Health Phys. 19: Abstract 232; 147; 1970.

Thomas, R.G. Studies On Polonium In The Blood. Ph.D. Dissertation, University of Rochestor; 1955.

Thomas, R.G. The Binding Of Polonium By Red Cells And Plasma Proteins. Rad. Res. Supplement 5; 29-39; 1964.

Thomas, R.G. and Stannard, J.N. Influence Of Physicochemical State Of Intravenously Administered Polonium-210 On Uptake And Distribution. Rad. Res. Supplement 5: $16-22 ; 1964 a$. 
Thomas, R.G. and Stannard, J.N. Some Characteristics Of Polonium Solutions Of Importance In Biological Experiments. Rad. Res. Supplement 5: 23-28; $1964 \mathrm{~b}$.

Thomas, R.G. and Stannard, J.N. Distribution And Excretion Of Polonium-210. VI. After Intratracheal Administration In The Rat. Rad. Res. Supplement 5: 106-123; 1964c.

Vagtborg, $\mathrm{H}$. (ed.) The Baboon In Medical Research, Volume II. Proceedings of the second international symposium on the baboon and its use as an experimental animal. Library of Congress No. 65-11149; 1967.

Volkova, K.V. Proc. all-union Congr. Pathologic Anatomists 3; 1961 (Cited by Morox and Parfenov; 1972).

Zipf, R.L. Hematological And Pathological Studies In Sprague-Dawley Rats Injected Intravenously With Varying Amounts Of Polonium. Mound Laboratory, Report MLM-471-2; 1950. 